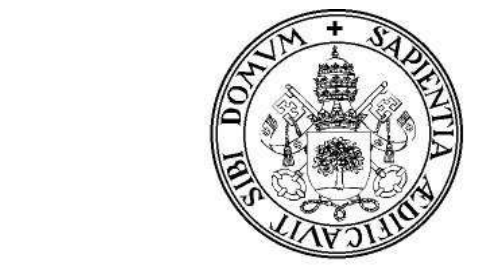

Universidad deValladolid

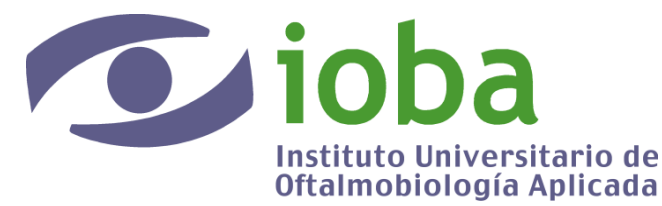

\author{
UNIVERSIDAD DE VALLADOLID \\ INSTITUTO DE OFTALMOBIOLOGÍA APLICADA (IOBA)
}

TESIS DOCTORAL:

\title{
FIABILIDAD DE LA TOMOGRAFÍA DE COHERENCIA ÓPTICA DE DOMINIO ESPECTRAL PARA LA MEDICIÓN DEL ESPESOR CORNEAL CENTRAL
}

Presentada por Ma ENCARNACIÓN CORREA PÉREZ para optar al grado de Doctora por

la Universidad de Valladolid

Dirigida por:

Dr. Miguel José Maldonado López

Dra. Natalia María Olmo Jiménez

Dr. Alberto López Miguel 



\section{Qioba}

\section{Universidad deValladolid}

\section{AUTORIZACIÓN DEL DIRECTOR DE TESIS}

(Art. 2.1. c de la Normativa para la presentación y defensa de la Tesis Doctoral en la UVa)

El Dr. Miguel José Maldonado López, con D.N.I. no 25149971-T, Profesor titular del Departamento de Cirugía, Oftalmología, Otorrinolaringología y Fisioterapia de la Universidad de Valladolid (UVa) e investigador principal del Instituto de Oftalmobiología Aplicada (IOBA) de la Universidad de Valladolid, la Dra. Natalia María Olmo Jiménez, con D.N.I. $\mathrm{n}^{\circ}$ 77324402-N, Doctora por la Universidad de Navarra, y el Dr. Alberto López Miguel, con DNI $\mathrm{n}^{\mathrm{o}}$ 71121957-T, Doctor por la Universidad de Valladolid e investigador del Instituto de Oftalmobiología Aplicada de la Universidad de Valladolid, como Directores de la Tesis Doctoral titulada "Fiabilidad de la Tomografía de Coherencia Óptica de Dominio Espectral para la medición del espesor corneal central”, presentada por Dña. Ma Encarnación Correa Pérez, alumna del Programa de Doctorado en Ciencias de la Visión, que el IOBA imparte,

AUTORIZAN la presentación de la misma, considerando que es APTA para su defensa.

Valladolid, 04 de Julio de 2013

Los Directores de la Tesis,

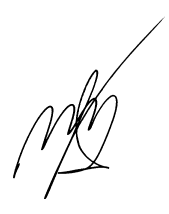

Fdo.: Dr. Miguel J Maldonado López

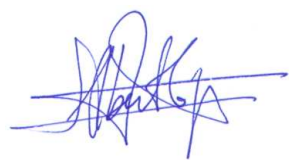

Fdo.: Alberto López Miguel

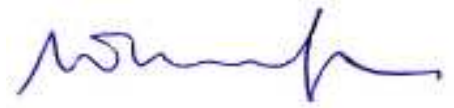

Fdo. Dra. Natalia María Olmo Jiménez 



\section{DIVULGACIÓN CIENTÍFICA}

\section{ARTÍCULOS CIENTÍFICOS}

La presente tesis doctoral ha dado lugar a las siguientes publicaciones en revistas científicas especializadas:

- Precision of High Definition Spectral-Domain Optical Coherence Tomography for Measuring Central Corneal Thickness.

María E. Correa-Pérez, Alberto López-Miguel, Silvia Miranda-Anta, Darío IglesiasCortiñas, Jorge L. Alió, Miguel J. Maldonado.

Invest Ophthalmol Vis Sci. 2012 Apr 6;53(4):1752-7. Factor impacto: 3.59 (6/58).

- Comparison of central corneal thickness using optical low-coherence reflectometry and spectral-domain optical coherence tomography.

Alberto López-Miguel, María Encarnación Correa-Pérez, Silvia Miranda-Anta, Darío Iglesias-Cortiñas, María Begoña Coco-Martín, Miguel J. Maldonado.

J Cataract Refract Surg. 2012 May;38(5):758-64. Factor impacto: 2.26 (16/58).

El siguiente manuscrito se encuentra a la espera de ser aceptado en publicación:

- Repeatability and Reproducibility of Posterior-Segment Spectral-Domain Optical Coherence Tomography for Measuring Central Corneal Thickness.

María E Correa-Pérez, Natalia Olmo, Alberto López-Miguel, Itziar Fernández, María B. Coco-Martín, Miguel J Maldonado.

Invest Ophthalmol Vis Sci. 2013 (Bajo revisión por pares). 


\section{COMUNICACIONES EN CONGRESOS CIENTÍFICOS}

La presente tesis doctoral ha dado lugar a la siguiente comunicación en panel en el Congreso de la Sociedad Americana de Oftalmología de 2011 (Orlando, EEUU):

- Retinal Fourier Domain Ocular Coherence Tomography can reliably measure central corneal thickness.

Maldonado MJ, López A, Correa ME, Miranda S, Coco B, Nieto JC.

Annual Meeting of the American Academy of Ophthalmology (AAO). October 22 25, 2011. Orlando. EEUU

La siguiente comunicación en panel se encuentra a la espera de ser aceptada en el Congreso de la Sociedad Americana de Oftalmología de 2013 (Nueva Orleans, EEUU):

- Reliability of Central Corneal Thickness Using Retinal Spectral-Domain Optical Coherence Tomography.

María E Correa-Pérez, Natalia Olmo, Alberto López-Miguel, Itziar Fernández, María B Coco-Martin, Miguel J Maldonado. 
Agradecimientos. 

Me gustaría que estas líneas sirvieran para expresar mi más profundo y sincero agradecimiento a todas aquellas personas que con su ayuda han colaborado en la realización del presente trabajo.

En primer lugar al Profesor Dr. Miguel José Maldonado López, por enseñarme en cada momento el camino a seguir y por ayudarme, con tanta maestría, a superar cada uno de los obstáculos que han surgido hasta la consecución de este objetivo. Sin su apoyo constante, sus ánimos, sus consejos, su confianza y toda su sabiduría, nada de esto hubiera sido posible. Por despertar en mí el interés por la investigación y el desarrollo de nuevas ideas.

Quiero expresar también mi más sincero agradecimiento a la Dra. Natalia María Olmo Jiménez, por su importante apoyo, aporte y participación activa en el desarrollo de esta tesis. Por todos sus consejos y enseñanzas.

Al Dr. Alberto López Miguel, por su dedicación, disponibilidad, y ayuda. No cabe duda que su participación ha enriquecido el trabajo realizado, y sin él no hubiera sido posible.

A Itziar Fernández, por ofrecerme tan valiosa ayuda en el análisis estadístico de los datos recogidos.

A todos mis compañeros del Servicio de Oftalmología del Hospital Universitario Rio Hortega de Valladolid, por ayudarme a dar mis primeros pasos como oftalmóloga.

A mis compañeras residentes. A las que me recibieron a mi llegada y a las que se han ido sumando después, por haber hecho que mis años en el hospital fueran inolvidables. Han sido unas compañeras extraordinarias, y mucho más que eso. Numerosos los buenos y malos momentos vividos en esos cuatro años, pero que sé qué aún son más numerosos los que nos quedan por vivir.

A mis nuevos compañeros del Servicio de Oftalmología del Hospital La Inmaculada de Huércal-Overa, por haberme acogido con tanto cariño, y por cuidarme tan bien.

A todos mis amigos. Gracias por sus ánimos y paciencia. 
A mis padres, por quererme, cuidarme y educarme. Porque son la causa de que hoy yo sea quien soy.

A Anabel, mi hermana. Por su incondicional apoyo.

A Remo, por entenderme y apoyarme, y por su inestimable ayuda con las tecnologías. 
Índice. Abreviaturas.

Tablas y Figuras. 



\section{INDICE GENERAL}

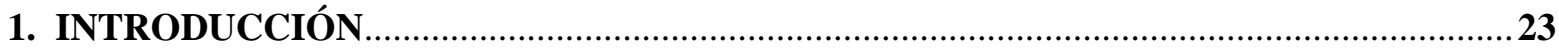

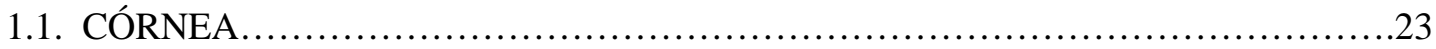

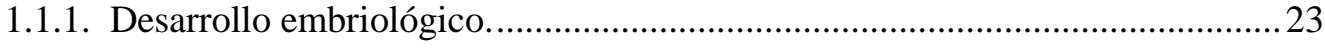

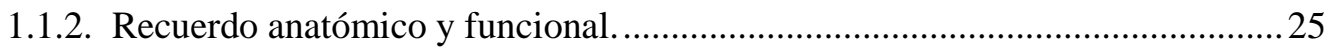

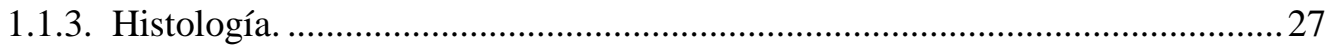

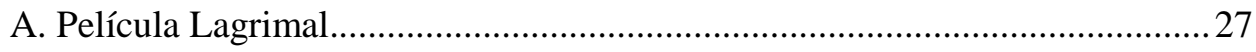

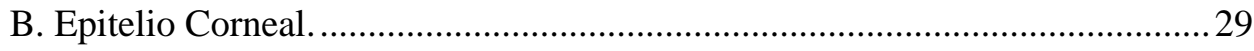

C. Membrana de Bowman................................................................................. 30

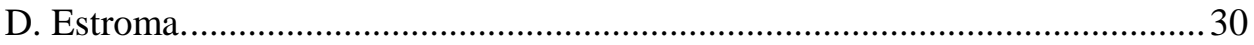

E. Membrana de Descemet.............................................................................. 33

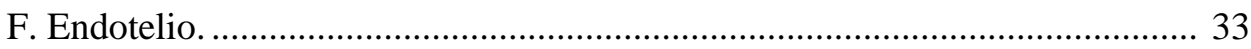

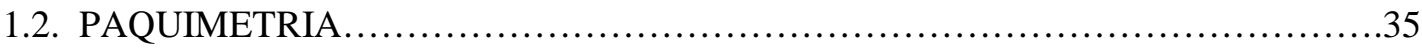

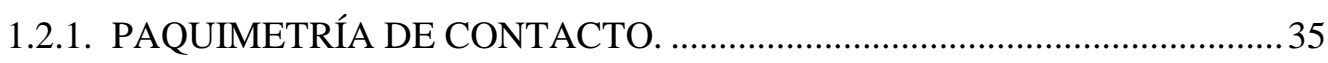

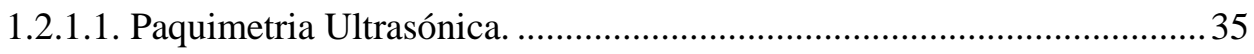

1.2.1.2. Ecografía del Segmento Anterior: Biomicroscopía Ultrasónica. ............36

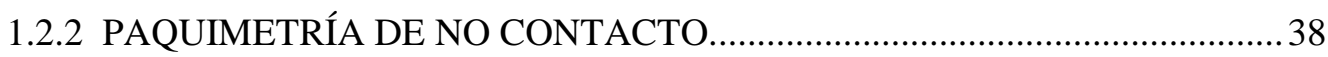

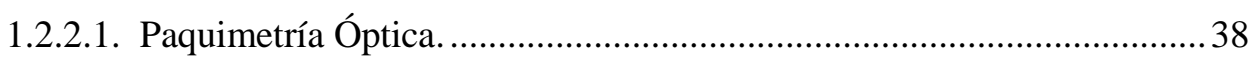

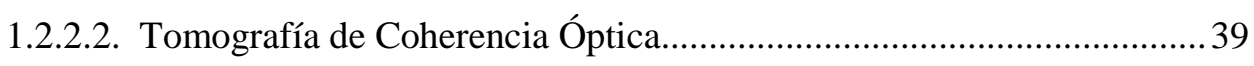

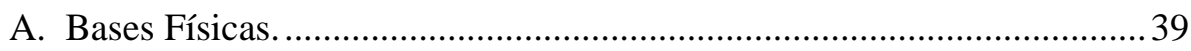

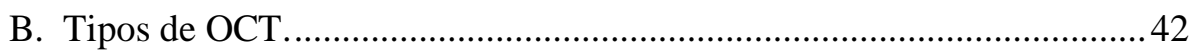

$\square$ OCT de Dominio en el Tiempo. ....................................................42

$\neg$ OCT de Dominio Espectral ..........................................................42

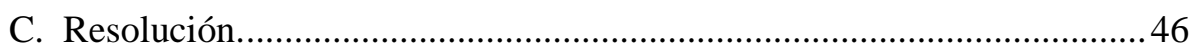

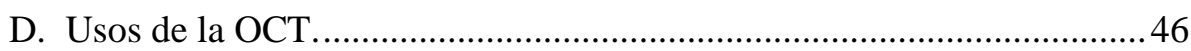

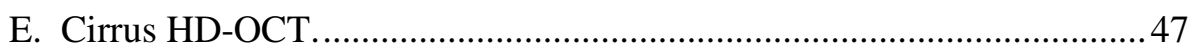

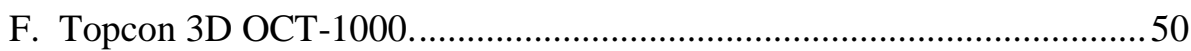

1.2.2.3. Reflectometria Optica De Baja Coherencia...........................................53

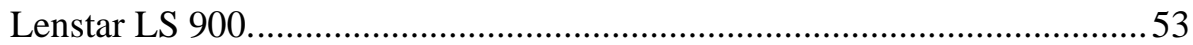

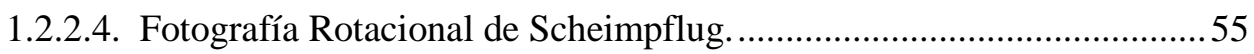

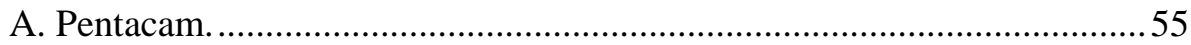

B. Galilei................................................................. 56

1.2.2.5. Topografia De Barrido De Hendidura (TBH) ......................................56

Orbscan. ........................................................... 56 


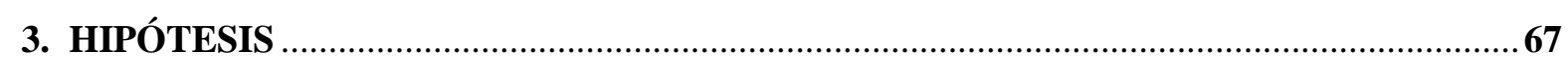

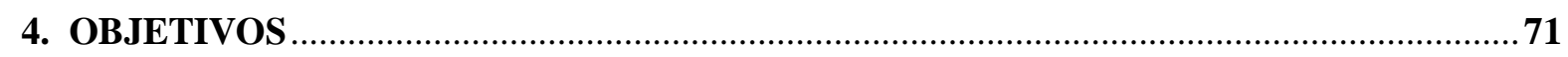

4.1. OBJETIVO GENERAL ........................................................ 71

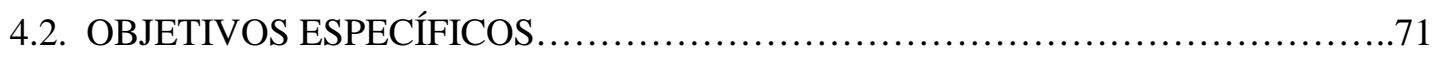

5. PACIENTES, MATERIALES Y MÉTODOS............................................................... 75

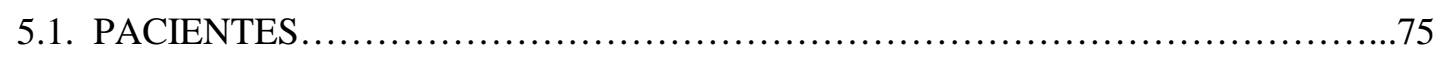

5.2. INSTRUMENTOS DE MEDICIÓN PAQUIMÉTRICA.............................76

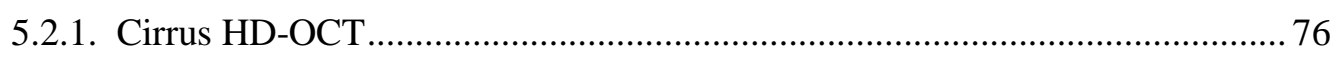

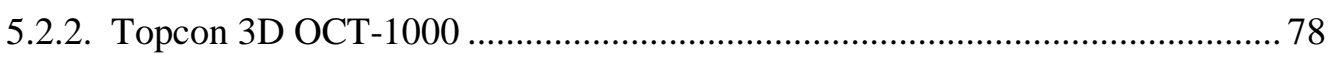

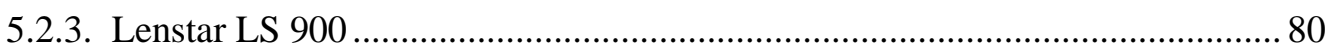

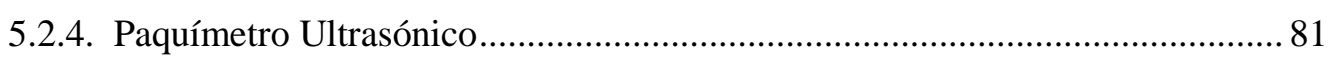

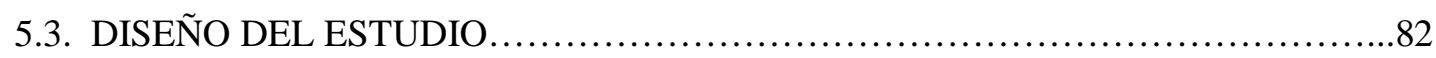

5.3.1. REPETIBILIDAD INTRA-OBSERVADOR Y REPRODUCIBILIDAD INTER-OBSERVADOR DE LAS MEDIDAS PAQUIMÉTRICAS OBTENIDAS CON EL SISTEMA DE TOMOGRAFÍA DE COHERENCIA ÓPTICA DE DOMINIO ESPECTRAL CIRRUS HD-OCT.

5.3.2. GRADO DE ACUERDO EXISTENTE ENTRE LA PAQUIMETRÍA CENTRAL OBTENIDA POR UN SISTEMA DE TOMOGRAFÍA DE COHERENCIA ÓPTICA DE DOMINIO ESPECTRAL Y POR LA ULTRASONOGRAFÍA CONVENCIONAL.

5.3.3. REPETIBILIDAD INTRA-OBSERVADOR Y REPRODUCIBILIDAD INTER-OBSERVADOR DE LAS MEDIDAS PAQUIMÉTRICAS OBTENIDAS CON UN SISTEMA DE REFLECTOMETRÍA ÓPTICA DE BAJA COHERENCIA.

5.3.4. GRADO DE ACUERDO EXISTENTE ENTRE LA PAQUIMETRÍA CENTRAL OBTENIDA POR UN SISTEMA DE TOMOGRAFÍA DE COHERENCIA ÓPTICA DE DOMINIO ESPECTRAL Y POR LA REFLECTOMETRÍA ÓPTICA DE BAJA COHERENCIA. 85

5.3.5. REPETIBILIDAD INTRA-OBSERVADOR Y REPRODUCIBILIDAD INTER-OBSERVADOR E INTER-SESIÓN DE LAS MEDIDAS PAQUIMÉTRICAS OBTENIDAS CON EL SISTEMA DE TOMOGRAFÍA DE COHERENCIA ÓPTICA DE DOMINIO ESPECTRAL TOPCON 3D OCT-1000. .85

5.4. DISEÑO DEL ANÁLISIS ESTADÍSTICO.................................. 86

5.4.1. REPETIBILIDAD INTRA-OBSERVADOR (E INTRA-SESIÓN)................86

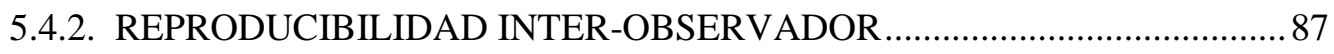

5.4.3. INTERCAMBIABILIDAD (GRADO DE ACUERDO) ENTRE SISTEMAS

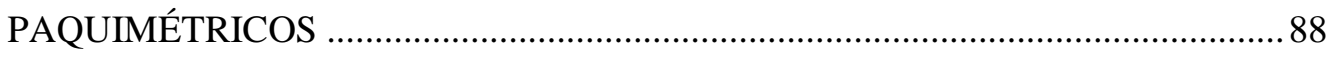

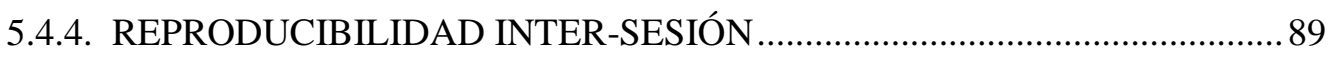


6.1. REPETIBILIDAD INTRA-OBSERVADOR Y REPRODUCIBILIDAD INTEROBSERVADOR DE LAS MEDIDAS PAQUIMÉTRICAS OBTENIDAS CON EL SISTEMA DE TOMOGRAFÍA DE COHERENCIA ÓPTICA DE DOMINIO ESPECTRAL CIRRUS HD-OCT. . .93

6.1.1. Repetibilidad Intra-observador de Cirrus HD-OCT ........................93

6.1.2. Reproducibilidad Inter-observador del sistema Cirrus HD-OCT..............93

6.2. GRADO DE ACUERDO EXISTENTE ENTRE LA PAQUIMETRÍA CENTRAL OBTENIDA POR UN SISTEMA DE TOMOGRAFÍA DE COHERENCIA ÓPTICA DE DOMINIO ESPECTRAL Y POR LA ULTRASONOGRAFÍA CONVENCIONAL..........96

6.3. REPETIBILIDAD INTRA-OBSERVADOR Y REPRODUCIBILIDAD INTEROBSERVADOR DE LAS MEDIDAS PAQUIMÉTRICAS OBTENIDAS CON UN SISTEMA DE REFLECTOMETRÍA ÓPTICA DE BAJA COHERENCIA...................97

6.3.1. Repetibilidad Intra-observador del sistema Lenstar LS 900........................... 97

6.3.2. Reproducibilidad Inter-observador del sistema Lenstar LS 900.....................98

6.4. GRADO DE ACUERDO EXISTENTE ENTRE LA PAQUIMETRÍA CENTRAL OBTENIDA POR UN SISTEMA DE TOMOGRAFÍA DE COHERENCIA ÓPTICA DE DOMINIO ESPECTRAL Y POR LA REFLECTOMETRÍA ÓPTICA DE BAJA

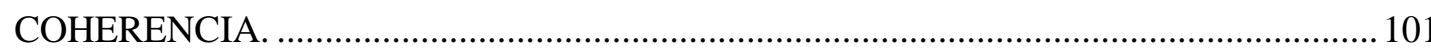

6.5. REPETIBILIDAD INTRA-OBSERVADOR Y REPRODUCIBILIDAD INTEROBSERVADOR E INTER-SESIÓN DE LAS MEDIDAS PAQUIMÉTRICAS OBTENIDAS CON EL SISTEMA DE TOMOGRAFÍA DE COHERENCIA ÓPTICA DE DOMINIO ESPECTRAL TOPCON 3D OCT-1000..... 103

6.5.1. Repetibilidad Intra-observador del sistema Topcon 3D OCT-1000............... 104

6.5.2. Reproducibilidad Inter-observador del sistema Topcon 3D OCT-1000. ......... 104

6.5.3. Reproducibilidad Inter-sesión de 3D OCT-1000. ........................................... 107

7. DISCUSIÓN.

7.1 DE LA METODOLOGÍA UTILIZADA............................................113

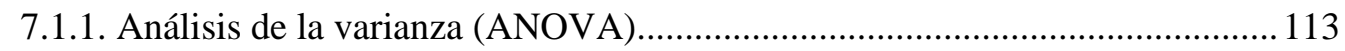

7.1.2. Coeficiente de correlación intraclase. ............................................................ 113

7.1.3. Metodología de bland \& altman.................................................................. 113

7.2. DE LOS RESULTADOS OBTENIDOS..................................... 115

7.2.1. REPETIBILIDAD INTRA-OBSERVADOR Y REPRODUCIBILIDAD

INTER-OBSERVADOR DE LAS MEDIDAS PAQUIMÉTRICAS OBTENIDAS CON EL SISTEMA DE TOMOGRAFÍA DE COHERENCIA ÓPTICA DE

DOMINIO ESPECTRAL CIRRUS HD-OCT. ......................................................... 115

7.2.1.1. Repetibilidad Intra-observador del sistema Cirrus HD-OCT.............. 116

7.2.1.2. Reproducibilidad Inter-observador del sistema Cirrus HD-OCT........ 119

7.2.2. GRADO DE ACUERDO EXISTENTE ENTRE LA PAQUIMETRÍA CENTRAL OBTENIDA POR UN SISTEMA DE TOMOGRAFÍA DE 
COHERENCIA ÓPTICA DE DOMINIO ESPECTRAL Y POR LA

ULTRASONOGRAFÍA CONVENCIONAL.

7.2.3. REPETIBILIDAD INTRA-OBSERVADOR Y REPRODUCIBILIDAD INTER-OBSERVADOR DE LAS MEDIDAS PAQUIMÉTRICAS OBTENIDAS CON UN SISTEMA DE REFLECTOMETRÍA ÓPTICA DE BAJA COHERENCIA.

7.2.3.1. Repetibilidad Intra-observador del sistema Lenstar LS 900. 122

7.2.3.2. Reproducibilidad Inter-observador de Lenstar LS 900

7.2.4. GRADO DE ACUERDO ENTRE LA PAQUIMETRÍA CENTRAL OBTENIDA POR UN SISTEMA DE TOMOGRAFÍA DE COHERENCIA ÓPTICA DE DOMINIO ESPECTRAL Y POR LA REFLECTOMETRÍA ÓPTICA DE BAJA COHERENCIA.

7.2.5. REPETIBILIDAD INTRA-OBSERVADOR Y REPRODUCIBILIDAD INTER-OBSERVADOR E INTER-SESIÓN DE LAS MEDIDAS PAQUIMÉTRICAS OBTENIDAS CON EL SISTEMA DE TOMOGRAFÍA DE COHERENCIA ÓPTICA DE DOMINIO ESPECTRAL TOPCON 3D OCT-1000.127

7.2.5.1. Repetibilidad Intra-observador del sistema 3D OCT-1000................ 127

7.2.5.2. Reproducibilidad Inter-observador de 3D OCT-1000_........................ 128

7.2.1.1. Reproducibilidad Inter-sesión del sistema 3D OCT 1000_................... 130

8. CONCLUSIONES 135

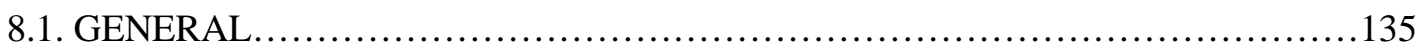

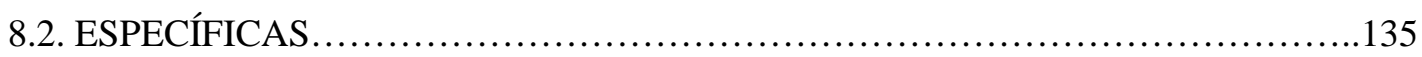

9. BIBLIOGRAFÍA. 139

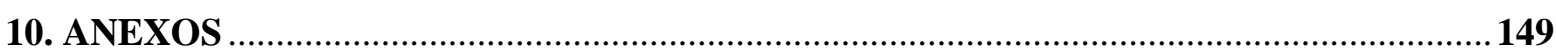

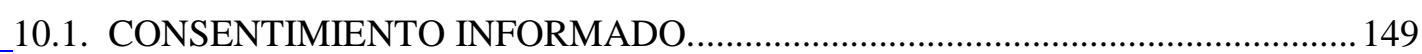

10.2. ARTÍ́CULOS............................................................ 153 


\section{ABREVIATURAS}

- BMU: Biomicroscopía ultrasónica del segmento anterior.

- OCT: Optical Coherence Tomography (Tomografía de Coherencia Óptica).

- TD-OCT: Time Domain (Dominio Tiempo) OCT.

- SD-OCT: Spectral Domain (Dominio Espectral) OCT.

- EDI-OCT: Enhaced Depth Imaging (imágenes de profundidad mejorada) OCT.

- SS-OCT: Swept-Source (Fuente con Barrido) OCT.

- OLCR: Optical Low Coherence Reflectometry (Reflectometría Óptica de Baja Coherencia).

- DS: Desviación estándar.

- $\mathrm{DS}_{\mathrm{i}}$ : Desviación estándar intra-sesión/inter-observador/inter-sesión.

- $\mathrm{CV}_{\mathrm{i}}$ : Coeficiente de variación intra-sesión/inter-observador/inter-sesión.

- CCI: Coeficiente de correlación intraclase.

- LdC: Límites de concordancia o acuerdo.

- DS: Desviación estándar. 



\section{ÍNDICE DE TABLAS}

- Tabla 1. Características distintivas de dispositivos de Tomografía de Coherencia Óptica comercializados.

- Tabla 2. Repetibilidad de la paquimetría corneal central del dispositivo Cirrus HDOCT.

- Tabla 3. Reproducibilidad inter-observador de la paquimetría corneal central del dispositivo Cirrus HD-OCT.

- Tabla 4. Repetibilidad de la paquimetría corneal central con el dispositivo Lenstar LS 900.

- Tabla 5. Reproducibilidad inter-observador del dispositivo Lenstar LS 900.

- Tabla 6. Repetibilidad de la paquimetría corneal central con del dispositivo Topcon 3D OCT-1000.

- Tabla 7. Reproducibilidad inter-observador de la paquimetría corneal central del dispositivo Topcon 3D OCT-1000.

- Tabla 8. Reproducibilidad inter-sesión de la paquimetría corneal central del dispositivo Topcon 3D OCT-1000. 



\section{ÍNDICE DE FIGURAS}

- Figura 1. Separación de la placoda del cristalino e inicio del desarrollo corneal.

- Figura 2. Tres oleadas sucesivas de células mesenquimales de la cresta neural.

- Figura 3. Corte histológico de una córnea normal (tinción con Hematosilina y Eosina).

- Figura 4. Estructura de la película lagrimal.

- Figura 5. Epitelio corneal.

- Figura 6. Organización de los queratocitos en el estroma corneal, mostrando la conexión entre las lamelas.

- Figura 7. Capa celular endotelial adherida a la membrana de Descemet.

- Figura 8. Paquímetro Ultrasónico.

- Figura 9. Imagen de Biomicroscopía Ultrasónica del segmento anterior.

- Figura 10. Paquímetro Óptico Haag-Streit en lámpara de hendidura Haag-Streit 900.

- Figura 11. Representación del barrido B-scan compuesto por múltiples A-scan.

- Figura 12. Interferómetro de Michelson.

- Figura 13. Diferencias entre TD-OCT y SD-OCT en forma y velocidad de captura de imagen.

- Figura 14. Imagen del dispositivo Cirrus HD-OCT.

- Figura 15. Medición del espesor corneal central mediante el dispositivo Cirrus HDOCT.

- Figura 16. Imagen del dispositivo Topcon 3D OCT-1000

- Figura 17. Accesorio para la adquisición de imágenes de segmento anterior con el dispositivo Topcon 3D OCT-1000.

- Figura 18. Medición del espesor corneal central mediante el dispositivo Topcon 3D OCT-1000.

- Figura 19. Imagen del dispositivo Lenstar LS 900.

- Figura 20. Parámetros evaluados por el dispositivo Lenstar LS 900.

- Figura 21. Sistema topográfico basado en fotografía de Scheimpflug (Pentacam).

- Figura 22. Pantalla de adquisición del patrón “Anterior Segment 5 Line Raster” en el dispositivo Cirrus HD-OCT.

- Figura 23. Pantalla de selección de un corte corneal de los 5 realizados en el dispositivo Cirrus HD-OCT con el patrón “Anterior Segment 5 Line Raster”. 
- Figura 24. Medición del espesor corneal central mediante un cursor en el dispositivo Cirrus HD-OCT.

- Figura 25. Instrucciones en la pantalla para la colocación del accesorio de apoyo para la frente, y cambio en el foco mediante el giro de una manivela, al seleccionar la opción de obtención de imágenes de segmento anterior en el 3D OCT-1000.

- Figura 26. Selección del patrón "Radial-Scan" para el estudio corneal en el dispositivo Topcon 3D OCT-1000.

- Figura 27. Medición del espesor corneal central mediante un cursor en el dispositivo Topcon 3D OCT-1000.

- Figura 28. Imagen de la visualización de los 32 diodos emisores de luz (LEDs) proyectados sobre la córnea, y su enfoque, en el dispositivo Lenstar LS 900.

- Figura 29. Pantalla que muestra las mediciones en el dispositivo Lenstar LS 900.

- Figura 30. Gráfica Bland-Altman describiendo la reproducibilidad inter-observador con el dispositivo Cirrus HD-OCT.

- Figura 31. Distribución de las diferencias paquimétricas entre ambos examinadores con el dispositivo Cirrus HD-OCT.

- Figura 32. Gráfica Bland-Altman describiendo la reproducibilidad inter-observador con el dispositivo Lenstar LS 900.

- Figura 33. Distribución de las diferencias paquimétricas de las medidas realizadas por ambos examinadores en el mismo paciente con el dispositivo Lenstar LS 900.

- Figura 34. Gráfica Bland-Altman describiendo la intercambiabilidad de las medidas paquimétricas centrales obtenidas con los dispositivos Lenstar LS 900 y Cirrus HDOCT.

- Figura 35. Distribución de las diferencias paquimétricas de las medidas realizadas por ambos dispositivos (Lenstar LS 900 y Cirrus HD-OCT).

- Figura 36. Gráfica Bland-Altman describiendo la reproducibilidad inter-observador con el dispositivo Topcon 3D OCT-1000.

- Figura 37. Distribución de las diferencias paquimétricas de las medidas realizadas por ambos examinadores en el mismo paciente con el dispositivo Topcon 3D OCT1000.

- Figura 38. Gráfica Bland-Altman describiendo la reproducibilidad inter-sesión con el dispositivo Topcon 3D OCT-1000.

- Figura 39. Distribución de las diferencias paquimétricas entre ambas sesiones en el mismo paciente con Topcon 3D OCT-1000. 
Introducción. 



\section{INTRODUCCIÓN}

\subsection{CÓRNEA.}

\subsubsection{Desarrollo embriológico.}

El desarrollo ocular comienza en la semana 4 de gestación, como una evaginación del neuroectodermo. La invaginación de la vesícula óptica forma el cáliz óptico con una doble capa de ectodermo, en la semana 5. Es entonces cuando el ectodermo superficial forma la placoda del cristalino (vesícula del cristalino), separándose para dar lugar al epitelio corneal y conjuntival, y a la epidermis palpebral [1]

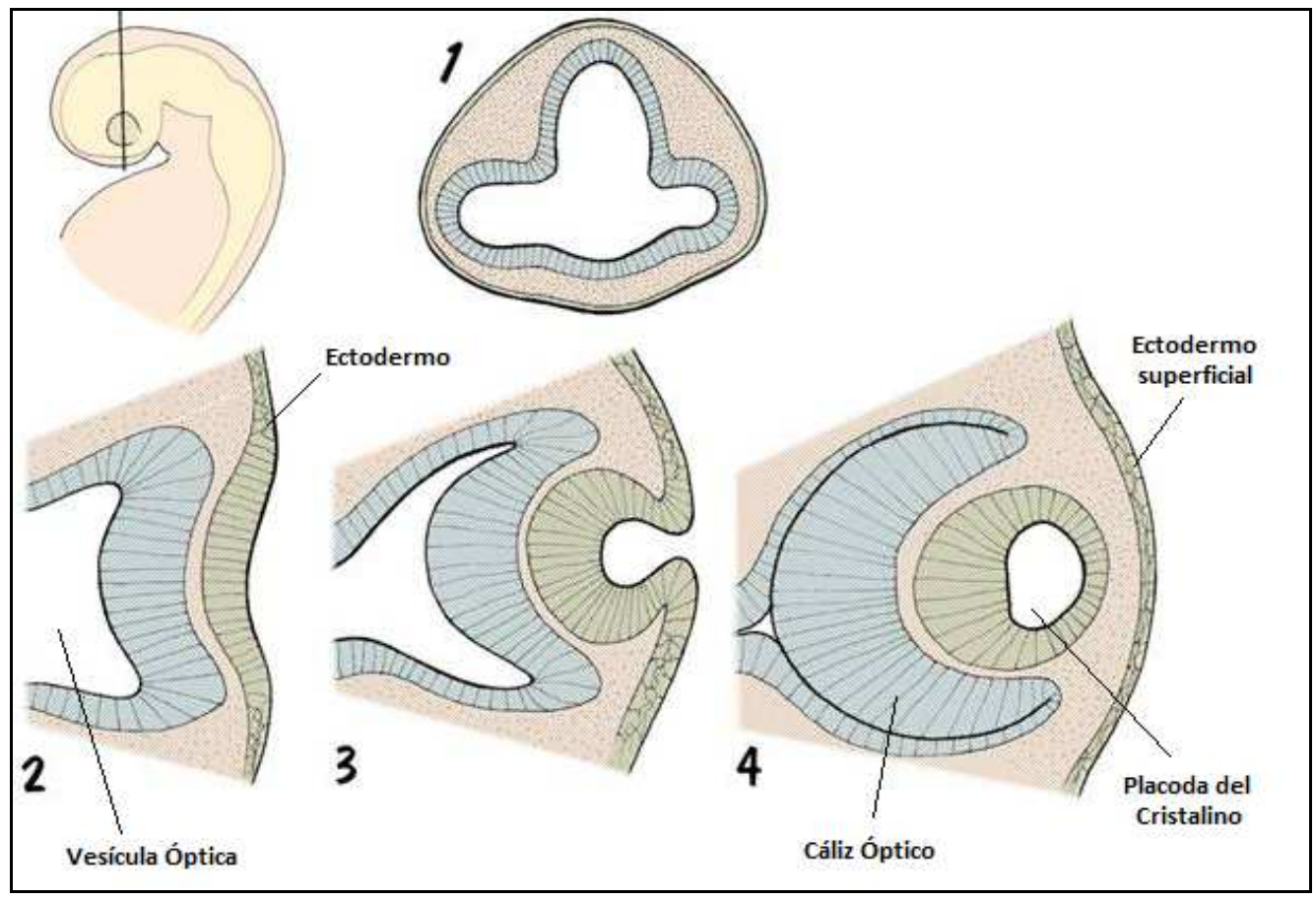

Figura 1. Separación de la placoda del cristalino e inicio del desarrollo corneal (Imagen tomada de www.bionalogy.com/eye_and_ear.htm. Dryden, $R.)^{[2]}$.

Al final de la quinta semana de gestación, el ectodermo superficial está formado por dos capas de células epiteliales sobre una membrana basal fina. Tras la separación de la placoda del cristalino, la capa basal de las células epiteliales comienza a secretar 
fibrillas de colágeno y glucosaminoglucanos, que ocupan el espacio entre el cristalino y el epitelio corneal, constituyendo el estroma primario. Una primera oleada de células mesenquimales migran desde el cáliz óptico a lo largo de la superficie posterior del estroma primario, para dar lugar al endotelio corneal. En torno a la semana 6 la segunda oleada de células mesenquimales desde el cáliz óptico, darán lugar al iris y parte de la membrana pupilar entre en endotelio corneal y el epitelio del cristalino. La tercera migración de células mesenquimales se produce en torno a la semana 7 hacia el estroma corneal para diferenciarse en queratinocitos, que segregan fibrillas de colágeno tipo I y formará la matriz corneal madura ${ }^{[3]}$.

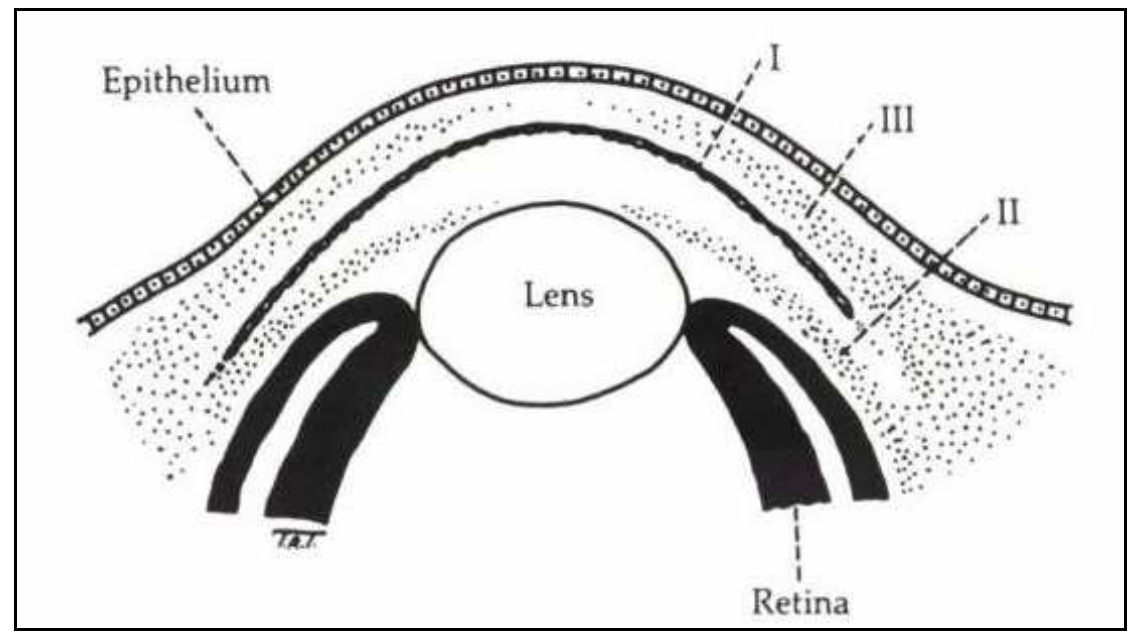

Figura 2. Tres oleadas sucesivas de células mesenquimales de la cresta neural. Dichas oleadas (I, II, III), darán lugar a la diferenciación de la cámara anterior (Imagen tomada de Fundamentals and Principes of Ophtahalmology, American Academy of Ophthalmology) ${ }^{[3]}$.

A los 3 meses, todos los componentes corneales están presentes, salvo la capa de Bowman, que aparecerá junto al espolón escleral, en el cuarto mes.

El grosor y el diámetro corneal se van incrementando progresivamente durante el desarrollo embrionario. Se ha podido demostrar un aumento del diámetro de la córnea en el periodo prenatal, de una media de $2.7 \mathrm{~mm}$ a las 12 semanas pasa a $9.7 \mathrm{~mm}$ a las 40 semanas ${ }^{[4]}$, aunque existen aún muchas dudas acerca del crecimiento corneal en el periodo embrionario. Se cree que tras el nacimiento, el crecimiento de los radios corneales más rápido se produce en los primeros meses de vida ${ }^{[4]}$. Aunque hay pocos datos al respecto, se ha descrito un mayor edema corneal al nacimiento, siendo el grosor 
corneal central en recién nacidos significantemente mayor que en adultos, con valores que varían según las publicaciones. Así entre otros, Remon y colaboradores determinaron valores de $585 \pm 52 \mu \mathrm{m}(446-706 \mu \mathrm{m})^{[5]}$, mientras que Doughty y colaboradores describen una media de $571 \mu \mathrm{m}$ centrales en recién nacidos a término ${ }^{[6]}$. El grosor corneal es mayor en los prematuros, en los que disminuye durante los 3 primeros meses de vida para igualarse en ese tiempo a los nacidos a término ${ }^{[7]}$, habiéndose publicado valores medios de $656 \mu \mathrm{m}$ centrales en esta población ${ }^{[6]}$.

La transparencia va aumentando de manera gradual, alcanzando el valor final antes del nacimiento debido principalmente a la maduración e hidratación del endotelio. Al nacimiento el ojo presenta un tamaño que es el $80 \%$ del tamaño adulto, que se consigue entorno a la edad de dos años ${ }^{[8]}$.

\subsubsection{Recuerdo anatómico y funcional.}

La cornea forma parte del segmento anterior del ojo, con tres funciones principales:

1. Transmisión de la luz con la mínima distorsión y absorción de luz posible.

2. Refracción, existiendo el principal poder refractivo en la interfase entre el aire y la película lagrimal. Dicha interfase debe estar libre de imperfecciones, siendo responsable de aproximadamente dos tercios del poder refractivo del ojo.

3. Protección de la porción anterior del globo ocular, para lo cual la córnea es mecánica y químicamente impermeable.

La consecución de estas funciones se logra gracias a que la córnea es una estructura avascular, estructural y funcionalmente especializada. Suple sus necesidades de oxigenación desde la atmósfera a través de la superficie corneal anterior, y la mayor parte de sus necesidades metabólicas desde el humor acuoso por la superficie corneal posterior $^{[8,9]}$.

La córnea tiene una de las densidades más altas de terminaciones nerviosas del organismo. Las fibras nerviosas sensitivas surgen de los nervios ciliares largos procedentes de la rama oftálmica del nervio trigémino, formando un plexo subepitelial a 
nivel corneal ${ }^{[1]}$. Se calcula que en la córnea hay una inervación sensitiva que es 300 veces mayor que la de la piel y 80 la del tejido dentario ${ }^{[10]}$. Tras formar un plexo anular en el limbo, pierden sus vainas de mielina y penetran en el estroma anterior, desde donde perforan la membrana de Bowman y penetran en el epitelio, en donde se encuentran sus terminaciones. La concentración de estas terminaciones es de 20 a 40 veces mayor que en la pulpa dental y entre 300 a 600 veces más que la piel, con mayor densidad en los dos tercios centrales de la córnea. Esto indicaría que la lesión sobre una sola célula epitelial sería suficiente para provocar la percepción dolorosa ${ }^{[10]}$.

Tiene una morfología cóncava-convexa, constituyendo la sexta parte de la circunferencia del ojo.

El espesor o grosor corneal central normal en un adulto varía según los autores, así Doughty y Zaman ${ }^{[6]}$ determinaron en su meta-análisis una media de $535 \mu \mathrm{m}$, considerándose normales valores entre 503 y $565 \mu \mathrm{m}$. Se ha establecido que la córnea periférica puede ser sustancialmente más gruesa, sobre todo a nivel nasal y temporal ${ }^{[6,}$ ${ }^{9]}$, con valores entre un 9 y un $52 \%$ (media de $21 \%$ ) mayores ${ }^{[6]}$. Igualmente, se han descrito cambios a lo largo del día, con una variación media del espesor corneal central de $14 \mu \mathrm{m}{ }^{[11]}$, apareciendo el espesor corneal máximo al abrir el ojo tras el descanso nocturno, debido a cambios metabólicos que se producen durante el sueño ${ }^{[6,11]}$. Cómo se ha comentado anteriormente, se ha descrito un mayor grosor corneal central al nacimiento ${ }^{[5-7]}$.

La córnea transparente se une a la esclera opaca, a través del limbo córneoescleral. Siendo circular en su visión posterior, se aprecia oval al visualizarla desde su superficie anterior, por un limbo más prominente superior e inferiormente. El diámetro corneal medio en el adulto es de $12.6 \mathrm{~mm}$ horizontalmente y $11.7 \mathrm{~mm}$ verticalmente ${ }^{[8]}$.

Su superficie anterior no es curva de manera homogénea, sino que se caracteriza por un aplanamiento y disminución de de la potencia hacia la periferia (asfericidad corneal) ${ }^{[12]}$. El tercio corneal central de aproximadamente $4 \mathrm{~mm}$ de diámetro recibe el nombre de zona óptica, con una media de curvatura a dicho nivel de $7.8 \mathrm{~mm}^{[8]}$. El poder refractivo corneal total es próximo a las 44 dioptrías (+48 dioptrías de la cara anterior, y -5 dioptrías de la cara posterior) ${ }^{[9]}$. 


\subsubsection{Histología.}

La córnea se divide en 5 capas, siendo de la más externa a la más interna: Epitelio, Membrana de Bowman, Estroma, Membrana de Descemet y Endotelio.

Aunque la película lagrimal no es parte de la córnea, está íntimamente asociada anatómica y funcionalmente a la misma.

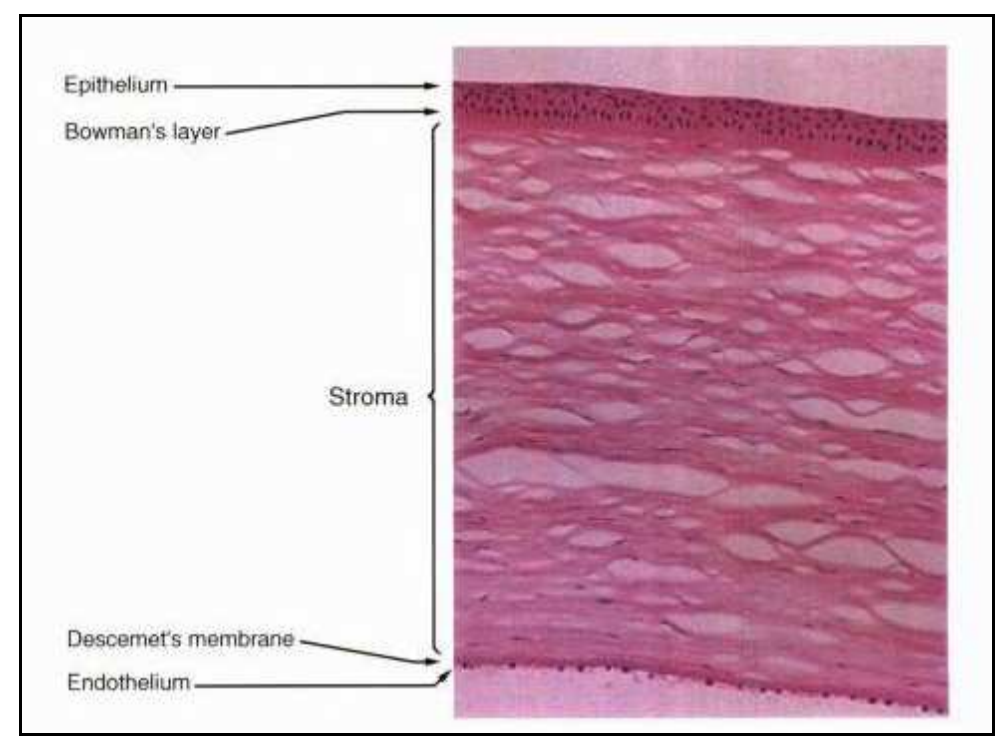

Figura 3. Corte histológico de una córnea normal (tinción con Hematoxilina y Eosina) (Imagen tomada de External disease and Cornea, American Academy of Ophthalmology) ${ }^{[1]}$.

\section{A. Película Lagrimal.}

Recubre la superficie corneal, estando estrechamente unida anatómica y funcionalmente a la misma.

Las principales funciones de la película lagrimal son:

1. Proporcionar una superficie óptica lisa en la interfase aire-ojo.

2. Eliminar materiales de desecho.

3. Proteger la superficie ocular.

4. Aportar oxígeno y factores de crecimiento a la córnea ${ }^{[3]}$.

Clásicamente, la película lagrimal se ha separado en tres capas: lipídica, acuosa y mucosa. No obstante, actualmente se considera más como una estructura bilaminar formada por una fina capa lipídica $(0.5 \mu \mathrm{m})$ y otra gruesa hidro-mucosa (6 $\mu \mathrm{m}$ o más), con un espesor total de aproximadamente $7 \mu \mathrm{m}^{[9]}$. 


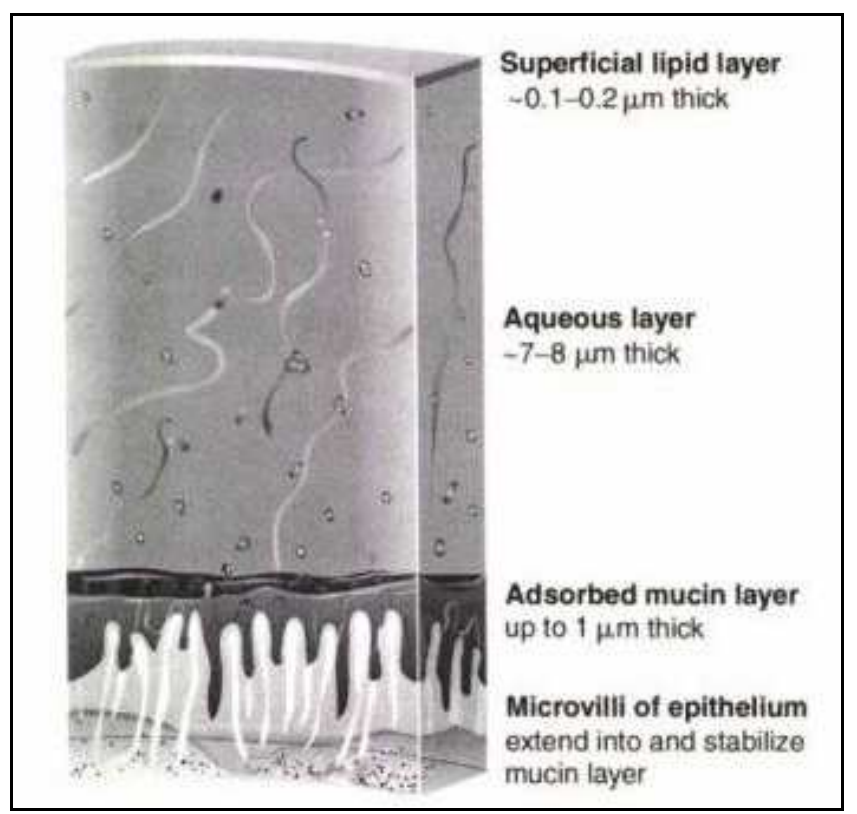

Figura 4. Estructura de la película lagrimal (Imagen tomada de Fundamentals and Principes of Ophtalmology, American Academy of Ophthalmology) ${ }^{[3]}$.

La capa lipídica es la capa anterior de la película lagrimal. Está formada por lípidos secretados principalmente por las glándulas de Meibomio (sebáceas) situadas en el tarso de párpado superior e inferior, e inervadas por nervios parasimpáticos. Las glándulas de Zeiss (sebáceas) y Moll (sudoríparas apocrinas) también contribuyen. Sus principales funciones son prevenir la evaporación de la lágrima, contribuir a sus propiedades ópticas (interfase aire-lágrima), formar una barrera hidrofóbica (evitar rebosamiento de la lágrima), y prevenir la lesión de la piel de los párpados ${ }^{[3,13-15]}$.

La capa acuosa es la capa intermedia de la lágrima. Está formada por electrolitos, proteínas y agua (98.3\%). La secreción basal es realizada por las glándulas lagrimales accesorias (Krause y Wolfring), mientras que la secreción refleja corre a cargo de la glándula lagrimal principal. Sus principales funciones son aportar oxígeno al epitelio corneal (siendo la mayor fuente del mismo), mantener los electrolitos en la superficie ocular, alisar las irregularidades de la superficie corneal, eliminar los productos de desecho, modular la función de las células epiteliales corneales y conjuntivales, y proporcionar defensa antibacteriana y antivírica (IgA, lisozima, lactoferrina, fosfolipasa $\mathrm{A}_{2}$, lipocalinas, defensinas, interferón, citokinas y factores de crecimiento) ${ }^{[3,13,14]}$. 
La capa mucosa está en contacto directo con los micropliegues de las células del epitelio corneal y superficie conjuntival. Contiene mucinas, proteínas, electrolitos y agua, secretados mayoritariamente por las células caliciformes conjuntivales. Sus principales funciones son estabilizar la película lagrimal, ejercer una defensa y limpieza de la superficie (atrapando células superficiales exfoliadas, partículas extrañas y bacterias), y lubricar los párpados ${ }^{[3,14]}$.

\section{B. Epitelio Corneal.}

Es un epitelio no queratinizado, escamoso estratificado, que constituye el 5-10\% $(50 \mu \mathrm{m})$ del espesor corneal total. Está dividido morfológicamente en tres capas: la capa escamosa superficial, una capa intermedia y la capa basal más profunda ${ }^{[9]}$. El epitelio corneal y la película lagrimal forman una superficie ópticamente lisa. Las uniones estrechas entre las células epiteliales superficiales impiden la penetración de la lágrima al estroma ${ }^{[1]}$. Las células germinales del epitelio corneal se encuentran en el limbo, y dan lugar a una proliferación continuada de las células epiteliales basales que son las únicas que experimentan mitosis. La pérdida de estas células germinales puede determinar la pérdida de la trasparencia corneal ${ }^{[9,16,17]}$. Las células epiteliales basales van avanzando anteriormente, diferenciándose hasta dar lugar a las células superficiales, que al madurar se recubren de microvellosidades en su superficie. En su fase final se descamarán hacia la lágrima ${ }^{[1]}$. El recambio celular se completa aproximadamente cada 7 días $[1,9,18]$.

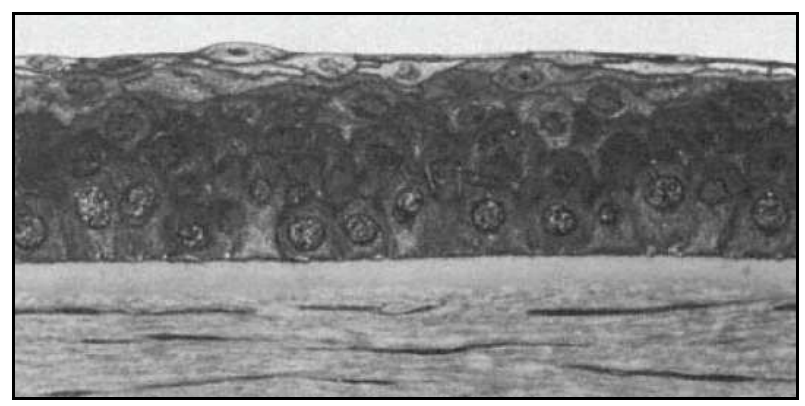

Figura 5. Epitelio corneal (Imagen tomada de The Cornea. Kaufman H.E.) ${ }^{[9]}$. 
El epitelio corneal actúa como una barrera, limitando los fluidos que entran desde la lágrima y protegiendo el ojo de muchos patógenos. Para ello, es fundamental su constante renovación para así mantener la integridad celular y su capacidad de respuesta ante una agresión ${ }^{[10]}$.

Utiliza primariamente glucosa, que toma desde el humor acuoso y acumula intracelularmente en grandes cantidades. El acumulo de glucógeno celular disminuye en situaciones de stress, como pueden ser un traumatismo o el uso de lentes de contacto [10]

El epitelio recibe el oxígeno directamente desde la atmósfera, con el ojo abierto, por lo que con los ojos cerrados la cantidad de oxígeno decrece. Así, en el cierre palpebral nocturno el aporte de oxígeno a la córnea se reduce a 1/3 del que recibe durante el día. Por ello, sufre un edema nocturno por la formación y acumulo de lactato intracelular que clínicamente se manifiesta en formación de halos y reducción de sensibilidad al contraste ${ }^{[10]}$.

\section{Membrana de Bowman.}

La membrana o capa de Bowman tiene un espesor total de aproximadamente 8$12 \mu \mathrm{m}$, y está compuesta por fibras de colágeno con un diámetro de 20-25 nm dispuestas en varias direcciones. Su cara anterior es contigua al epitelio corneal, mientras que su cara posterior no está completamente bien definida, al encontrarse sus fibras colágenas entremezcladas con las estromales ${ }^{[19]}$. Se considera resistente al traumatismo, y ofrece una barrera a la invasión corneal por microorganismos y células tumorales. Se ha demostrado que no tiene capacidad regeneradora tras lesionarse, pudiéndose formar una nueva capa de estructura idéntica pero mucho más fina ${ }^{[9,20]}$.

\section{Estroma.}

$\mathrm{Su}$ grosor central es de 0,5-0,54 $\mathrm{mm}(500-540 \mu \mathrm{m})$, siendo mayor en la periferia donde puede alcanzar hasta $0,7 \mathrm{~mm} \quad(700 \mu \mathrm{m}){ }^{[10]}$. Constituye 
aproximadamente el $90 \%$ de la córnea. Está formado por fibras de colágeno, sustancia fundamental y células del estroma, siendo el 78\% agua.

Las fibras de colágeno constituyen aproximadamente el $80 \%$ del peso seco de la córnea ${ }^{[20]}$. Los tres tipos de colágeno (I, III y V) existen en la córnea humana adulta, siendo el colágeno tipo I el predominante. Dichas fibras se cruzan entre sí de forma regular, discurriendo paralelas entre sí y a la superficie de la córnea, recorriendo cada una toda la longitud corneal. Presentan aproximadamente 250-300 $\mu \mathrm{m}$ de diámetro, con escaso recambio anual ${ }^{[20-22]}$.

La sustancia fundamental constituye aproximadamente el $15 \%$ del peso seco de la córnea ${ }^{[20]}$. Ésta sustancia, que rodea las fibrillas de colágeno, está formada principalmente por proteoglicanos (decorina y lumicán los más abundantes), a los que se unen oligosacáridos y glucosaminoglucanos (queratán-sulfato y condroitín sulfato principalmente). Las concentraciones y la relación entre los proteoglicanos varían desde la zona anterior a la posterior ${ }^{[1,21]}$. La sustancia fundamental desempeña un papel para mantener la disposición regular de las fibras de colágeno, la decorina y el lumicán inhiben el crecimiento del diámetro de las mismas.

Los elementos celulares constituyen aproximadamente el 5\% del peso seco de la córnea ${ }^{[20]}$. El queratocito es la célula que predomina en el estroma, encontrándose entre láminas de colágeno, con prolongaciones de forma estrellada dentro del mismo plano lamerar. Los queratocitos elaboran el colágeno y la matriz extracelular estromal. En respuesta a una lesión del estroma, éstos migran a la zona y se transforman en fibroblastos, contribuyendo a la formación de la cicatriz. Además de los queratocitos, se observa una pequeña cantidad de leucocitos polimorfonucleares, células plasmáticas, y macrófagos, entre las láminas de las fibras de colágeno ${ }^{[20]}$. 


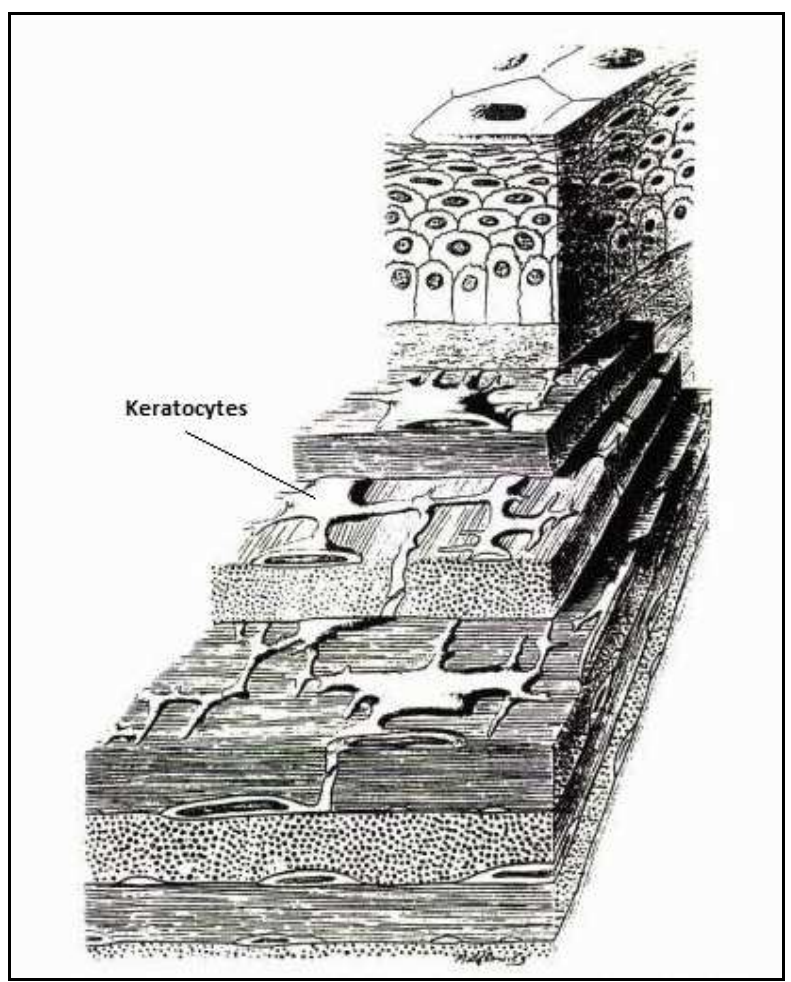

Figura 6. Organización de los queratocitos en el estroma corneal, mostrando la conexión entre las lamelas (Imagen tomada de External disease and Cornea, American Academy of Ophthalmology) ${ }^{[1]}$.

La transparencia corneal depende de la distribución y diámetro de las fibrillas de colágeno embebidas en la matriz extracelular, que actúan como una rejilla de difracción para reducir la dispersión de la luz. Por ello, para que la córnea pueda cumplir con la función de transmisión de la luz, es esencial que la disposición y diámetro de las fibras estromales sean constantes. Depende también del contenido de agua del estroma corneal, siendo más abundante más cerca del endotelio ${ }^{[1,10,23]}$. Cuando hay edema estromal, el tamaño de las fibras de colágeno no cambia, pero sí lo hacen la sustancia fundamental y el espacio entre las fibrillas y su orientación ${ }^{[10,20]}$. Cuando la córnea se edematiza, las fibras cambian su orientación y la luz sufre una dispersión al atravesarla, explicando la pérdida de transparencia que se aprecia cuando se observa clínicamente un edema corneal ${ }^{[10]}$. La hidratación corneal está controlada principalmente por las barreras epiteliales y endoteliales intactas y por el funcionamiento de la bomba endotelial $^{[1]}$. 


\section{E. Membrana de Descemet.}

Se trata de una lámina basal gruesa producida por el endotelio. Tiene un espesor que aumenta desde $3 \mu \mathrm{m}$ al nacer hasta aproximadamente $10-12 \mu \mathrm{m}$ en los adultos, ya que las capas de endotelio van acumulándose gradualmente hasta formar una zona posterior amorfa sin segmentos apreciables, dando lugar a la membrana de Descemet ${ }^{[1,}$ 20]. Contiene colágeno tipo IV, VIII y fibronectina. En el ojo normal, puede presentar engrosamientos localizados en su periferia, que reciben el nombre de cuerpos de Hassall-Henle, formados por restos celulares y otros depósitos no bien conocidos, y que se relacionan con el envejecimiento.

Ante un estímulo inflamatorio, traumatismo o alteraciones genéticas, las células endoteliales pueden producir un engrosamiento de la membrana de Descemet, así como acumular depósitos de sustancias metálicas en determinados procesos patológicos ${ }^{[20]}$. La membrana de Descemet se puede desprender del estroma con facilidad, regenerándose espontáneamente con rapidez tras su lesión cuando es un desprendimiento localizado ${ }^{[24,25]}$.

\section{F. Endotelio.}

El endotelio tiene un grosor de 4-6 $\mu \mathrm{m}$ aproximadamente ${ }^{[9]}$. Está formado por células íntimamente entrelazadas distribuidas en un patrón de mosaico con formas casi hexagonales. La densidad celular varía a lo largo de la superficie corneal, siendo generalmente la concentración mayor en la periferia. Su población disminuye con la edad desde 3.500-4.000 células $/ \mathrm{mm}^{2}$ al nacer hasta $1.400-2.500$ células $/ \mathrm{mm}^{2}$ en la córnea adulta $^{[9]}$, no existiendo por lo general actividad mitótica en el endotelio tras el nacimiento. La pérdida de células endoteliales ya sea por la edad, o por un traumatismo, provoca el aumento de tamaño del resto de células, así como su diseminación hacia células vecinas para cubrir la zona defectuosa $[1,9,20]$. Éstas pueden continuar su función pese al aumento de tamaño, manteniendo la función corneal, incluso con densidades celulares muy reducidas, considerándose críticas cifras de 500 células $/ \mathrm{mm}^{2}$ o menos $[9,10,26]$. 


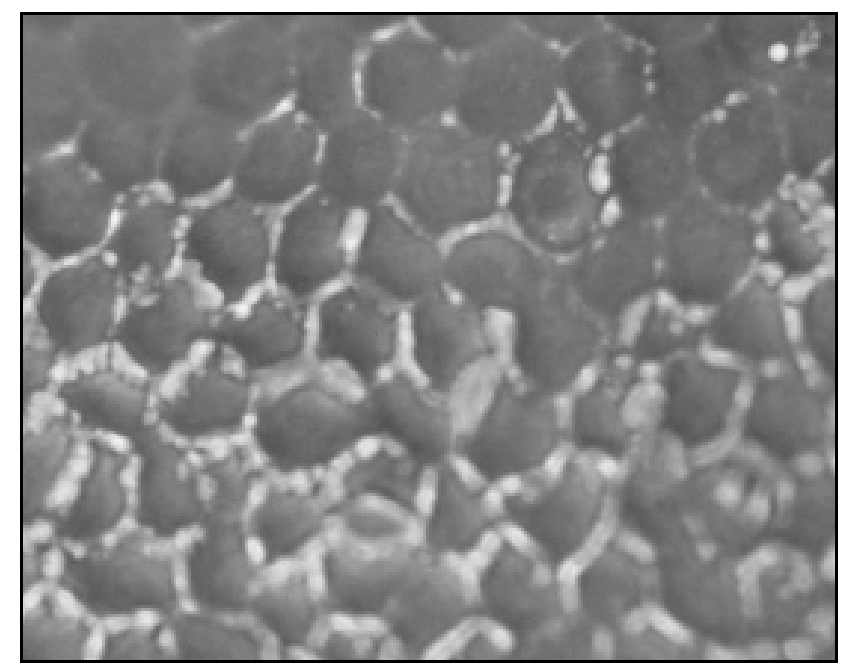

Figura 7. Capa celular endotelial adherida a membrana de Descemet (Imagen tomada de Peh G.S. $y$ colaboradores) ${ }^{[27]}$.

Las células endoteliales actúan como una barrera para el fluido desde la cámara anterior hacia el estroma, que tiene la capacidad de absorber grandes cantidades de agua, originando edema corneal. La barrera endotelial regula el movimiento de agua y sustancias desde la cámara anterior hacia el estroma, pero a pesar de ello, existe un paso constante de humor acuoso a través de los espacios intercelulares hacia el estroma, transportando glucosa, aminoácidos y otros nutrientes esenciales. Las uniones celulares son las responsables de limitar este paso ${ }^{[10,27]}$.

Aparte de su función como barrera, las células endoteliales son las más activas metabólicamente dentro de la córnea, actuando continuamente para mover de forma activa el exceso de fluido estromal hacia la cámara anterior (la córnea en condiciones normales contiene un $78 \%$ de agua) ${ }^{[10,27]}$. De esta manera se mantiene la transparencia corneal y su grosor constante. Esta actividad, llamada bomba endotelial, resulta del flujo de iones sodio y bicarbonato por la membrana celular, siendo la Na+-K+ ATPasa la actividad más importante en este mecanismo de bombeo ${ }^{[10]}$.

A pesar de los cambios producidos por la edad, la actividad de barrera y bombeo del endotelio no sufren alteraciones, aunque si lo hace la población celular ${ }^{[10]}$. 


\subsection{PAQUIMETRIA}

Hablando de grosor corneal, existe la posibilidad de poder medirlo. Así, definimos paquimetría como el espesor o grosor de la córnea en cualquiera de sus localizaciones ${ }^{[8,9]}$. Ha adquirido especial relevancia en los últimos años como un elemento fundamental en la evaluación pre y postoperatoria de la cirugía refractiva ${ }^{[28-}$ 30], así como en el seguimiento de la hipertensión ocular y del glaucoma ${ }^{[31]}$. Su medición facilita además el diagnóstico y manejo de los trastornos con adelgazamiento corneal ${ }^{[32]}$, y también se puede usar para evaluar de manera indirecta la función del endotelio corneal $^{[1]}$.

Existen distintos métodos para valorar la paquimetría. Los más utilizados clásicamente son los paquímetros ópticos y ultrasónicos, pero en los últimos años han aparecido nuevas técnicas que se están empleando con este mismo fin. Así, podríamos clasificar los paquímetros como de contacto y no contacto.

\subsubsection{PAQUIMETRÍA DE CONTACTO.}

\subsubsection{Paquimetría Ultrasónica.}

Se considera el patrón oro ("gold standard") para la estimación del grosor corneal central ${ }^{[28,33]}$, siendo la técnica más usada clásicamente, al considerarse un método válido y fiable para ello ${ }^{[32,34]}$. El aparato emite una onda ultrasónica de 20 $\mathrm{MHz}$ mediante activación por una corriente eléctrica de material piezoeléctrico. Esa onda atraviesa la córnea, es reflejada por la interfase endotelio-humor acuoso, y vuelve al terminal del paquímetro, que calcula el tiempo que tardó la señal desde su salida a su regreso. Se basa en la velocidad del sonido en la córnea normal $(1640 \mathrm{~m} / \mathrm{s})$. El rango de medicines del aparato es de 200-900 $\mu \mathrm{m}$, con una seguridad de $\pm 5 \mu \mathrm{m}$ y una resolución de $\pm 1 \mu \mathrm{m}^{[28]}$.

El terminal del paquímetro debe estar perpendicular a la superficie corneal previa instilación de colirio anestésico, procurando que la punta esté seca y la córnea 
adecuadamente lubricada. Ofrece automáticamente la medición, dando un promedio de las distintas tomas realizadas ${ }^{[1,28]}$.

Cómo desventajas presenta la necesidad de tocar la superficie corneal, con la necesidad de instilar anestesia tópica, y el consecuente malestar ocular en el paciente. Existe por dicho contacto un riesgo de infección y de daño epitelial asociado. La exactitud de la medida depende de la perpendicularidad con la que el terminal se apoya en la córnea, y la reproducibilidad se basa en la colocación en el centro corneal ${ }^{[32]}$.

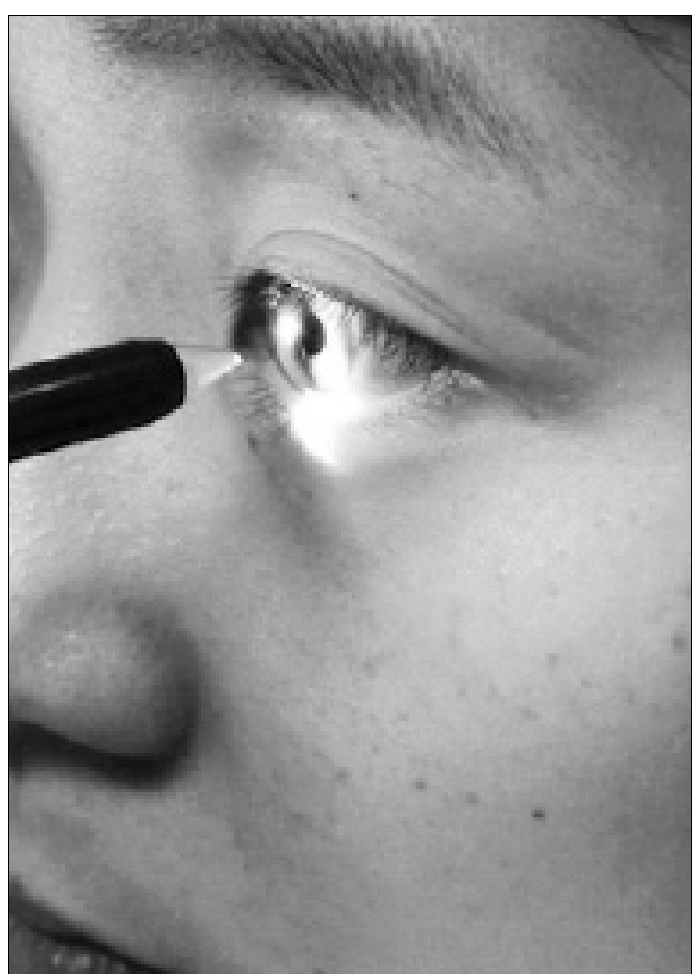

Figura 8. Paquímetro Ultrasónico (Imagen tomada de Hong J.P. y colaboradores) ${ }^{[35]}$.

\subsubsection{Ecografía del Segmento Anterior: Biomicroscopía Ultrasónica.}

Al ser una técnica ecográfica, se basa en la emisión de ultrasonidos que al atravesar los diferentes tejidos y ser reflejados hacia nuestro receptor van a transmitirnos información acerca de los tejidos atravesados. 
La ecografía del segmento anterior puede usar los métodos de escáner A y B. El método de escáner B se conoce como Biomicroscopía Ultrasónica (BMU).

La BMU es una técnica ecográfica de alta resolución que permite analizar con detalle las estructuras del segmento anterior ocular, siendo útil para evaluar córnea, cámara anterior, iris, cristalino, espacios retrolentales y retroiridianos, así como el cuerpo ciliar. Este instrumento de $50 \mathrm{~Hz}$ proporciona gran detalle de las estructuras anteriores, pero su mayor frecuencia no penetra más de 1.5-2 $\mathrm{mm}$ en el ojo ${ }^{[1]}$.

La BMU Es una técnica de inmersión, por ello es preciso utilizar un medio transmisor adecuado que se interponga entre el transductor y la superficie del globo ocular. Este medio puede ser acuoso (suero) o un gel (metilcelulosa). Con cualquiera de ellos necesitamos utilizar un receptáculo (copa ocular u orbitaria). Al ser una técnica de inmersión, el paciente debe ser explorado en decúbito supino y por ello, necesitamos una camilla o un sillón de exploración que pueda ser colocado en posición horizontal. Tras la instilación de la anestesia tópica y colocar al paciente en decúbito se procederá a colocar la copa ocular. Todo esto debe conllevar una buena colaboración por parte del paciente. Otra de las características que puede condicionar la exploración es el constante movimiento lineal oscilatorio del transductor ${ }^{[36]}$, que puede ocasionar molestias en el paciente con la consiguiente mala colaboración.

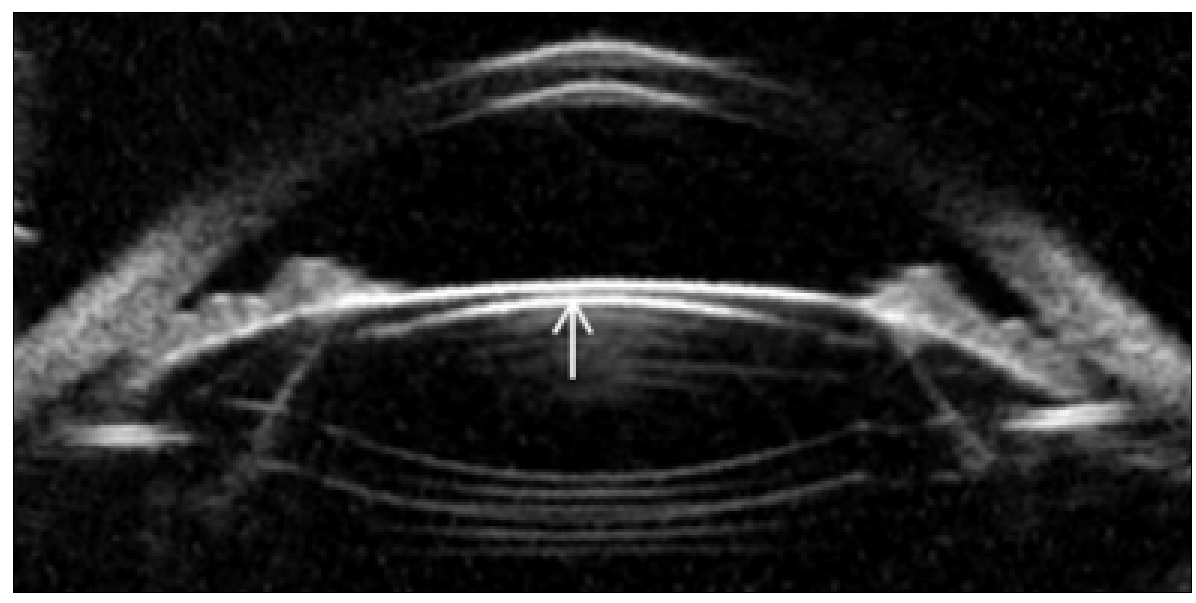

Figura 9. Imagen de Biomicroscopía Ultrasónica del segmento anterior (Imagen tomada de Dougherty P.J. y colaboradores) ${ }^{[37]}$. 


\subsubsection{PAQUIMETRÍA DE NO CONTACTO.}

\subsubsection{Paquimetría Óptica.}

La paquimetría óptica ha sido usada en diversas poblaciones en distintos estudios de glaucoma. Otros usos incluyen la medida de la profundidad de la cámara anterior $^{[38,39]}$.

El paquímetro de Haag-Streit (Haag-Streit, Bern, Suiza) es probablemente el más utilizado para paquimetría óptica. Para ser usado con la lámpara de hendidura Haag-Streit 900, presenta dos opciones:

- Opción I: mide anchuras de hasta $1.2 \mathrm{~mm}$, y es empleada para la medición del espesor corneal.

- Opción II: mide anchuras de hasta $6.0 \mathrm{~mm}$, siendo usada para medir profundidad de la cámara anterior, incluyendo o no del grosor corneal ${ }^{[39]}$.

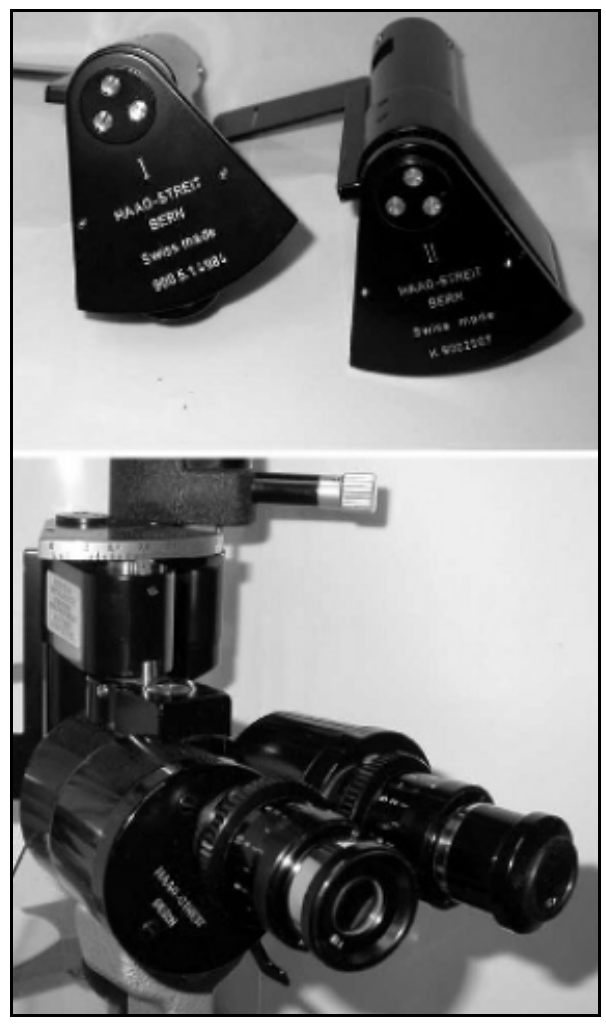

Figura 10. Paquímetro Óptico Haag-Streit en lámpara de hendidura Haag-Streit 900 (Imagen tomada de Bourne R.R. y colaboradores) ${ }^{[39]}$. 
El dispositivo que se une a la lámpara de hendidura, con una iluminación en hendidura desplazada $40^{\circ}$ respecto al eje del observador. La imagen obtenida es duplicada por medio de un dispositivo de doble espejo que se coloca delante de los objetivos del microscopio. Al desplazar uno de los espejos, para hacer coincidir el borde epitelial de una imagen con el borde endotelial de la otra, obtendremos la medida real del espesor corneal, calculada a partir del grado de rotación realizado en el plato superior, que se lee directamente en el instrumento. Luego se aplica un factor de corrección según el radio de curvatura de la córnea explorada (escalas adjuntas con el paquímetro). Para realizar una paquimetría en otras zonas diferentes al centro debe procurarse mantener una orientación perpendicular del eje del haz luminoso con respecto a la superficie.

Sus principales ventajas son la evaluación del grosor corneal de forma dinámica, la posibilidad de medir prácticamente cualquier zona de la córnea, y que se trata de un instrumento sencillo y económico ${ }^{[28]}$.

\subsubsection{Tomografía de Coherencia Óptica.}

La Tomografía de Coherencia Óptica (Optical Coherence Tomography: OCT) es una técnica diagnóstica no invasiva, objetiva y versátil, proporcionando rápidamente un corte transversal en dos dimensiones, de las distintas estructuras. La primera OCT de retina fue realizada por David Huang en $1989^{[40]}$, publicando sus resultados junto a sus colaboradores en $1991^{[41]}$.

\section{A. Bases Físicas.}

Presenta un funcionamiento similar a la ecografía, basándose ambos en la medición de la latencia y la intensidad de la onda que se refleja tras incidir sobre un tejido. La principal diferencia con la ecografía es que en ésta se emplean ultrasonidos, y en la OCT radiación luminosa. Esto es importante, pues la velocidad con la que se desplazan las ondas lumínicas es mucho mayor, permitiendo representar una imagen en dos dimensiones con una resolución espacial muy elevada. Las variaciones que se 
producen sobre esa radiación al penetrar en profundidad en el tejido, nos llevan a obtener un registro axial o longitudinal, llamado "A-scan". Si obtenemos múltiples Ascans desplazando nuestro haz incidente sobre el tejido siguiendo una línea recta, lograremos un corte transversal o de barrido, que se denomina "B-scan". La obtención de varios B-scans en paralelo generará un cubo tridimensional, con toda la información en profundidad del tejido sobre el que ha incidido la radiación ${ }^{[40]}$.

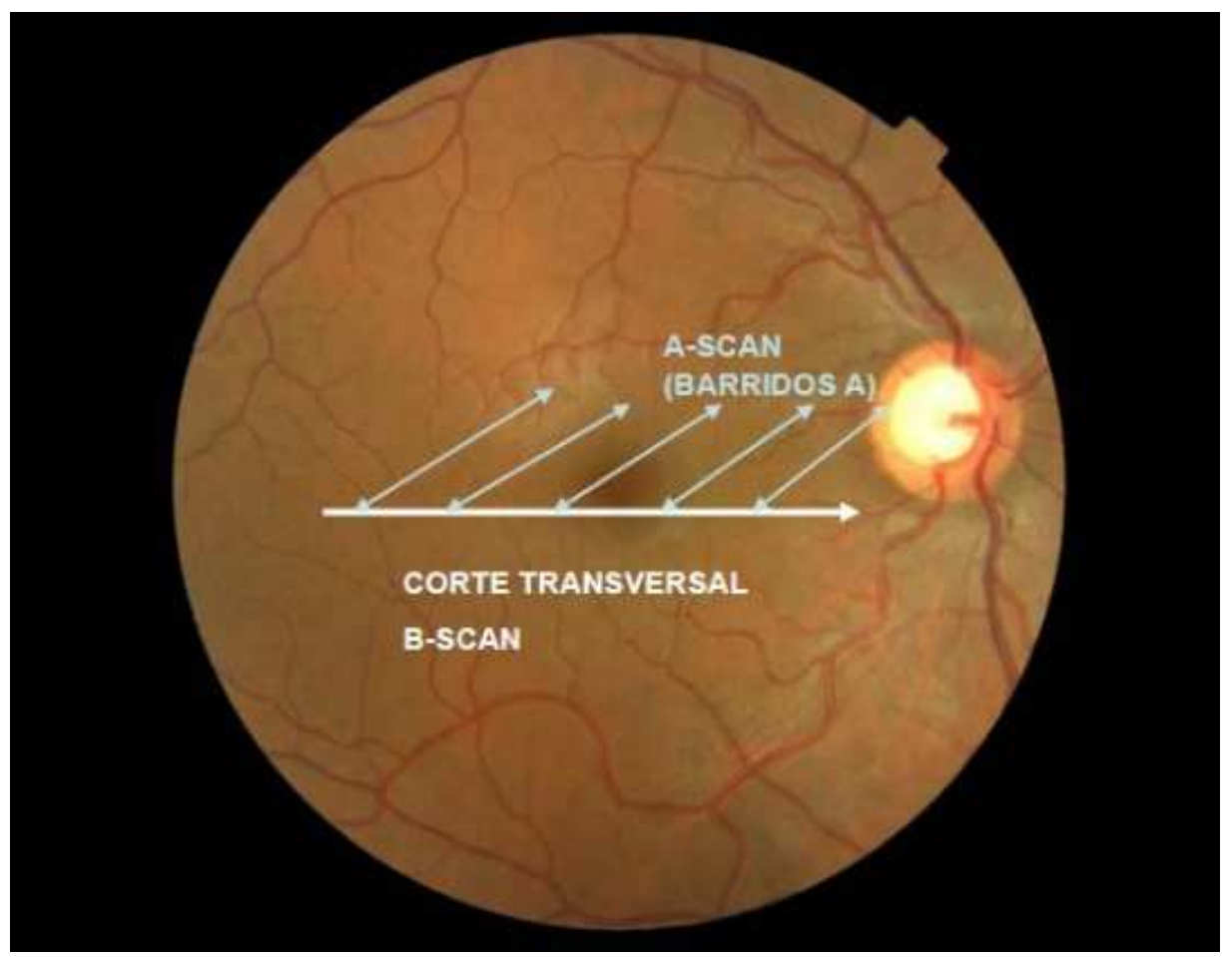

Figura 11. Representación del barrido B-scan compuesto por múltiples A-scan (Imagen tomada de Flores Rodriguez P.C. ${ }^{[42]}$.

Se basa en el principio de interferometría de baja coherencia (principio de interferometría de Michelson ${ }^{[43]}$ ), dónde un rayo de luz monocromático producido por una fuente de diodos superluminiscentes, es proyectado desde la unidad de OCT. Éste se encuentra en el rango próximo al infrarrojo y por tanto apenas visible, con la comodidad que ésto representa para el paciente. Un divisor de haces separa dicho rayo en dos, uno a un espejo en el brazo de referencia (recorre un camino de longitud conocida, a través de un medio conocido) y otro de medida al tejido ocular del paciente en forma de barrido, que sufrirá modificaciones según las propiedades de dicho medio. Tras este recorrido los dos rayos se vuelven a reflejar para coincidir ambos en el mismo 
punto, y el fotodiodo detecta la señal interferométrica resultante tras interferir los dos haces entre sí. La unidad de OCT emplea un interferómetro de Michelson para llevar a cabo todo este proceso. El OCT mide el retraso del tiempo del eco luminoso y la intensidad de la reflectividad. Cada capa de la retina tiene diferentes propiedades de reflectividad y se presenta en diferente escala de colores o grises en la pantalla. Las estructuras con más alta reflectividad se representan en color rojo o blanco (significa que el tejido tiene una gran reflexión, bloqueando la transmisión de la luz), las de media reflectividad aparecen en verde y amarillo, y las menos reflejantes lo hacen en negro y azul (poca reflexión de la luz). ${ }^{[40,44,45]}$.

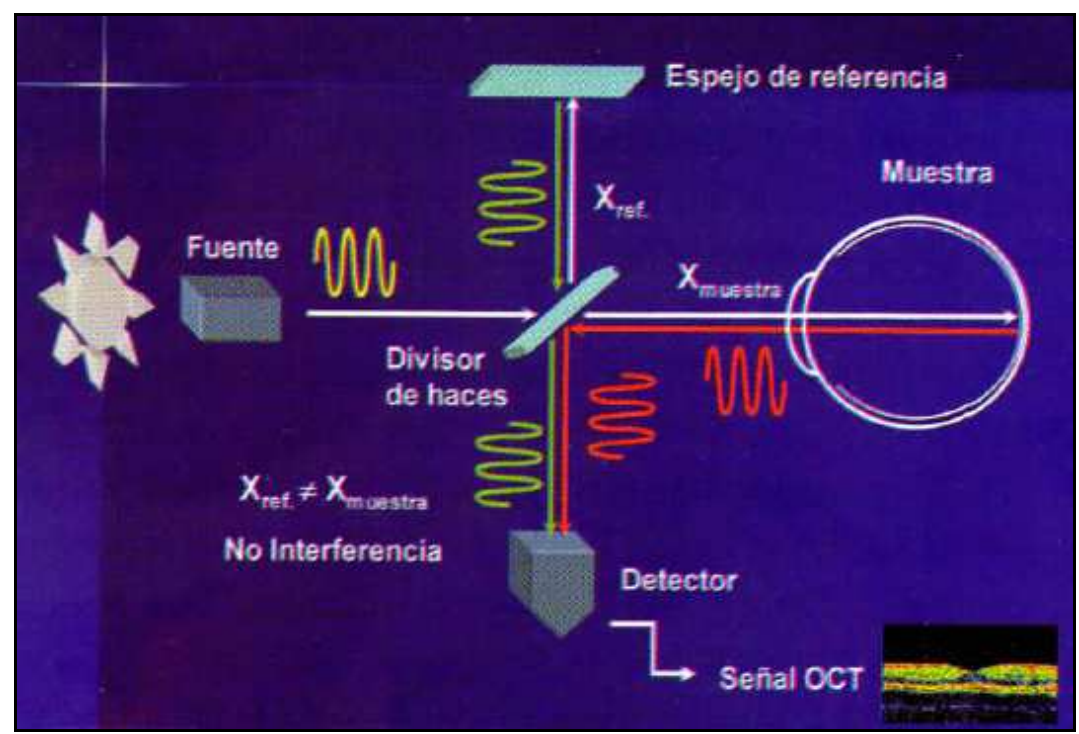

Figura 12. Interferómetro de Michelson (Imagen tomada de la LXXXVII Ponencia Oficial de la Sociedad Española de Oftalmología. Muñoz Negrete F.J., Rebolleda G., Díaz Llopis M.) ${ }^{[40]}$.

La OCT está basada en la interferometría de baja coherencia. En ella la longitud a la que la interferencia de la luz ocurre es acortada a micras, debido al uso de fuentes de luz de banda ancha (que pueden emitir luz sobre una amplia gama de frecuencias). En contraposición a la interferometría convencional con longitud de coherencia larga (interferometría láser), en la que la interferencia de la luz ocurre en una distancia de metros. La luz de banda ancha puede ser generada usando diodos superluminiscentes (LED superbrillantes) o láseres con pulsos extremadamente cortos (láseres de femtosegundo) ${ }^{[40]}$. 


\section{B. Tipos de OCT.}

Hay dos categorías principales de la instrumentación de OCT: la de dominio en el tiempo OCT (Time-Domain: TD-OCT) y la de dominio espectral (Spectral Domain: SD-OCT). Los equipos basados en el dominio espectral están reemplazando rápidamente a la tecnología "Time-Domain" en la mayoría de las aplicaciones, ya que ofrece ventajas significativas en la sensibilidad y la velocidad de imagen.

- OCT de Dominio en el Tiempo (anglosajón, Time-domain OCT).

Los más representativos de este tipo fueron los aparatos denominados OCT Version 1 y 2, y el Stratus OCT. El sistema compara el retraso de la luz reflejada desde la retina con el retraso del haz proyectado desde el espejo de referencia a una distancia conocida. Se produce una interferencia al combinar ambos haces de luz, que es detectada y medida por un fotodetector usando interferometría de baja coherencia. La distancia de los ecos (A-scans) reflejados desde la retina se determina mediante variaciones en la posición del espejo de referencia ${ }^{[46]}$, distancias que dependerán de la reflectividad de la muestra ${ }^{[45]}$. La velocidad de obtención de las imágenes está limitada por la velocidad de oscilación del espejo del brazo de referencia. En la OCT de dominio en el tiempo, el espejo de referencia tiene que moverse un ciclo completo en cada barrido axial. La necesidad de este movimiento limita la velocidad del sistema a unos 400 barridos por segundo ${ }^{[40,45]}$; ej. 512 A-scans en 1.3 segundos en el Stratus OCT ${ }^{[46]}$.

- $\quad$ OCT de Dominio Espectral (anglosajón, Spectral-domain OCT).

En la OCT de dominio espectral el espejo de referencia se mantiene fijo, permitiendo así, la ausencia de elementos mecánicos, dando lugar a un gran aumento en la velocidad de adquisición ${ }^{[40,46]}$. La señal es detectada variando la longitud de onda de la fuente de luz en el tiempo. Estas características permiten aumentar a 18.000-40.000 A-scans por segundo según dispositivos, disminuyendo los artefactos por movimiento involuntario del ojo ${ }^{[46]}$.

El SD-OCT presenta dos métodos de adquirir la información de un tejido bajo estudio: "Fourier-domain" OCT (FD-OCT) y el "Swept-Source" OCT (SS-OCT; OCT de Fuente con Barrido). 
En el FD-OCT, la información se obtiene a gran rapidez, pudiéndose llegar hasta 26.000 A-scan/segundo. Esto es 65 veces más rápido que el TD-OCT ${ }^{\text {[45] }}$.

Comparando la técnica TD-OCT y FD-OCT, ésta última puede obtener mayor sensibilidad y velocidad en la captura de la imagen, mejorándose la relación señal-ruido y disminuyendo artefactos. Su mayor velocidad permite la adquisición de más cortes, pudiéndose crear imágenes tridimensionales de las estructuras de la retina, controlándose todas las zonas sin que ninguna quede fuera, frente a los 6 cortes radiales que realiza el TD-OCT ${ }^{[45]}$.

Spaide y colaboradores ${ }^{[47]}$ introdujeron cambios en la adquisición de los datos del SD-OCT (EDI-OCT: enhaced depth imaging OCT -imágenes de profundidad mejorada-), que permite una mayor visualización de estructuras como la coroides. Los nuevos dispositivos de OCT, permitirán alcanzar estructuras más profundas gracias a longitudes de onda de entre 1.040 y $1.060^{[48]}$, en lugar de los aproximadamente $800 \mathrm{~nm}$ de los SD-OCT actuales. Los nuevos sistemas de alta penetrancia SS-OCT (SweptSource OCT -OCT de Fuente con Barrido-) se caracterizan por una alta velocidad de escaneo y una gran penetración en el tejido de estudio, en comparación a los TD-OCT, debido a un empleo de longitud de onda más larga, permitiendo obtener imágenes tridimensionales de gran contraste de la coroides ${ }^{[48]}$.

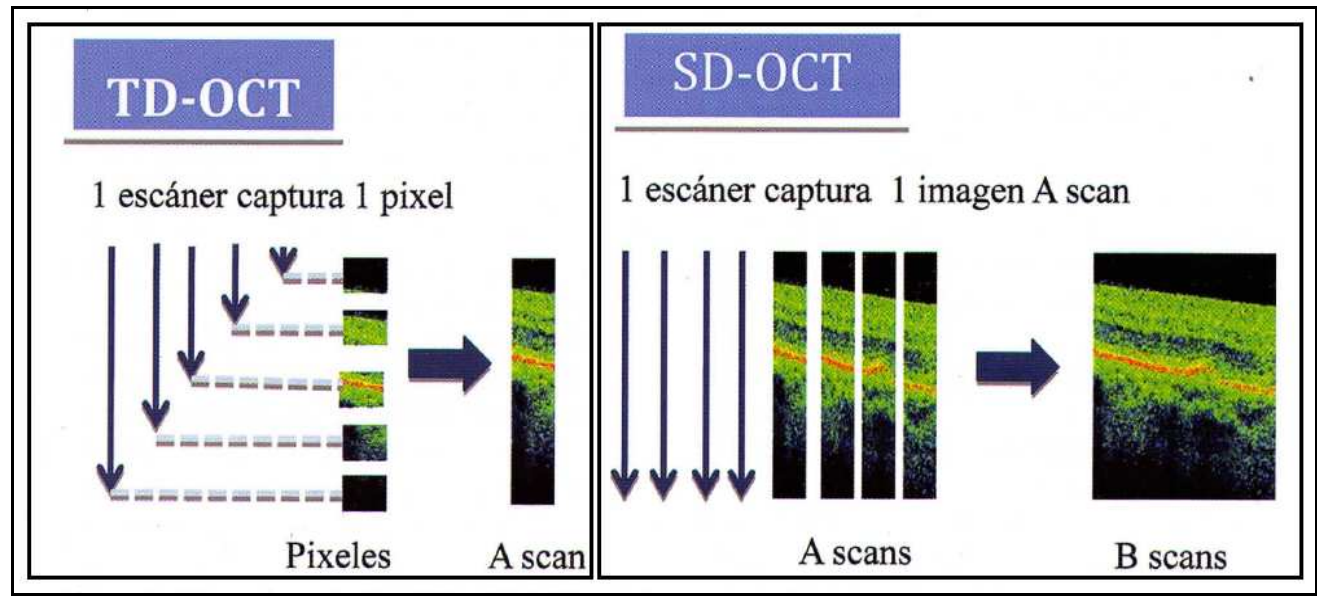

Figura 13. Diferencias entre TD-OCT y SD-OCT en forma y velocidad de captura de imagen (Imagen tomada de la LXXXVII Ponencia Oficial de la Sociedad Española de Oftalmología. Muñoz Negrete F.J., Rebolleda G., Díaz Llopis M.) ${ }^{[40]}$. 
Tabla 1. Características distintivas de dispositivos de Tomografía de Coherencia Óptica comercializados (Tabla tomada de la LXXXVII Ponencia Oficial de la Sociedad Española de Oftalmología . Muñoz Negrete F.J., Rebolleda G., Díaz Llopis M.) ${ }^{[49]}$.

\section{CARACTERISTICAS DE LOS PRINCIPALES OCT COMERCIALIZADOS}

\begin{tabular}{|c|c|c|c|c|c|}
\hline EQUIPO & FABRICANTE & $\begin{array}{l}\text { RESOLUCIÓN } \\
\text { AXIAL }(\mu \mathrm{m})\end{array}$ & $\begin{array}{c}\text { RESOLUCIÓN } \\
\text { TRANSVERSAL } \\
(\mu \mathrm{m})\end{array}$ & $\begin{array}{c}\text { VELOCIDAD } \\
\text { DE ESCANEO } \\
\text { (A-Scans/seg) }\end{array}$ & CARACTERÍSTICAS \\
\hline $\begin{array}{c}\text { OCT } 3 \\
\text { (Stratus } \\
\text { OCT) }\end{array}$ & $\begin{array}{l}\text { Carl Zeiss } \\
\text { Meditec }\end{array}$ & 10 & 20 & 400 & TD-OCT. \\
\hline $\begin{array}{c}\text { Cirrus } \\
\text { HD- OCT }\end{array}$ & $\begin{array}{l}\text { Carl Zeiss } \\
\text { Meditec }\end{array}$ & 5 & 15 & 27.000 & $\begin{array}{l}\text { SD-OCT. Segmentación MLI } \\
\text { y EPR. Imagen SLO. Módulo } \\
\text { de SA. Imágenes HD. }\end{array}$ \\
\hline RTVue OCT & $\begin{array}{l}\text { OptoVue/ } \\
\text { OftalTech }\end{array}$ & 5 & 15 & 26.000 & $\begin{array}{c}\text { SD-OCT. Segmentación } \\
\text { múltiples capas de la retina. } \\
\text { Módulo SA. }\end{array}$ \\
\hline Spectralis & $\begin{array}{l}\text { Heidelberg } \\
\text { Eng./Bloss }\end{array}$ & $4-7$ & 14 & 40.000 & $\begin{array}{l}\text { SD-OCT. } \\
\text { SLO alta resolución. Eye } \\
\text { tracking. Sistema reducción } \\
\text { de ruido Heidelberg. Imagen } \\
\text { infrarroja. Módulo de AGF, } \\
\text { ICG, autofluorescencia. EDI. }\end{array}$ \\
\hline $\begin{array}{l}\text { 3D OCT- } \\
1000\end{array}$ & Topcon & $5-6$ & 20 & 18.000 & $\begin{array}{c}\text { SD-OCT. } \\
\text { Retinógrafo no midriático } \\
\text { incorporado }(3,1 \\
\text { megapíxeles })\end{array}$ \\
\hline $\begin{array}{l}\text { 3D OCT- } \\
2000\end{array}$ & Topcon & $5-6$ & 20 & 27.000 & $\begin{array}{c}\text { SD-OCT. } \\
\text { Retinógrafo no midriático } \\
\text { incorporado (12,3 } \\
\text { megapíxeles) } \\
\text {. Módulo OCT-SA. } \\
\text { Estereofotografía papila. }\end{array}$ \\
\hline $\begin{array}{l}\text { 3D OCT- } \\
2000 \text { FA plus }\end{array}$ & Topcon & 5 & 20 & 50.000 & $\begin{array}{c}\text { SD-OCT. } \\
\text { AGF y autofluorescencia. }\end{array}$ \\
\hline $\begin{array}{c}\text { SOCT } \\
\text { Copernicus } \\
\text { HR }\end{array}$ & $\begin{array}{c}\text { Optopol } \\
\text { /Canon/AJL }\end{array}$ & 3 & $12-18$ & 52.000 & $\begin{array}{c}\text { SD-OCT. } \\
\text { Doppler vasos sanguíneos } \\
\text { retinianos. DDLS glaucoma. } \\
\text { Quistes intrarretinianos. } \\
\text { Módulo OCT-SA. }\end{array}$ \\
\hline
\end{tabular}




\begin{tabular}{|c|c|c|c|c|c|}
\hline $\begin{array}{c}\text { SOCT } \\
\text { Copernicus+ }\end{array}$ & $\begin{array}{c}\text { Optopol/ } \\
\text { Canon/AJL }\end{array}$ & 5 & $12-18$ & 27.000 & $\begin{array}{c}\text { SD-OCT. } \\
\text { Doppler vasos sanguíneos } \\
\text { retinianos. DDLS glaucoma. } \\
\text { Quistes intrarretinianos. } \\
\text { Módulo OCT-SA. }\end{array}$ \\
\hline $\begin{array}{c}\text { RS-3000 } \\
\text { OCT } \\
\text { RetinaScan }\end{array}$ & Nidek/Indo & 4 & 20 & 53.000 & $\begin{array}{c}\text { SD-OCT. } \\
\text { SLO incorporado. Auto- } \\
\text { tracking. Medida complejo } \\
\text { células ganglionares. }\end{array}$ \\
\hline $\begin{array}{c}\text { Spectral } \\
\text { OCT and } \\
\text { SLO }\end{array}$ & OTI/OPKO & 5 & 15 & 27.000 & $\begin{array}{l}\text { SD-OCT. } \\
\text { Microperimetría. Lente } \\
\text { adicional OCT-SA. }\end{array}$ \\
\hline $\begin{array}{l}\text { Bioptigen } \\
\text { SDOCT }\end{array}$ & Bioptigen & 4,5 & 10 & 20.000 & $\begin{array}{c}\text { SD-OCT. } \\
\text { Portátil. Sonda flexible. } \\
\text { Investigación animal. Flujo } \\
\text { doppler. }\end{array}$ \\
\hline \multicolumn{6}{|c|}{ OCT Exclusivos de segmento anterior } \\
\hline $\begin{array}{l}\text { Visante AS- } \\
\text { OCT }\end{array}$ & $\begin{array}{l}\text { Carl Zeiss } \\
\text { Meditec }\end{array}$ & 18 & 60 & 2.000 & $\begin{array}{c}\text { TD-OCT. } \\
\text { Exclusivo segmento anterior. }\end{array}$ \\
\hline $\begin{array}{l}\text { Slit-Lamp } \\
\text { OCT }\end{array}$ & Heidelberg & 25 & 75 & 200 & $\begin{array}{c}\text { SD-OCT adaptado a lámpara } \\
\text { de hendidura. }\end{array}$ \\
\hline $\begin{array}{c}\text { CASSIA SS } \\
1000\end{array}$ & TOMEY/ AJL & 10 & 30 & 30.000 & $\begin{array}{l}\text { Segmento anterior. Plano } \\
\text { corte } 16 \times 16 \mathrm{~mm}, \\
\text { profundidad } 6 \mathrm{~mm} .\end{array}$ \\
\hline
\end{tabular}

TD: time domain (dominio tiempo); SD: spectral domain (dominio tiempo), SLO: scanning laser ophthalmoscope; MLI: membrane limitante interna; DDLS: Disk Damage Likely Scale; EDI: Enhanced depth imaging (visualización de estructuras posteriores); EPR: epitelio pigmentario de la retina; HD: High definition; OCT-SA: tomografía de coherencia óptica de segmento anterior; GPA: glaucoma progression analysis; TSNIT: temporal-superior-nasal-inferior-temporal; ANR: anillo neurorretiniano; AGF: angioflouresceingrafía, ICG: verde indocianina. 


\section{Resolución.}

Entendemos como resolución la mínima distancia a la que dos puntos próximos distintos se identifican como diferentes.

La resolución axial se ve limitada por la luz incidente, es decir por las propiedades de la luz utilizada ${ }^{[40]}$, y determina la precisión con la que estructuras como el espesor corneal central o grosor corneal son medidas ${ }^{[50]}$. En el TD-OCT es de 10 $\mu \mathrm{m}$, mientras que en el SD-OCT es de unas $5 \mu \mathrm{m}{ }^{[40]}$. La resolución transversal depende de la anchura del haz incidente, estando limitada por la calidad de los medios ópticos que atraviese. En el TD-OCT es de $20 \mu \mathrm{m}$, mientras que en los SD-OCT oscila entre 12$20 \mu \mathrm{m}^{[40]}$.

\section{Usos de la OCT.}

La OCT se diseñó inicialmente para la evaluación de la retina, pero tiene actualmente numerosas aplicaciones en la oftalmología, como la evaluación del segmento anterior ${ }^{[51]}$ o la cuantificación de la capa de fibras nerviosas peripapilares (CFNR) en patología glaucomatosa ${ }^{[52]}$ y en enfermedades neurodegenerativas y lesiones del sistema nervioso central, ya que es un sistema de imagen adecuado para su seguimiento y posee gran valor pronóstico ${ }^{[53,54]}$. Están surgiendo además aplicaciones no oftalmológicas prometedoras, como su uso para el diagnóstico y seguimiento de patologías cutáneas ${ }^{[55]}$ o vasculares ${ }^{[56]}$.

Su uso para el segmento anterior fue descrito por primera vez en 1994 por Izatt y colaboradores, usando la misma longitud de onda de luz que la OCT de retina (830 nm) [57]. Sin embargo la penetración de los tejidos de la OCT es inferior a los ultrasonidos, presentando una limitación para atravesar estructuras como la esclera o el iris. De ahí que se desarrollara más adelante una longitud de $1.310 \mathrm{~nm}$ que permite una mejor captura de imágenes en el segmento anterior ${ }^{[40,51]}$.

La OCT de segmento anterior obtiene imágenes con una resolución de 10 a 25 veces mayor a la obtenida con la BMU ${ }^{[40]}$. Habiéndose publicado datos de resolución axial de $18 \mu \mathrm{m}$ y lateral $60 \mu \mathrm{m}$ para el OCT de segmento anterior Visante OCT ${ }^{[58]}$; 
frente a cifras que oscilan entre 20 y $80 \mu \mathrm{m}$ en el caso de la resolución axial, y de 50 a $420 \mu \mathrm{m}$ en cuanto a resolución lateral para distintos equipos de BMU ${ }^{[58]}$.

En la actualidad la mayoría de los sistemas de OCT del segmento posterior presentan la opción de ser empleados también para segmento anterior mediante diversos adaptadores o modificaciones del software, pero existen además aparatos de OCT específicos para la evaluación del polo anterior.

\section{E. Cirrus HD-OCT.}

El Cirrus OCT de la compañía Carl Zeiss Mediatec, surge como una evolución del dispositivo previo, el Stratus OCT (TD-OCT), con claras diferencias respecto al anterior.

Es un sistema con tecnología "Fourier Domain", con un diodo superluminiscente de $840 \mathrm{~nm}$ de longitud de onda como fuente de luz. Presenta una velocidad de 27.000 A-scans/segundo. La resolución axial es de $5 \mu \mathrm{m}$ y la resolución horizontal es de $15 \mu \mathrm{m}$ $[40,45]$. Su velocidad de escaneo es 50 veces mayor que en el Stratus OCT ${ }^{[45]}$, permitiendo explorar un área más extensa de retina.

Presenta una base de datos compuesta por los valores obtenidos en sujetos normales, que permite la comparación cuantitativa de la capa de fibras nerviosas de la retina y de la mácula ${ }^{[59]}$.

Los algoritmos de procesamiento de la imagen del OCT hacen que el aparato detecte automáticamente los límites internos y externos de la retina neurosensorial para así realizar mediciones, proceso que se denomina segmentación. Stratus y Cirrus presentan distinto algoritmo de segmentación, lo que hace que las medidas de ambos no sean intercambiables, midiendo el sistema Cirrus HD-OCT siempre 43-61 $\mu \mathrm{m}$ de grosor retiniano más que el dispositivo Stratus OCT ${ }^{[40]}$. 


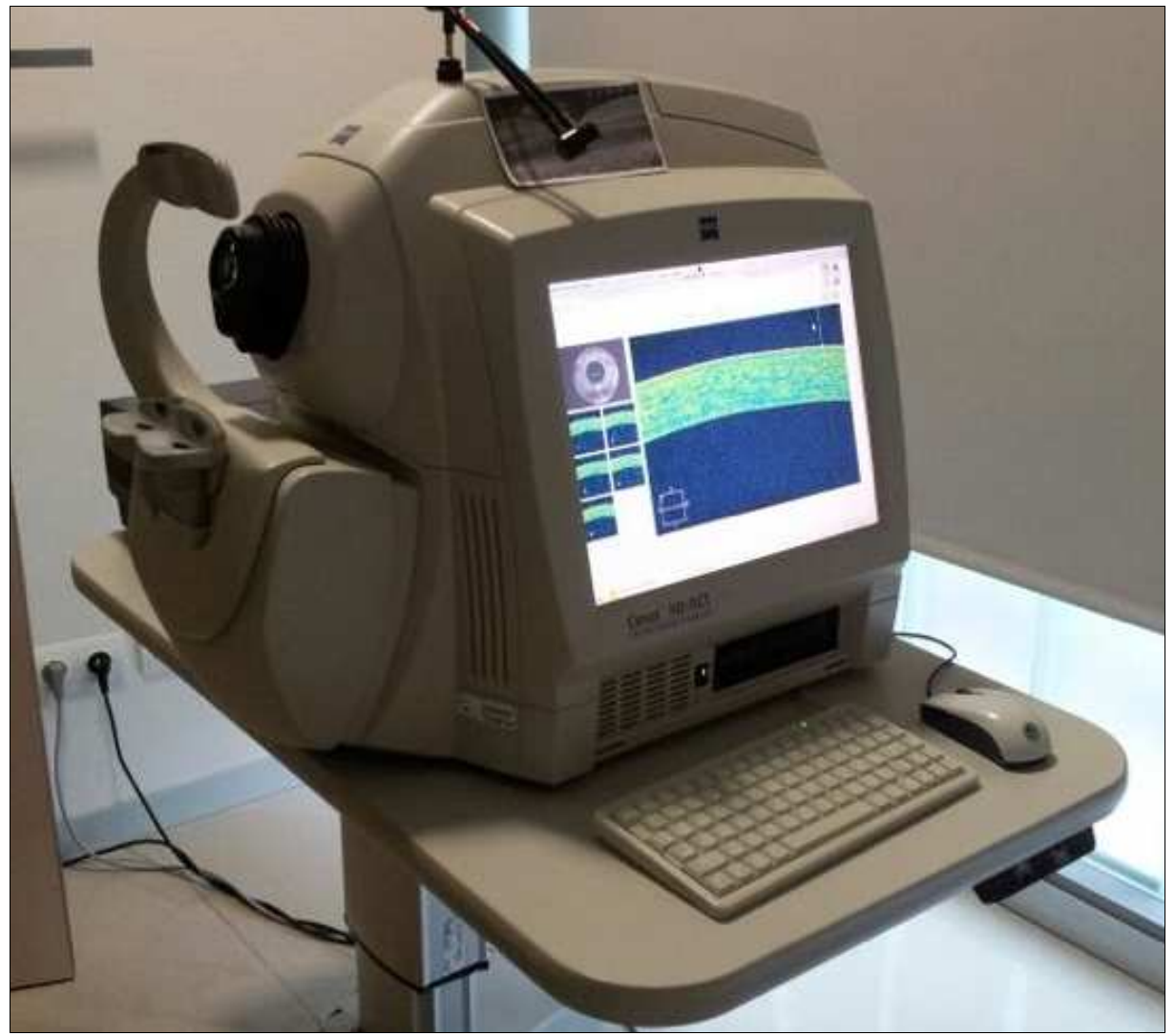

Figura 14. Imagen del dispositivo Cirrus HD-OCT.

Los patrones de escaneo que presenta son ${ }^{[40,45]}$ :

- "Macular Cube 200 x 200": escanea un área de 6 x 6 mm, obteniéndose la imagen a partir de 200 líneas horizontales (B-scans) que constan de 200 cortes axiales (A-scans), salvo las líneas centrales vertical y horizontal, que constan de 1.000 A-scans cada una.

- "Macular Cube 512 x 128": área 6 x 6 mm con 128 líneas horizontales que constan de 512 cortes axiales, salvo las líneas centrales vertical y horizontal, que constan de 1.024 A-scans cada una.

- “5 Line Raster”: 5 líneas paralelas con 4.096 cortes axiales cada una.

El principal uso del Cirrus HD-OCTes captar y medir estructuras en el segmento posterior del ojo. Permite la captura y medida de estructuras del segmento anterior como la córnea cambiando el foco del haz del OCT ${ }^{[59]}$.

Para segmento anterior presenta dos patrones de adquisición ${ }^{[59]}$ : 
- "Anterior Segment Cube 512 x 128": 128 líneas horizontales que constan de 512 cortes axiales, salvo las líneas centrales vertical y horizontal, que constan de 1.024 A-scans cada una.

- “Anterior Segment 5 Line Raster": 5 líneas paralelas compuestas por 4.096 A-scans cada una, separadas entre sí $250 \mu \mathrm{m}(0.25 \mathrm{~mm})$, cubriendo en total 1 mm de ancho. Este patrón es útil para obtener imágenes de gran resolución de la cornea y ángulo de la cámara anterior.

Una vez tomada la imagen corneal, se puede visualizar, y realizar manualmente las mediciones deseadas mediante cursores de medición ${ }^{[60]}$.

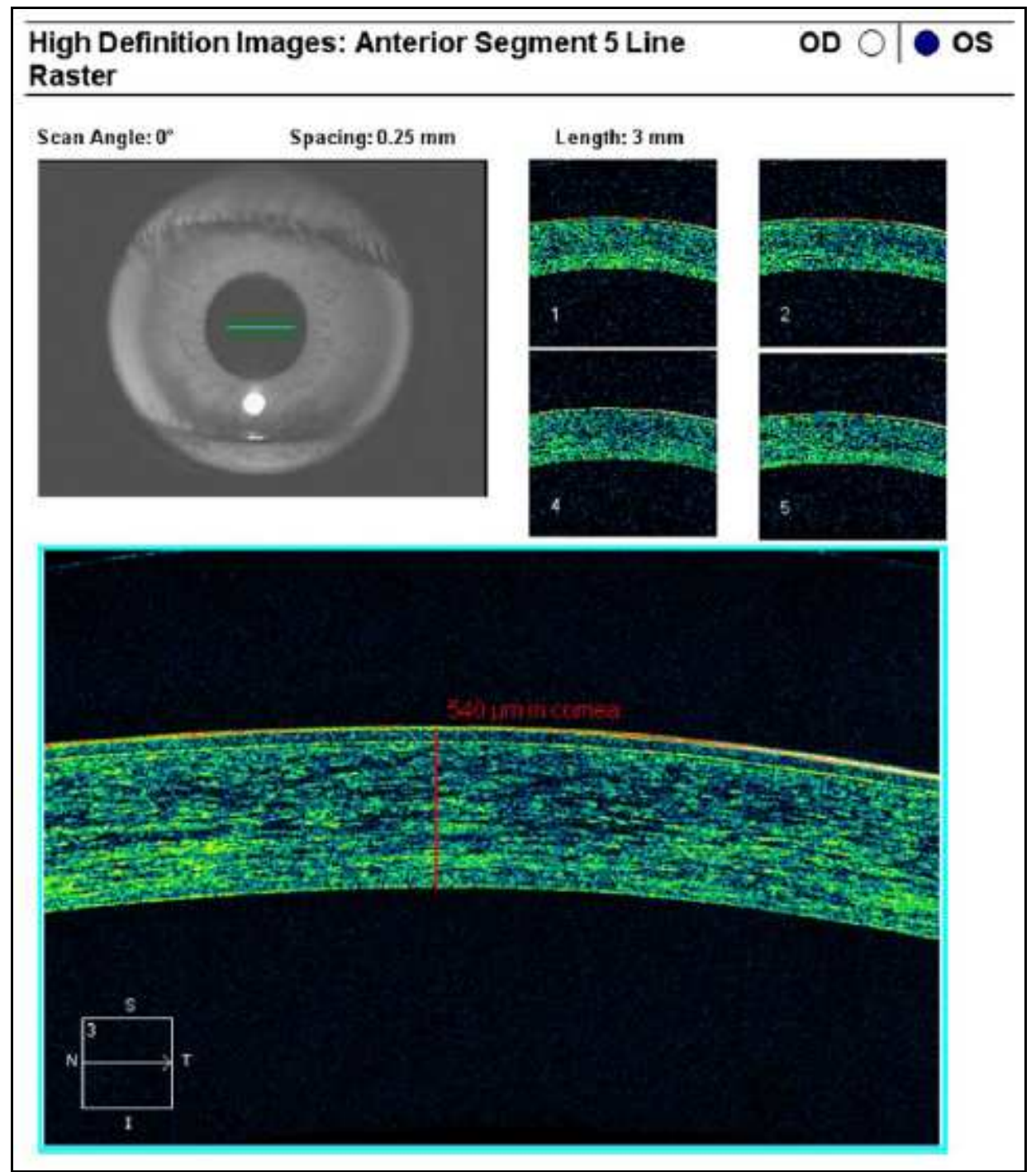

Figura 15. Medición del espesor corneal central mediante el Cirrus HD-OCT (Imagen tomada de Correa Pérez M.E. y colaboradores) ${ }^{[60]}$. 


\section{F. Topcon 3D OCT-1000.}

El dispositivo Topcon 3D OCT-1000 ${ }^{[61]}$ se trata de un sistema de OCT que además presenta una cámara de retina de tipo no midriático de 3,1 megapixels. Emplea la tecnología Fourier Domain, utilizando como fuente de luz un diodo superluminiscente con $840 \mathrm{~nm}$ de longitud de onda y un ancho de banda de $50 \mathrm{~nm}$. Presenta una velocidad de 18.000 cortes axiales/segundo. La resolución axial es de 6 $\mu \mathrm{m}$ y la resolución horizontal o transversal es de $20 \mu \mathrm{m}^{[40,45]}$.

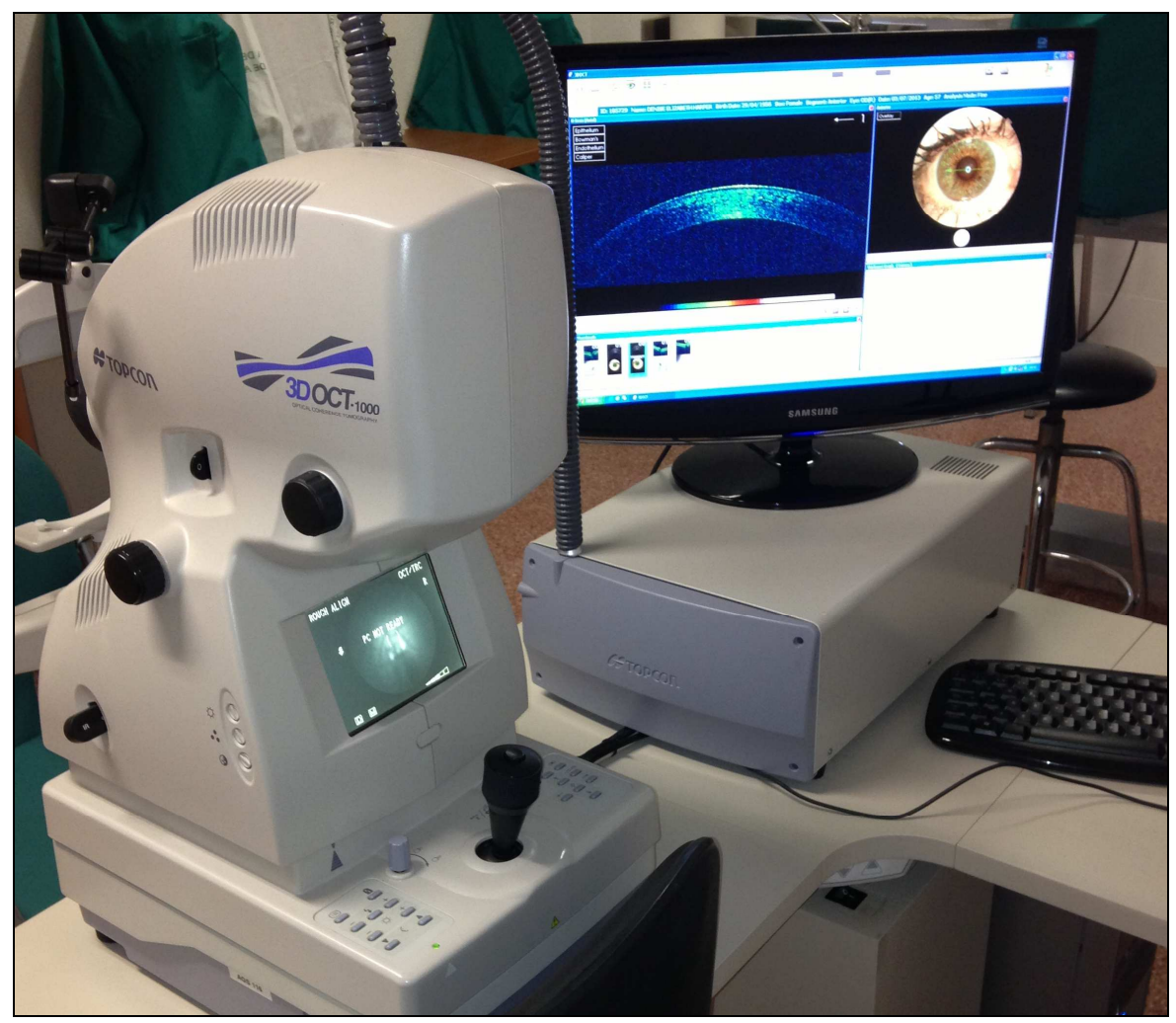

Figura 16. Imagen del dispositivo Topcon 3D OCT-1000.

Presenta varios patrones de escáner retiniano ${ }^{[61]}$ :

- “3D Scan": puede ser 5,5 x 4,5 mm, 3 x $3 \mathrm{~mm}$ o el más empleado de 6 x 6 mm (escanea un área de 6 x 6 mm, con una resolución de 512 x 128, es decir, 128 líneas horizontales -B Scans- que constan de 512 cortes axiales -A scans-).

- "Line scan": puede ser de $3 \mathrm{~mm}, 4,5 \mathrm{~mm}$ o $6 \mathrm{~mm}$ de longitud. 
- "Circular scan": 2,4 mm, 3 mm o 3,45 mm de diámetro.

- "Radial pattern scan": 6 líneas radiales con $3 \mathrm{~mm}, 4,5 \mathrm{~mm}$ o $6 \mathrm{~mm}$ de longitud.

El sistema permite elegir entre 3 modos distintos de OCT: "macula mode" (retina), "glaucoma mode" (nervio óptico) y "anterior segment mode" (segmento anterior). Una vez seleccionado el "anterior segment mode", es necesario colocar un accesorio en el área de soporte frontal del paciente (Figura 18) , que aumentará la distancia de éste al aparato, así como cambiar el foco mediante el giro de una manivela en el lateral del aparato, según las indicaciones del fabricante ${ }^{[61]}$.

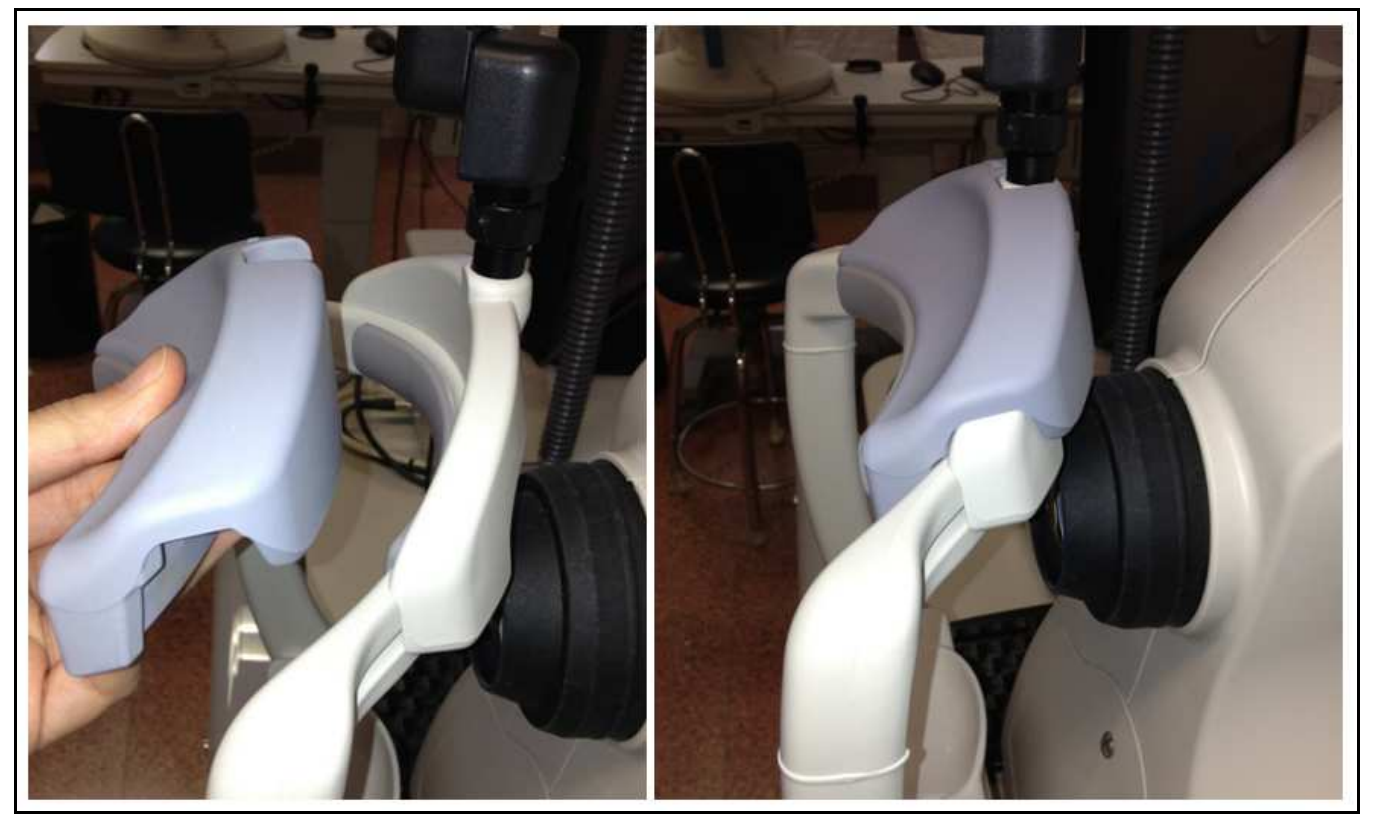

Figura 17. Accesorio para la adquisición de imágenes de segmento anterior con el dispositivo Topcon 3D OCT-1000.

Las opciones de escaneo para el segmento anterior son ${ }^{[61]}$ :

- "Radial-Scan": 6 mm de anchura, con una resolución de 1024 Ascans cada uno. En este patrón el espejo de referencia está posicionado sobre la córnea. 
- "Line-Scan": área de 6 mm, con una resolución de 1034 horizontal y 1024 vertical. En este patrón el espejo de referencia está posicionado sobre la córnea o lente.

- “3D Scan”: 3 x 3 mm (resolución 256 x 256), o 6 x 6 mm (resolución 215 x 128). En este patrón el espejo de referencia está posicionado sobre la córnea.

El fabricante en su manual de usuario recomienda para el estudio de segmento anterior los siguientes patrones ${ }^{[61]}$ :

- Córnea: "Radial-Scan" o "3D-Scan".

- Ángulo de la cámara anterior: "Line-Scan".

- Cristalino: "Line-Scan".

Una vez tomada la imagen corneal, se puede visualizar, y mediante cursores de medición de forma manual, realizar la medición del espesor corneal.

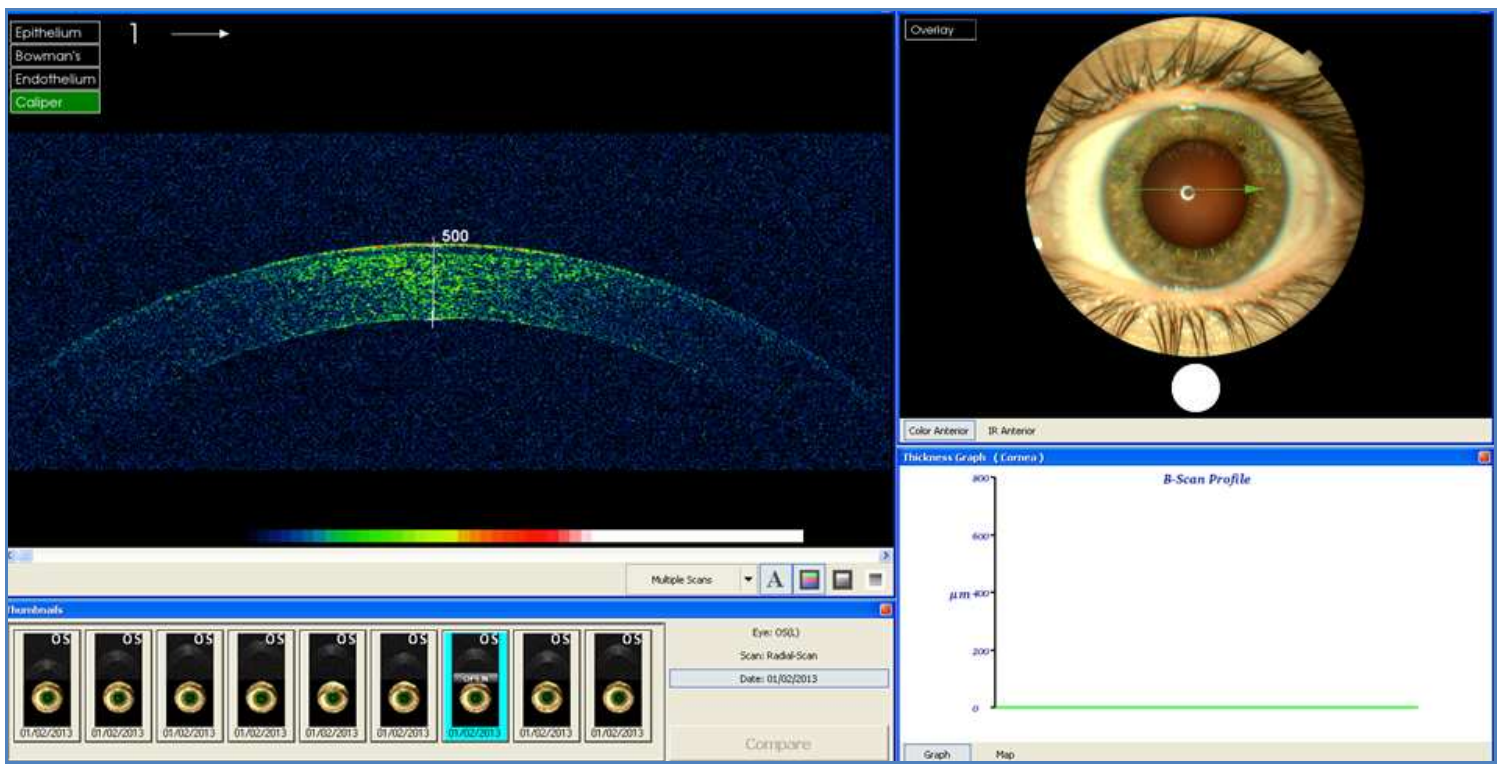

Figura 18. Medición del espesor corneal central mediante el dispositivo Topcon 3D OCT-1000. 


\subsubsection{Reflectometría Óptica De Baja Coherencia.}

La reflectometría óptica de baja coherencia (Optical Low Coherence Reflectometry-OLCR-) fue desarrollada a finales de los años 80 para su empleo en el sector de la telecomunicación; siendo aplicada en tejidos biológicos in vivo por primera vez por Fercher y colaboradores en $1988^{[62,63]}$.

La tecnología de Reflectometría Óptica de Baja Coherencia (OLCR) se basa en la interferometría de Michelson ${ }^{[64]}$, empleando una fuente de luz de banda ancha (20$30 \mathrm{~nm}$ ) con una longitud de onda central de $820 \mathrm{~nm}^{[65]}$ producida por un diodo superluminiscente, de una manera similar a la OCT ${ }^{[66]}$.

\section{Lenstar LS 900.}

El Lenstar LS 900 (Haag-Streit AG) es un biómetro de no contacto que se basa en esta tecnología, habiendo sido diseñado como un instrumento para ayudar en los procedimientos de cirugía refractiva y de catarata ${ }^{[67]}$. En su procedimiento, las reflexiones de las distintas estructuras oculares son interferométricamente superpuestas a las reflexiones desde los brazos de referencia ${ }^{[68]}$. Permite medir el espesor corneal, la profundidad de cámara anterior, grosor del cristalino, espesor retiniano, longitud axial, queratometría, diámetro pupilar, y distancia blanco-blanco simultáneamente en una sola medida ${ }^{[67,68]}$, lo que supone una gran comodidad para el paciente por su gran rapidez. El dispositivo también obtiene medidas queratométricas de los meridianos corneales mediante el análisis del patrón generado al proyectarse sobre la córnea 32 diodos emisores de luz (LEDs), dispuestos en 2 anillos de $1.65 \mathrm{~mm}$ y $2.30 \mathrm{~mm}$ de radio y 16 puntos de medida cada uno ${ }^{[66,68]}$. El sistema realiza 5 mediciones, y presenta los valores medios de todas estas estructuras de manera automatizada ${ }^{[68]}$, sin necesidad de manipulación por parte del observador. 


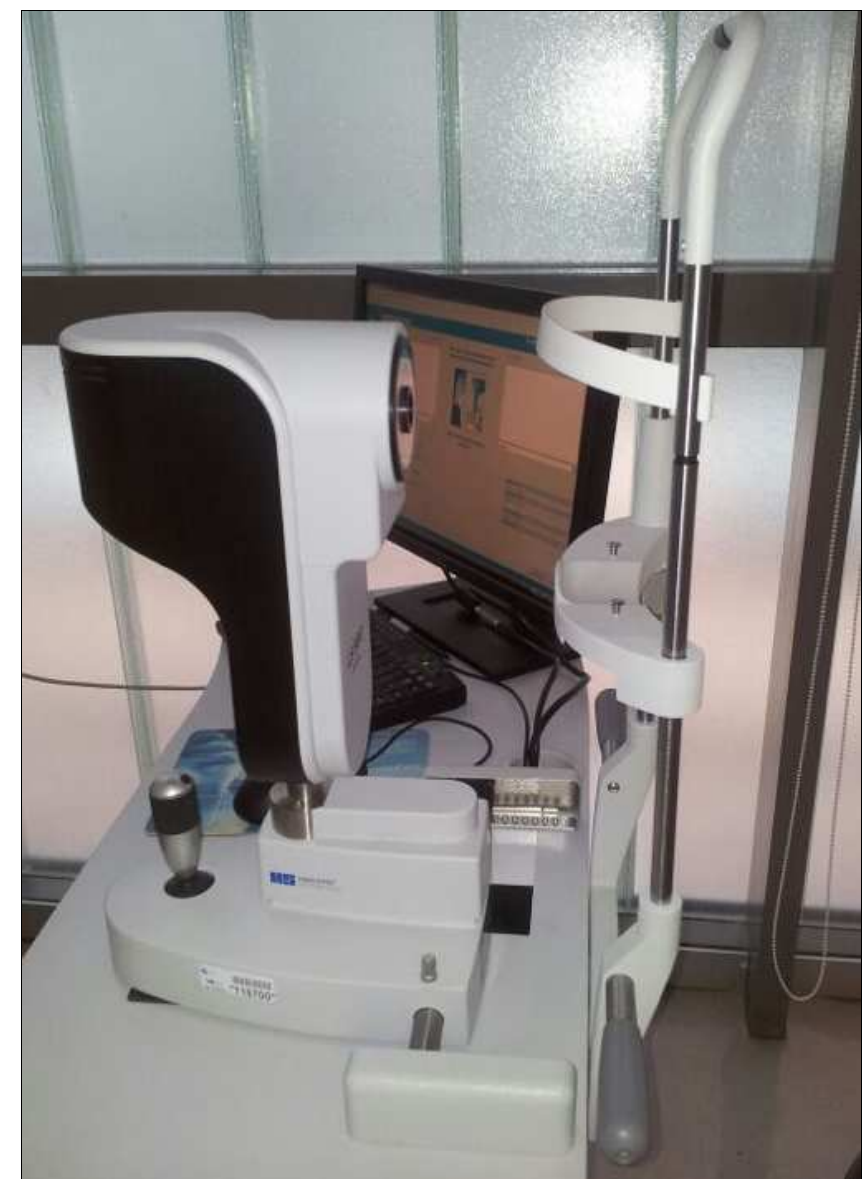

Figura 19. Imagen del dispositivo Lenstar LS 900.

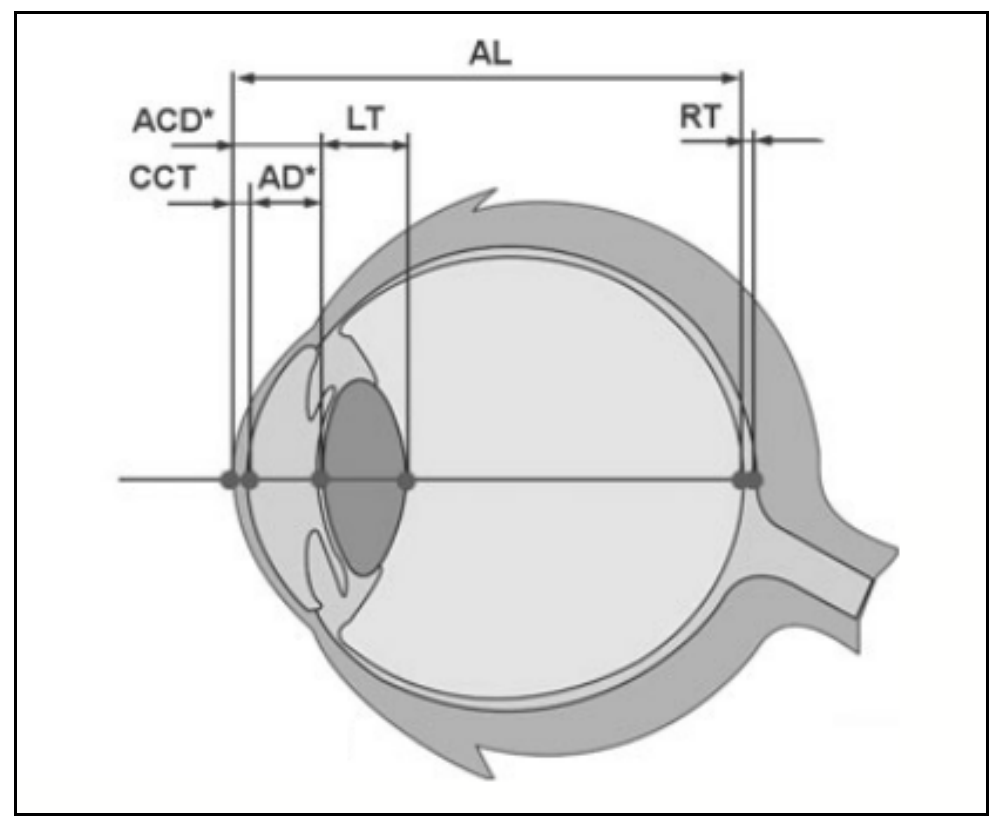

Figura 20. Parámetros evaluados por Lenstar LS 900 (Imagen tomada de Mylonas G. y colaboradores) ${ }^{[69]}$. AL: axial length (longitud axial); ACD: anterior chamber depth (profundidad cámara anterior); AD: anatomical anterior chamber depth (profundidad de la cámara anterior anatómica); LT: 
lens thickness (grosor cristalino); CCT: central corneal thickness (grosor corneal central); RT: retinal thickness (grosor retiniano).

\subsubsection{Fotografía Rotacional de Scheimpflug.}

Se trata de un sistema capaz de digitalizar imágenes y mediciones del segmento anterior mediante una cámara rotatoria, emitiendo una luz LED azul de $475 \mathrm{~nm}{ }^{\text {[66] }}$. Capaz de realizar una biometría del segmento anterior con gran precisión, aportando datos reproducibles de sus características ${ }^{[70]}$. Permite además evaluar los cambios en la dispersión de la luz debido a la edad, a una patología o toxicidad de un agente ${ }^{[70]}$.

\section{A. Pentacam.}

Dentro de esta categoría encontramos el dispositivo Pentacam (Oculus), como dispositivo más conocido, capaz de realizar paquimetría, topografía corneal, medición de la curvatura anterior y posterior corneal y del astigmatismo, y realizar fotografías del cristalino $^{[70]}$.

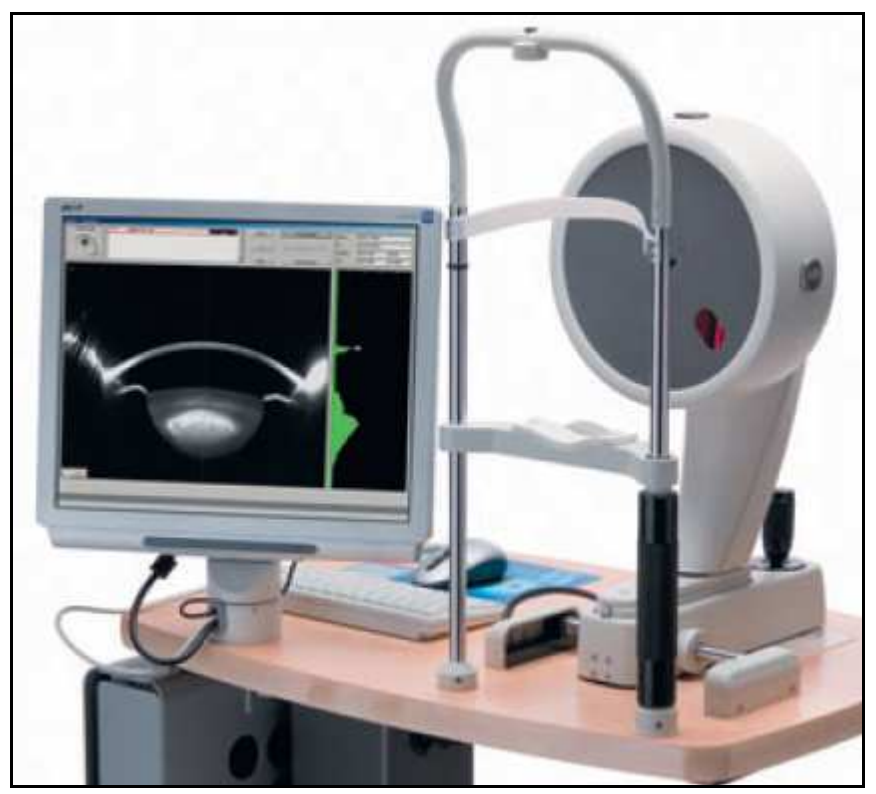

Figura 21. Sistema topográfico basado en fotografía de Scheimpflug (Pentacam) (Imagen tomada de Wegener A. y colaboradores) ${ }^{[70]}$. 


\section{B. Galilei.}

El dispositivo Galilei (Ziemer, Port, Switzerland) es un sistema más avanzado que presenta una doble cámara de Scheimpflug. Es un sistema de diagnóstico no invasivo basado en la rotación de la mencionada doble cámara, con un topógrafo de Plácido integrado. Proporciona imágenes corneales mejoradas y una mejor compensación del movimiento ocular, optimizando las mediciones paquimétricas y profundidad de la cámara anterior desde la superficie corneal posterior a la cara anterior del cristalino ${ }^{[71]}$.

\subsubsection{Topografía De Barrido De Hendidura (TBH).}

El sistema de TBH corneal es un sistema de adquisición de información que utiliza una técnica óptica de no contacto que proyecta 40 haces de luz consecutivos sobre la córnea con una angulación de $45^{\circ}{ }^{[72]}$.

Cuando los haces de luz atraviesan la córnea se produce una reflexión de la luz en la cámara anterior y posterior, que es detectada por el sistema de imagen del topógrafo para obtener la información corneal necesaria y reconstruirla en forma de imagen topográfica ${ }^{[72]}$.

\section{Orbscan.}

El Orbscan II (Bausch \& Lomb) utiliza este método de adquisición de imágenes corneales. Se trata de un tomógrafo y topógrafo corneal computarizado que emplea tecnología de disco de Plácido combinada con escaneo por hendidura de la córnea. Utiliza 40 haces ópticos proyectados sobre la cámara anterior con un ángulo de $45^{\circ}$. Dicha proyección de haces es grabada y un software gestiona la información para realizar un mapeo corneal, obteniendo información de las superficies corneales anterior y posterior y la reconstrucción tridimensional de la cámara anterior ${ }^{[73]}$. El grosor corneal es calculado a partir de los datos de los mapas de elevación anterior y posterior 
${ }^{[72]}$. El software es capaz de compensar posibles movimientos oculares mínimos, ya que monitoriza el ojo durante la adquisición ${ }^{[73]}$.

\subsubsection{Microscopia Especular.}

Es una técnica óptica que mediante una exploración de no contacto similar a la de la lámpara de hendidura, es capaz de captar in vivo el endotelio dando lugar a imágenes del mismo para su evaluación. Además mediante la distancia focal interpreta el grosor corneal ${ }^{[74]}$. En una sola medida se obtiene información de la integridad endotelial y de la magnitud paquimétrica de la córnea. Emplea un haz de luz en forma de sección óptica que se proyecta con una angulación determinada, reflejándose en la cara anterior y posterior corneal, determinando así la magnitud de la paquimetría ${ }^{[74]}$. 

Justificación. 



\section{JUSTIFICACIÓN}

La medida de la paquimetría corneal central tiene en la actualidad una importante relevancia clínica, para el diagnóstico y seguimiento de múltiples patologías oculares.

Ésta ha adquirido especial relevancia en los últimos años como un elemento fundamental en la evaluación pre y postoperatoria de la cirugía refractiva ${ }^{[28-30,75]}$, siendo un estudio imprescindible previo a todo paciente que desee someterse a cirugía de láser excímer: LASIK (Laser In Situ Keratomileusis), LASEK (Laser Assisted Subepithelial Keratomileusis), PRK (Photorefractive keratectomy) o epi-LASIK (epipolis láser in-situ keratomileusis). Se considera como requerimiento, el cálculo de un lecho estroma residual mínimo de $250 \mu \mathrm{m}$ para considerar la cirugía como segura ${ }^{[75,}$ 76], siendo de riesgo una paquimetría corneal central preoperatoria de $450 \mu \mathrm{m}$ o menor ${ }^{[76]}$. Se ha descrito incluso una asimetría en la paquimetría entre ambos ojos como único factor de riesgo para el desarrollo de ectasia post LASIK ${ }^{[76]}$. Paralelamente, su medición facilita además el diagnóstico y manejo de los trastornos con adelgazamiento corneal $^{[32,77]}$, cómo pueden ser ectasias primarias o secundarias.

Ha adquirido también un valor importante en el seguimiento de la hipertensión ocular y del glaucoma ${ }^{[31]}$. Se considera factor pronóstico positivo una cornea de mayor grosor, en comparación con una córnea más fina ${ }^{[31]}$. Distintos autores han intentado establecer una fórmula para establecer la presión intraocular (PIO) real, empleando la tonometría de Goldmann y la paquimetría corneal central, sin éxito. La corrección de la PIO con la paquimetría continúa siendo una pregunta abierta, y no se puede considerar que existe una correlación lineal entre ambas ${ }^{[78]}$. No obstante, sí que se ha estimado que por cada $10 \mu \mathrm{m}$ de paquimetría corneal central se debería realizar una corrección de la PIO de 0.1 a $0.7 \mathrm{mmHg}^{[31,79]}$.

Se considera a la paquimetría como un indicador del grado y severidad de disfunción endotelial ${ }^{[80,81]}$, aportándonos información de manera indirecta sobre la función del endotelio ${ }^{[1]}$. Sirve por tanto, para monitorizar el edema corneal previo y posterior a la realización de queratoplastias lamelares en distrofias endoteliales ${ }^{\left[{ }^{82}\right]}$, 
Existen distintos métodos para valorar este grosor. Los más utilizados clásicamente han sido los paquímetros ópticos (no contacto corneal) y ultrasónicos (sí contacto). El paquímetro considerado actualmente como "gold standard" (patrón oro) para la medida del espesor corneal central es el paquímetro ultrasónico ${ }^{[28,33]}$, al considerarse un método válido y fiable para ello ${ }^{[32,34]}$. Éste requiere contacto corneal, con la necesidad de aplicar anestesia tópica, lo que conlleva un malestar en el paciente y un mayor riesgo de infección o daño epitelial. Proporciona la medida de un solo punto de la córnea, y depende de la perpendicularidad y presión con que se apoya la sonda sobre la superficie ocular, así como su correcta colocación en el centro corneal por parte del examinador ${ }^{[32-34]}$. Por ello la tendencia actual es emplear métodos de no contacto validos y de fiabilidad similar al método ultrasónico, que aporten la misma información, pero con una mayor comodidad para el paciente, y un menor riesgo de infección y daño epitelial.

En los últimos años cada vez más aparatos presentes en las consultas de oftalmología integran la opción de poder medir el grosor corneal. Ésta se ha incluido como una medición adicional dentro de equipos diagnósticos más complejos de no contacto, como los biómetros (por ejemplo, Lenstar LS 900) y los tomógrafos de coherencia óptica de dominio espectral (entre ellos, Cirrus HD-OCT y Topcon 3D OCT). Por ello, en la situación actual, la posibilidad de contar con un equipo diagnóstico versátil, capaz de realizar una paquimetría correcta, además de otras funciones, supone un gran avance hacia la optimización de recursos y abaratamiento de costes. Estos equipos presentan además ventajas como evitar el contacto corneal, (sin riesgo de contaminación microbiana o de dañar el epitelio corneal), y con el consecuente mayor confort del paciente. Sin embargo, es imprescindible conocer la exactitud y fiabilidad de estos nuevos sistemas, para saber si su incorporación como paquímetros es apropiada y evitar así diagnósticos o tratamientos erróneos basados en sus mediciones.

Se debe tener en cuenta que existen básicamente dos tipos diferentes de errores cuando se realizan medidas biométricas, como puedan ser las paquimétricas. En primer lugar, los errores sistemáticos (errores de calibración), los cuales engloban principalmente las diferencias de medida de un determinado sistema en relación al método considerado "gold standard", que en el caso de la paquimetría es la técnica ultrasónica. Estos errores determinan la presencia o ausencia de exactitud del sistema 
objeto de estudio (si el sistema mide lo que realmente se propone medir). Y en segundo lugar, los errores aleatorios, los cuales determinan la fiabilidad (repetibilidad y reproducibilidad) de las medidas obtenidas por un sistema, en función de la similitud de las medidas sucesivas ofrecidas por dicho sistema, independiente de que exista o no un error sistemático. Dichos errores nos indican la variabilidad de un sistema cuando se realizan varias medidas, en este caso del grosor corneal central ${ }^{[83]}$.

La tomografía de coherencia óptica (OCT) es una técnica diagnóstica no invasiva y de no contacto, objetiva y versátil, que proporciona rápidamente un corte transversal en dos dimensiones, de las distintas estructuras oculares ${ }^{[40]}$. Inicialmente fue diseñada para realizar análisis del segmento posterior, sin embargo en los últimos años su aplicación se ha extendido, y actualmente nos permite obtener imágenes de otras partes del globo ocular, cómo es la córnea, habiéndose publicado recientemente estudios sobre la exactitud de algunos de dichos sistemas para tal fin ${ }^{[34,35,84-88]}$. La mayoría de los autores concluyeron que las medidas paquimétricas ofrecidas por estos sistemas de OCT están levemente infraestimadas, sin embargo sí que podrían ser intercambiables con las ofrecidas por el paquímetro ultrasónico convencional. También se ha estudiado su repetibilidad ${ }^{[35,86-93]}$, reproducibilidad inter-observador ${ }^{[86-94]}$ e inter-sesión ${ }^{[35,91]}$ o su intercambiabilidad con otros dispositivos, como la fotografía rotacional de Scheimpflug ${ }^{[93]}$. En cambio, sobre los sistemas Cirrus HD-OCT y Topcon 3D OCT1000, presentes en numerosas consultas, no se han publicado previamente datos sobre su exactitud y fiabilidad de medida como paquímetros. Por lo tanto, desde un punto de vista clínico, se antoja necesario determinar si dichos dispositivos son exactos y fiables en la medición del grosor corneal central.

Igualmente existen otras técnicas de no contacto que no han sido específicamente diseñadas para determinar la magnitud paquimétrica, pero que sin embargo nos permiten igualmente obtener valores del grosor corneal in vivo, como pueda ser la reflectometría óptica de baja coherencia (acrónimo anglosajón, OLCR). Estudios previos han determinado su buena exactitud al compararla con la paquimetría ultrasónica ${ }^{[95-98]}$, así como su buena repetibilidad ${ }^{[96]}$ y reproducibilidad interobservador ${ }^{[96]}$. Más concretamente, en lo que se refiere al biómetro Lenstar LS 900, se han publicado estudios determinando su buena exactitud en sujetos sanos ${ }^{[99]}$. De la misma manera, se ha estudiado la intercambiabilidad de sus medidas paquimétricas con 
aquellas ofrecidas por la técnica de fotografía rotacional de Scheimpflug (Pentacam) ${ }^{[100]}$, por la tomografía de coherencia óptica de segmento anterior (Visante OCT) ${ }^{[65,69,}$ 101] y con el biómetro ultrasónico de contacto Tomey AL $3000{ }^{[102]}$. Por último, se ha determinado también su buena repetibilidad ${ }^{[63,65,99,103]}$, reproducibilidad inter-sesión ${ }^{[63]}$ e inter-observador ${ }^{[103,104]}$, en pacientes sanos o diagnosticados de catarata senil. No obstante, no se ha estudiado su fiabilidad de medida en pacientes con otro tipo de alteraciones oculares típicas de la clínica diaria, ni su intercambiabilidad con un sistema de OCT de dominio espectral.

La demostración de una buena exactitud y fiabilidad de medida, en este caso de la paquimetría, por parte de un sistema de no contacto, con independencia del observador que realice la adquisición de las mediciones, añadiría un plus de versatilidad a estos sistemas biométricos, que muy frecuentemente están sujetos a la rotación del personal técnico, y de cuya actuación clínica se derivan decisiones importantes desde el punto de vista diagnóstico y terapéutico. Por lo tanto, es objeto principal de la presente tesis doctoral determinar la fiabilidad de medida paquimétrica de los sistemas OCT de dominio espectral Cirrus HD-OCT y Topcon 3D OCT-1000. 
Hipótesis. 



\section{HIPÓTESIS}

Las medidas de la paquimetría corneal central obtenidas por sistemas basados en la tomografía de coherencia óptica de dominio espectral, primariamente diseñados para la evaluación del segmento posterior, son clínicamente fiables (repetibles y reproducibles). 

Objetivos. 



\section{OBJETIVOS}

\subsection{OBJETIVO GENERAL}

Determinar la fiabilidad de la medida de la paquimetría central obtenida de forma manual mediante la técnica de tomografía de coherencia óptica de dominio espectral.

\subsection{OBJETIVOS ESPECÍFICOS}

1. Establecer la repetibilidad intra-observador y la reproducibilidad inter-observador de la medida de la paquimetría central con el sistema de tomografía de coherencia óptica de dominio espectral Cirrus HD-OCT.

2. Determinar las diferencias existentes entre la medida de la paquimetría central obtenida por un sistema de no contacto basado en la tomografía de coherencia óptica de dominio espectral y la obtenida por uno basado en la técnica de ultrasonido convencional.

3. Evaluar la repetibilidad intra-observador y la reproducibilidad inter-observador de la medida de la paquimetría central con el sistema de reflectometría óptica de baja coherencia Lenstar LS 900.

4. Calcular la variabilidad existente en la medida de la paquimetría central obtenida por los sistemas de no contacto basados en la tomografía de coherencia óptica de dominio espectral y en la reflectometría óptica de baja coherencia.

5. Estimar la repetibilidad intra-observador y la reproducibilidad inter-observador e inter-sesión de la medida de la paquimetría central con el sistema de tomografía de coherencia óptica de dominio espectral Topcon 3D OCT-1000. 

Pacientes, Materiales y Métodos. 



\section{PACIENTES, MATERIALES Y MÉTODOS}

\subsection{PACIENTES}

\section{A. Criterios de Inclusión.}

Para el estudio se seleccionaron de manera consecutiva pacientes que acudieron a las consultas externas del servicio de oftalmología, a los que se les ofertó la posibilidad de participar en el estudio tras explicarles detalladamente la metodología y el objetivo del mismo.

Todos los procedimientos se llevaron a cabo de acuerdo con la Declaración de Helsinki. Los comités éticos institucionales aprobaron la realización de este estudio.

A todos los pacientes candidatos a participar, se les realizó una exploración que incluyó agudeza visual, biomicroscopía de segmento anterior, tonometría de aplanación y oftalmoscopía indirecta. Los criterios de inclusión comunes para todos los estudios realizados fueron edad mayor o igual a 18 años y capacidad cognitiva suficiente para entender la naturaleza del estudio y para firmar libremente el consentimiento informado.

\section{B. Criterios de Exclusión.}

En todos los estudios realizados se excluyeron los pacientes, a los que tras realizarles una exhaustiva anamnesis y exploración oftalmológica completa, presentaron alguno de los siguientes supuestos:

- Historia clínica de cirugía corneal.

- Portadores de lentes de contacto en el momento del estudio.

- Sospecha de ectasia corneal clínica o subclínica.

- Enfermedad del segmento anterior activa.

- Patología ocular que pueda alterar la calidad óptica de la imagen a obtener.

- Agudeza visual corregida inferior a 20/40.

- Edad inferior a 18 años de edad, o cuyo nivel cognitivo impida el entendimiento del estudio y su libre aceptación. 


\subsection{INSTRUMENTOS DE MEDICIÓN PAQUIMÉTRICA}

\subsubsection{CIRRUS HD-OCT}

El Cirrus HD-OCT es un sistema tomográfico y biomicroscópico de alta resolución y de no contacto. Indicado para la visualización in-vivo y la medida de las estructuras de polo posterior y anterior, incluyendo córnea, retina, capa de fibras nerviosas, mácula y nervio óptico ${ }^{[59]}$.

El principal uso del Cirrus es captar y medir estructuras en el segmento posterior del ojo, pero permite la captura y medida de estructuras del segmento anterior, como la córnea, cambiando el foco del haz del OCT ${ }^{[59]}$.

En nuestro estudio empleamos el patrón “Anterior Segment 5 Line Raster”, compuesto por 5 lineas paralelas compuestas por 4.096 A-scans cada una, separadas entre sí $250 \mu \mathrm{m}(0.25 \mathrm{~mm})$, cubriendo en total $1 \mathrm{~mm}$ de ancho. Este patrón es útil para obtener imágenes de gran resolución de la cornea y ángulo de la cámara anterior ${ }^{\text {[59] }}$.

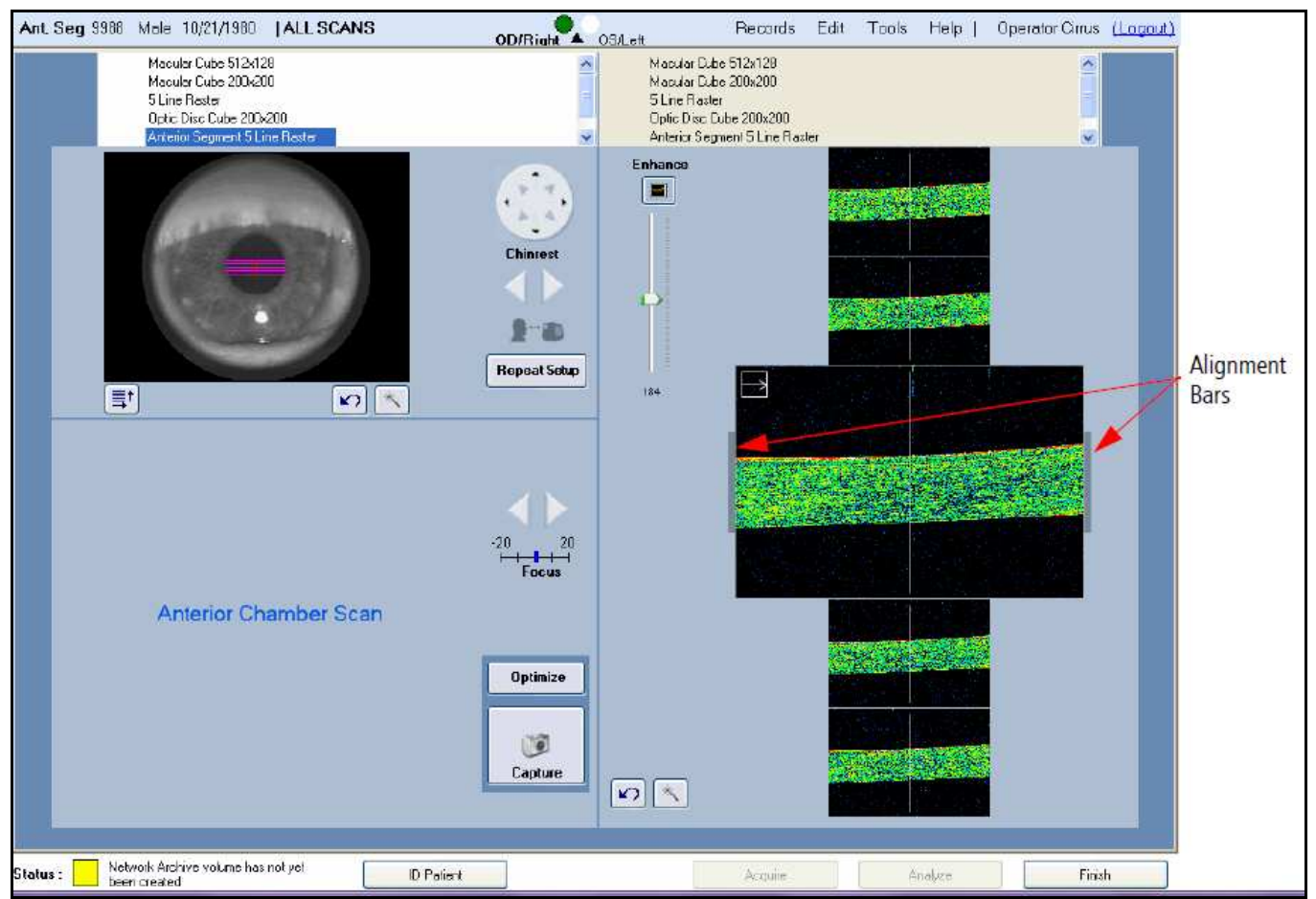

Figura 22. Pantalla de adquisición del patrón “Anterior Segment 5 Line Raster” en el dispositivo Cirrus HD-OCT (Imagen tomada del manual de usuario Cirrus HD-OCT) ${ }^{[59]}$. 
El fabricante recomienda medir el grosor corneal central posicionando el corte en el centro pupilar, al encontrarnos así con mayor probabilidad en el área corneal apical ${ }^{[59]}$. Por ello, a todos los pacientes se les instruyó para la fijación de la mirada en el punto de fijación interno, y el examinador fijó el escáner tomando como referencia el centro pupilar.

El sistema aporta de manera automática un valor de calidad a la imagen capturada, del 1 al 10. Únicamente se procesaron las imágenes corneales que presentaban una calidad mínima de 7.

Tras tomar la imagen, se seleccionó para su medición la línea de las 5 que se consideró estar más centrada en el ápex corneal.

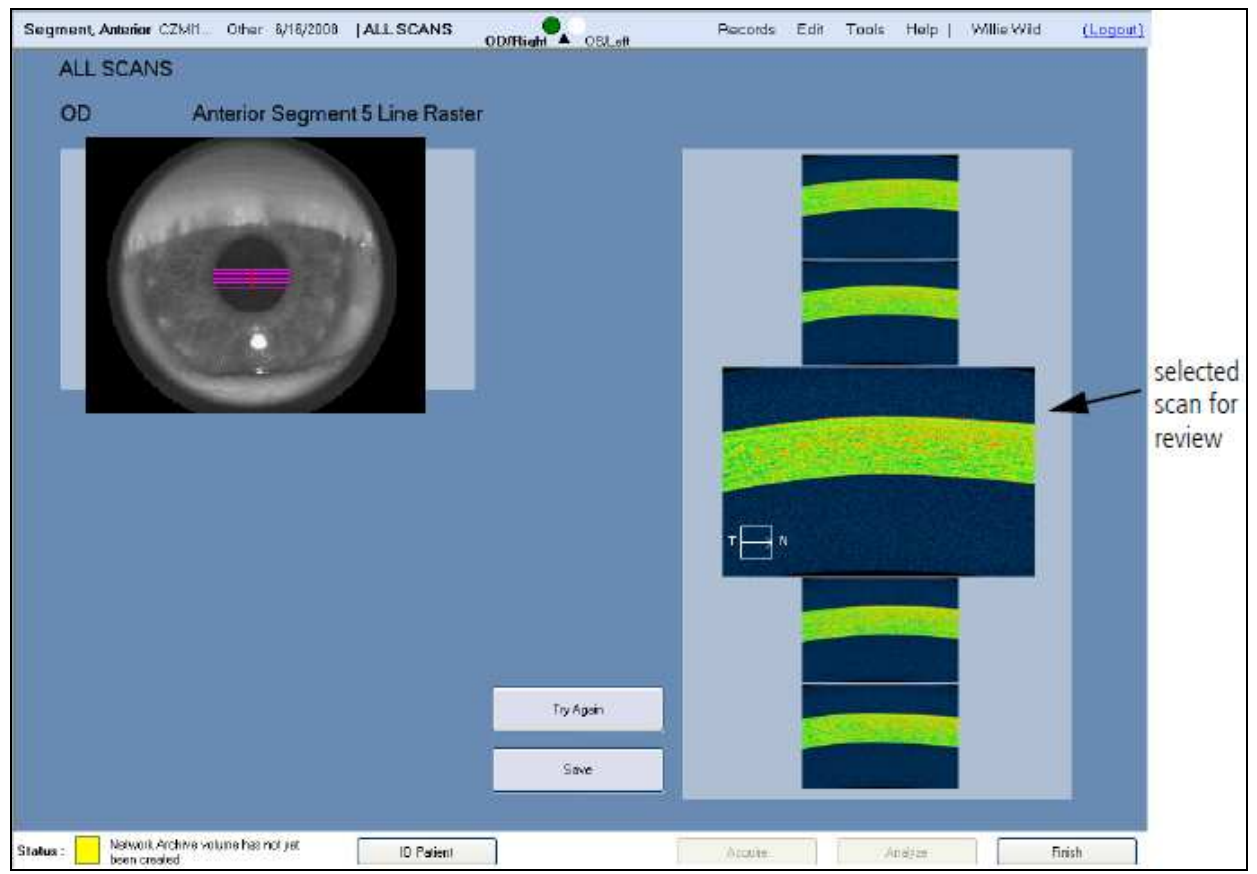

Figura 23. Pantalla de selección de un corte corneal de los 5 realizados en el dispositivo Cirrus HDOCT con el patrón “Anterior Segment 5 Line Raster” (Imagen tomada del manual de usuario Cirrus HDOCT) ${ }^{[59]}$.

Una vez en el corte elegido, de manera manual se posicionó un cursor vertical entre los dos límites de la imagen corneal, midiéndose así el grosor corneal central entre interfase epitelio-aire y endotelio-humor acuoso ${ }^{[59]}$. 


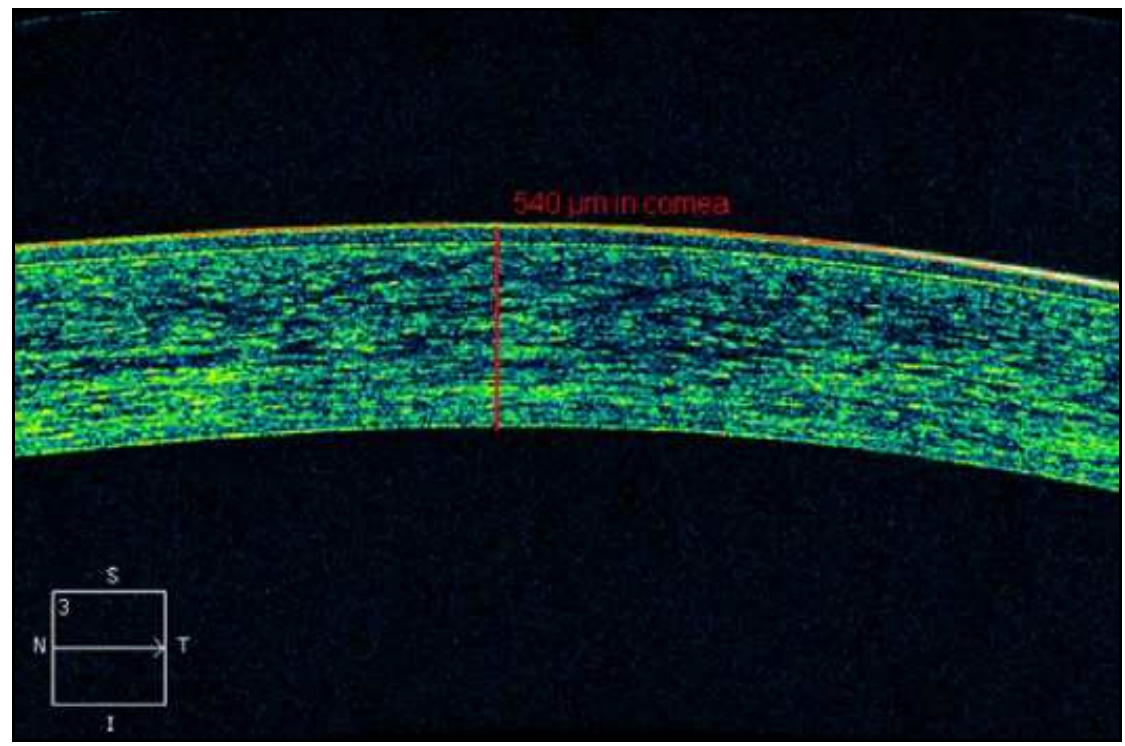

Figura 24. Medición del espesor corneal central mediante un cursor en el dispositivo Cirrus HD-OCT (Imagen tomada de Correa Pérez M.E. y colaboradores) ${ }^{[60]}$.

\subsubsection{TOPCON 3D OCT-1000}

El sistema permite elegir entre 3 modos distintos de OCT: "macula mode" (retina), "glaucoma mode" (nervio óptico) y "anterior segment mode" (segmento anterior). Una vez seleccionado el "anterior segment mode", es necesario colocar un accesorio en el apoyo de la frente del paciente (Figura 17), que aumentará la distancia de éste al aparato, así como cambiar el foco mediante el giro de una manivela en el lateral del aparato, según las indicaciones del fabricante ${ }^{[61]}$.

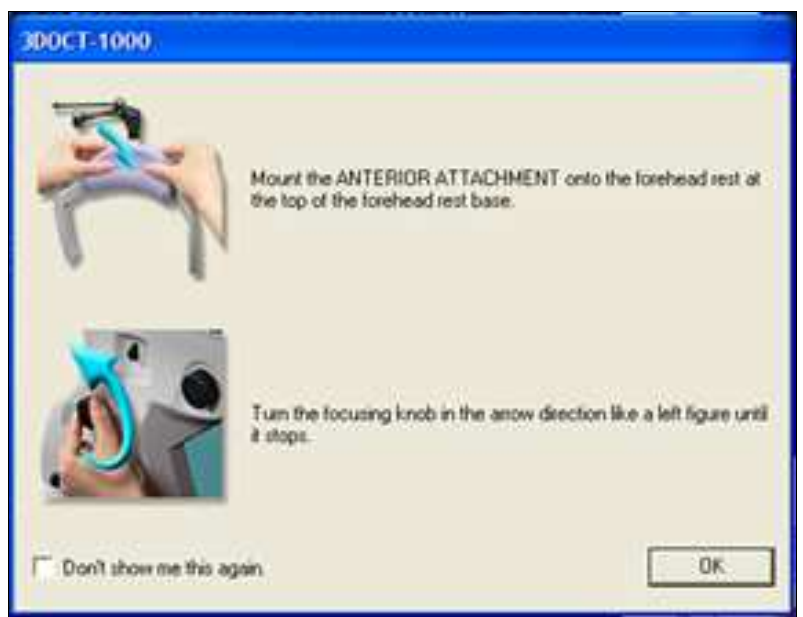


Figura 25. Instrucciones en la pantalla para la colocación del accesorio de apoyo para la frente, y cambio en el foco mediante el giro de una manivela, al seleccionar la opción de obtención de imágenes de segmento anterior en el 3D OCT-1000.

Se seleccionó la opción de "Radial-Scan", formado por escáneres radiales de 6 mm de anchura, con una resolución de 1024 A-scans cada uno, por ser el recomendado por el fabricante para el estudio corneal ${ }^{[61]}$.

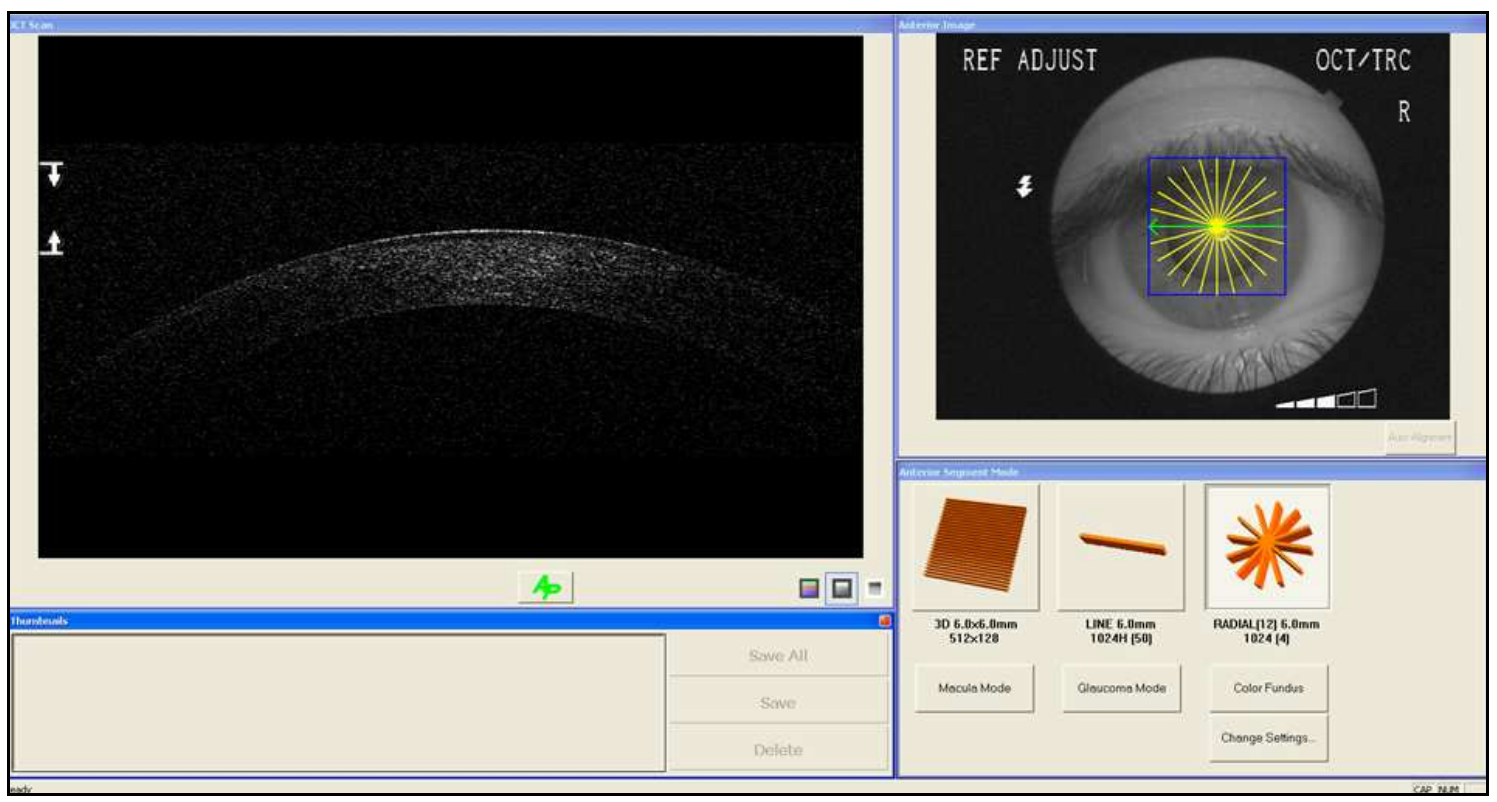

Figura 26. Selección del patrón "Radial-Scan" para el estudio corneal en el dispositivo 3D OCT1000.

A todos los pacientes se les instruyó de igual manera para fijación de la mirada en el punto de fijación interno, y el examinador fijó el centro del escáner radial en el ápex corneal, tomando como referencia el centro pupilar.

En el caso del 3D OCT-1000 de Topcon, el software no proporciona un índice de calidad de la imagen corneal capturada (cosa que sí hace al estudiar la retina o el nervio óptico), con lo cual el examinador de manera subjetiva consideró como apropiadas aquellas imágenes bien enfocadas, sin artefactos y en las que se visualizan claramente todas las estructuras corneales.

Se seleccionó el escáner horizontal, midiéndose la distancia vertical entre los dos límites de la imagen corneal usando el cursor existente para ello (software versión 3.51). 


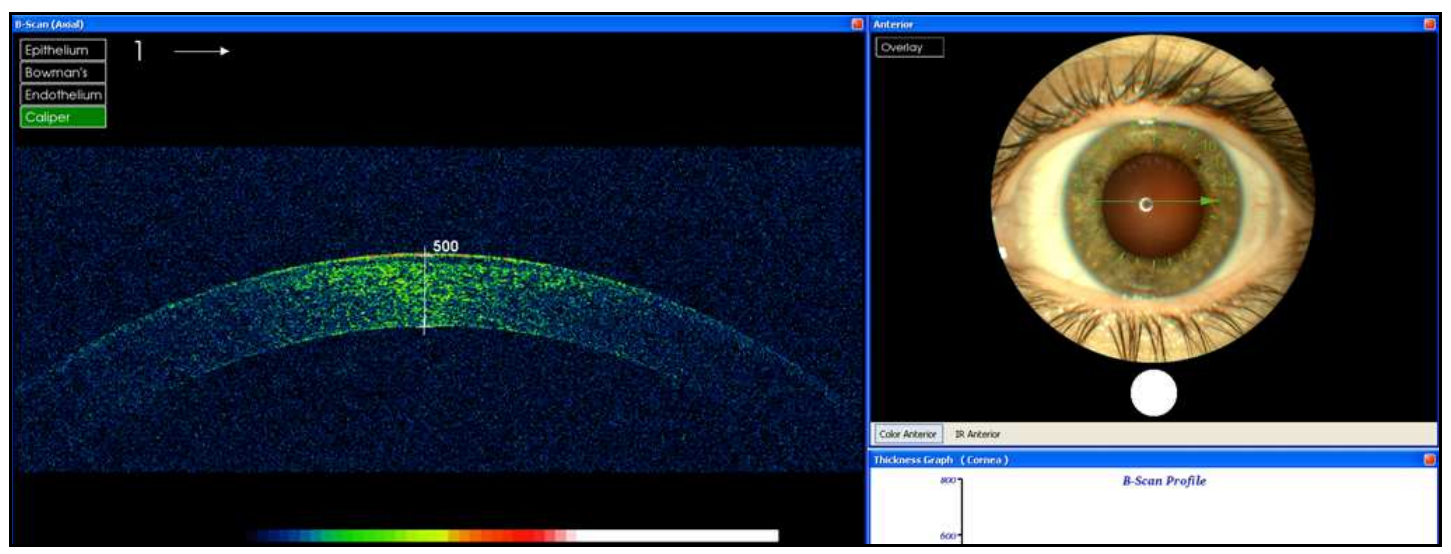

Figura 27. Medición del espesor corneal central mediante un cursor en el dispositivo Topcon 3D OCT-1000,

\subsubsection{LENSTAR LS 900}

Es un biómetro óptico de no contacto que permite obtener medidas de nueve estructuras a lo largo del eje visual del ojo de manera automática y en una sola medición: espesor corneal, queratometría, distancia blanco-blanco, pupilometría, espesor de la lente, profundidad de la cámara anterior, longitud axial, espesor retinal, y excentricidad de la línea óptica visual ${ }^{[67,68]}$.

El paciente fijó el ojo que iba a ser medido en un punto luminoso rojo al frente (punto de fijación interno), sin moverlo mientras se tomaban las medidas ${ }^{[105]}$. El sistema proyecta sobre la córnea 32 diodos emisores de luz (LEDs), dispuestos en 2 anillos de $1.65 \mathrm{~mm}$ y $2.30 \mathrm{~mm}$ de radio y 16 puntos de medida cada uno ${ }^{[66,68]}$. Se realizó en cada caso el enfoque de dichos puntos sobre la córnea (en la imagen en pantalla), apareciendo entonces un círculo verde como indicador de que se puede pulsar para realizar la medida (Figura 28).

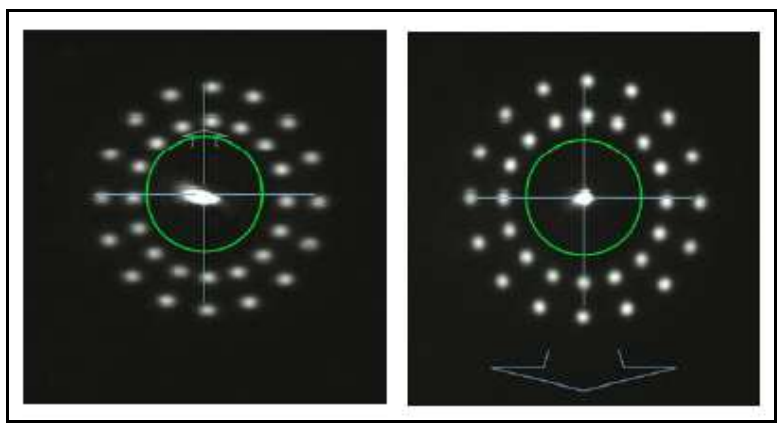

Figura 28. Imagen de la visualización de los 32 diodos emisores de luz (LEDs) proyectados sobre la córnea, y su enfoque, en el dispositivo Lenstar LS 900. 
El sistema tomó hasta un total de 5 medidas, apareciendo una señal de alerta en pantalla indicando que se debía volver a realizar la captura si alguna de éstas tenía una mala calidad. Tras las 5 mediciones presentó automáticamente los valores biométricos medios de todas ellas, entre ellos el grosor corneal central ${ }^{[68]}$.

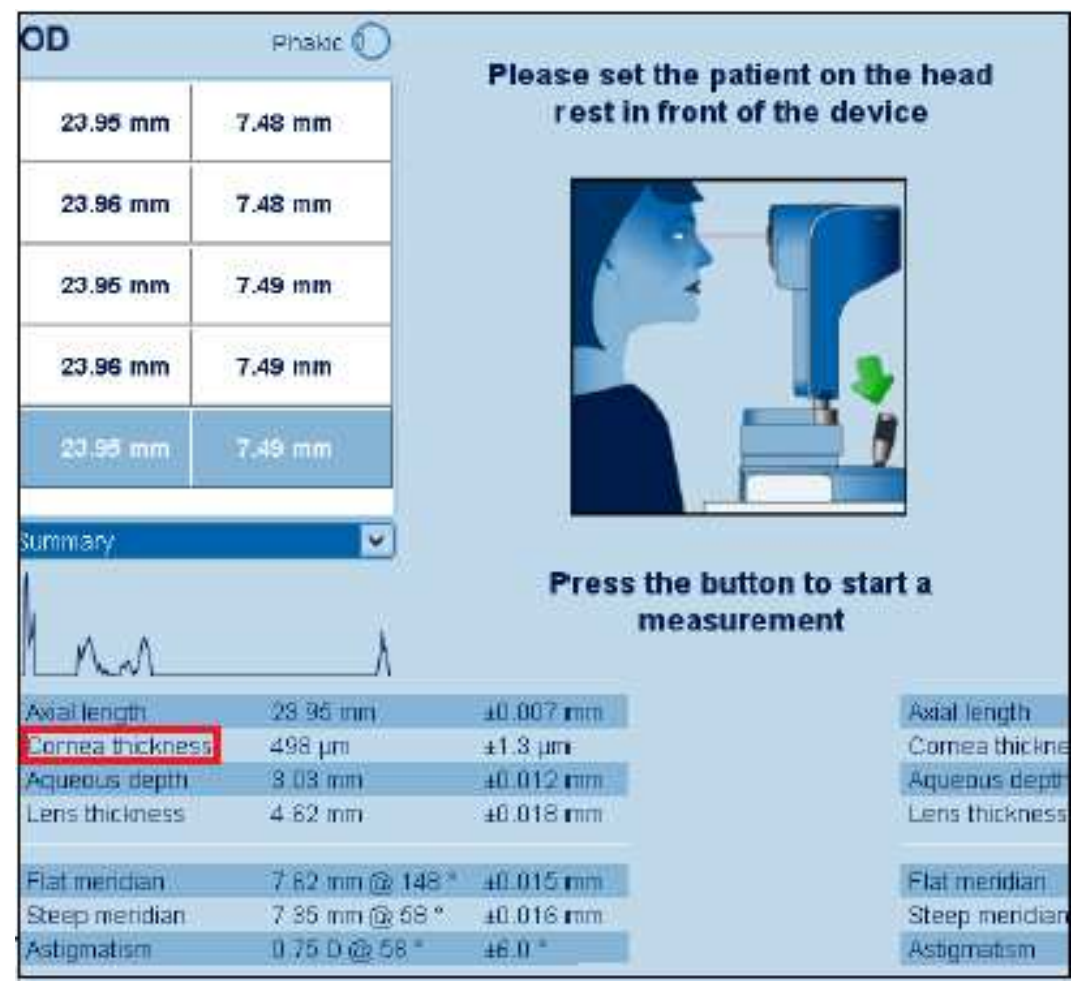

Figura 29. Pantalla que muestra las mediciones en el dispositivo Lenstar LS 900.

\subsubsection{PAQUÍMETRO ULTRASÓNICO}

Se considera el patrón oro ("gold standard") para la estimación del grosor corneal central $^{[28,33]}$.

Previa a la medición del grosor corneal, en todos los pacientes se instiló en el ojo 1 gota de tetracaína al $0.1 \%$ combinada con oxybuprocaina al $0.4 \%$ (Anestésico Doble. Alcon, Barcelona, España).

Se empleó el paquímetro ultrasónico Corneo-Gage Plus II (Sonogage Inc., Cleveland, $\mathrm{OH}$ ), colocando la sonda manualmente lo más perpendicularmente posible sobre el centro corneal, mientras se le indicó al paciente fijar en un punto lejano ${ }^{[87,88]}$. 
Teniendo en cuenta los ajustes por defecto del paquímetro ultrasónico, 5 mediciones consecutivas se promediaron automáticamente para obtener un valor de grosor corneal central en cada paciente ${ }^{[34,86-88,92]}$.

\subsection{DISEÑO DEL ESTUDIO}

Todas las medidas paquimétricas fueron realizadas por observadores experimentados. El orden en el que se emplearon los paquímetros de no contacto cuando se evaluó la intercambiabilidad entre los sistemas basados en tomografía de coherencia óptica y reflectometría óptica de baja coherencia, fue aleatorio. Cuando se compararon las medidas paquimétricas del sistema OCT de dominio espectral y las de la técnica ultrasónica, la técnica que requería contacto corneal se realizó en segundo lugar. El orden en que los observadores tomaron las medidas fue también aleatorio, al igual que el ojo medido en cada paciente (derecho / izquierdo), tomándose un único ojo en cada sujeto. El proceso se basó en tablas de aleatorización generadas mediante un software específico para ello.

Cuando se realizaron medidas de manera consecutiva, los pacientes fueron instruidos para parpadear entre ellas, y así reponer la película lagrimal. Igualmente, el aparato de medida se desplazó hacia atrás y se realineó tras cada medición, para evitar la interdependencia entre las capturas sucesivas ${ }^{[93]}$.

Las medidas siempre se tomaron entre las 10:00 h y las 14:00 h. para minimizar el efecto de las variaciones diurnas en el grosor corneal central ${ }^{[6,11]}$.

Se seleccionaron las imágenes con mejor calidad para posteriormente ser más precisos en la medición del grosor corneal central, repitiéndose la adquisición de la imagen en caso de que fuera necesario.

Para evitar una influencia del examinador al realizar las paquimetrías de manera consecutiva utilizando los sistemas OCT de dominio espectral, en primer lugar las imágenes corneales no fueron medidas hasta que todos los pacientes estuvieron incluidos en el estudio (todas las imágenes de OCT ya adquiridas), y en segundo lugar, el examinador no midió la paquimetría consecutivamente en todas las imágenes corneales obtenidas del mismo paciente, sino que lo realizó primero en todas las primeras imágenes corneales de todos los pacientes, después en todas las segundas, y así sucesivamente, con el objetivo de evitar sesgos que alterasen el resultado final. 
Tal y como recomiendan Bland y Altman ${ }^{[106]}$, para evaluar la fiabilidad de medida de cualquier instrumento nos basamos en las definiciones de repetibilidad y reproducibilidad adoptadas por la "British Standards Institution" [35, 83, 91, 93, 107, 108]. Siendo la repetibilidad el grado de acuerdo entre medidas (mínimo 2) obtenidas por el mismo operador en el mismo sujeto, con el mismo equipo y en el menor tiempo posible. Se entiende como reproducibilidad el grado de acuerdo de las medidas obtenidas usando el mismo equipo y método, pero con una variación en el examinador (reproducibilidad inter-observador), o en el momento de la medición (reproducibilidad inter-sesión). Para que un sistema sea fiable, es decir que no exista error aleatorio (fiabilidad, término anglosajón: reliability), es necesaria una buena repetibilidad y reproducibilidad. Fiabilidad es análoga de precisión. Por el contrario, la validez (exactitud, término anglosajón: accuracy) se entiende como la cercanía de las mediciones al valor verdadero; es decir, en qué grado el procedimiento o tecnología mide la magnitud real que se desea cuantificar. Para poder evaluar la exactitud de medida de una tecnología, en primer lugar debemos determinar un método "gold standard", y en segundo lugar, realizar un estudio comparativo entre nuestra tecnología de estudio y el acordado internacionalmente como patrón oro, para cuantificar cual es el error sistemático (error de calibración) de nuestra tecnología, si la hubiera.

Consecuentemente, es deseable en la clínica diaria que los profesionales de la salud dispongan de aparatos de medida, en este caso paquímetros, que ofrezcan medidas válidas (exactas) y fiables (precisas).

A continuación se describe de manera pormenorizada la metodología realizada para conseguir cada objetivo específico.

\subsubsection{REPETIBILIDAD INTRA-OBSERVADOR Y REPRODUCIBILIDAD INTER-OBSERVADOR DE LAS MEDIDAS PAQUIMÉTRICAS OBTENIDAS CON EL SISTEMA DE TOMOGRAFÍA DE COHERENCIA ÓPTICA DE DOMINIO ESPECTRAL CIRRUS HD- OCT.}

El examinador 1 adquirió de manera consecutiva, y en el menor tiempo posible, 4 imágenes corneales con el sistema Cirrus HD-OCT en un total de 77 pacientes. 
Posteriormente, el examinador 2, obtuvo únicamente una imagen corneal con el mencionado sistema en cada sujeto.

El orden en el que se obtuvieron las imágenes corneales por parte de ambos examinadores se aleatorizó. Una vez incluidos los 77 pacientes, cada examinador midió el grosor corneal en el ápex de cada una de las imágenes que había obtenido, nunca de manera consecutiva en cada paciente para evitar sesgos.

Para calcular la repetibilidad (intra-sesión e intra-observador) se tuvieron en cuenta las 4 mediciones realizadas por el examinador 1, mientras que para calcular la reproducibilidad inter-observador se tuvo en cuenta la primera medida realizada por el examinador 1 y la realizada por el examinador 2.

\subsubsection{GRADO DE ACUERDO EXISTENTE ENTRE LA PAQUIMETRÍA CENTRAL OBTENIDA POR UN SISTEMA DE TOMOGRAFÍA DE COHERENCIA ÓPTICA DE DOMINIO ESPECTRAL Y POR LA ULTRASONOGRAFÍA CONVENCIONAL.}

Se obtuvieron en primer lugar imágenes corneales con un sistema de tomografía de coherencia óptica de dominio espectral (Cirrus HD-OCT) en 20 ojos de 20 sujetos voluntarios. Posteriormente, se les aplicó una gota de colirio anestésico, y un segundo examinador, desconocedor de los posibles valores obtenidos con el sistema SD-OCT, realizó 5 medidas consecutivas con el paquímetro ultrasónico de contacto Corneo-Gage Plus II. Teniendo en cuenta los ajustes por defecto del PU, 5 mediciones consecutivas se promediaron automáticamente para obtener un valor de grosor corneal central en cada paciente $^{[34,86-88,92]}$.

\subsubsection{REPETIBILIDAD INTRA-OBSERVADOR Y REPRODUCIBILIDAD INTER-OBSERVADOR DE LAS MEDIDAS PAQUIMÉTRICAS OBTENIDAS CON UN SISTEMA DE REFLECTOMETRÍA ÓPTICA DE BAJA COHERENCIA.}

El examinador 1 realizó de manera consecutiva 4 medidas con el sistema de reflectometría óptica de baja coherencia Lenstar LS 900 en un total de 75 sujetos (75 ojos) empleando siempre el mismo método y en el menor tiempo posible. Mientras que 
el examinador 2 realizó una única medida en el ojo seleccionado aleatoriamente, antes o después del examinador 1, en función de la tabla de aleatorización.

Se tuvieron en cuenta las 4 medidas realizadas por el examinador 1 para evaluar la repetibilidad (intra-sesión e intra-observador), mientras que para evaluar la reproducibilidad inter-observador únicamente se consideró la primera de las 4 medidas realizadas por dicho examinador y la única medida realizada por el examinador 2.

\subsubsection{GRADO DE ACUERDO EXISTENTE ENTRE LA PAQUIMETRÍA CENTRAL OBTENIDA POR UN SISTEMA DE TOMOGRAFÍA DE COHERENCIA ÓPTICA DE DOMINIO ESPECTRAL Y POR LA REFLECTOMETRÍA ÓPTICA DE BAJA COHERENCIA.}

Un solo examinador realizó un sola medida de la paquimetría central en 75 sujetos (75 ojos) utilizando el sistema basado en reflectometría óptica de baja coherencia (Lenstar LS 900) y el dispositivo basado en tomografía de coherencia óptica de dominio espectral Cirrus HD-OCT.

El orden de adquisición de la paquimetría con ambos sistemas se aleatorizó para evitar sesgos. Las mediciones manuales con el sistema de SD-OCT se realizaron siempre 1 semana más tarde a las capturas, para que de esa manera el examinador no pudiera recordar los valores aportados automáticamente por el dispositivo de OLCR durante la sesión de adquisición.

Las dos medidas realizadas en cada sujeto se tuvieron en cuenta para evaluar la intercambiabilidad entre ambos sistemas

\subsubsection{REPETIBILIDAD INTRA-OBSERVADOR Y REPRODUCIBILIDAD INTER-OBSERVADOR E INTER-SESIÓN DE LAS MEDIDAS PAQUIMÉTRICAS OBTENIDAS CON EL SISTEMA DE TOMOGRAFÍA DE COHERENCIA ÓPTICA DE DOMINIO ESPECTRAL TOPCON 3D OCT-1000.}

Durante una primera sesión el examinador 1 obtuvo 6 imágenes de la córnea de manera consecutiva y en el menor tiempo posible con el sistema Topcon 3D OCT-1000, en 60 ojos de 60 pacientes. Durante una segunda sesión realizada una semana más tarde de la primera, el mismo examinador obtuvo otra imagen con el sistema Topcon 3D 
OCT-1000 en los mismas pacientes, y además, el examinador 2, también obtuvo otra imagen corneal en los mismos sujetos de estudio. El orden de ambos en esa segunda sesión para la obtención de imágenes corneales fue aleatorizado.

Para el estudio de la repetibilidad (intra-sesión e intra-observador) se consideraron las medidas paquimétricas de las 6 imágenes obtenidas durante la primera sesión por el mismo observador.

Para el estudio de la reproducibilidad inter-sesión, se consideraron la primera imagen obtenida durante la primera sesión y la obtenida durante la segunda sesión, ambas por el examinador 1 .

En el estudio de la reproducibilidad inter-observador se consideraron las medidas paquimétricas de las dos imágenes obtenidas por ambos examinadores durante la segunda sesión.

\subsection{DISEÑO DEL ANÁLISIS ESTADÍSTICO}

Para la ejecución del análisis estadístico de la presente tesis doctoral se ha utilizado principalmente la metodología desarrollada por Bland y Altman, descrita por primera vez en $1986^{[106]}$.

Los datos correspondientes a las variables incluidas se introdujeron en una base de datos, realizándose los cálculos estadísticos mediante el programa SPSS versión 18.0 para Windows (SPSS, Chicago, IL).

Las medias y desviaciones estándar (DS) se calcularon para las variables que siguieron una distribución normal. Sin embargo, cuando los datos no se correspondieron con tal distribución, la mediana $\left(50^{\circ}\right.$ percentil $)$ y el rango intercuartil, es decir, los valores entre los percentiles $25^{\circ}$ y $75^{\circ}$ de la distribución, se usaron en su lugar.

Para todos los test estadísticos, se consideró estadísticamente significativa una $\mathrm{P}$ $<0.05$.

\subsubsection{REPETIBILIDAD INTRA-OBSERVADOR (E INTRA-SESIÓN).}

La DS de las medidas repetidas en el mismo individuo nos va a permitir medir el tamaño del error de medida que se puede producir en cada medición que hagamos con 
un determinado aparato oftálmico. Para realizar una determinación del mencionado error se necesitan mínimo 2 medidas sucesivas en el mismo individuo ${ }^{[109]}$. Para posteriormente aplicar la metodología estadística de análisis de la varianza (término anglosajón "ANOVA") ${ }^{[83,109]}$, de tal forma que se pueda calcular la desviación estándar intrasujeto $\left(\mathrm{DS}_{\mathrm{i}}\right)$, que corresponde a la raíz cuadrada de los cuadrados medios intra-sujetos ${ }^{[83,109,110]}$.

La precisión, desde un punto de vista estadístico, se definió como la diferencia entre la paquimetría obtenida en un sujeto y la paquimetría verdadera (valor medio que se obtendría mediante numerosas mediciones) en el $95 \%$ de las observaciones. Estadísticamente, la precisión se define como 1.96 veces la $\mathrm{DS}_{\mathrm{i}}{ }^{[83]}$. Igualmente, se calculó la repetibilidad, que se definió como 2.77 veces la $\mathrm{DS}_{\mathrm{i}}$, y representa el valor máximo de la diferencia entre dos medidas consecutivas con una probabilidad de un $95 \%[83,109,110]$. La repetibilidad también se expresó como un porcentaje, denominándose coeficiente de repetibilidad, y se definió como 2.77 veces la $\mathrm{DS}_{\mathrm{i}}$ / media x 100 (valor máximo de la diferencia de dos medidas consecutivas con una probabilidad de un $95 \%$ en términos porcentuales) ${ }^{[30]}$.

La variabilidad intrasesión también se calculó mediante el CCI (coeficiente de correlación intraclase) ${ }^{[83,111]}$, y el coeficiente de variación intrasujeto $\left(\mathrm{CV}_{\mathrm{i}}\right)^{[83]}$ definido como $\mathrm{DS}_{\mathrm{i}} /$ media x 100, expresándose como un porcentaje. Un bajo $\mathrm{CV}_{\mathrm{i}}$ corresponde con alto grado de repetibilidad.

\subsubsection{REPRODUCIBILIDAD INTER-OBSERVADOR}

Con el objetivo de determinar el grado de acuerdo entre las diferentes medidas paquimétricas obtenidas por dos observadores distintos, en primer lugar, se aplicó el test "t pareado" para establecer si hubo errores sistemáticos significativos entre observadores empleando un mismo instrumento de medida. Además, se realizó el análisis gráfico tipo Bland y Altman, ${ }^{[110]}$ en la que se representan las diferencias de las paquimetrías obtenidas por ambos observadores (A - B), frente a las medias de las medidas paquimétricas $(\mathrm{A}+\mathrm{B} / 2)$, que nos ayuda a establecer el grado de acuerdo entre ambos, más fácilmente. Igualmente, se calculó el $95 \%$ de los $\mathrm{LdC}$, que se 
definieron con la media de la diferencia de las mediciones entre ambos examinadores \pm 1.96 veces la DS de la diferencia entre examinadores; ${ }^{[83]}$ siendo el LdC superior igual a la media +1.96 veces dicha DS, y el inferior igual a la media -1.96 veces la DS. Por lo tanto, la amplitud de los LdC es la diferencia entre ambos límites. ${ }^{[83]}$.

Paralelamente también se calculo la $\mathrm{DS}_{\mathrm{i}}$ de la reproducibilidad inter-observador mediante el ANOVA ${ }^{[83,109,110]}$; con el objetivo de obtener la precisión interobservador $\left(1.96\right.$ veces $\left.1 \mathrm{a} \mathrm{DS}_{\mathrm{i}}\right){ }^{[83]}$, y la reproducibilidad en magnitudes absolutas $(2.77$ veces la $\left.\mathrm{DS}_{\mathrm{i}}\right)^{[83,110]}$, y porcentuales (coeficiente de reproducibilidad $=2.77$ veces la $\mathrm{DS}_{\mathrm{i}} /$ media x 100) ${ }^{[30]}$; así como el $\mathrm{CV}_{\mathrm{i}}$ inter-observador ${ }^{[83]}$.

\subsubsection{INTERCAMBIABILIDAD (GRADO DE ACUERDO) ENTRE SISTEMAS PAQUIMÉTRICOS}

Para validar clínicamente un nuevo método de medida, debe ser comparado con el método internacionalmente aceptado como "gold standard", de tal forma que si el nuevo método presenta un grado de acuerdo suficiente con el considerado patrón oro, éste podría ser reemplazado ${ }^{[106]}$.

Cuando ambas variables paquimétricas presentaron un distribución normal (Gaussiana), en primer lugar se utilizó el test "t pareado" para determinar si había diferencias sistemáticas significativas entre las medidas paquimétricas centrales obtenidas con ambos sistemas de medida; y en segundo lugar, para calcular el grado de acuerdo o concordancia entre los dos sistemas, se utilizó metodología estadística tipo Bland y Altman ${ }^{[110]}$

Por lo tanto, se realizaron gráficos en los que se representaban las diferencias paquimétricas entre ambos sistemas de medición $(\mathrm{A}-\mathrm{B})$ frente a las medias de las medidas $(\mathrm{A}+\mathrm{B} / 2)$ para determinar si había relación entre la diferencias y el rango de medida paquimétrico, de tal forma que ayudaba a establecer el grado de acuerdo más fácilmente.

Igualmente se calculó el 95\% de los límites de concordancia (LdC), los cuales se definieron como la diferencia media de las medidas paquimétricas centrales obtenidas con cada sistema \pm 1.96 veces la desviación estándar (DS) de la diferencia entre ambos 
sistemas. ${ }^{[83]}$ Idealmente, la diferencia media de los valores paquimétricos entre ambos sistemas debería ser cero. Además, el $95 \%$ de las diferencias entre sistemas deberían localizarse dentro de los $\mathrm{LdC}^{[106]}$. El límite superior de confianza se definió como la diferencia media +1.96 veces la DS de la diferencia entre sistemas, mientras que el límite inferior se definió como la diferencia media - 1.96 veces la DS, de tal forma que la amplitud de los LdC se calculó como la diferencia existente entre el límite superior e inferior. Cómo de pequeña debe de ser la diferencia entre los dos sistemas de medición para considerarlos intercambiables, es una cuestión clínica y no estadística ${ }^{[83]}$.

Cuando la distribución de los datos relativos a un sistema de medida paquimétrico no se correspondieron con una distribución normal (no pudiéndose aplicar el método de Bland y Altman), la mediana $\left(50^{\circ}\right.$ percentil) y el rango intercuartil (rango comprendido entre los percentiles $25^{\circ}$ y $75^{\circ}$ de la distribución) de las diferencias paquimétricas se usaron para describir el grado de acuerdo existente entre ambos sistemas de medida.

\subsubsection{REPRODUCIBILIDAD INTER-SESIÓN}

Para poder determinar el grado de acuerdo entre las diferentes medidas paquimétricas obtenidas por el mismo observador de dos sesiones distintas en diferentes días, en primer lugar, se aplicó el test "t pareado" con el objetivo de establecer la existencia de errores sistemáticos significativos entre días distintos manteniendo las mismas condiciones de medida. Posteriormente, para calcular la reproducibilidad intersesión de la paquimetría central se utilizó metodología estadística descrita por Bland y Altman ${ }^{[110]}$. Se obtuvieron gráficos representando las diferencias de las medidas entre ambas sesiones y las medias de ambas sesiones, para determinar si había relación entre las diferencias paquimétricas y el rango de medida paquimétrico. El 95\% de los LdC se definieron como la diferencia media de las paquimetrías centrales realizadas durante ambas sesiones \pm 1.96 veces la desviación estándar (DS) de la diferencia entre sesiones $[83,106]$. También se calculó la $\mathrm{DS}_{\mathrm{i}}$ inter-sesión (metodología estadística ANOVA) ${ }^{[83,}$ 109, 110]; la precisión (1.96 veces el $\mathrm{DS}_{\mathrm{i}}$ inter-sesión), la reproducibilidad (2.77 veces el $\mathrm{DS}_{\mathrm{i}}$ inter-sesión), el coeficiente de la reproducibilidad (2.77 veces el $\mathrm{DS}_{\mathrm{i}}$ inter-sesión / media $x$ 100) ${ }^{[30,83,110]}$ y el $\mathrm{CV}_{\mathrm{i}}$ inter-sesión que se definió como el cociente entre la DSi inter-sesión y la media paquimétrica central en términos porcentuales ${ }^{[83]}$. 

Resultados. 



\section{RESULTADOS}

\subsection{REPETIBILIDAD INTRA-OBSERVADOR Y REPRODUCIBILIDAD INTER-OBSERVADOR DE LAS MEDIDAS PAQUIMÉTRICAS OBTENIDAS CON EL SISTEMA DE TOMOGRAFÍA DE COHERENCIA ÓPTICA DE DOMINIO ESPECTRAL CIRRUS HD- OCT.}

La repetibilidad intra-observador y la reproducibilidad inter-observador se estudió en 77 ojos (46 mujeres y 31 hombres), con una edad media de $54.27 \pm 19.43$ años (rango, de 18 a 91 años).

\subsubsection{Repetibilidad Intra-observador de Cirrus HD-OCT.}

La media de las medidas paquimétricas centrales repetidas intra-sujeto fue de $541.78 \pm 35.37 \mu \mathrm{m}$. Los datos correspondientes a la $\mathrm{DS}_{\mathrm{i}}$, precisión, repetibilidad, coeficiente de repetibilidad, $\mathrm{CV}_{\text {i y }}$ CCI se detallan en la Tabla 2.

La repetibilidad de la medida manual de la paquimetría con el sistema Cirrus HD-OCT fue buena, dado que debemos esperar una variación máxima en dos medidas consecutivas de solo un $2.48 \%$ entre ellas.

Tabla 2. Repetibilidad de la paquimetría corneal central del dispositivo Cirrus HD-OCT.

\begin{tabular}{ccccccc}
\hline $\begin{array}{c}\text { Repetibilidad } \\
\text { CIRRUS }\end{array}$ & $\begin{array}{c}\text { Media } \\
(\text { Rango) }\end{array}$ & DS $_{\mathbf{i}}$ & Precisión & $\begin{array}{c}\text { Repetibilidad } \\
\text { (Coeficiente) }\end{array}$ & $\mathbf{C V}_{\mathrm{i}}$ & $\begin{array}{c}\text { CCI } \\
\text { (95\% IC) }\end{array}$ \\
\cline { 2 - 7 } HD- OCT & 541.64 & 4.86 & 9.52 & $\begin{array}{c}13.46 \\
(2.48 \%)\end{array}$ & $0.89 \%$ & $\begin{array}{c}0.981 \\
(481 / 623)\end{array}$ \\
& & & $0.974 / 0.987)$
\end{tabular}

\subsubsection{Reproducibilidad Inter-observador del sistema Cirrus HD-OCT.}

La media total de las medidas paquimétricas centrales en el análisis de grado de acuerdo entre ambos observadores fue de $541.71 \pm 35.35 \mu \mathrm{m}$. 
Los datos correspondientes a la $\mathrm{DS}_{\mathrm{i}}$, precisión, reproducibilidad, coeficiente de reproducibilidad, $\mathrm{CV}_{\mathrm{i}}$ inter-observador se determinan en la Tabla 3. Aunque la reproducibilidad del sistema Cirrus HD-OCT para la medida del grosor corneal central fue menor cuando la realizan dos observadores en vez de uno solo, el sistema tuvo una variabilidad máxima para el $95 \%$ de la mediciones de un $3.87 \%$.

No hubo una diferencia estadísticamente significativa entre el grupo de medidas obtenidas por cada observador $(\mathrm{p}=0.87)$. Siendo la media de las diferencias entre observadores de únicamente $0.13 \mu \mathrm{m}$.

Tabla 3. Reproducibilidad inter-observador de la paquimetría corneal central del dispositivo Cirrus HD-OCT.

\begin{tabular}{|c|c|}
\hline \multicolumn{2}{|c|}{ Reproducibilidad inter-observador CIRRUS HD-OCT } \\
\hline Media Global [ $\mu \mathrm{m}]$ (Rango) & $541.71(480 / 619)$ \\
\hline $\mathrm{DS}_{\mathrm{i}}[\mu \mathrm{m}]$ & 7.58 \\
\hline Precisión $[\mu \mathrm{m}]$ & 14.85 \\
\hline Reproducibilidad $[\mu \mathrm{m}]$ (Coeficiente) & $20.99(3.87 \%)$ \\
\hline $\mathbf{C V}_{\mathbf{i}}$ & $1.40 \%$ \\
\hline Media de las diferencias $[\mu \mathrm{m}](95 \%$ IC) & $-0.13(-1.85 / 1.58) \cdot p=0.87$ \\
\hline LdC Superior $[\mu \mathrm{m}](95 \% \mathrm{IC})$ & $14.64(11.74 / 17.63)$ \\
\hline LdC Inferior $[\mu \mathrm{m}](95 \% \mathrm{IC})$ & $-14.95(-17.90 /-12.01)$ \\
\hline Amplitud LdC [ $\mu \mathrm{m}]$ & 29.64 \\
\hline
\end{tabular}

Se empleó la gráfica de Bland y Altman para representar la diferencia entre las paquimetrías realizadas en función de la media de las medidas obtenidas por ambos examinadores en el mismo sujeto (Figura 30). Representándose en la misma no solo la diferencia media, sino también los LdC al 95\%, cuyos valores se determinan en la Tabla 3.

La gráfica de Bland y Altman (Figura 30) muestra la ausencia de tendencia o correlación significativa entre las medias y las diferencias de las medidas, ya que los distintos valores se distribuyen en forma de nube dispersa dentro del intervalo LdC, y en torno a la media de las diferencias, y nunca presentando una correlación de tipo lineal que dependa de la magnitud paquimétrica media. 


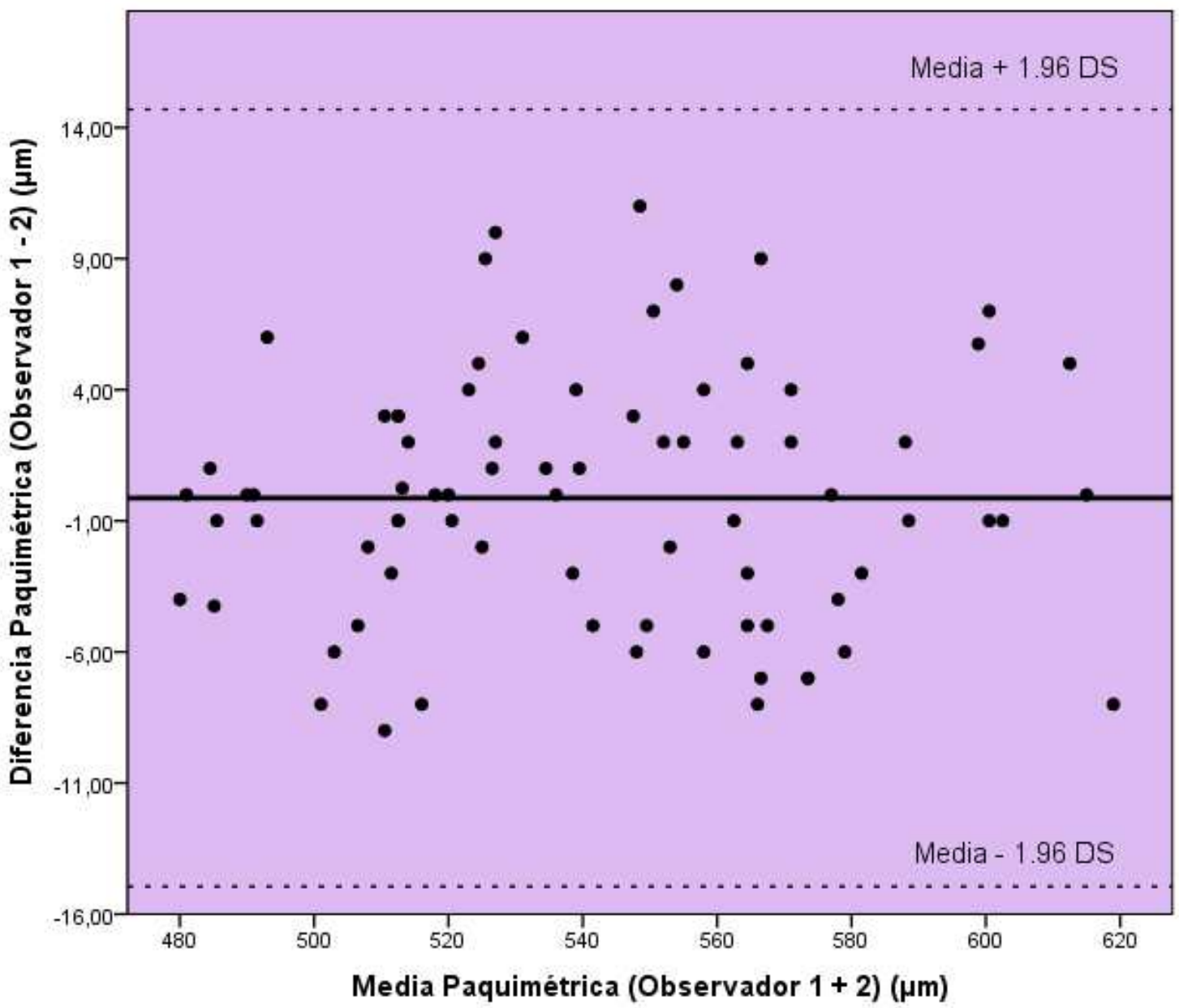

Figura 30. Gráfica Bland-Altman describiendo la reproducibilidad inter-observador con el dispositivo Cirrus HD-OCT. Las líneas horizontales discontinuas superior e inferior indican los límites de concordancia $(\mathrm{LdC})$ superior e inferior. La línea central indica la diferencia media de las medidas tomadas por ambos examinadores usando el Cirrus HD-OCT.

Además, en la Figura 31 se demuestra que todos los valores de las diferencias, se sitúan cercanos a la media, siguiendo una distribución aproximadamente normal, con lo que se confirma la idoneidad del análisis de Bland y Altman. 


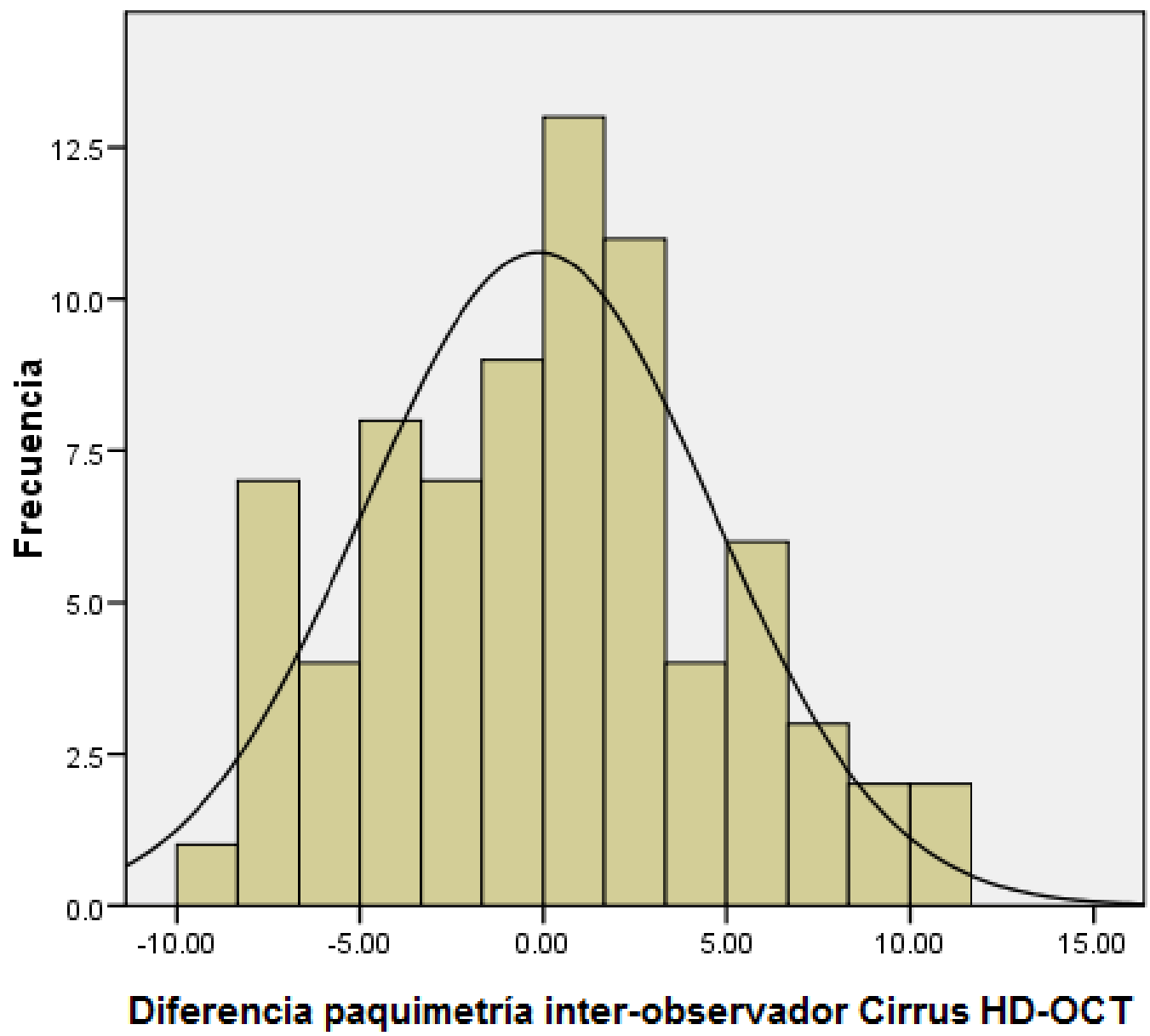

Figura 31. Distribución de las diferencias paquimétricas entre ambos examinadores con el dispositivo Cirrus HD-OCT.

\subsection{GRADO DE ACUERDO EXISTENTE ENTRE LA PAQUIMETRÍA CENTRAL OBTENIDA POR UN SISTEMA DE TOMOGRAFÍA DE COHERENCIA ÓPTICA DE DOMINIO ESPECTRAL Y POR LA ULTRASONOGRAFÍA CONVENCIONAL.}

Se evaluó la paquimetría corneal en 20 ojos de 20 voluntarios (16 mujeres, 4 hombres) con una edad media de $49.10 \pm 19.56$ años (rango de 26 a 82 años), utilizando el sistema Cirrus HD-OCT y el paquímetro ultrasónico de contacto.

La media de las medidas paquimétricas centrales con el sistema Cirrus HD-OCT fue de $544 \pm 28.16 \mu \mathrm{m}$, y de $547.7 \pm 29.03 \mu \mathrm{m}$ con el paquímetro ultrasónico. 
La diferencia entre ambos sistemas no siguió una distribución normal (test de Shapiro-Wilk, $\mathrm{p}=0.001$ ), por lo que no se pudo emplear el método de Bland y Altman.

La mediana de las diferencias de las mediciones entre ambos sistemas de medida fue de $-4.5 \mu \mathrm{m}$. El rango intercuartil comprendió los valores de -7.0 a 0.0 (siendo -7.0 el valor del percentil 25, y 0.0 el valor del percentil 75).

El rango de las diferencias de las medidas entre ambos aparatos fue de -12.00 a +18.00 , y fue estadísticamente significativa $(\mathrm{p}=0.04)$, aunque clínicamente no se puede considerar significativo ya que la mediana de la diferencia entre sistemas paquimétricos fue de solo $4.5 \mu \mathrm{m}$.

\subsection{REPETIBILIDAD INTRA-OBSERVADOR Y REPRODUCIBILIDAD INTER-OBSERVADOR DE LAS MEDIDAS PAQUIMÉTRICAS OBTENIDAS CON UN SISTEMA DE REFLECTOMETRÍA ÓPTICA DE BAJA COHERENCIA}

Se evaluó la repetibilidad intra-observador y la reproducibilidad interobservador de la paquimetría central en 75 ojos de 75 voluntarios (37 mujeres y 28 hombres), con una edad media de $61.38 \pm 17.26$ años (rango de 27 a 82 años).

No presentaban patología ocular el $61.3 \%$, el $21.3 \%$ eran postoperados de catarata, 9.3\% tenían retinopatía diabética leve, el 5.3\% eran vitrectomizados con pelado de membrana epirretiniana, y el $2.7 \%$ estaban en seguimiento por hipertensión ocular.

\subsubsection{Repetibilidad Intra-observador del sistema Lenstar LS 900.}

La media de las medidas paquimétricas centrales repetidas intra-sujeto fue de $551.18 \pm 35.02 \mu \mathrm{m}$.

Los datos relativos a la $\mathrm{DS}_{\mathrm{i}}$, la precisión, la repetibilidad, el coeficiente de repetibilidad y el $\mathrm{CV}_{\mathrm{i}}$ intra-observador, junto con el CCI se determinan en la Tabla 4. La repetibilidad del sistema de reflectometría óptica de baja coherencia es excelente, ya 
que la máxima diferencia esperable entre dos medidas repetidas es de únicamente 6.47 $\mu \mathrm{m}$.

Tabla 4. . Repetibilidad de la paquimetría corneal central con del dispositivo Lenstar LS 900.

\begin{tabular}{ccccccc}
\hline $\begin{array}{c}\text { Repetibilidad } \\
\text { Lenstar LS } \\
\mathbf{9 0 0}\end{array}$ & $\begin{array}{c}\text { Media } \\
(\text { Rango) }\end{array}$ & DS $_{\mathbf{i}}$ & Precisión & $\begin{array}{c}\text { Repetibilidad } \\
\text { (Coeficiente) }\end{array}$ & $\mathbf{C V}_{\mathbf{i}}$ & $\begin{array}{c}\text { CCI } \\
\text { (95\% IC) }\end{array}$ \\
\cline { 2 - 7 } & $\begin{array}{c}551.18 \\
(492 / 636)\end{array}$ & 2.33 & 4.56 & $\begin{array}{c}6.47 \\
(1.17 \%)\end{array}$ & $0.42 \%$ & $\begin{array}{c}0.996 \\
(0.994 / 0.997)\end{array}$ \\
\hline
\end{tabular}

\subsubsection{Reproducibilidad Inter-observador del sistema Lenstar LS 900 .}

La media total de las medidas paquimétricas centrales inter-observador fue de $551.86 \pm 37.0 \mu \mathrm{m}$. Los valores relativos a la $\mathrm{DS}_{\mathrm{i}}$, la precisión, la reproducibilidad, el coeficiente de reproducibilidad y el $\mathrm{CV}_{\mathrm{i}}$ inter-observador, junto con el $\mathrm{CCI}$ se detallan en la Tabla 5.

No hubo una diferencia estadísticamente significativa entre el grupo de medidas obtenidas por cada observador $(\mathrm{p}=0.307)$. Siendo la media de las diferencias entre observadores de $1.35 \mu \mathrm{m}$.

Tabla 5. Reproducibilidad inter-observador del dispositivo Lenstar LS 900.

\begin{tabular}{|c|c|}
\hline \multicolumn{2}{|c|}{ Reproducibilidad inter-observador Lenstar LS 900} \\
\hline Media Global [ $\mu \mathrm{m}]$ (Rango) & $551.86(491 / 638)$ \\
\hline $\mathrm{DS}_{\mathrm{i}}[\mu \mathrm{m}]$ & 11.59 \\
\hline Precisión $[\mu \mathrm{m}]$ & 22.71 \\
\hline Reproducibilidad $[\mu \mathrm{m}]$ (coeficiente) & $32.10(5.81 \%)$ \\
\hline $\mathbf{C V}_{\mathbf{i}}$ & $2.10 \%$ \\
\hline Media de las diferencias $[\mu \mathrm{m}](95 \%$ IC) & $-1.35(-3.97 / 1.26) \cdot p=0.307$ \\
\hline LdC Superior $[\mu \mathrm{m}](95 \% \mathrm{IC})$ & $21.28(16.78 / 25.78)$ \\
\hline LdC Inferior $[\mu \mathrm{m}](95 \%$ IC) & $-23.99(-28.49 /-19.49)$ \\
\hline Amplitud LdC [ $\mu \mathrm{m}]$ & 45.27 \\
\hline
\end{tabular}


Se utilizó el análisis gráfico de Bland y Altman para representar la diferencia entre las paquimetrías realizadas en función de la media de las medidas obtenidas por ambos examinadores en el mismo sujeto (Figura 32). Representándose en la misma no solo la diferencia media, sino también los $\mathrm{LdC}$ al 95\%, cuyos valores se determinan en la Tabla 5 .

Dicha gráfica de Bland y Altman (Figura 32) muestra la ausencia de tendencia o correlación significativa entre las medias y las diferencias de las medidas, ya que los distintos valores se distribuyen en forma de nube dispersa dentro del intervalo LdC (excepto los dos valores inferiores al intervalo), y en torno a la media de las diferencias, y nunca presentando una correlación de tipo lineal que dependa de la magnitud paquimétrica media.

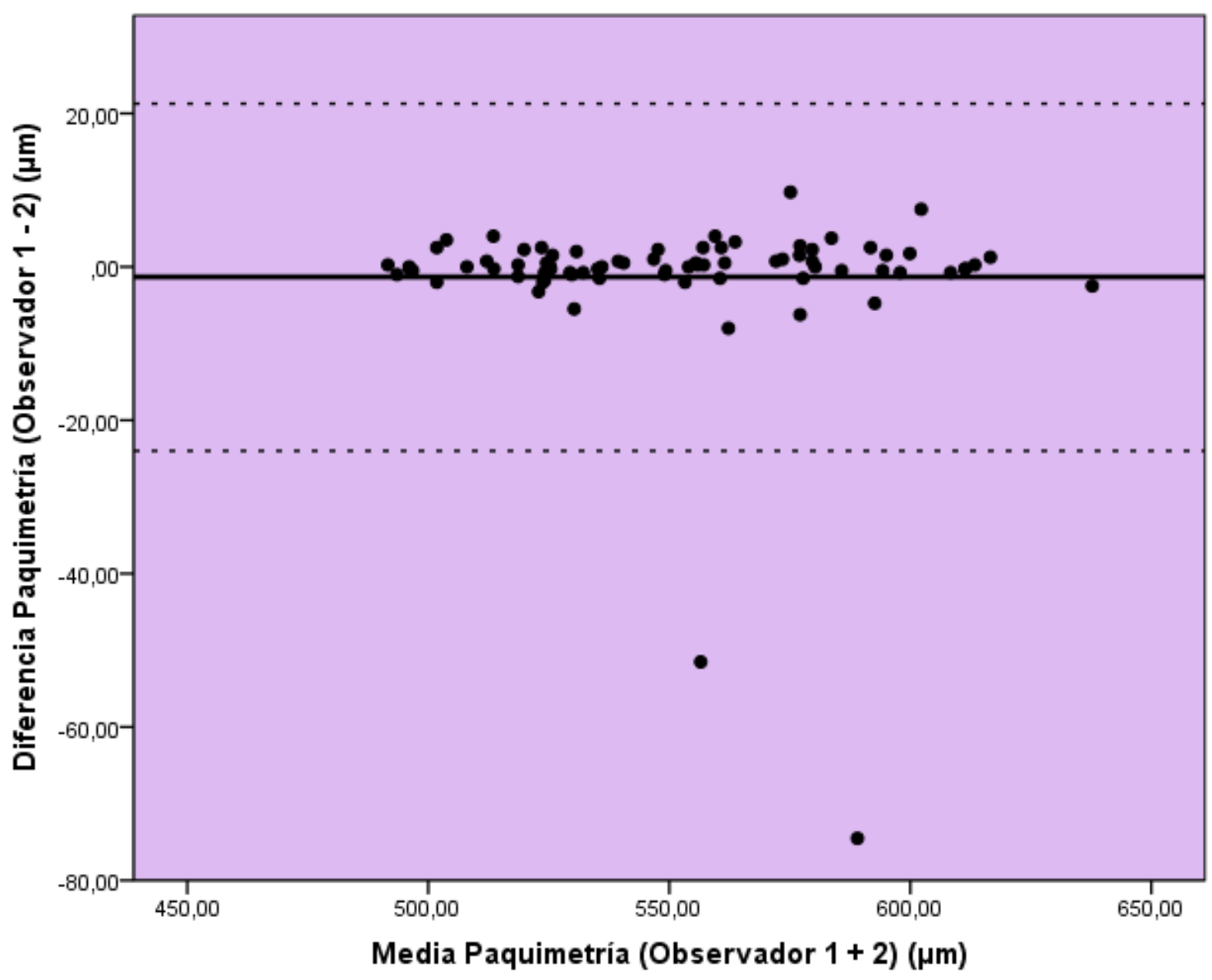

Figura 32. Gráfica Bland-Altman describiendo la reproducibilidad inter-observador con el dispositivo Lenstar LS 900. Las líneas horizontales discontinuas superior e inferior indican los límites de 
concordancia $(\mathrm{LdC})$ superior e inferior. La línea central indica la diferencia media de las medidas tomadas por ambos examinadores usando el Lenstar LS 900.

La mayoría de los valores correspondientes a las diferencias entre las medidas paquimétricas obtenidas por ambos observadores, están en torno a la media, siguiendo una distribución aproximadamente normal (Figura 33), requisito necesario para poder emplear el método de Bland y Altman.

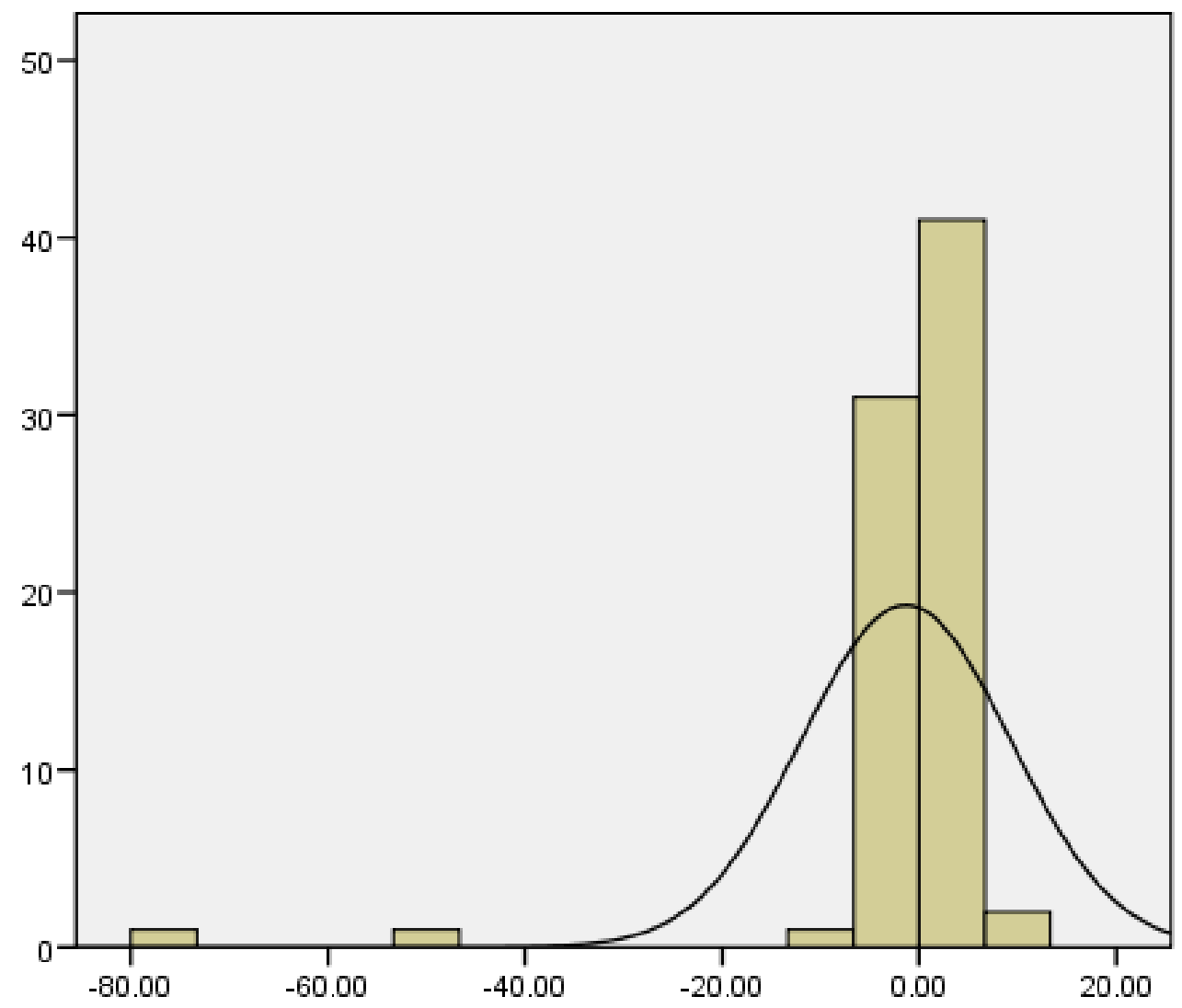

Diferencia paquimetría inter-observador Lenstar LS 900

Figura 33. Distribución de las diferencias paquimétricas de las medidas realizadas por ambos examinadores en el mismo paciente con el dispositivo Lenstar LS 900. 


\subsection{GRADO DE ACUERDO EXISTENTE ENTRE LA PAQUIMETRÍA CENTRAL OBTENIDA POR UN SISTEMA DE TOMOGRAFÍA DE COHERENCIA ÓPTICA DE DOMINIO ESPECTRAL Y POR LA REFLECTOMETRÍA ÓPTICA DE BAJA COHERENCIA.}

Se estudió en un grupo de 75 ojos en 75 pacientes ( 37 mujeres y 28 hombres), con una edad media de $61.38 \pm 17.26$ años (rango de 27 a 82 años).

La media de las medidas paquimétricas centrales con Lenstar LS 900 fue de $551.21 \pm 35.13 \mu \mathrm{m}$ (rango 488/639), y de $556.90 \pm 38.65 \mu \mathrm{m}$ (rango 490/643) en el caso de Cirrus HD-OCT.

La media de la diferencia de las mediciones paquimétricas entre ambos sistemas fue de $5.68 \pm 11.46 \mu \mathrm{m} \quad$ (95\% IC: 3.08/8.29 $\mu \mathrm{m}$ ), y fue estadísticamente significativa $(\mathrm{p}=0.0001)$.

Se empleó la gráfica de Bland y Altman para representar la diferencia entre las paquimetrías obtenidas en el mismo individuo y realizadas por los dos sistemas, en función de la media de las medidas de ambos aparatos (Figura 34). Representándose en la misma el 95\% de los LdC, con un LdC superior de $16.79 \mu \mathrm{m}$ (95\% IC: 13.55/20.02 $\mu \mathrm{m})$ y de $-28.14 \mu \mathrm{m}(95 \%$ IC: $-31.38 /-24.91 \mu \mathrm{m})$ en el caso del LdC inferior, siendo la amplitud del LdC de $44.93 \mu \mathrm{m}$. 


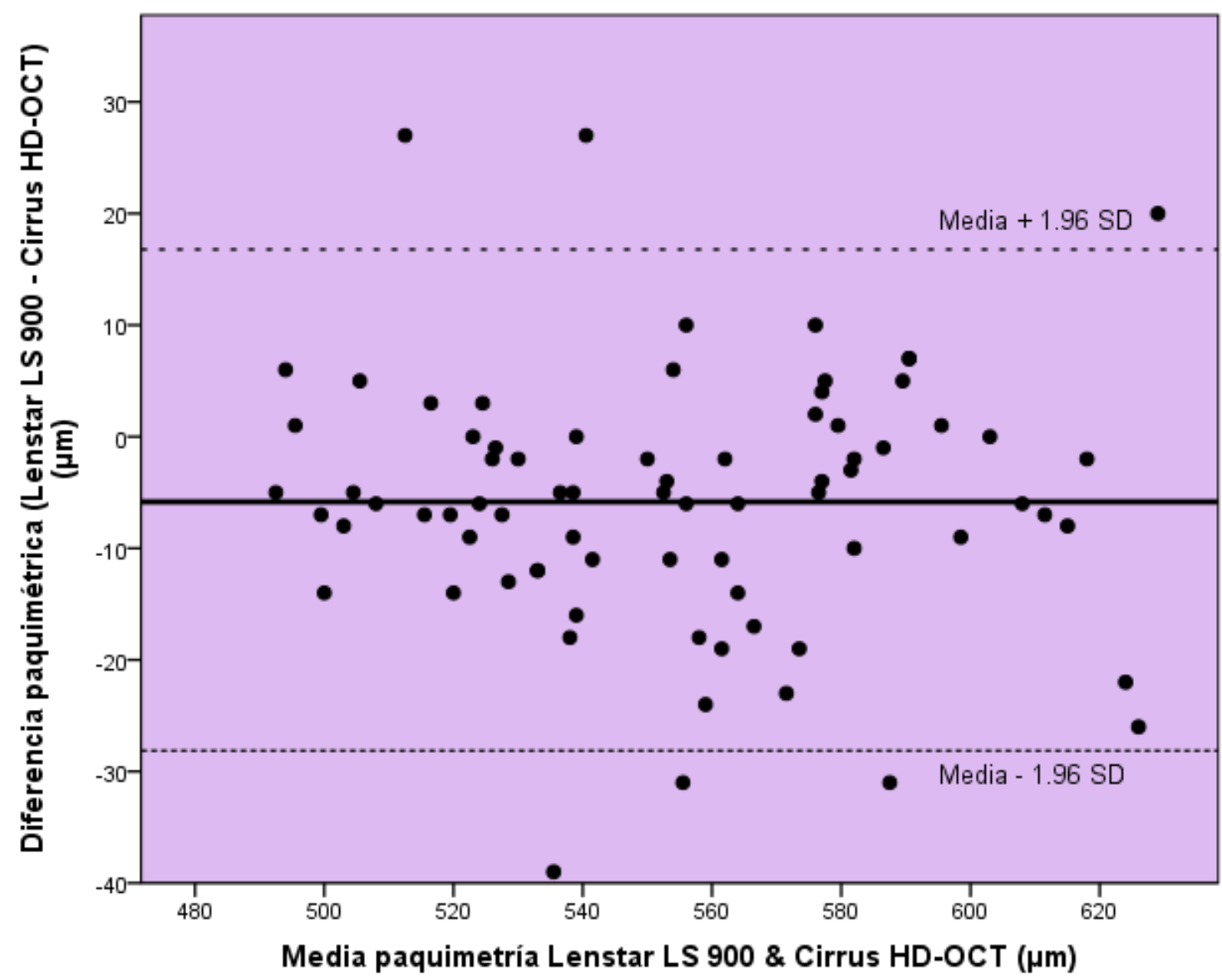

Figura 34. Gráfica Bland-Altman describiendo la intercambiabilidad de las medidas paquimétricas centrales obtenidas con los dispositivos Lenstar LS 900 y Cirrus HD-OCT. Las líneas discontinuas horizontales superior e inferior indican los límites de concordancia (LdC) superior e inferior. La línea central indica la diferencia media de las medidas tomadas por ambos sistemas (Cirrus HD-OCT y Lenstar LS 900) en el mismo sujeto.

Igualmente, se comprobó que todos los valores de las diferencias estaban en torno a la media, siguiendo una distribución aproximadamente normal en la Figura 35, imprescindible para poder utilizar el método de Bland y Altman. 


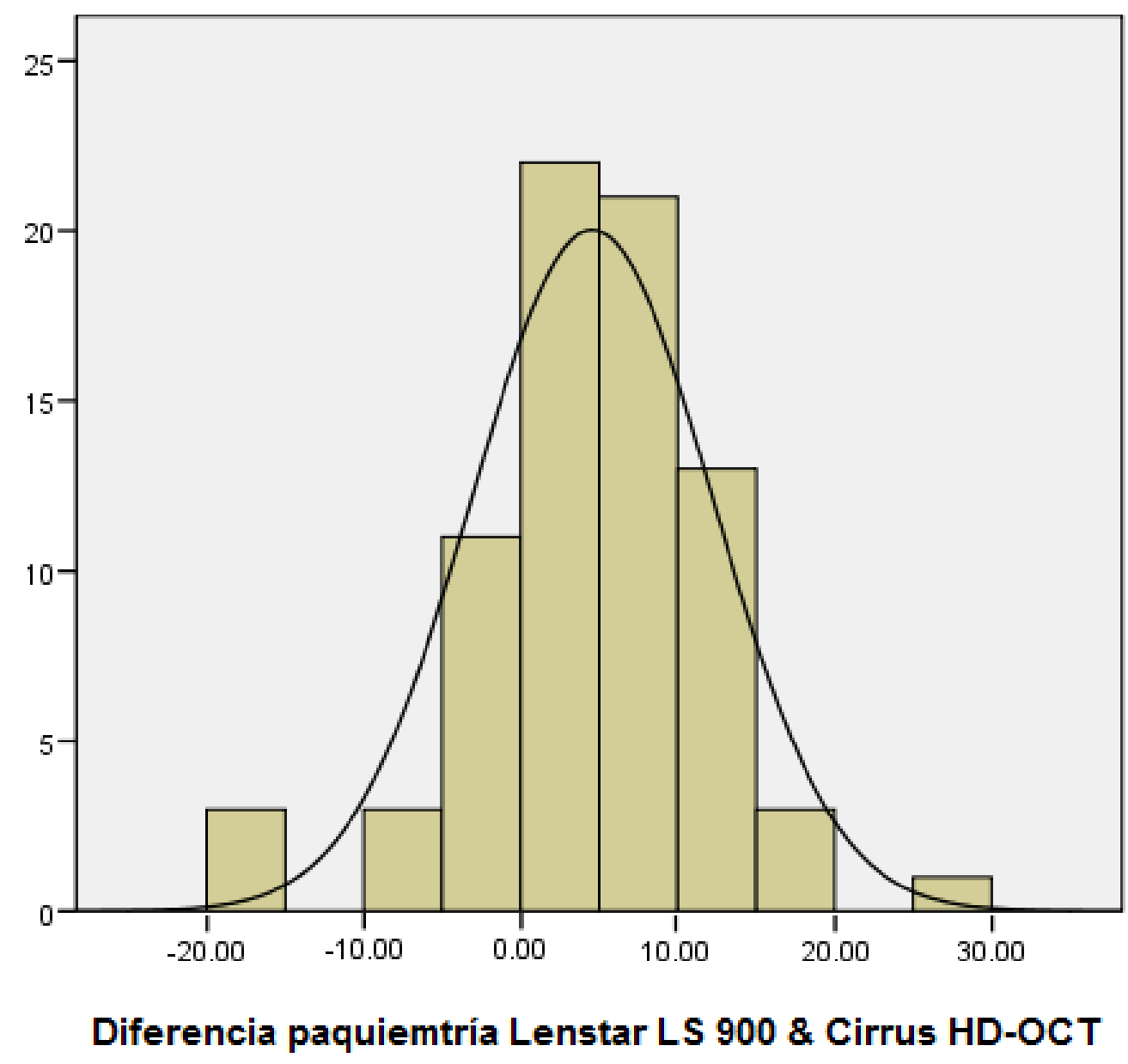

Figura 35. Distribución de las diferencias paquimétricas de las medidas realizadas por ambos dispositivos (Lenstar LS 900 y Cirrus HD-OCT).

\subsection{REPETIBILIDAD INTRA-OBSERVADOR Y REPRODUCIBILIDAD} INTER-OBSERVADOR E INTER-SESIÓN DE LAS MEDIDAS PAQUIMÉTRICAS OBTENIDAS CON EL SISTEMA DE TOMOGRAFÍA DE COHERENCIA ÓPTICA DE DOMINIO ESPECTRAL TOPCON 3D OCT-1000.

Se estudiaron un total de 60 ojos en 60 pacientes ( 23 mujeres y 37 hombres), con una edad media de $64.3 \pm 14.7$ años (rango 26-86).

De los pacientes incluidos, 24 (40\%) no tenían ninguna patología a nivel ocular, $10(16.7 \%)$ eran postoperados de catarata, $9(15 \%)$ presentaba catarata incipiente, 8 $(13.3 \%)$ tenían retinopatía diabética leve, $6(10 \%)$ eran en pacientes en seguimiento por glaucoma y $3(5 \%)$ lo estaba por degeneración macular asociada a la edad. 


\subsubsection{Repetibilidad Intra-observador del sistema Topcon 3D OCT-1000.}

La media de las medidas paquimétricas centrales repetidas intra-sujeto fue de $525.07 \pm 33.21 \mu \mathrm{m}$.

Los resultados correspondientes a la $\mathrm{DS}_{\mathrm{i}}$, precisión, repetibilidad, coeficiente de repetibilidad, $\mathrm{CV}_{\mathrm{i}}$ y CCI se detallan en la Tabla 6.

La repetibilidad de la medida manual de la paquimetría con el sistema Topcon 3D OCT-1000 fue clínicamente buena, ya que la máxima variación esperable de la paquimetría en dos medidas repetidas debería de ser del $2.72 \%$.

Tabla 6. . Repetibilidad de la paquimetría corneal central con el dispositivo Topcon 3D OCT1000

\begin{tabular}{ccccccc}
\hline \multirow{2}{*}{$\begin{array}{c}\text { Repetibilidad } \\
\text { Topcon 3D }\end{array}$} & $\begin{array}{c}\text { Media } \\
(\text { Rango) }\end{array}$ & DS & Precisión & $\begin{array}{c}\text { Repetibilidad } \\
\text { (Coeficiente) }\end{array}$ & CV $_{\mathbf{i}}$ & $\begin{array}{c}\text { CCI } \\
\text { (95\% IC) }\end{array}$ \\
\cline { 2 - 7 } OCT-1000 & $\begin{array}{c}525.07 \\
(446 / 602)\end{array}$ & $\begin{array}{c}5.16 \\
(4.59 / 5.72)\end{array}$ & 10.11 & 14.29 & $0.99 \%$ & 0.97 \\
& & & $(2.72 \%)$ & $(0.87 / 1.10)$ & $(0.96 / 0.98)$ \\
\hline
\end{tabular}

\subsubsection{Reproducibilidad Inter-observador del sistema Topcon 3D OCT-1000.}

La media total de las medidas paquimétricas corneales centrales inter-observador fue de $525.63 \pm 33.22 \mu \mathrm{m}$.

Los resultados obtenidos de la $\mathrm{DS}_{\mathrm{i}}$, precisión, reproducibilidad, coeficiente de reproducibilidad, $\mathrm{CV}_{\mathrm{i}}$ inter-observador se determinan en la Tabla 7. Los valores de fiabilidad de medida paquimétrica del sistema Topcon 3D OCT-1000 son peores si lo utilizan dos examinadores distintos, sin embargo siguen siendo buenos ya que la diferencia máxima esperable entre dos medidas consecutivas sería del 3.12\%.

No hubo una diferencia estadísticamente significativa entre el grupo de medidas obtenidas por cada observador $(\mathrm{p}=0.29)$. Siendo la media de las diferencias entre observadores de $1.57 \mu \mathrm{m}$.

Tabla 7. Reproducibilidad inter-observador de la paquimetría corneal central del dispositivo Topcon 3D OCT-1000. 


\begin{tabular}{|c|c|}
\hline \multicolumn{2}{|c|}{ Reproducibilidad Inter-observador Topcon 3D OCT-1000 } \\
\hline Media Global $[\mu \mathrm{m}]$ & $525.63(441 / 605)$ \\
\hline $\mathbf{D S}_{\mathrm{i}}[\mu \mathrm{m}]$ & $5.94(4.56 / 7.31)$ \\
\hline Precisión $[\mu \mathrm{m}]$ & 11.64 \\
\hline Reproducibilidad [ $\mu \mathrm{m}]$ (Coeficiente) & $16.45(3.12 \%)$ \\
\hline $\mathbf{C V}_{\mathrm{i}}$ & $1.13 \%(0.87 / 1.38)$ \\
\hline Media de las diferencias $[\mu \mathrm{m}](95 \%$ IC) & $-1.57(-4.41 / 1.36) \cdot p=0.29$ \\
\hline LdC Superior $[\mu \mathrm{m}](95 \% \mathrm{IC})$ & $20.9(16.706 / 25.088)$ \\
\hline LdC Inferior $[\mu \mathrm{m}](95 \%$ IC) & $-23.96(-28.154 /-19.773)$ \\
\hline Amplitud LdC [ $\mu \mathrm{m}]$ & 44.86 \\
\hline
\end{tabular}

Se empleó la gráfica de Bland y Altman para representar la diferencia entre las paquimetrías en el mismo individuo realizadas por dos examinadores distintos, en función de la media de las medidas de ambas sesiones (Figura 36). Representándose en la misma el 95\% de los LdC, siendo el límite superior de $20.9 \mu \mathrm{m}$ y de $-23.96 \mu \mathrm{m}$ el inferior, por lo que se obtuvo una amplitud del LdC de $44.86 \mu \mathrm{m}$.

En la Figura 36 se demuestra la ausencia de de tendencia o correlación significativa entre las medias y las diferencias de las medidas: los distintos valores se distribuyeron en forma de nube dispersa dentro del intervalo $\mathrm{LdC}$, y en torno a la media de las diferencias, y nunca presentando una correlación de tipo lineal. 


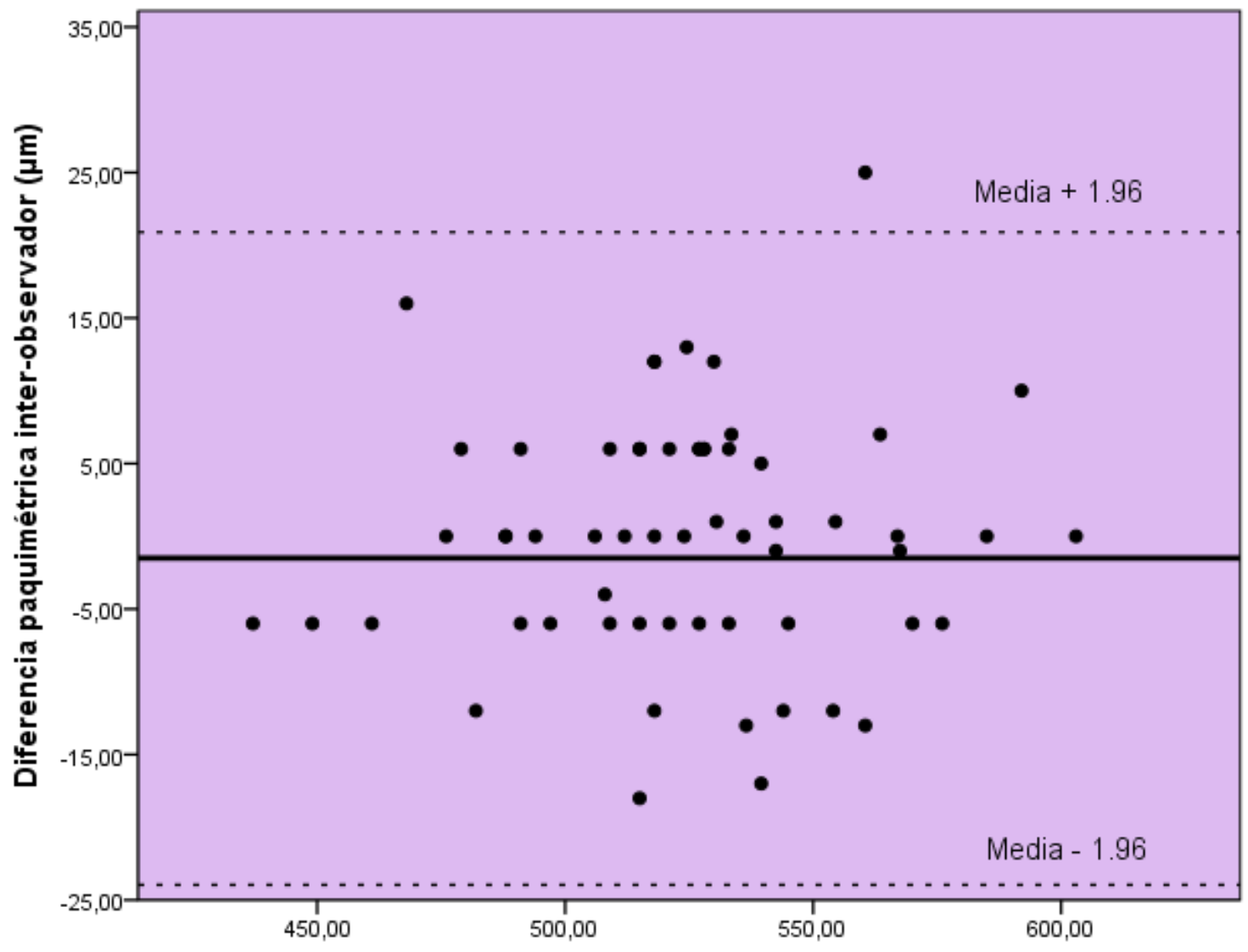

Paquimetría media inter-observador Topcon 3D OCT-1000

Figura 36. Gráfica Bland-Altman describiendo la reproducibilidad inter-observador con el dispositivo Topcon 3D OCT-1000. Las líneas horizontales superior e inferior (discontinuas) indican los límites de concordancia ( $\mathrm{LdC}$ ) superior e inferior. La línea central indica la diferencia media de las medidas tomadas por ambos examinadores usando el 3D OCT-1000.

La asunción necesaria para demostrar la idoneidad del análisis de Bland y Altman, consistente en que los valores de las diferencias están en torno a la media, siguiendo una distribución aproximadamente normal, se demuestra en la Figura 37. 


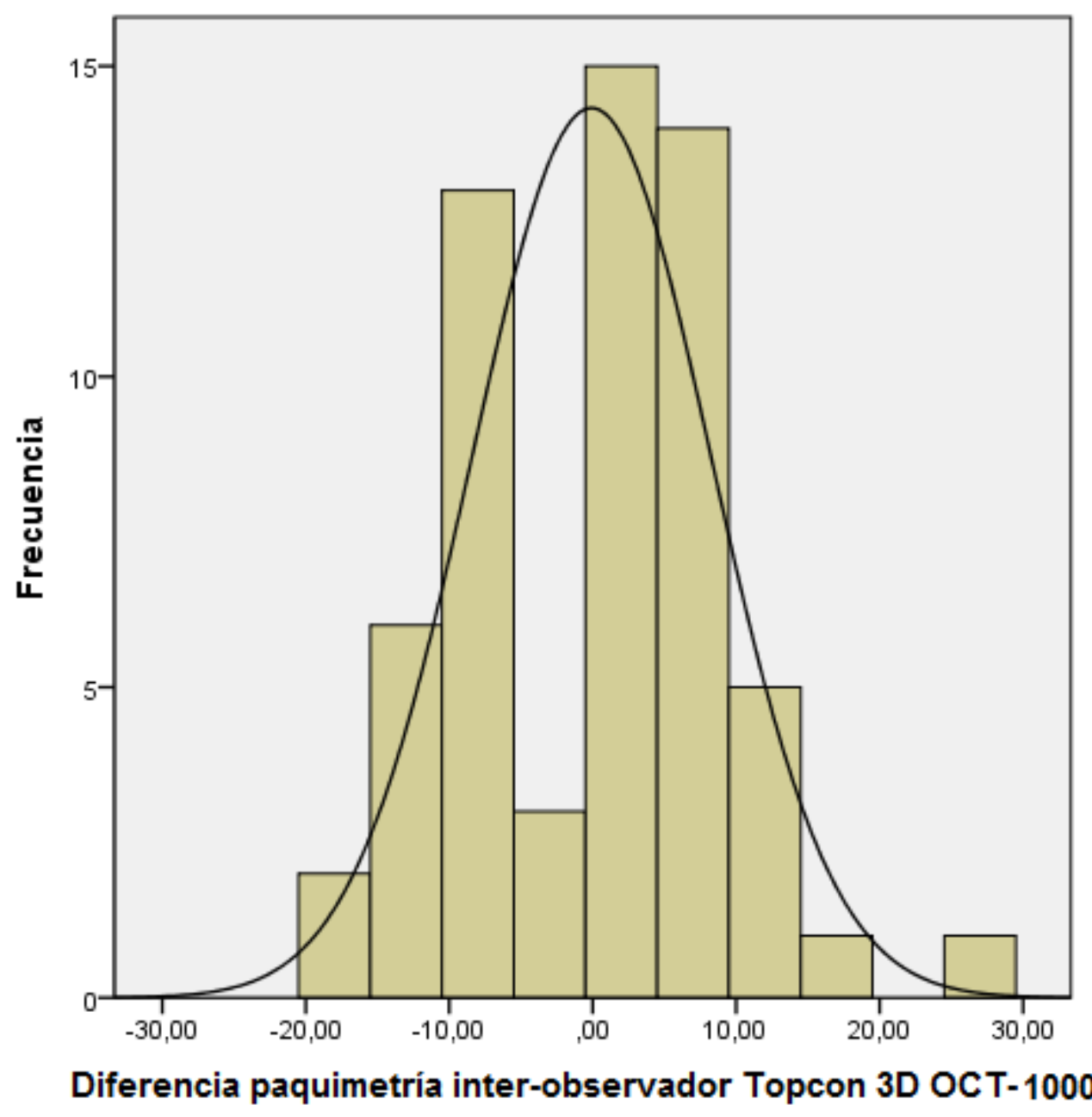

Figura 37. Distribución de las diferencias paquimétricas de las medidas realizadas por ambos examinadores en el mismo paciente con el dispositivo Topcon 3D OCT-1000.

\subsubsection{Reproducibilidad Inter-sesión de 3D OCT-1000.}

La media total de las medidas paquimétricas corneales centrales inter-sesión fue de $524.87 \pm 33.69 \mu \mathrm{m}$.

Los datos correspondientes a la $\mathrm{DS}_{\mathrm{i}}$, precisión, reproducibilidad, coeficiente de reproducibilidad, $\mathrm{CV}_{\mathrm{i}}$ inter-sesión se detallan en la Tabla 8. Los resultados indican que debemos esperar una variabilidad máxima de un $2.42 \%$ en la magnitud de la paquimetría central en dos sesiones distintas realizadas en días diferentes, lo cual indica que el sistema es bastante reproducible. 
No hubo una diferencias estadísticamente significativas entre el grupo de medidas obtenidas en cada sesión $(\mathrm{p}=0.15)$. Siendo la media de las diferencias entre ellas de $1.7 \mu \mathrm{m}$.

Tabla 8. Reproducibilidad inter-sesión de la paquimetría corneal central del dispositivo Topcon 3D OCT-1000.

\begin{tabular}{|c|c|}
\hline \multicolumn{2}{|c|}{ Reproducibilidad Inter-sesión Topcon 3D OCT-1000 } \\
\hline Media Global [ $\mu \mathrm{m}]$ (Rango) & $524.87(443 / 603)$ \\
\hline $\mathrm{DS}_{\mathrm{i}}[\mu \mathrm{m}]$ & 4.60 \\
\hline Precisión $[\mu \mathrm{m}]$ & 9.1 \\
\hline Reproducibilidad $[\mu \mathrm{m}]$ (Coeficiente) & $12.74(2.42 \%)$ \\
\hline $\mathbf{C V}_{\mathrm{i}}$ & $0.89 \%(0.66 / 1.11)$ \\
\hline Media de las diferencias $[\mu \mathrm{m}](95 \%$ IC) & $1.7(-0.64 / 4.04) \cdot p=0.15$ \\
\hline LdC Superior $[\mu \mathrm{m}](95 \% \mathrm{IC})$ & $19.85(16.46 / 23.24)$ \\
\hline LdC Inferior $[\mu \mathrm{m}](95 \% \mathrm{IC})$ & $-16.45(-19.84 /-13.06)$ \\
\hline Amplitud LdC [ $\mu \mathrm{m}]$ & 36.30 \\
\hline
\end{tabular}

Se empleó la gráfica de Bland y Altman para representar la diferencia entre las paquimetrías en el mismo individuo en dos sesiones diferentes en función de la media de las medidas de ambas sesiones (Figura 38). Representándose en la misma el 95\% de los $\mathrm{LdC}$, con un límite superior de $19.85 \mu \mathrm{m}$ y de $-16.45 \mu \mathrm{m}$ en el caso del inferior, siendo la amplitud de $36.30 \mu \mathrm{m}$.

En la Figura 38 se demuestra la ausencia de de tendencia o correlación significativa entre las medias y las diferencias de las medidas: los distintos valores se distribuyen en forma de nube dispersa dentro del intervalo $\mathrm{LdC}$, y cercanos a la media de las diferencias, y nunca presentando una correlación de tipo lineal. 


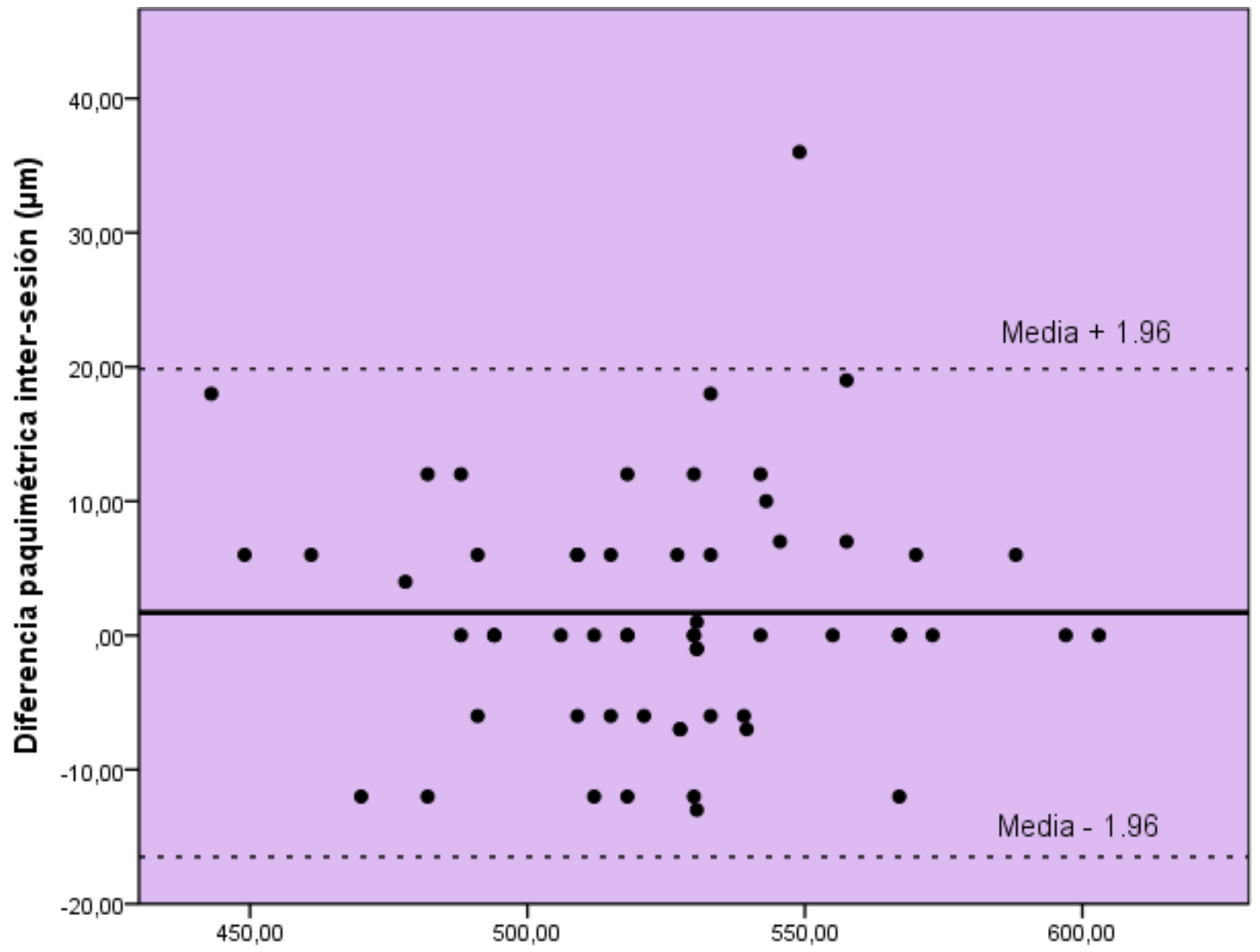

Paquimetría media inter-sesión Topcon 3D OCT-1000

Figura 38. Gráfica Bland-Altman describiendo la reproducibilidad inter-sesión con el dispositivo Topcon 3D OCT-1000. Las líneas horizontales superior e inferior (continuas) indican los límites de concordancia (LdC) superior e inferior. La línea central (discontinua) indica la diferencia media de las medidas tomadas en dos sesiones en el mismo sujeto, con 3D-OCT 1000.

Todos los valores de las diferencias, están en torno a la media, siguiendo una distribución aproximadamente normal (Figura 39), con lo que se comprueba la idoneidad de emplear el método de Bland y Altman. 


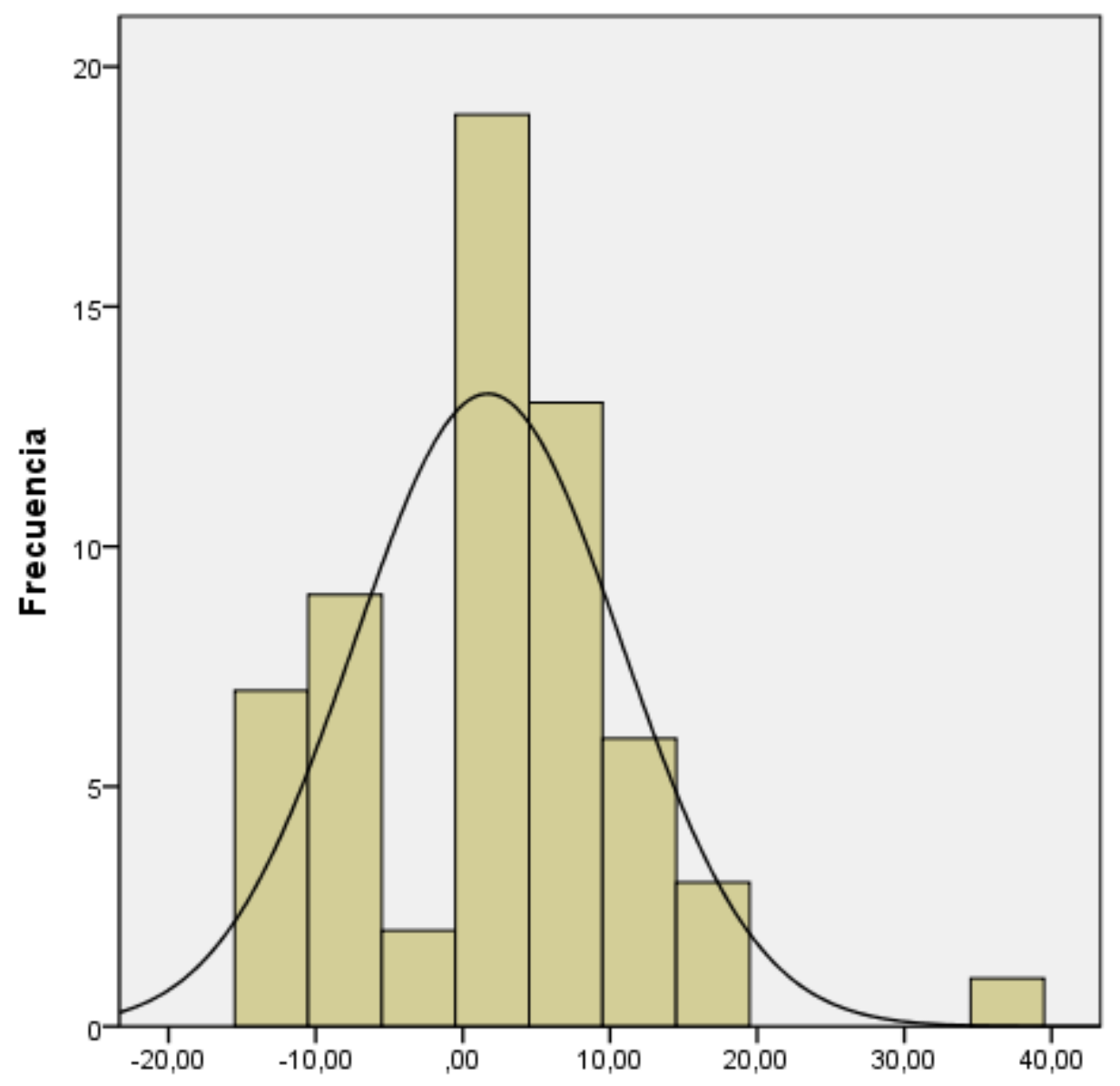

Diferencia paquimetría inter-sesión Topcon 3D OCT-1000

Figura 39. Distribución de las diferencias paquimétricas entre ambas sesiones en el mismo paciente con Topcon 3D OCT-1000. 


\section{Discusión.}





\section{DISCUSIÓN}

\subsection{DE LA METODOLOGÍA UTILIZADA.}

\subsubsection{ANÁLISIS DE LA VARIANZA (ANOVA).}

En la investigación médica, cuando se desea comparar varias medidas realizadas de forma repetida, un método poco acertado de análisis es utilizar el test de "t de Student", debido a que se debería entonces utilizar comparaciones múltiples. Por el contrario, el análisis de la varianza (ANOVA) de medidas repetidas, es la metodología más adecuada para evaluar a la vez varios grupos, ya que compara la variación entre grupos con la variación dentro del grupo ${ }^{[112]}$.

Por otra parte, el método de Bland y Altman, diseñado para evaluar grado de acuerdo entre dos grupos de datos obtenidos tras realizar las mediciones en una sola ocasión, no debe ser aplicado para evaluar el acuerdo entre medidas repetidas de forma consecutiva en el mismo sujeto ${ }^{[113]}$.

\subsubsection{COEFICIENTE DE CORRELACIÓN INTRACLASE.}

Un índice habitual para evaluar la repetibilidad es la proporción de la variabilidad total que se debe a la variabilidad de los sujetos, conocido habitualmente como coeficiente de correlación intra-clase, siendo no apropiado para ello el coeficiente de correlación de Pearson. El CCI no tiene en cuenta el orden en el que las medidas fueron tomadas, y puede ser empleado con más de dos observaciones por sujeto, siendo de elección para esta aplicación, tal y como Bland describió ${ }^{[83]}$.

\subsubsection{METODOLOGÍA DE BLAND \& ALTMAN.}

En el ámbito de las Ciencias de la salud, es frecuente querer comparar dos métodos de medida. Para ello, en nuestro trabajo hemos empleado el método estadístico de Bland y Altman, considerando otros métodos como la comparación de medias, el 
coeficiente de correlación (" $r$ "), o la regresión, no apropiados para comparar dos instrumentos de medida ${ }^{[110]}$.

El uso del coeficiente de correlación " $r$ " sirve para relacionar las medidas tomadas por dos aparatos y conocer la fuerza de la relación entre ellas, sin darnos información alguna sobre la concordancia o acuerdo que presentan. Datos que presentan una pobre concordancia, pueden producir una alta correlación y viceversa ${ }^{[106]}$. El coeficiente de correlación depende en gran parte de los sujetos seleccionados en la muestra, así una alta variación entre ellos comparado con el error de medición, dará lugar a una correlación alta, sucediendo lo contrario si la variación entre individuos es baja ${ }^{[110]}$. El coeficiente de correlación establece una relación lineal entre dos variables cuantitativas (medidas tomadas por cada aparato), dando el valor de $r=1$ a la relación lineal perfecta entre ellas, siendo +1 en la que proporcionalmente al aumento del valor de una de las variables, también lo hará la otra, y -1 si al aumento de una, la otra disminuye ${ }^{[114]}$. Un cambio en la escala de una de las dos mediciones, no afectará a la correlación, en cambio sí que modificará la concordancia ${ }^{[106]}$. Si se desea comparar dos aparatos que han sido diseñados para medir la misma variable, es lógico que siempre exista una cierta correlación entre ellos, pero dicho hecho no implica que tengan una concordancia apropiada como para permitirnos sustituir indistintamente uno por otro [106]

Hemos utilizado el método de Bland y Altman, que tiene por objetivo conseguir una mejor descripción de la relación entre diferentes métodos de medida de un mismo elemento, diferentes observadores midiendo un mismo elemento o la medida de dicha variable con el mismo dispositivo, pero en días distintos, siempre comparando dos grupos de observaciones ${ }^{[115]}$. En él comparamos las diferencias al medir con ambos aparatos, con las medias de las medidas obtenidas por ellos, estableciendo los Límites de Concordancia (" $L d C$ ") ${ }^{[83,106,115]}$, que cómo hemos visto a lo largo del trabajo, nos aportarán mucha más información. El $95 \%$ del intervalo LdC significa que si las diferencias presentan una distribución normal (Gaussiana), el 95\% se situarían entre ambos límites ${ }^{[106]}$. La magnitud máxima de la diferencia entre dos sistemas de medición (amplitud del LdC) para considerarlos intercambiables, es una cuestión de valoración clínica y no estadística ${ }^{[83,106]}$. 
Las premisas para poder realizar un análisis de Bland y Altman son dos:

1) Ausencia de tendencia o correlación significativa entre las medias y las diferencias de las medidas. Lo adecuado es que los valores se distribuyan en forma de nube dispersa dentro del intervalo $\mathrm{LdC}$, y en torno a la media de las diferencias, y nunca presentando una correlación de tipo lineal, en cuyo caso se debería de aplicar otro método basado en los residuos absolutos a partir del análisis de regresión de Bland y Altman ${ }^{[115]}$.

2) Distribución aproximadamente normal de los valores de las diferencias entre las medidas ${ }^{[83,115]}$.

Estos dos puntos se cumplieron en todos los apartados de nuestro trabajo, a excepción del estudio de la intercambiabilidad (grado de acuerdo) entre el sistema Cirrus HD-OCT y el paquímetro ultrasónico de contacto, dónde se demostró que la diferencia entre las medidas no seguía una distribución normal, no pudiéndose por tanto realizar el análisis de Bland y Altman. Situación en la que la mediana (50 percentil) y el rango intercuartil (rango comprendido entre los percentiles $25^{\circ}$ y $75^{\circ}$ de la distribución) de las diferencias paquimétricas se usaron para describir el grado de acuerdo existente entre ambos sistemas de medida.

\subsection{DE LOS RESULTADOS OBTENIDOS.}

En la actualidad es de gran interés clínico la medición del espesor corneal central. Los aparatos evaluados en nuestro estudio suponen métodos de fácil empleo, siendo no invasivos, y por tanto bien tolerados por el paciente para la obtención de los valores paquimétricos.

7.2.1. REPETIBILIDAD

INTRA-OBSERVADOR

REPRODUCIBILIDAD INTER-OBSERVADOR DE LAS MEDIDAS PAQUIMÉTRICAS OBTENIDAS CON EL SISTEMA DE TOMOGRAFÍA DE COHERENCIA ÓPTICA DE DOMINIO ESPECTRAL CIRRUS HD-OCT. 


\subsubsection{Repetibilidad Intra-observador del sistema Cirrus HD-OCT.}

La repetibilidad es relevante al estudiar el grado de acuerdo entre dos sistemas de medida, porque ésta limita la cantidad de acuerdo que va a ser posible entre ambos. Si un método tiene baja repetibilidad (existe una variación considerable al realizar mediciones repetidas sobre el mismo sujeto), el grado de acuerdo entre los dos métodos va a ser pobre también. Lo que evidentemente se verá empeorado si dicha condición de baja repetibilidad se da en ambos sistemas de medición ${ }^{[106]}$.

Los valores de fiabilidad de medida intra-observador en la paquimetría central con el sistema Cirrus HD-OCT que obtuvimos (Tabla 2) se pueden considerar buenos.

La repetibilidad se entendió como el valor por debajo del cual la diferencia entre dos medidas consecutivas en el mismo paciente se encuentra con una probabilidad del 95\%. Según nuestros resultados, $13.46 \mu \mathrm{m}$ sería la diferencia máxima esperable entre medidas realizadas de forma seguida en un mismo paciente por el mismo examinador con el sistema Cirrus HD-OCT. Si además queremos conocer la variabilidad esperable en términos porcentuales, nos fijaremos en el coeficiente de repetibilidad que fue de $2.48 \%$, de tal forma que ese es el valor máximo en que se diferenciarían dos medidas consecutivas. Además, el valor del CCI fue de 0.981, muy próximo a 1, por lo tanto estos datos nos muestran que la paquimetría obtenida a través del sistema Cirrus HDOCT ofrece valores fiables.

Teniendo en cuenta que las medidas de la paquimetría se iban a obtener a partir de las imágenes que ofreciese el sistema Cirrus HD-OCT, se empleó el patrón “Anterior Segment 5 Line Raster"; en el cual se utilizan 5 líneas paralelas compuestas por 4.096 A-scans cada una. Patrón útil para obtener imágenes de gran resolución de la cornea ${ }^{[59]}$, favoreciendo una colocación del cursor más exacta en el centro pupilar. Además, únicamente se aceptaron las imágenes corneales que presentaban una calidad de 7 o mayor.

Dado que el sistema Cirrus HD-OCT no ofrece la paquimetría de forma automática, y esta debe ser obtenida de manera manual, se decidió que para evitar una influencia del examinador al realizar las medidas paquimétricas de manera consecutiva, en primer lugar las imágenes corneales no fueran medidas hasta que todos los pacientes 
estuvieran incluidos en el estudio, y en segundo lugar, el examinador no midiese consecutivamente todas las imágenes del mismo paciente, sino que lo realizase primero en todas las primeras medidas de todos los pacientes, después en las segundas, y así sucesivamente. De esa manera no era posible recordar las medidas paquimétricas correspondientes a cada paciente.

Nuestro estudio ${ }^{[60]}$ es el primero que evalúa la repetibilidad del sistema Cirrus HD-OCT para medir la paquimetría central, existiendo únicamente estudios de la fiabilidad de dicho sistema para su empleo en segmento posterior. Sin embargo, otros autores sí han estudiado previamente la fiabilidad intra-observador en otros sistemas de OCT. Así, Chen et al ${ }^{[93]}$ describió un valor del CCI de 0.997 para el RTVue OCT (SDOCT. Optovue Inc., Fremont, CA, USA.), en su uso de medición automática, en ápex corneal, que fue levemente mejor al nuestro (0.981); Huang et al ${ }^{[116]}$ estudió la repetibilidad intra-observador para el OCT de segmento anterior Visante OCT (TDOCT. Carl Zeiss Meditec, Dublin, CA.) y para el RTVue OCT. Obteniendo un CV $_{\text {i }}$ peor para Visante OCT (1.02\%) que el nuestro para Cirrus HD-OCT (0.89\%), pero superior en el caso del RTVue OCT $(0.72 \%)$. Nam et al ${ }^{[92]}$ obtuvo valores mejores para las mediciones automáticas con RTVue OCT que los nuestros para Cirrus HD-OCT, tanto para las medidas del grosor corneal localizadas en el centro pupilar (repetibilidad: 4.7; $\mathrm{CV}_{\mathrm{i}}:$ 0.1\%; CCI: 0.996), como para las medidas corneales centradas en el ápex corneal (repetibilidad: $\left.3.9 ; \mathrm{CV}_{\mathrm{i}}: 0.26 ; \mathrm{CCI}: 0.997\right) . \mathrm{Li}$ et al ${ }^{[87]}$ estudió la repetibilidad de la paquimetría central manual y automática en dos sistemas OCT específicos de segmento anterior, Visante OCT y Slit-Lamp OCT (SD-OCT. Heidelberg Engineering, Dossenheim, Germany). Obteniendo en el Visante OCT valores de $\mathrm{CV}_{\mathrm{i}}$ de un $0.9 \%$ y $1.2 \%$ para mediciones automáticas y manuales, respectivamente; y de un $1.0 \%$ en ambas modalidades en el caso del Slit-Lamp OCT; valores en todos los casos levemente peores a nuestro $\mathrm{CV}_{\mathrm{i}}$ para Cirrus HD-OCT (0.89\%). Sus valores de CCI fueron similares o levemente peores al nuestro (0.981) para Cirrus HD-OCT (Visante OCT automático: 0.98; Visante OCT manual: 0.96; Slit-Lamp OCT automático: 0.97; SlitLamp OCT manual: 0.98). Finalmente, Prakash et al ${ }^{[94]}$ obtuvo excelentes valores de CCI en Visante OCT (0.962), y RTVue OCT (0.999) en sus mediciones automáticas en el ápex corneal, similares al nuestro en Cirrus HD-OCT (0.98). 
Un hecho importante a tener en cuenta es que el sistema RTVue OCT ofrece el valor de la paquimetría central como una media del grosor corneal en los $2 \mathrm{~mm}$ centrales, en contraposición de la medida del espesor corneal en un solo punto en el caso del Cirrus HD-OCT. Hecho que podría explicar los altos valores de repetibilidad intra-observador descritos para dicho sistema RTVue OCT en comparación a los obtenidos por nosotros, siendo ambos dispositivos de dominio espectral (SD-OCT).

Paralelamente, las medidas paquimétricas en nuestro caso se han obtenido de manera manual, lo que puede haber influido negativamente en la obtención de valores más altos de repetibilidad. Sin embargo autores como Li et al ${ }^{[87]}$ han demostrado una buena repetibilidad en mediciones manuales de Visante OCT y Slit-Lamp OCT con valores similares a los obtenidos automáticamente con los mismos sistemas $\left(\mathrm{CV}_{\mathrm{i}}\right.$ Visante OCT automático: 0.9\%, manual: 1.2\%. $\mathrm{CV}_{\mathrm{i}}$ Slit-Lamp OCT automático: 1\%, manual: $1 \%$ ).

Los resultados de los estudios mencionados muestran que los dispositivos SDOCT (RTVue OCT, Slit-Lamp OCT, Cirrus HD-OCT) proporcionan una mejor fiabilidad que los de tecnología TD-OCT (Visante OCT), como sería de esperar. En primer lugar, la mayor resolución axial de los SD-OCT permite imágenes mejoradas debido a la mayor reflectividad, por lo que ya sea automática o manualmente, las mediciones del grosor corneal central pueden realizarse con una mayor facilidad. Por otra parte, la rápida adquisición de barrido minimiza los artefactos por movimiento ocular durante la medición, lo que también representa una menor variabilidad. Por lo tanto, los dispositivos SD-OCT podrían llegar a ser una buena opción para medir la paquimetría corneal central, con la ventaja añadida de ser un método no invasivo y de no contacto.

El presentes estudio es el primero en evaluar la repetibilidad intra-observador del sistema Cirrus HD-OCT en su uso como paquímetro, habiéndose obtenido valores similares a otros autores con otros sistemas OCT, demostrándose una buena repetibilidad del mismo. Sin embargo, serían necesarios trabajos que además de incluir córnea sanas, estudiaran variabilidad en pacientes que hayan sido sometidos a cirugía láser excimer, o con patologías corneales como puede ser el queratocono. 


\subsubsection{Reproducibilidad Inter-observador del sistema Cirrus HD- OCT.}

En la práctica clínica es habitual que no sea siempre el mismo observador el que realice la medida en el mismo paciente, por lo que se consideró un objetivo de estudio evaluar el acuerdo entre dos examinadores independientes para la medición del grosor corneal central.

Con el sistema Cirrus HD-OCT, los datos de acuerdo inter-observador no fueron tan buenos como los obtenidos en el estudio de su repetibilidad, sin embargo no se encontró una diferencia estadísticamente significativa entre ambos examinadores ( $\mathrm{p}=$ 0.87). La amplitud del intervalo de concordancia ( $\mathrm{LdC}$, intervalo dónde se encuentran el 95\% de las diferencias entre ambos examinadores), también presentó un valor aceptable $(29.64 \mu \mathrm{m})$, teniendo en cuenta que un error de medida de $20 \mu \mathrm{m}$ en el grosor corneal, resulta en un aceptable error de $1 \mathrm{mmHg}$ en la medida de presión intraocular por aplanación con tonómetro de Goldmann (correlación 0.02-0.07 mmHg / $\mu \mathrm{m}$ de grosor corneal central) ${ }^{[92]}$. Adicionalmente su representación gráfica siguiendo la metodología de Bland y Altman (Figura 30), no mostró una asociación entre las medias y las diferencias de la paquimetría entre observadores (los valores se distribuyen en forma de nube dispersa dentro del intervalo $\mathrm{LdC}$ en torno a la media de las diferencias, no presentando una correlación de tipo lineal), lo que significa que no se detectó una tendencia dependiente de la magnitud de grosor corneal central.

Otros autores también han considerado la importancia de valorar la fiabilidad inter-observador de otros sistemas de OCT para su uso en la paquimetría, aunque previo a nuestro trabajo no se había hecho para el sistema Cirrus HD-OCT. Así, respecto al RTVue OCT (SD-OCT), Chen et al ${ }^{[93]}$ publicó un $\mathrm{CV}_{\mathrm{i}}$ inter-observador de sólo $0.45 \%$, con una amplitud del LdC de $10.2 \mu \mathrm{m}$ y Mohamed et al ${ }^{[89]}$ un valor de $0.5 \%$ para el $\mathrm{CV}_{\mathrm{i}}$ en el caso del Visante OCT (TD-OCT). Ambos autores presentaron mejores datos que los nuestros para el sistema Cirrus HD-OCT $\left(\mathrm{CV}_{\mathrm{i}}: 1.40 \%\right.$; Amplitud LdC: 29.64 $\mu \mathrm{m})$, pero debemos tener en cuenta dos importantes factores que podrían haber afectado negativamente a nuestros resultados en comparación con los suyos. En primer lugar, tanto Visante OCT como RTVue OCT aportaron en ambos estudios el valor paquimétrico central de manera automática, en contraste a Cirrus HD-OCT en el que se 
obtiene de forma manual. En segundo lugar, ambos dispositivos obtienen dicho valor como una media de varios puntos explorados en el área central de $2 \mathrm{~mm}$, y no de un único punto en el ápex corneal, como sí ocurre con el dispositivo Cirrus HD-OCT.

Dado que la máxima diferencia esperable entre dos observadores que utilicen el sistema Cirrus HD-OCT para evaluar la paquimetría central en un mismo sujeto es menor a $21 \mu \mathrm{m}$, podemos determinar que es un sistema con una fiabilidad aceptable de medida en el caso en el que dos clínicos experimentados tengan que utilizarlo en la clínica diaria.

\subsubsection{GRADO DE ACUERDO EXISTENTE ENTRE LA PAQUIMETRÍA CENTRAL OBTENIDA POR UN SISTEMA DE TOMOGRAFÍA DE COHERENCIA ÓPTICA DE DOMINIO ESPECTRAL Y POR LA ULTRASONOGRAFÍA CONVENCIONAL.}

Se entiende como validez (exactitud), la cercanía de las mediciones al valor verdadero; es decir, en qué grado el procedimiento mide la magnitud que se desea cuantificar. Que un sistema sea válido significa que no existe un error sistemático (error de calibración y/o tendencias en función de la magnitud de la medida) en el proceso de medición, y se suele estimar por comparación con una prueba de referencia ("gold standard"). Según la definición de Bland y Altman, existe acuerdo entre dos métodos de medida si la diferencia entre las observaciones en un mismo sujeto usando ambos métodos es lo suficientemente pequeña para usar estos métodos de manera intercambiable ${ }^{[83]}$. En la actualidad, el paquímetro ultrasónico sigue considerándose el patrón oro ${ }^{[28,33]}$, aunque muchos autores están de acuerdo en que presenta diversas desventajas, cómo son el riesgo de infección o daño epitelial, la incomodidad para el paciente y la necesidad de colocar la sonda en la posición correcta ${ }^{[32-34]}$. Por este motivo, se empleó para compararlo con el sistema Cirrus HD-OCT, siempre usándolo en último lugar por el riesgo de daño corneal anteriormente comentado [34, 86-88, 92, 117] y la necesidad de aplicar una gota anestésica, colocando la sonda lo más perpendicular posible en el centro corneal, indicando un punto de fijación lejano al paciente. 
Teniendo en cuenta los ajustes por defecto del paquímetro ultrasónico, 5 mediciones consecutivas se promediaron automáticamente para obtener un valor de grosor corneal central en cada paciente ${ }^{[34,86-88,92]}$, las cuales se compararon con las realizadas con el sistema Cirrus HD-OCT en un pequeño grupo de 20 pacientes.

En nuestros resultados podemos observar que existe una diferencia estadísticamente significativa $(\mathrm{p}=0.04)$ entre las mediciones de ambos, con una subestimación del grosor corneal por parte del sistema Cirrus HD-OCT. Diversos autores han publicado resultados similares, determinando valores paquimétricos más finos con los sistemas OCT al compararlos con el paquímetro ultrasónico. Así Ishibazawa et al ${ }^{[86]}$ determinó que RTVue-100 OCT infraestimaba el grosor corneal en $14 \pm 8 \mu \mathrm{m}$ en comparación al paquímetro clásico en córneas sanas. Williams et al ${ }^{[117]}$ también obtuvo un grosor corneal $13 \mu \mathrm{m}$ de media más fino con el sistema OCT 3 Stratus Carl Zeiss Meditec, Dublin, CA.) y Bechmann et al ${ }^{[118]}$ determinó una infraestimación constante por parte del mismo OCT de 49.4 $\pm 5.9 \mu \mathrm{m}$. Igualmente, Zhao et al ${ }^{[119]}$ determinó que el sistema de OCT específico de segmento anterior VisanteOCT medía $16.5 \pm 11.7 \mu \mathrm{m}$ menos que el ultrasónico en una muestra de 285 sujetos, y Li et al ${ }^{[33]}$ estudio el mismo aparato de OCT, determinando una infraestimación del grosor corneal de $14.74 \pm 10.84 \mu \mathrm{m}$. En contraste, Nam et al ${ }^{[92]}$ describió mediciones corneales más gruesas con RTVue OCT al compararlo con el paquímetro ultrasónico, con valores de $12.8 \mu \mathrm{m}$ y $13.7 \mu \mathrm{m}$ según si la medida se tomó en el centro pupilar o en el vertex corneal, respectivamente.

Se ha postulado que estas diferencias de resultados pueden ser explicadas por la distinta metodología que ambos sistemas utilizan. La paquimetría ultrasónica requiere contacto corneal, y depende de la reflexión del ultrasonido desde la superficie anterior corneal a la posterior. Teóricamente, la velocidad de las ondas de ultrasonidos podría verse enlentecida con un aumento de la hidratación corneal, dando lugar a medidas artificialmente más altas en casos de edema corneal ${ }^{[120]}$. El punto de reflexión corneal anterior puede verse variado al contactar con la superficie corneal y desplazar la película lagrimal, no incluyéndola en la medida ${ }^{[33,99,121]}$, realizando además una indentación del epitelio ${ }^{[99]}$, considerándose también la presencia de la anestesia tópica como un factor que puede influir en la medición ${ }^{[99,120]}$. No es bien conocido el punto 
exacto de reflexión corneal posterior, que se presupone entre la membrana de Descemet y la cámara anterior, y que puede variar en su localización exacta $[33,99,120,121]$. También se ha descrito como un hecho importante en el paquímetro ultrasónico la necesidad del examinador de colocar la sonda exactamente en el centro corneal y perpendicular a la superficie, hecho que junto a la indentación con la que la prueba se haga, puede afectar a las medidas tomadas ${ }^{[96,120]}$. Por ello podemos decir que existe un importante factor examinador-dependiente.

Por otra parte, los sistemas de no contacto sí incluirían la película lagrimal en la imagen que capturan, siendo en el caso del Cirrus HD-OCT de forma manual, mediante cursores, la manera de medir el grosor corneal.

En resumen, aunque la media de la diferencia entre el sistema Cirrus HD-OCT y el paquímetro ultrasónico que hemos obtenido en nuestro estudio podría considerarse clínicamente irrelevante $(4.50 \mu \mathrm{m})$, el clínico debe ser consciente de la tendencia a infraestimar el grosor corneal de manera sistemática por parte del sistema Cirrus HDOCT, lo cual igualmente sucede con la mayoría de sistemas SD-OCT según la literatura.

Nuestro estudio es el primero en comparar el sistema Cirrus HD-OCT con el paquímetro ultrasónico clásico. Sin embargo, las principales limitaciones de este trabajo son el pequeño grupo de pacientes incluidos (20), y la presencia únicamente de córneas sin patología. Se determinó estudiar la variabilidad existente entre las medidas paquimétricas obtenidas por ambos sistemas en un pequeño grupo, dado que ya había numerosos estudios que habían realizado previamente la comparación entre sistemas SD-OCT y ultrasónicos convencionales.

7.2.3. REPETIBILIDAD

INTRA-OBSERVADOR

REPRODUCIBILIDAD INTER-OBSERVADOR DE LAS

MEDIDAS PAQUIMÉTRICAS OBTENIDAS CON UN SISTEMA

DE REFLECTOMETRÍA ÓPTICA DE BAJA COHERENCIA.

\subsubsection{Repetibilidad Intra-observador del sistema Lenstar LS 900 .}


El sistema Lenstar LS 900 es un biómetro basado en la técnica de reflectometría óptica de baja coherencia, que ha demostrado previamente una buena validez de las mediciones del grosor corneal central que realiza, al compararlo con el paquímetro ultrasónico ${ }^{[68,99]}$.

El sistema emplea el valor medio de 5 mediciones consecutivas, lo que da lugar a una mayor fiabilidad intra-sesión de los datos biométricos, dado que el uso de la media de tomas repetidas disminuye la variabilidad. El valor del CCI obtenido por nosotros estuvo cerca de 1 (0.996), y el valor del $\mathrm{CV}_{\mathrm{i}}$ intra-sesión fue excelente $(0.42 \%)$. Los datos de su repetibilidad intra-sesión han sido también previamente estudiados, con valores similares a los nuestros. Cruysberg et al ${ }^{[65]}$ demostró un $\mathrm{CV}_{\mathrm{i}}$ intra-sesión de $0.3 \%$ (frente al nuestro de $0.42 \%$ ). Tai et al ${ }^{[99]}$ obtuvo un valor de repetibilidad de $1.51 \%$ frente al $0.91 \%$ de Barkana et al ${ }^{[96]}$, valores entre los cuales se situaría el de nuestro estudio (1.17\%). Además la $\mathrm{DS}_{\mathrm{i}}$ que obtuvimos $(2.33 \mu \mathrm{m})$ fue similar a otros estudios, con valores que oscilaron desde $1.5^{[65]}$ a $2.0 \mu \mathrm{m}^{[63]}$.

Estos excelentes resultados son similares o incluso mejores en algunos casos, a los hallados para otras técnicas bien conocidas para el estudio de segmento anterior, cómo la fotografía rotacional de Scheimpflug, con un $\mathrm{CV}_{\mathrm{i}}$ de $0.67 \%$ para el sistema Pentacam (Oculus) ${ }^{[92]}$, y de $0.4 \%$ para Galilei (Ziemer, Port, Switzerland) ${ }^{[122]}$, o valores de $0.3 \%$ para el sistema Visante $\mathrm{OCT}^{[89]}$, o $0.67 \%$ para el sistema de topografia de barrido de hendidura, Orbscan II (Bausch \& Lomb, Rochester, NY) ${ }^{[123]}$.

Las medidas siempre se tomaron de la manera más rápida posible, sin que los pacientes retirasen la cabeza de la mentonera, siendo únicamente animados a parpadear entre ellas, y así reponer la película lagrimal, desplazándose hacia atrás y realineándose de nuevo el dispositivo tras cada medición, para evitar la interdependencia entre las capturas sucesivas. Sin embargo, se ha descrito que el tiempo de adquisición de las medidas con el sistema Lenstar LS 900 es más largo que con otros dispositivos, debido a la metodología de alineamiento y enfoque del aparato, y su toma de 5 medidas consecutivas para el cálculo del valor medio, requiriendo de una mayor fijación por parte del sujeto examinado. Cuanto más se tarde en realizar las medidas, más probable es que aparezca fatiga por parte del paciente, disminuyendo su colaboración y pudiendo afectar a la alineación del sistema de adquisición ${ }^{[104]}$. Sin embargo, los datos acerca de su repetibilidad pueden considerarse excelentes. 
La principal limitación del presente estudio, es que Lenstar LS 900 no fue comparado con el paquímetro ultrasónico de contacto, considerado el "gold standard". Aunque existen trabajos que lo han evaluado previamente, como Tai et al ${ }^{\text {[99] }}$ y Rohrer et al ${ }^{[68]}$, que determinaron que las diferencias entre las medidas de éste en comparación con el paquímetro ultrasónico no son estadísticamente significativas, o Tappeiner et al ${ }^{[102]}$, que sí determino una significancia estadística aunque no clínica, hallando una supra estimación de $3.6 \mu \mathrm{m}$ por parte del sistema Lenstar LS 900 en pacientes con catarata, respecto al paquímetro clásico.

Por tanto en futuros estudios se debe incluir su comparación con el paquímetro aceptado como "gold standard", así como muestras más grandes de pacientes, contando no únicamente con córneas sanas, sino también con sujetos sometidos a cirugía corneal o con situaciones patológicas.

\subsubsection{Reproducibilidad Inter-observador de Lenstar LS 900 .}

No se encontraron diferencias estadísticamente significativas entre las medidas de grosor corneal central obtenidas por ambos examinadores $(p=0.307)$, con una media de las diferencias de tan sólo $1.35 \mu \mathrm{m}$. Sin embargo, el $\mathrm{CV}_{\mathrm{i}}$ inter-observador (2.10\%), no fue tan bueno como el obtenido para la repetibilidad intra-sesión (0.42\%), y hay también que tener en cuenta que el intervalo LdC tuvo un valor de $45.27 \mu \mathrm{m}$, por lo que las diferencias sí podrían tener una relevancia clínica. Al comparar nuestros resultados con los obtenidos por otros autores, encontramos que Bjeloš Rončević et al ${ }^{[103]}$ publicó el mismo buen valor para $\mathrm{CV}_{\mathrm{i}}$ tanto intra-sesión cómo inter-observador $(0.4 \%)$, y un intervalo LdC más estrecho $(7.08 \mu \mathrm{m})$, en pacientes antes de la cirugía de catarata.

Estas discrepancias entre observadores en nuestro trabajo, podría venir explicado por la variabilidad asociada al paciente y no al sistema de medida. El sistema Lenstar LS 900 determina el grosor corneal central, entre otros datos biométricos, mientras el paciente mira un punto de fijación interno, para tomar 5 medidas y con ellas obtener el valor medio. Éste procedimiento puede conllevar un tiempo de adquisición más largo que con otros sistemas, con lo que es más probable que aparezca fatiga por parte del sujeto examinado, disminuyendo su colaboración y pudiendo afectar a la alineación del sistema de adquisición ${ }^{[104]}$. En el presente trabajo, se incluyó una gran variabilidad de 
pacientes, todos con una agudeza visual corregida mayor de 20/40, pero entre ellos algunos presentaban retinopatía diabética, o habían tenido cirugía vítreo-retiniana con pelado de membrana epirretiniana, con lo que su habilidad para mantener la fijación podría ser más limitada. Así, la reproducibilidad se podría ver disminuida en caso de pacientes con una peor agudeza visual y/o capacidad de fijación. Éste fue el caso de los dos valores atípicos por debajo del LdC inferior en la gráfica de Bland y Altman (Figura 32); ambos sujetos habían sido vitrectomizados por membrana epirretiniana, y tenía una agudeza visual corregida de 20/40. Por tanto, los examinadores deben asegurarse de que los pacientes estén mirando correctamente el punto de fijación interno mientras las mediciones se estén realizando.

Consideramos que la variabilidad de los pacientes ha podido ser un factor importante a la hora de obtener nuestros resultados. Futuros estudios deberían incluir grupos de pacientes en función de la patología oftálmica presente, así como grupos según la agudeza visual, para de esta forma poder evaluar en qué grado afecta dicha situación a los resultados finales. Próximos trabajos deberían también incluir córneas con patología o sometidas a cirugía.

\subsubsection{GRADO DE ACUERDO ENTRE LA PAQUIMETRÍA CENTRAL OBTENIDA POR UN SISTEMA DE TOMOGRAFÍA DE COHERENCIA ÓPTICA DE DOMINIO ESPECTRAL Y POR LA REFLECTOMETRÍA ÓPTICA DE BAJA COHERENCIA.}

Según la definición de Bland y Altman, existe acuerdo entre dos métodos de medida si la diferencia entre las observaciones en un mismo sujeto usando ambos métodos es lo suficientemente pequeña para usar estos métodos de manera intercambiable ${ }^{[83]}$.

Al comparar las mediciones con los dos sistemas paquimétricos por parte de un mismo examinador, se encontró que las diferencias entre ambos sistemas eran significativas $(\mathrm{p}=0.0001 ; 5.68 \pm 11.46 \mu \mathrm{m})$, ofreciendo el sistema Lenstar LS 900 infraestimación del grosor corneal central en comparación con el sistema Cirrus HDOCT.

Sin embargo, la gráfica de Bland y Altman (Figura 34) muestra un buen acuerdo entre ambos sistemas, y ausencia de relación entre las diferencias y el rango de medida. 
Por lo tanto, tras la aplicación de un factor de corrección apropiado $(5.68 \mu \mathrm{m})$, dicha gráfica debería presentar una mejor intercambiabilidad entre ambos métodos de medida.

Otros autores han estudiado la intercambiabilidad entre Lenstar LS 900 y otros sistemas, como el Visante OCT, con resultados dispares, pero siempre con una buena concordancia entre ambos. Al igual que nosotros, Shen et al ${ }^{[101]}$ halló una infraestimación por parte de Lenstar LS 900 de $21.55 \mu \mathrm{m}$ que si fue estadísticamente significativa, mientras que Cruysberg et al ${ }^{[65]}$ o Myolonas et al ${ }^{[69]}$ obtuvieron la conclusión contraria con una supra estimación de $11.1 \mu \mathrm{m}$ y $10 \mu \mathrm{m}$ respectivamente, siendo no estadísticamente significativa en ambos casos. Huang at al ${ }^{[100]}$ halló una diferencia de $3.72 \mu \mathrm{m}$, no estadísticamente significativa, entre Lenstar LS 900 y Pentacam (Oculus, Inc.), y Tappeiner et al ${ }^{[102]}$ lo hizo de $3.6 \mu \mathrm{m}$ al compararlo con el biómetro de contacto Tomey AL-3000 (Tomey, Erlangen, Germany), que sí fue significativa.

Estas pequeñas diferencias no deberían ser clínicamente relevantes, pero que sí deberían tenerse en cuenta al evaluar la paquimetría corneal central para el diagnóstico de glaucoma, y especialmente para propósitos de cirugía refractiva.

Creemos que un factor que ha podido influir negativamente en los resultados de nuestro trabajo, es por una parte la subjetividad a la hora de realizar manualmente las mediciones corneales con Cirrus OCT, y por otro lado la dificultad de algunos de los pacientes con patología retiniana incluidos en el estudio, para la fijación, con un agotamiento mayor y por tanto peor colaboración, hecho que sería de mayor importancia para las mediciones con Lenstar LS 900.

Nuestro estudio presenta la limitación de no haber incluido un paquímetro de ultrasonido con el que haber comparado los instrumentos de medida relativamente novedosos que hemos analizado, aunque otros autores ya lo han hecho previamente para otros sistemas de OCT ${ }^{[34,35,84-88]}$, y para Lenstar LS $900{ }^{[99]}$, pero siempre de dichos dispositivos por separado. En el análisis realizado tras la recogida de datos, se apreció que en pacientes que presentaban patologías retinianas que podían comprometer su capacidad de fijación, los datos del espesor corneal obtenidos presentaban mayores diferencias entre las distintas mediciones. Por ello pensamos que un futuro estudio debería de analizarse la variabilidad asociada a la agudeza visual, para determinar en qué medida la reproducibilidad y repetibilidad se pueden ver afectadas. 
7.2.5. REPETIBILIDAD

INTRA-OBSERVADOR

REPRODUCIBILIDAD INTER-OBSERVADOR E INTERSESIÓN DE LAS MEDIDAS PAQUIMÉTRICAS OBTENIDAS CON EL SISTEMA DE TOMOGRAFÍA DE COHERENCIA ÓPTICA DE DOMINIO ESPECTRAL TOPCON 3D OCT-1000.

\subsubsection{Repetibilidad Intra-observador del sistema 3D OCT-1000.}

Para el estudio de repetibilidad obtuvimos 6 medidas de manera consecutiva en el mismo paciente y en el menor tiempo posible. El sistema no aporta un índice de calidad de la imagen, así que el examinador jugó un papel importante en aceptar las capturas con más nitidez y menos artefactadas, repitiéndose en caso de que fuera necesario. Para evitar una influencia del examinador al realizar las paquimetrías de manera consecutiva, las imágenes no fueron medidas hasta que todos los pacientes estuvieron incluidos en el estudio, al igual que se hizo para el sistema Cirrus HD-OCT, midiéndose primero todas las primeras imágenes de todos los pacientes, después en las segundas, y así sucesivamente.

Dado que actualmente se sigue considerando al paquímetro ultrasónico como el sistema "gold standard" [28, 33], las nuevas técnicas de no contacto cada vez más empleadas, deberían presentar una fiabilidad similar. No existen estudios previos de validez ni fiabilidad para el sistema 3D OCT-1000 en su uso como paquímetro. En nuestro estudio obtuvimos un valor de repetibilidad intrasesión (14.29 $\mu \mathrm{m})$ e CCI (0.97) que se asemejan a los valores descritos en otros trabajos para el paquímetro ultrasónico (repetibilidad intrasesión:15.22 $\mu \mathrm{m}$; ICC: 0.96$)^{[124]}$, lo cual indica que este sistema de no contacto puede llegar a ofrecer medidas igualmente fiables que el "gold standard" actual, por lo tanto, si fuese también intercambiable con dicho sistema ultrasónico, el sistema de no contacto podría reemplazar al de contacto en la clínica diaria.

$\mathrm{Al}$ igual que ya se ha indicado anteriormente, existen numerosos artículos que ya han determinado la repetibilidad de otros sistemas de OCT. Así, Hong et al ${ }^{[35]}$ obtuvo valores para el sistema Visante OCT ( $\mathrm{CV}_{\mathrm{i}}$ : 0.79\%; ICC: 0.978) similares a los nuestros, siendo mejores sus resultados para el sistema RTVue OCT $\left(\mathrm{CV}_{\mathrm{i}}\right.$ : 0.50\%; CCI 0.922) a los obtenidos por nosotros para el Topcon 3D OCT-1000 ( $\mathrm{CV}_{\mathrm{i}}$ : 0.99\%; CCI: 0.97). Igualmente, otros autores obtuvieron mejores resultados para el sistema RTVue OCT 
que los nuestros; Huang et al ${ }^{[116]}\left(\mathrm{CV}_{\mathrm{i}} 0.72 \%\right)$ y Nam et al ${ }^{[92]}\left(\mathrm{CV}_{\mathrm{i}}\right.$ de $0.1 \%$ o $0.26 \%$, en centro pupilar o en ápex corneal respectivamente; CCI 0.99 en ambos casos). Los valores de $\mathrm{CV}_{\mathrm{i}}$ descritos para Visante OCT variaron desde $0.9 \%\left(\mathrm{Li}\right.$ et al ${ }^{[87]}$ ) a $1.02 \%$ (Huang et al ${ }^{[116]}$, valores entre los cuales estaría el hallado en el presente trabajo (0.99\%). Mientras que para el nuevo sistema SOCT Copernicus (SD-OCT; Optopol SA, Poland) ${ }^{[125]}$ los valores de medida del grosor corneal central obtenidos de manera automática fueron $\mathrm{CV}_{\mathrm{i}}$ de $0.33 \%$ e CCI de 0.995 , siendo el $\mathrm{CV}_{\mathrm{i}}$ de $0.49 \%$ y el CCI de 0.973, en el caso de las medidas realizadas de forma manual, lo que demuestra un grado de repetibilidad muy bueno también para las mediciones hechas de forma manual por el observador, con valores en ambas situaciones levemente mejores a los obtenidos por nosotros.

Resulta interesante mencionar el trabajo realizado por Northey et al ${ }^{[124]}$, en el que estudió la repetibilidad intra-observador de una versión más reciente de nuestro sistema de OCT (Topcon 3D OCT versión 2000), y que obtuvo valores de repetibilidad $(14.07 \mu \mathrm{m})$ y CCI (0.99) similares a los que obtuvimos nosotros. Estos datos no son llamativos, dado que dicha versión no aporta una mayor resolución axial, siendo de 6 $\mu \mathrm{m}$ en ambas ${ }^{[124]}$.

De nuevo debemos recordar que sistemas como Visante OCT y RTVue OCT calculan el valor paquimétrico central de manera automática (mientras que en el sistema Topcon 3D OCT-1000 se hace de forma manual), obtenido la media de los puntos explorados en el área central de $2 \mathrm{~mm}$, y no de un único punto en el ápex corneal, lo que puede explicar los mejores datos obtenidos por distintos autores en relación al RTVue OCT en comparación al sistema que nos encontramos estudiando (3D OCT-1000).

Las principales limitaciones de esta parte del estudio, es el hecho de estar realizado únicamente en pacientes con córneas sanas, y el no haber realizado un estudio comparativo con el sistema "gold standard" (paquímetro ultrasónico), para así conocer datos relativos a su exactitud. Sin embargo, al igual que se ha mencionado anteriormente, numerosos autores ya han realizado dicho estudio en otros sistemas SDOCT.

\subsubsection{Reproducibilidad Inter-observador de 3D OCT-1000.}


El cálculo de la fiabilidad al realizar mediciones en el mismo sujeto pero llevadas a cabo por examinadores diferentes constituye también un dato importante a conocer en todo nuevo sistema de medición, pues no siempre va a ser el mismo clínico el que realice el mismo test en el mismo paciente.

Si se trata de un aparto de medición altamente dependiente del examinador, como es el paquímetro ultrasónico, la consistencia de los resultados puede variar enormemente, con las consecuencias que esto puede conllevar. Nuestro valor para la reproducibilidad inter-observador (valor máximo de diferencia entre las medidas esperable con una probabilidad del 95\%) fue de $16.45 \mu \mathrm{m}$, que podemos considerar un valor aceptable, teniendo en cuenta que la repetibilidad para el mismo observador fue sólo $2 \mu \mathrm{m}$ mejor $(14.29 \mu \mathrm{m})$. Además, no se encontraron diferencias estadísticamente significativas entre las medidas tomadas por los dos observadores $(\mathrm{p}=0.29)$.

El sistema Visante OCT, ha aportado valores mejores a los obtenidos por nosotros, con un valor de $\mathrm{CV}_{\mathrm{i}}$ inter-observador de $0.51 \%$ en sujetos sanos obtenido por Fukuda et al ${ }^{[88]}$ frente al nuestro de $1.13 \%$, o un intervalo LdC más estrecho según Chan el at ${ }^{[126]}(26.71 \mu \mathrm{m}$ vs $44.86 \mu \mathrm{m})$. Otros sistemas como RTVue OCT han obtenido valores excelentes de $\mathrm{CV}_{\mathrm{i}}$ de sólo $0.45 \%$ según $\mathrm{Chen}$ et al ${ }^{[93]}$, similar al del SOCT Copernicus (SD-OCT) en el estudio de Vollmer et al ${ }^{[84]}(0.50 \%)$ y de Vidal et al $^{[125]}\left(0.50 \%\right.$ y $0.49 \%$ automática y manualmente respectivamente). Muscat et al ${ }^{\text {[91] }}$ obtuvo para el OCT de Humphrey-Zeiss (Humphrey-Zeiss Medical Systems) un CV $_{\mathrm{i}}$ de sólo $0.18 \%$.

En el presente trabajo, ambos examinadores fueron formados para adquirir una correcta habilidad en la medición manual del grosor corneal, reconociendo las interfases aire-epitelio y endotelio-humor acuoso. Sin embargo, otros sistemas de OCT que obtienen la medida de manera automática, tal como se ha reflejado en los datos mencionados, han obtenido mejores resultados, con lo que se puede deducir que el factor de medida de manera manual ha podido ser determinante.

Por tanto, podemos considerar al sistema Topcon 3D OCT-1000, cuya principal aplicación es el estudio de segmento posterior, una herramienta útil para el estudio y seguimiento de patologías a nivel corneal. No obstante, el hecho de que las mediciones deban hacerse de manera manual con un cursor, es un factor limitante a considerar que 
le hace inferior en cuanto a reproducibilidad inter-observador se refiere respecto a otros sistemas de OCT. Pese a todo, se puede considerar que presenta una aceptable fiabilidad inter-observador.

\subsubsection{Reproducibilidad Inter-sesión del sistema 3D OCT 1000.}

Se evaluó el acuerdo entre dos mediciones del grosor corneal central realizadas en el mismo sujeto y por el mismo examinador en días distintos, hecho importante en la práctica clínica para poder monitorizar determinadas patologías corneales y evolución de procesos clínicos.

No se encontraron diferencias significativas $(\mathrm{p}=0.15)$ entre las medidas tomadas con una semana de diferencia por el mismo observador, en el mismo paciente, con un valor de reproducibilidad inter-sesión $(12.74 \mu \mathrm{m})$ ligeramente mejor a la repetibilidad obtenida con el mismo. Dicho valor de reproducibilidad inter-sesión constituye un dato importante en la práctica clínica, para asegurar una consistencia en las medidas de cualquier sistema, pues indica el valor por debajo del cual la diferencia entre dos medidas en dos sesiones distintas y en el mismo paciente se encuentra con una probabilidad del 95\%. Dicho de otro modo, una diferencia mayor a 12.74 obtenida en el seguimiento de un paciente, se puede interpretar como diferencia real y no como fruto de un error de medición.

Teniendo en cuenta que un error de medida $20 \mu \mathrm{m}$ en el grosor corneal, resulta en aproximadamente un error de $1 \mathrm{mmHg}$ en la medida de presión intraocular por aplanación con tonómetro de Goldmann (correlación 0.02-0.07 mmHg / $\mu \mathrm{m}$ de grosor corneal central) ${ }^{[92]}$, que cada reducción en $40 \mu \mathrm{m}$ del grosor corneal central se ha asociado con un riesgo relativo de 1.71 para desarrollar glaucoma de ángulo abierto ${ }^{[127]}$, y que se considera de riesgo para una cirugía de ablación con láser excimer la existencia de una paquimetría corneal central preoperatoria de $450 \mu \mathrm{m}$ o menos ${ }^{[76]}$, podríamos considerar al dispositivo 3D OCT-1000 un sistema fiable para monitorizar el grosor corneal central en glaucoma, córnea y procedimientos refractivos.

La variabilidad inter-sesión también ha sido medida en otros sistemas de OCT, como Visante OCT o RTVue OCT. Hong et al ${ }^{[35]}$ obtuvo valores de $\mathrm{CV}_{\mathrm{i}}$ inter-sesión 
ligeramente mejores a los nuestros $(0.89 \%)$ en el sistema Visante OCT $(0.79 \%)$, y RTVue OCT $(0.50 \%)$. Mohamed et al ${ }^{[89]}$ y Prakash ${ }^{[94]}$ obtuvieron valores muy dispares para Visante $\mathrm{OCT}$, con un $\mathrm{CV}_{\mathrm{i}}$ de $0.5 \%$ y $3.64 \%$ respectivamente. Obteniendo éste último autor además un $\mathrm{CV}_{\mathrm{i}}$ para RTVue $(0.80 \%){ }^{[94]}$ similar al hallado por nosotros. Posiblemente el hecho ya comentado de que la medición de los sistemas Visante OCT y RTVue OCT sea automática y consista en el promedio de mediciones de un área, pueda explicar que algunos de los resultados acerca de la reproducibilidad inter-sesión en dichos dispositivos sea levemente superior a la de Topcon 3D OCT-1000. Muscat et al [91] obtuvo para el OCT de Humphrey-Zeiss, sistema que también da la medición de forma automática, un $\mathrm{CV}_{\mathrm{i}}(1.11 \%)$ peor que el nuestro, pero una amplitud del LdC algo mejor con un valor de $23 \mu \mathrm{m}$, frente al que obtuvimos nosotros $(36.30 \mu \mathrm{m})$ para el sistema que estamos estudiando.

Nuestro estudio es el primero en estudiar la reproducibilidad inter-sesión del sistema Topcon 3D OCT-1000 en su uso como paquímetro, habiéndose obtenido valores bastante similares a otros autores con otros sistemas OCT, demostrándose una buena fiabilidad del mismo. 

Conclusiones. 



\section{CONCLUSIONES}

\subsection{GENERAL}

La medida de la paquimetría corneal central obtenida de forma manual utilizando sistemas basados en la tomografía de coherencia óptica de domino espectral, posee una fiabilidad adecuada para su aplicación en la clínica diaria, aunque estos sistemas estén diseñados primariamente para la evaluación de anomalías del segmento posterior. Dicha fiabilidad se sitúa cercana a la ofrecida por otros instrumentos diagnósticos específicamente diseñados para la evaluación del segmento anterior.

\subsection{ESPECÍFICAS}

1) El sistema de tomografía de coherencia óptica de dominio espectral Cirrus HDOCT ofrece medidas fiables de la paquimetría central de forma manual cuando se realizan tanto por un mismo observador como cuando son obtenidas por dos observadores distintos.

2) El sistema de tomografía de coherencia óptica de dominio espectral Cirrus HDOCT infraestima de forma estadísticamente significativa la paquimetría central cuando se compara con el sistema ultrasónico convencional; sin embargo, la diferencia entre sistemas de medida es menor a $5 \mu \mathrm{m}$, por lo tanto, aun no siendo técnicas directamente intercambiables, su utilización puede ser recomendada en el ámbito clínico teniendo en cuenta dicha infraestimación.

3) El sistema de reflectometría óptica de baja coherencia Lenstar LS 900 ofrece valores de la paquimetría central muy fiables independiente de que la medición la realice uno o dos observadores distintos. No obstante, la fiabilidad del sistema se puede reducir muy considerablemente en pacientes con una agudeza visual moderada, ya que se necesita una buena fijación por parte del paciente durante la adquisición de la medida biométrica.

4) Las medidas de la paquimetría central obtenidas por un sistema basado en la tomografía de coherencia óptica de dominio espectral y por otro basado en la reflectometría óptica de baja coherencia no son directamente intercambiables. La 
aplicación de un factor de corrección de entorno a $6 \mu \mathrm{m}$, mejoraría la concordancia entre sistemas debido a la infraestimación sistemática de la técnica de reflectometría óptica de baja coherencia.

5) El sistema de tomografía de coherencia óptica de dominio espectral Topcon 3D OCT-1000 permite la obtención de manera fiable de la paquimetría central de forma manual debido a que se debe esperar una variabilidad máxima de $17 \mu \mathrm{m}$ entre medidas, independientemente de que las obtenga uno o dos examinadores o se realicen en días distintos. 
Bibliografía. 



\section{BIBLIOGRAFÍA}

1. External disease and Cornea. Section 8. American Academy of Ophthalmology. El sevier. Boston 2007. Pp 6-14.

2. Dryden, R. Eye and Ear [En línea].<www.bionalogy.com/eye_and_ear.htm>. 2004.

3. Fundamentals and Principes of Ophthalmology. Section 2. American Academy of Ophthalmology. El Sevier. Boston 2007. Pp 150-152, 287-302.

4. Ronneburger, A., J. Basarab, and H.C. Howland, Growth of the cornea from infancy to adolescence. Ophthalmic Physiol Opt, 2006. 26(1): p. 80-7.

5. Remon, L., et al., Central and peripheral corneal thickness in full-term newborns by ultrasonic pachymetry. Invest Ophthalmol Vis Sci, 1992. 33(11): p. 3080-3.

6. Doughty, M.J. and M.L. Zaman, Human corneal thickness and its impact on intraocular pressure measures: a review and meta-analysis approach. Surv Ophthalmol, 2000. 44(5): p. 367-408.

7. Rushood, A.A., et al., Central corneal thickness in full-term Saudi newborns. Acta Ophthalmol, 2012. 90(5): p. e355-8.

8. Spalton, D.J., Atlas de Oftalmología Clínica, Segunda edición. Mosby/Doyma. Madrid. 1995. Pp 6.2-6.5.

9. Kaufman, H.E., The Cornea, Second edition. Newton. Ed Butterworth-Heinemann 1998. Pp 3-51.

10. Durán de la Colina, J.A., LXXIV Pontencia Oficial de la Sociedad Española de Oftalmología (740, 1998, Alicante). Complicaciones de las lentes de contacto. Capítulo 1. Tecnimedia. Madrid. 1998. Pp 13-27.

11. Giraldez-Fernandez, M.J., et al., [Diurnal variations of central and paracentral corneal thickness and curvature]. Arch Soc Esp Oftalmol, 2008. 83(3): p. 183-91.

12. Gutierrez Ortega, A.R., et al., Congreso Sociedad Española de Oftalmología (78ㅇ, 2002, Murcia). Simposium de Patología Corneal. Murcia, España. 2002. [En línea]. <http://www.laboratoriosthea.com/archivos/publicaciones/00064.pdfw>. Thea Formación. 2002. Pp 3-26.

13. Tsubota, K., Tear dynamics and dry eye. Prog Retin Eye Res, 1998. 17(4): p. 565-96.

14. Murube del Castillo, J., Congreso de la Sociedad Española de Oftalmología (73a , 1997, Granada). Ojo Seco-Dry Eye. Granada, España. 1997. Capítulo 2.

15. Butovich, I.A., J.C. Arciniega, and J.C. Wojtowicz, Meibomian lipid films and the impact of temperature. Invest Ophthalmol Vis Sci, 2010. 51(11): p. 5508-18.

16. Lopez-Paniagua, M., et al., Consecutive expansion of limbal epithelial stem cells from a single limbal biopsy. Curr Eye Res, 2013. 38(5): p. 537-49.

17. Casaroli-Marano, R.P., N. Nieto-Nicolau, and E.M. Martinez-Conesa, Progenitor cells for ocular surface regenerative therapy. Ophthalmic Res, 2013. 49(3): p. 115-21.

18. Rowsey, J.J., A.E. Reynolds, and R. Brown, Corneal topography. Corneascope. Arch Ophthalmol, 1981. 99(6): p. 1093-1100.

19. Komai, Y. and T. Ushiki, The three-dimensional organization of collagen fibrils in the human cornea and sclera. Invest Ophthalmol Vis Sci, 1991. 32(8): p. 2244-58.

20. Arffa, R.C. and M. Grayson, Enfermedades de la córnea $4 \underline{a}$ edición. Harcourt Brace. Madrid 1998. Pp 5-18.

21. Meek, K.M. and A.J. Quantock, The use of X-ray scattering techniques to determine corneal ultrastructure. Prog Retin Eye Res, 2001. 20(1): p. 95-137. 
22. Meek, K.M. and C. Boote, The use of X-ray scattering techniques to quantify the orientation and distribution of collagen in the corneal stroma. Prog Retin Eye Res, 2009. 28(5): p. 369-92.

23. Hassell, J.R. and D.E. Birk, The molecular basis of corneal transparency. Exp Eye Res, 2010. 91(3): p. 326-35.

24. Mahmood, M.A., et al., Detachment of Descemet's membrane. J Cataract Refract Surg, 1998. 24(6): p. 827-33.

25. Marcon, A.S., et al., Descemet's membrane detachment after cataract surgery: management and outcome. Ophthalmology, 2002. 109(12): p. 2325-30.

26. Yamazoe, K., et al., Outcomes of cataract surgery in eyes with a low corneal endothelial cell density. J Cataract Refract Surg, 2011. 37(12): p. 2130-6.

27. Peh, G.S., et al., Human corneal endothelial cell expansion for corneal endothelium transplantation: an overview. Transplantation, 2011. 91(8): p. 811-9.

28. Castanera de Molina, A., et al., Técnicas diagnósticas en oftalmología. Capítulo: Técnicas de exploración del segmento anterior. Prous Cience. Barcelona, 2003. Pp 2358.

29. Maldonado, M.J., et al., Optical coherence tomography evaluation of the corneal cap and stromal bed features after laser in situ keratomileusis for high myopia and astigmatism. Ophthalmology, 2000. 107(1): p. 81-7; discussion 88.

30. Maldonado, M.J., et al., Reliability of noncontact pachymetry after laser in situ keratomileusis. Invest Ophthalmol Vis Sci, 2009. 50(9): p. 4135-41.

31. lester, M., et al., Incorporating corneal pachymetry into the management of glaucoma. J Cataract Refract Surg, 2009. 35(9): p. 1623-8.

32. Kawana, K., et al., Central corneal thickness measurements using Orbscan II scanning slit topography, noncontact specular microscopy, and ultrasonic pachymetry in eyes with keratoconus. Cornea, 2005. 24(8): p. 967-71.

33. Li, E.Y., et al., Agreement among 3 methods to measure corneal thickness: ultrasound pachymetry, Orbscan II, and Visante anterior segment optical coherence tomography. Ophthalmology, 2007. 114(10): p. 1842-7.

34. Lazaro, C., et al., Comparison of central corneal thickness measured with anterior segment optical coherence tomography versus ultrasonic pachymetry. Arch Soc Esp Oftalmol, 2013. 88(2): p. 45-49.

35. Hong, J.P., et al., Reliability of RTVue, Visante, and slit-lamp adapted ultrasonic pachymetry for central corneal thickness measurement. Yonsei Med J, 2012. 53(3): p. 634-41.

36. Sánchez Salorio, M., J. García Feijoo, and B. Pazos González, Biomicroscopia Ultrasónica en Oftalmología. Tecnimedia Editorial, 1998.

37. Dougherty, P.J., et al., Improving accuracy of phakic intraocular lens sizing using highfrequency ultrasound biomicroscopy. J Cataract Refract Surg, 2011. 37(1): p. 13-8.

38. Meinhardt, B., et al., Evaluation of biometric methods for measuring the anterior chamber depth in the non-contact mode. Graefes Arch Clin Exp Ophthalmol, 2006. 244(5): p. 559-64.

39. Bourne, R.R. and P.H. Alsbirk, Anterior chamber depth measurement by optical pachymetry: systematic difference using the Haag-Streit attachments. $\mathrm{Br} J$ Ophthalmol, 2006. 90(2): p. 142-5.

40. Muñoz Negrete, F.J., G. Rebolleda, and M. Díaz Llopis, Tomografía de Coherencia Óptica. LXXXVII Ponencia Oficial de la Sociedad Española de Oftalmología. Mac Line. 2011. Sección I, Capítulo 1. Pp 27-38.

41. Huang, D., et al., Optical coherence tomography. Science, 1991. 254(5035): p. 1178-81.

42. Flores Rodriguez, P.C., Sensibilidad y especificidad de la tomografía de coherencia óptica y la fotografía monocromática de fondo de ojo en el diagnóstico diferencial 
entre un pseudopapiledema por drusas de nervio óptico y edema de papila, in Facultad de Óptica y Optometría. Departamento de Óptica II (Optometría y Visión). 2012, Universidad Complutense de Madrid: Madrid. p. 262.

43. Jaffe, G.J. and J. Caprioli, Optical coherence tomography to detect and manage retinal disease and glaucoma. Am J Ophthalmol, 2004. 137(1): p. 156-69.

44. Ryan, S.J., Retina. Volúmen 2: Clínica. Marbán. Madrid. 2009.

45. Amat Peral, P., et al., Descripción de nuevos sistemas de tomografía de coherencia óptica. Studium Ophthalmologicum, 2008. Vol XXVI(№3): p. 157-162.

46. Sakata, L.M., et al., Optical coherence tomography of the retina and optic nerve - a review. Clin Experiment Ophthalmol, 2009. 37(1): p. 90-9.

47. Spaide, R.F., H. Koizumi, and M.C. Pozzoni, Enhanced depth imaging spectral-domain optical coherence tomography. Am J Ophthalmol, 2008. 146(4): p. 496-500.

48. Hirata, M., et al., Macular choroidal thickness and volume in normal subjects measured by swept-source optical coherence tomography. Invest Ophthalmol Vis Sci, 2011. 52(8): p. 4971-8.

49. Muñoz Negrete, F.J., G. Rebolleda, and M. Díaz Llopis, Tomografía de Coherencia Óptica. LXXXVII Ponencia Oficial de la Sociedad Española de Oftalmología. Mac Line. 2011. Sección I, Capítulo 3. P 62.

50. Ge, L., et al., The role of axial resolution of optical coherence tomography on the measurement of corneal and epithelial thicknesses. Invest Ophthalmol Vis Sci, 2013. 54(1): p. 746-55.

51. Radhakrishnan, S., et al., Real-time optical coherence tomography of the anterior segment at $1310 \mathrm{~nm}$. Arch Ophthalmol, 2001. 119(8): p. 1179-85.

52. Grewal, D.S. and A.P. Tanna, Diagnosis of glaucoma and detection of glaucoma progression using spectral domain optical coherence tomography. Curr Opin Ophthalmol, 2013. 24(2): p. 150-61.

53. Garcia Martin, E., et al., Usefulness of the new Spectral-Domain Optical Coherence Tomography (SD-OCT) devices in the study of degenerative dementias. Arch Soc Esp Oftalmol, 2011. 86(11): p. 347-50.

54. Jacob, M., et al., Predicting visual outcome after treatment of pituitary adenomas with optical coherence tomography. Am J Ophthalmol, 2009. 147(1): p. 64-70 e2.

55. Kuck, M., et al., Evaluation of optical coherence tomography as a non-invasive diagnostic tool in cutaneous wound healing. Skin Res Technol, 2013.

56. Sugimura, K., et al., Three-dimensional-optical coherence tomography imaging of chronic thromboembolic pulmonary hypertension. Eur Heart J, 2013.

57. Izatt, J.A., et al., Micrometer-scale resolution imaging of the anterior eye in vivo with optical coherence tomography. Arch Ophthalmol, 1994. 112(12): p. 1584-9.

58. Reinstein, D.Z., M. Gobbe, and T.J. Archer, Anterior segment biometry: a study and review of resolution and repeatability data. J Refract Surg, 2012. 28(7): p. 509-20.

59. Carl-Zeiss. Meditec Inc. Cirrus HD-OCT 4.0 User Manual Addendum. Dublin, CA: Anterior Segment Imaging.

60. Correa-Perez, M.E., et al., Precision of high definition spectral-domain optical coherence tomography for measuring central corneal thickness. Invest Ophthalmol Vis Sci, 2012. 53(4): p. 1752-7.

61. Topcon-Corporation. Manual del Usuario. Tomógrafo 3D de Coherencia Óptica. 3D OCT-1000. Edición de Software TrueMap ${ }^{\mathrm{TM}}$. Versión 2.12.

62. Fercher, A.F., K. Mengedoht, and W. Werner, Eye-length measurement by interferometry with partially coherent light. Opt Lett, 1988. 13(3): p. 186-8.

63. Buckhurst, P.J., et al., A new optical low coherence reflectometry device for ocular biometry in cataract patients. Br J Ophthalmol, 2009. 93(7): p. 949-53. 
64. Álvarez, M.I., et al., Reflectómetro de Baja Coherencia a Fibra Óptica. Revista Colombiana de Física, 2009. 41(No. 2).

65. Cruysberg, L.P., et al., Evaluation of the Lenstar LS 900 non-contact biometer. Br J Ophthalmol, 2010. 94(1): p. 106-10.

66. Chen, W., et al., Scheimpflug-Placido topographer and optical low-coherence reflectometry biometer: repeatability and agreement. J Cataract Refract Surg, 2012. 38(9): p. 1626-32.

67. Rabsilber, T.M., et al., Intraocular lens power calculation: clinical comparison of 2 optical biometry devices. J Cataract Refract Surg, 2010. 36(2): p. 230-4.

68. Rohrer, K., et al., Comparison and evaluation of ocular biometry using a new noncontact optical low-coherence reflectometer. Ophthalmology, 2009. 116(11): p. 2087-92.

69. Mylonas, G., et al., Performance of three biometry devices in patients with different grades of age-related cataract. Acta Ophthalmol, 2011. 89(3): p. e237-41.

70. Wegener, A. and $\mathrm{H}$. Laser-Junga, Photography of the anterior eye segment according to Scheimpflug's principle: options and limitations - a review. Clin Experiment Ophthalmol, 2009. 37(1): p. 144-54.

71. Patel, R.P. and R.T. Pandit, Comparison of Anterior Chamber Depth Measurements from the Galilei Dual Scheimpflug Analyzer with IOLMaster. J Ophthalmol, 2012. 2012: p. 430249.

72. Cairns, G. and C.N. McGhee, Orbscan computerized topography: attributes, applications, and limitations. J Cataract Refract Surg, 2005. 31(1): p. 205-20.

73. Lattimore, M.R., Jr., et al., Orbscan pachymetry: implications of a repeated measures and diurnal variation analysis. Ophthalmology, 1999. 106(5): p. 977-81.

74. Modis, L., Jr., A. Langenbucher, and B. Seitz, Scanning-slit and specular microscopic pachymetry in comparison with ultrasonic determination of corneal thickness. Cornea, 2001. 20(7): p. 711-4.

75. Randleman, J.B., et al., Risk assessment for ectasia after corneal refractive surgery. Ophthalmology, 2008. 115(1): p. 37-50.

76. Saad, A. and D. Gatinel, Bilateral corneal ectasia after laser in situ keratomileusis in patient with isolated difference in central corneal thickness between eyes. J Cataract Refract Surg, 2010. 36(6): p. 1033-5.

77. Saad, A. and D. Gatinel, Topographic and tomographic properties of forme fruste keratoconus corneas. Invest Ophthalmol Vis Sci, 2010. 51(11): p. 5546-55.

78. Brandt, J.D., et al., Central corneal thickness in the Ocular Hypertension Treatment Study (OHTS). Ophthalmology, 2001. 108(10): p. 1779-88.

79. Ventura, A.C., M. Bohnke, and D.S. Mojon, Central corneal thickness measurements in patients with normal tension glaucoma, primary open angle glaucoma, pseudoexfoliation glaucoma, or ocular hypertension. $\mathrm{Br} J$ Ophthalmol, 2001. 85(7): $\mathrm{p}$. 792-5.

80. Kopplin, L.J., et al., Relationship of Fuchs endothelial corneal dystrophy severity to central corneal thickness. Arch Ophthalmol, 2012. 130(4): p. 433-9.

81. Repp, D.J., et al., Fuchs' endothelial corneal dystrophy: subjective grading versus objective grading based on the central-to-peripheral thickness ratio. Ophthalmology, 2013. 120(4): p. 687-94.

82. Chang, D.T., M.B. Pantcheva, and R.J. Noecker, Corneal thickness and intraocular pressure in edematous corneas before and after Descemet stripping with automated endothelial keratoplasty. Cornea, 2010. 29(10): p. 1125-30.

83. Bland, J.M., An Introduction to Medical Statistics, Third Edition. . Oxford University Press. UK 2000. Pp 269-275. 
84. Vollmer, L., et al., Central corneal thickness measurements obtained with anterior segment spectral domain optical coherence tomography compared to ultrasound pachymetry in healthy subjects. Optometry, 2012. 83(5): p. 167-72.

85. Mencucci, R., et al., Corneal thickness measurements using time-domain anterior segment OCT, ultrasound, and Scheimpflug tomographer pachymetry before and after corneal cross-linking for keratoconus. J Refract Surg, 2012. 28(8): p. 562-6.

86. Ishibazawa, A., et al., Central corneal thickness measurements with Fourier-domain optical coherence tomography versus ultrasonic pachymetry and rotating Scheimpflug camera. Cornea, 2011. 30(6): p. 615-9.

87. Li, H., et al., Comparative study of central corneal thickness measurement with slitlamp optical coherence tomography and visante optical coherence tomography. Ophthalmology, 2008. 115(5): p. 796-801 e2.

88. Fukuda, S., et al., Anterior ocular biometry using 3-dimensional optical coherence tomography. Ophthalmology, 2009. 116(5): p. 882-9.

89. Mohamed, S., et al., Repeatability and reproducibility of pachymetric mapping with Visante anterior segment-optical coherence tomography. Invest Ophthalmol Vis Sci, 2007. 48(12): p. 5499-504.

90. Sandler, S.F., et al., Intra-observer and inter-observer reliability and reproducibility of slit-lamp-adapted optical coherence tomography for evaluation of anterior chamber depth and central corneal thickness. Ophthalmic Surg Lasers Imaging, 2008. 39(4): p. 299-303.

91. Muscat, S., et al., Repeatability and reproducibility of corneal thickness measurements by optical coherence tomography. Invest Ophthalmol Vis Sci, 2002. 43(6): p. 1791-5.

92. Nam, S.M., et al., Accuracy of RTVue optical coherence tomography, Pentacam, and ultrasonic pachymetry for the measurement of central corneal thickness. Ophthalmology, 2010. 117(11): p. 2096-103.

93. Chen, S., et al., Measurement of central corneal thickness by high-resolution Scheimpflug imaging, Fourier-domain optical coherence tomography and ultrasound pachymetry. Acta Ophthalmol, 2012. 90(5): p. 449-55.

94. Prakash, G., et al., Comparison of fourier-domain and time-domain optical coherence tomography for assessment of corneal thickness and intersession repeatability. Am J Ophthalmol, 2009. 148(2): p. 282-290 e2.

95. Spadea, L., et al., Comparison of optical low coherence reflectometry and ultrasound pachymetry in the measurement of central corneal thickness before and after photorefractive keratectomy. J Refract Surg, 2007. 23(7): p. 661-6.

96. Barkana, Y., et al., Central corneal thickness measurement with the Pentacam Scheimpflug system, optical low-coherence reflectometry pachymeter, and ultrasound pachymetry. J Cataract Refract Surg, 2005. 31(9): p. 1729-35.

97. Much, M.M. and W. Haigis, Ultrasound and partial coherence interferometry with measurement of central corneal thickness. J Refract Surg, 2006. 22(7): p. 665-70.

98. Beutelspacher, S.C., N. Serbecic, and A.F. Scheuerle, Assessment of central corneal thickness using OCT, ultrasound, optical low coherence reflectometry and Scheimpflug pachymetry. Eur J Ophthalmol, 2011. 21(2): p. 132-7.

99. Tai, L.Y., et al., Central corneal thickness measurements with different imaging devices and ultrasound pachymetry. Cornea, 2013. 32(6): p. 766-71.

100. Huang, J., et al., Comparison of anterior segment measurements with rotating Scheimpflug photography and partial coherence reflectometry. J Cataract Refract Surg, 2011. 37(2): p. 341-8.

101. Shen, P., et al., Comparison of anterior ocular biometry between optical low-coherence reflectometry and anterior segment optical coherence tomography in an adult Chinese population. J Cataract Refract Surg, 2012. 38(6): p. 966-70. 
102. Tappeiner, C., et al., Clinical comparison of biometry using the non-contact optical low coherence reflectometer (Lenstar LS 900) and contact ultrasound biometer (Tomey AL3000) in cataract eyes. Br J Ophthalmol, 2010. 94(5): p. 666-7.

103. Bjelos Roncevic, M., et al., Intraobserver and interobserver repeatability of ocular components measurement in cataract eyes using a new optical low coherence reflectometer. Graefes Arch Clin Exp Ophthalmol, 2011. 249(1): p. 83-7.

104. Koktekir, B.E., S. Gedik, and B. Bakbak, Comparison of central corneal thickness measurements with optical low-coherence reflectometry and ultrasound pachymetry and reproducibility of both devices. Cornea, 2012. 31(11): p. 1278-81.

105. Haag-Streit-International, Manual de Usuario Biómetro Lenstar LS 900 . 5a Edición/2012-4.

106. Bland, J.M. and D.G. Altman, Statistical methods for assessing agreement between two methods of clinical measurement. Lancet., 1986 Feb 8;1(8476):307-10.

107. British Standards Institution. Accuracy (trueness and precision) of measurement methods and results: basic methods for the determination of repeatibility and reproducibility of standard measurement method. London: HMO; 1994. BS ISO 5725 part 2.

108. British Standars Institution. Accuracy (trueness and precision) of measurement methods and results: general principles and definitions. . London; HMO; 1994. BS ISO 5725 part 1.

109. Bland, J.M. and D.G. Altman, Measurement error. BMJ, 1996. 313(7059): p. 744.

110. Altman, D.G. and J.M. Bland, Measurement in Medicine: the Analysis of Method Comparison Studies. The Statistician, 1983. 32: p. 307-317.

111. Bland, J.M. and D.G. Altman, Measurement error and correlation coefficients. BMJ, 1996. 313(7048): p. 41-2.

112. Bland, J.M., An Introduction to Medical Statistics, Third Edition. . Oxford University Press. UK 2000. Pp 172-173.

113. Myles, P.S. and J. Cui, Using the Bland-Altman method to measure agreement with repeated mesures. Br J Anaesth 2007. 99: p. 309-11.

114. Bland, J.M., An Introduction to Medical Statistics, Third Edition. . Oxford University Press. UK 2000. Pp 197-205.

115. Bland, J.M. and D.G. Altman, Measuring agreement in method comparison studies. Stat Methods Med Res, 1999 Jun. 8(2): p. 135-60.

116. Huang, J.Y., et al., Intra-examiner repeatability and agreement of corneal pachymetry map measurement by time-domain and Fourier-domain optical coherence tomography. Graefes Arch Clin Exp Ophthalmol, 2010. 248(11): p. 1647-56.

117. Williams, R., et al., Central corneal thickness measurements: using an ultrasonic instrument and 4 optical instruments. Cornea, 2011. 30(11): p. 1238-43.

118. Bechmann, M., et al., Central corneal thickness measurement with a retinal optical coherence tomography device versus standard ultrasonic pachymetry. Cornea, 2001. 20(1): p. 50-4.

119. Zhao, P.S., et al., Comparison of central corneal thickness measurements by visante anterior segment optical coherence tomography with ultrasound pachymetry. Am J Ophthalmol, 2007. 143(6): p. 1047-9.

120. Garcia-Medina, J.J., et al., Comparative study of central corneal thickness using Fourierdomain optical coherence tomography versus ultrasound pachymetry in primary openangle glaucoma. Cornea, 2013. 32(1): p. 9-13.

121. Tam, E.S. and D.S. Rootman, Comparison of central corneal thickness measurements by specular microscopy, ultrasound pachymetry, and ultrasound biomicroscopy. J Cataract Refract Surg, 2003. 29(6): p. 1179-84. 
122. Savini, G., et al., Repeatability of automatic measurements performed by a dual Scheimpflug analyzer in unoperated and post-refractive surgery eyes. J Cataract Refract Surg, 2011. 37(2): p. 302-9.

123. Fam, H.B., K.L. Lim, and D.Z. Reinstein, Orbscan global pachymetry: analysis of repeated measures. Optom Vis Sci, 2005. 82(12): p. 1047-53.

124. Northey, L.C., P. Gifford, and G.C. Boneham, Comparison of topcon optical coherence tomography and ultrasound pachymetry. Optom Vis Sci, 2012. 89(12): p. 1708-14.

125. Vidal, S., et al., Repeatability and reproducibility of corneal thickness using SOCT Copernicus HR. Clin Exp Optom, 2013. 96(3): p. 278-85.

126. Chan, J.B., et al., Reproducibility of cornea measurements in anterior segment OCT images of normal eyes and eyes with bullous keratopathy analyzed with the Zhongshan Assessment Program. Invest Ophthalmol Vis Sci, 2011. 52(12): p. 8884-90.

127. Gordon, M.O., et al., The Ocular Hypertension Treatment Study: baseline factors that predict the onset of primary open-angle glaucoma. Arch Ophthalmol, 2002. 120(6): p. 714-20; discussion 829-30. 

Anexos. 



\title{
10. ANEXOS
}

\subsection{CONSENTIMIENTO INFORMADO.}

\section{CONSENTIMIENTO INFORMADO}

\author{
ESTUDIO DE LA FIABILIDAD DE LA TOMOGRAFÍA DE COHERENCIA \\ ÓPTICA DE DOMINIO ESPECTRAL PARA LA MEDICIÓN DEL ESPESOR \\ CORNEAL CENTRAL.
}

\section{Declaración de Consentimiento}

Por este medio se le informa que ha sido seleccionado para participar en el estudio "Fiabilidad de la Tomografía De Coherencia Óptica de Dominio Espectral para la medición del espesor corneal central", cuyo objetivo principal es valorar la utilidad de esta técnica de imagen, para medir el espesor corneal central.

Le hacemos saber además que su participación en este estudio será ofrecida voluntariamente sin que medie coerción o fuerza. También entendemos que tiene el derecho de dar por finalizada la entrevista en el momento que desee.

De aceptar usted, se le realizarán varias medidas con el mismo dispositivo de Tomografía de Coherencia Óptica (OCT) en el mismo día, y por dos examinadores distintos. En algunos casos, deberá acudir en una semana para ser nuevamente avaluado con el mismo instrumento. La tecnología OCT es un método de imagen de no contacto, que se utiliza de manera habitual en la consulta de Oftalmología, pudiendo abandonar el estudio en el momento que considere oportuno sin tener que dar ninguna explicación.

En casos seleccionados, tras la medida tomada con el sistema de OCT, se le aplicará una gota de colirio anestésico y se realizará una nueva medición con un sistema distinto, igualmente empleado de manera habitual en la clínica, llamado paquímetro ultrasónico.

En determinados casos, tras las medidas realizadas con el sistema de OCT, se realizará nuevas mediciones con un dispositivo de Reflectometría Óptica De Baja Coherencia. El cual es un método de imagen de no contacto e indoloro, que es empleado de manera 
frecuente en la consulta de Oftalmología, especialmente para el cálculo preoperatorio en los pacientes que van a ser intervenidos de catarata

El tratamiento, la comunicación y la cesión de los datos de carácter personal de todos los sujetos participantes se ajustará a lo dispuesto en la Ley Orgánica 15/1999, de 13 de diciembre de protección de datos de carácter personal. De acuerdo a lo que establece la legislación mencionada, usted puede ejercer los derechos de acceso, modificación, oposición y cancelación de datos.

Si usted tuviera alguna duda o pregunta adicional sobre este estudio, puede resolverla a través de la Dra. Correa, o puede llamar al Servicio de Oftalmología a los teléfonos 950029179 o 950029212.

Se le informa además, que no obtendrá beneficio directo como participante en este estudio, salvo el conocimiento e interpretación de los resultados del mismo, si este fuera su deseo. Del mismo modo, debe saber que no existe riesgo alguno para su salud ni se va a experimentar con nuevas técnicas de tratamiento al involucrarse en el mismo.

Yo ${ }^{\text {(Nombre y apellidos): }}$

- He leído el documento informativo que acompaña a este consentimiento (Información al Paciente).

- He podido hacer preguntas sobre el estudio a la Dra. Correa.

- He recibido suficiente información sobre el estudio. He hablado con el profesional sanitario informador.

- Comprendo que mi participación es voluntaria y soy libre de participar o no en el estudio.

- Se me ha informado que todos los datos obtenidos en este estudio serán confidenciales y se tratarán conforme establece la Ley Orgánica de Protección de Datos de Carácter Personal 15/99.

- Se me ha informado de que la donación/información obtenida sólo se utilizará para los fines específicos del estudio. 
- Deseo ser informado/a de mis datos de carácter personal que se obtengan en el curso de la investigación, incluidos los descubrimientos inesperados que se puedan producir, siempre que esta información sea necesaria para evitar un grave perjuicio para mi salud o la de mis familiares biológicos.

$\mathrm{Si} \quad \mathrm{No}$

Comprendo que puedo retirarme del estudio:

- Cuando quiera

- Sin tener que dar explicaciones

- Sin que esto repercuta en mis cuidados médicos

Presto libremente mi conformidad para participar en el proyecto titulado "Estudio de la Fiabilidad de la Tomografía De Coherencia Óptica de Dominio Espectral para la medición del espesor corneal central"

Firma del paciente

(o representante legal en su caso)
Firma del profesional

sanitario informador

Nombre y apellidos:

Nombre y apellidos:

Fecha: 



\subsection{ARTÍCULOS.}

La presente tesis doctoral ha dado lugar a las siguientes publicaciones en revistas científicas especializadas:

1. Precision of High Definition Spectral-Domain Optical Coherence Tomography for Measuring Central Corneal Thickness.

María E. Correa-Pérez, Alberto López-Miguel, Silvia Miranda-Anta, Darío IglesiasCortiñas, Jorge L. Alió, Miguel J. Maldonado.

Invest Ophthalmol Vis Sci. 2012 Apr 6;53(4):1752-7.

2. Comparison of central corneal thickness using optical low-coherence reflectometry and spectral-domain optical coherence tomography.

Alberto López-Miguel, María Encarnación Correa-Pérez, Silvia Miranda-Anta, Darío Iglesias-Cortiñas, María Begoña Coco-Martín, Miguel J. Maldonado.

J Cataract Refract Surg. 2012 May;38(5):758-64.

3. El siguiente manuscrito se encuentra a la espera de ser aceptado en publicación: Repeatability and Reproducibility of Posterior-Segment Spectral-Domain Optical Coherence Tomography for Measuring Central Corneal Thickness.

María E Correa-Pérez, Natalia Olmo, Alberto López-Miguel, Itziar Fernández, María B. Coco-Martín, Miguel J Maldonado. 



\title{
Precision of High Definition Spectral-Domain Optical Coherence Tomography for Measuring Central Corneal Thickness
}

\author{
María E. Correa-Pérez, ${ }^{1}$ Alberto López-Miguel, ${ }^{2}$ Silvia Miranda-Anta, ${ }^{1}$ Darío Iglesias-Cortiñas, ${ }^{1}$ \\ Jorge L. Alió, ${ }^{3}$ and Miguel J. Maldonado ${ }^{2}$
}

Purpose. This study was intended to assess the reliability of central corneal thickness (CCT) measurements using Cirrus high-definition optical coherence tomography (HD-OCT) in healthy subjects and its accuracy compared with ultrasonic pachymetry.

Methods. Seventy-seven consecutive subjects were recruited for evaluating repeatability, and agreement between two examiners. To analyze repeatability, one examiner measured 77 eyes four times in succession. To study agreement between two observers, a second independently trained examiner obtained another CCT measurement. We also measured eyes in a subgroup of 20 patients using standard ultrasonic pachymetry. Within-subject standard deviation $\left(\mathrm{S}_{\mathrm{w}}\right)$, coefficient of variation (CV), limits of agreement (LoA), and intraclass correlation coefficient (ICC) data were obtained.

Results. For repeatability, the $S_{\mathrm{w}}$ and precision $\left(1.96 \times \mathrm{S}_{\mathrm{w}}\right)$ were 4.86 and $9.52 \mu \mathrm{m}$, respectively. Intraobserver $\mathrm{CV}$ was $0.89 \%$ and the ICC was 0.98 (95\% confidence interval [CI], 0.97-0.99). For agreement between two examiners, the $S_{w}$ and precision were 7.58 and $14.85 \mu \mathrm{m}$, respectively; the CV was $1.40 \%$. The mean difference between observers was $-0.13 \mu \mathrm{m}$ ( $95 \% \mathrm{CI},-1.85$ to $1.58 ; P=0.87$ ). The width of the LoA was $29.64 \mu \mathrm{m}$. Median difference between Cirrus HD-OCT and ultrasound CCT measurements was $-4.5 \mu \mathrm{m}$ (interquartile range, $-7.0-0.0 ; P=0.04)$.

Conclusions. Cirrus HD-OCT provides repeatable CCT measurements, good agreement between two independently trained examiners, and its systematic bias compared to ultrasonic pachymetry is clinically negligible. Therefore, research laboratories and eye clinics using Cirrus HD-OCT as a diagnostic imaging method, can also benefit from a reliable noncontact pachymeter when counseling patients with glaucoma and those undergoing corneal and refractive surgeries. (Invest Ophthalmol Vis Sci. 2012;53:1752-1757) DOI:10.1167/iovs.11-9033

From the ${ }^{1}$ Rio Hortega University Hospital, Valladolid, Spain; ${ }^{2}$ IOBA-Eye Institute, University of Valladolid, Valladolid, Spain; ${ }^{3}$ Vissum/Instituto Oftalmológico de Alicante, Alicante, Spain.

Supported in part by RETICS RD07/0062 (Oftalmología), and the Spanish Ministry of Science and Innovation through the research project SAF2009-14724-C02-01 and FIS PI10/01842.

Submitted for publication November 7, 2011; revised December 31, 2011 and January 31, 2012; accepted February 2, 2012.

Disclosure: M.E. Correa-Pérez, None; A. López-Miguel, None; S. Miranda-Anta, None; D. Iglesias-Cortiñas, None; J.L. Alió, None; M.J. Maldonado, None

Corresponding author: Miguel J. Maldonado, IOBA, Paseo Belén, 17, 47011 Valladolid, Spain; maldonado@ioba.med.uva.es.
Central corneal thickness (CCT) measurements are of paramount importance for diagnostic and therapeutic purposes. ${ }^{1}$ A reliable CCT measurement is required to monitor anterior segment anomalies, such as corneal ectasia ${ }^{2}$ and corneal edema, ${ }^{3}$ and for accurate diagnosis of ocular hypertension and glaucoma. ${ }^{4}$ Furthermore, the CCT measurement is critical when counseling candidates for primary excimer laser ablation $^{5}$ and enhancement procedures and when planning phototherapeutic keratectomy procedures. ${ }^{6}$

Several techniques are available for measuring the CCT. The current gold standard is conventional ultrasonic pachymetry because of its established reliability and utility $;^{7}$ however, this technique requires use of a probe contact, which has several shortcomings because of the contact between the probe and the eye: instillation of topical anesthesia, increased likelihood of patient discomfort, and risk of microbial contamination and epithelial alterations. ${ }^{7,8}$ In addition, measurement accuracy depends on the amount of epithelial indentation and the exact axial placement of the probe relative to the center of the cornea. ${ }^{9,10}$ Therefore, noncontact methods are preferable for corneal biometry, and alternative techniques such as scanningslit technology, ${ }^{11}$ a rotating Scheimpflug camera, ${ }^{12}$ interferometry, ${ }^{13}$ corneal confocal microscopy, noncontact specular microscopy, ${ }^{14}$ and optical coherence tomography (OCT) $)^{7,15-21}$ are being used increasingly as diagnostic tools to measure the CCT.

OCT uses coherence interferometry and optical backscattered light to achieve high-resolution cross-sectional images of ocular structures in vivo. ${ }^{22}$ OCT currently is the most frequently used method for diagnosing retinal anomalies ${ }^{22,23}$; however, its use for assessing the anterior segment has increased during the last years. ${ }^{16,18,20,21}$ The latest generations of OCT (i.e., Fourier and spectral-domain (SD) OCT, allow acquisition of more data in a shorter time and provide threedimensional image analysis with increased axial resolution. ${ }^{24}$

Cirrus HD-OCT (Carl Zeiss Meditec, Inc., Dublin, CA) is based on SD-OCT technology and has a scan speed of 27,000 Ascans per second and an axial resolution of $5 \mu \mathrm{m} .{ }^{25}$ Because of these features, it is currently used to diagnose several posterior segment anomalies such as age-related macular degeneration (AMD), ${ }^{22}$ diabetic retinopathy, ${ }^{26}$ central serous chorioretinopathy, ${ }^{27}$ epiretinal membranes, ${ }^{28}$ and glaucoma. ${ }^{29}$ Cirrus HDOCT also can image structures within the anterior segment by changing the OCT beam focus ${ }^{30}$; thus, it may be advantageous for the posterior segment as well as the anterior segment.

The reliability of the measurements obtained by any ophthalmic instrument should be determined to avoid misdiagnosis or erroneous treatment based on the readings. The test-retest variability of Cirrus HD-OCT for measuring the macular and peripapillary retinal nerve fiber layer thickness in AMD and glaucomatous eyes, respectively, has been reported. ${ }^{22,23}$ Nevertheless, to the best of our knowledge, the 

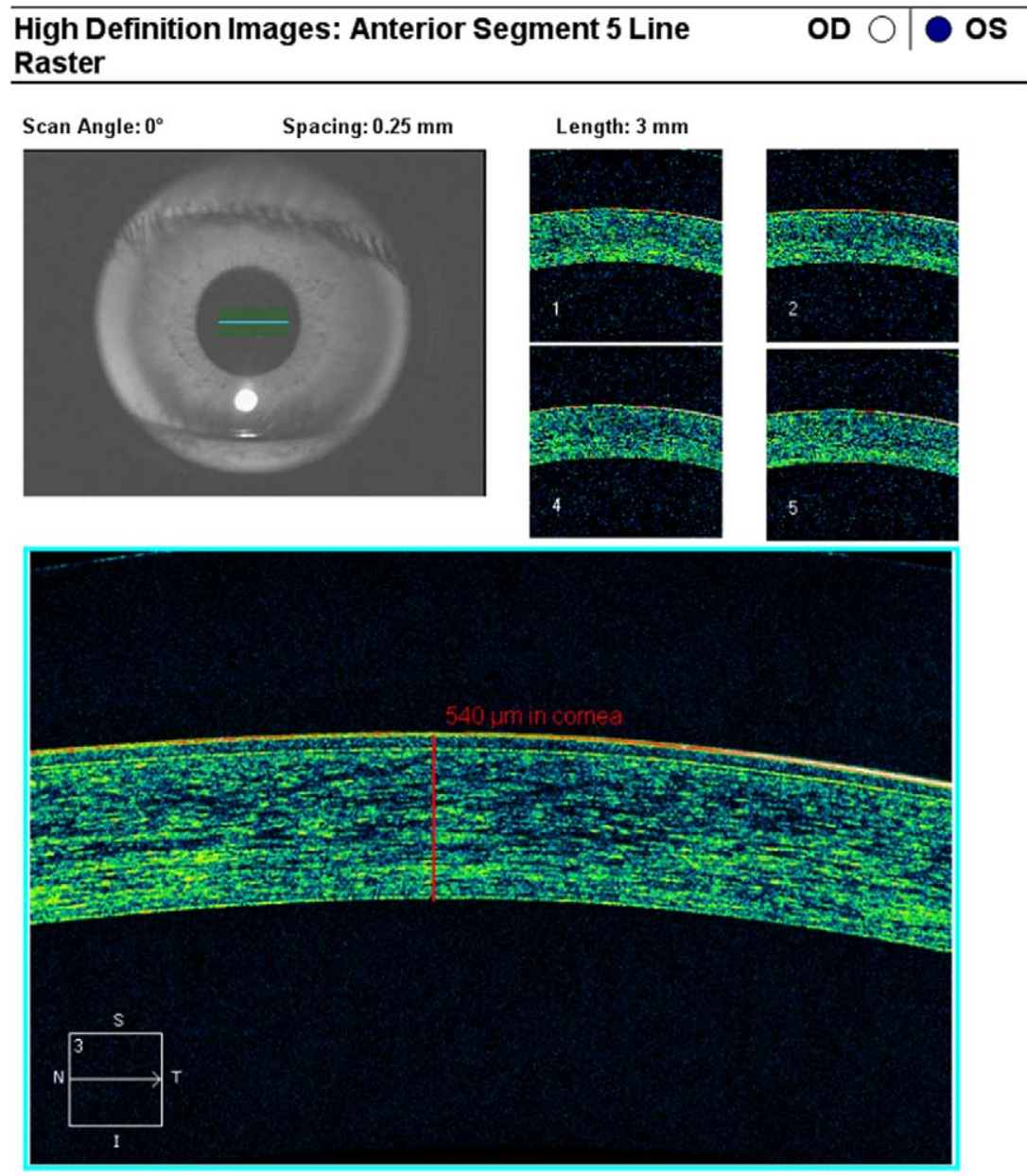

Figure 1. Central corneal thickness measurement using Cirrus HD-OCT.

reliability of Cirrus HD-OCT for measuring the CCT has not been investigated, and no published report of the ability of Cirrus HD-OCT to image the cornea has been published. Therefore, both researchers and clinicians using Cirrus HDOCT as a diagnostic imaging method, can also benefit from a reliable noncontact pachymeter when assessing glaucoma or cornea patients, and in refractive surgery.

\section{MeTHODS}

All procedures were performed in accordance with the Declaration of Helsinki. All candidates received detailed information about the nature of the investigation and provided written informed consent. The institutional ethics committee approved this study.

Exclusion criteria included subjects with a history of corneal surgery, contact lens wear, suspected clinical and subclinical keratectasia, active anterior segment disease, ocular pathology that might alter the optical quality or preclude proper viewing of the internal fixation target of the instrument, and a best-corrected visual acuity below 20/40. Before inclusion in the study, all eyes underwent a complete ophthalmic examination that included measurement of the manifest refraction, videokeratography, slit-lamp microscopy, applanation tonometry, and indirect ophthalmoscopy.

\section{Optical Coherence Tomography Imaging}

Cirrus HD-OCT is primarily used to image and measure structures in the posterior eye. By changing the focus of the OCT beam $(840 \mathrm{~nm})$, it also can image and measure the corneal thickness as the user manual indicates. ${ }^{30}$ Scanning with the Cirrus HD-OCT was performed using the five-line raster scan protocol that produces five horizontal scan lines 3 $\mathrm{mm}$ long separated by $250 \mu \mathrm{m}$; each scan line is comprised of $4096 \mathrm{~A}$ scans. ${ }^{30}$ We selected this protocol because it provides higher resolution than the horizontal high-definition scan of the $512 \times 128$ cube scan protocol (1024 A-scans). ${ }^{30}$ Thus, it was easier for the practitioner to manually perform the CCT measurement because the corneal resolution is higher and the caliper tool can be placed more accurately.

After the patient was seated and properly aligned, he or she was instructed to stare at an internal fixation target during image acquisition. One eye of each subject was selected randomly for CCT measurement. Subjects were realigned after each OCT scan. Only images with signal strength equal to or higher than seven were evaluated. Examinations were carried out from 10:00 AM to 2:00 PM to minimize the effect of diurnal variations of the corneal thickness. ${ }^{1}$ The CCT was measured manually with the caliper tool in the cross-line scan; the vertical distance between the two indicators of the caliper tool was considered the CCT. ${ }^{12}$ The CCT measurements were always manually performed at the corneal apex (Fig. 1). Two different examiners (MECP and SMA) obtained and manually gauged CCT measurements to evaluate Cirrus HD-OCT intraobserver repeatability and agreement between two observers.

After the Cirrus HD-OCT CCT measurements were performed, the corneas of the first 20 consecutive subjects were anesthetized with one drop of $0.1 \%$ tetracaine combined with $0.4 \%$ oxybuprocaine (Alcon, Barcelona, Spain) before the ultrasonic CCT measurements were performed to evaluate the accuracy of the CCT measurement using 
Agreement between two examiners

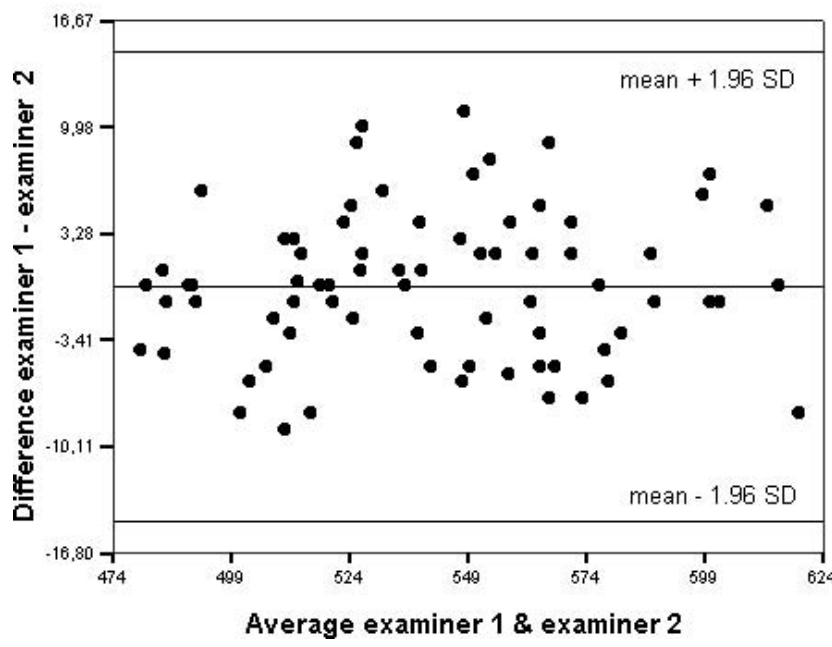

Figure 2. Agreement between two observers applying Bland-Altman analysis. The plot compares the central corneal thickness (CCT) measurements obtained by two examiners. The upper and lower solid lines represent the crude $95 \%$ limits of agreement; the middle solid line represents the mean difference in CCT values between two observers.

Cirrus HD-OCT. A third experienced examiner (DIC) who was masked to the Cirrus HD-OCT CCT measurements placed manually the ultrasonic probe of the Corneo-Gage Plus II (Sonogage Inc., Cleveland, $\mathrm{OH})$ as perpendicularly as possible to the center of the cornea, and the subjects were instructed to stare at a distant target. Five consecutive CCT measurements were obtained and averaged ${ }^{16}$ for comparison with the Cirrus HD-OCT values.

\section{Statistical Analyses}

To investigate the intraobserver repeatability, the first examiner obtained independent test results using the same method on the same subject and the same equipment with the shortest time possible between successive sets of readings. This first examiner performed four consecutive examinations in 77 eyes after ensuring proper focusing and alignment.

To calculate the intraobserver repeatability, the within-subject standard deviation $\left(S_{\mathrm{w}}\right)^{31}$ of four consecutive measurements was calculated by obtaining the square root of the value, referred to as the residual mean square, in one-way analysis of variance. ${ }^{31,32}$ The precision, from a statistical standpoint, is the difference between a subject's measurement and the true value (average value that would be obtained over many measurements) for $95 \%$ of observations and was defined as $\pm 1.96 \times \mathrm{S}_{\mathrm{w}}{ }^{31}$ Repeatability, or the value below which the difference between two measurements will lie with a probability of 0.95, also was analyzed and defined as $2.77 \times \mathrm{S}_{\mathrm{w}}{ }^{31,32}$ We also calculated the intrasession coefficient of variation $\left(\mathrm{CV}_{\mathrm{w}}\right)^{31}$ The intrasession reliability of the measurement method also was calculated with the intraclass correlation coefficient (ICC). ${ }^{33}$

To calculate agreement between two independently trained examiners, a second examiner obtained only one Cirrus HD-OCT CCT measurement. The first of the four CCT measurements performed by the first examiner was computed to establish agreement between observers. ${ }^{16}$ The order of the measurements performed by each examiner was random and within the shortest time to prevent any effect of fatigue bias. Graphs of the differences from the means were plotted to ascertain that there was no relation between the differences and the range of measurement and that the differences between measurements were approximately normally distributed. ${ }^{31,34}$ The $95 \%$ limits of agreement (LoA) were defined as the mean difference in measurements performed by two different examiners $\pm 1.96 \mathrm{SD}$, with lower values indicating higher interobserver reproducibility. ${ }^{31,34}$ Agreement between two observers also was analyzed by calculating the interobserver standard deviation $\left(\mathrm{S}_{\mathrm{w}}\right)$ with analysis of variance, ${ }^{31}$ the precision of the measurements (defined as 1.96 times the interobserver $\mathrm{S}_{\mathrm{w}}$ ), ${ }^{34}$ the reproducibility of the measurement (defined as 2.77 times the interobserver $S_{w}$ ), and the interobserver $\mathrm{CV}_{\mathrm{w}}$, which was defined as the $S_{w}$ divided by the average measurement value and expressed as a percentage. ${ }^{31}$ The paired $t$-test was used to establish whether there was a significant systematic bias between observers.

CCT measurements obtained by Cirrus HD-OCT and ultrasonic pachymetry were compared to establish whether or not there was a significant systematic bias between measurements. The first of the four Cirrus HD-OCT CCT measurements obtained to analyze the intraobserver repeatability was computed to analyze systematic bias between both devices.

Data from the prospectively completed forms were entered into a database, and statistical calculations were performed using SPSS version 18.0 for Windows (SPSS, Cary, NC). The means and standard deviations were calculated for normally distributed data. When the data did not correspond to a normal distribution, the median (50th percentile) and interquartile range (IR) (defined as values between the 25th and 75th percentiles of the distribution) were used instead. For all statistical tests, a two-tailed $P<0.05$ was considered significant.

\section{Results}

The intraobserver repeatability and agreement between two examiners was studied in 77 eyes of 77 subjects ( 31 men, 46 women; average age, $54.27 \pm 19.43$ years; range, $18-91$ years).

The intraobserver overall mean CCT measurement was $541.78 \pm 35.37 \mu \mathrm{m}$ (range, $481-623 \mu \mathrm{m}$ ). The intraobserver $\mathrm{S}_{\mathrm{w}}$, precision, and repeatability values were $4.86,9.52$, and 13.46 $\mu \mathrm{m}$, respectively; the intraobserver $\mathrm{CV}_{\mathrm{w}}$ was $0.89 \%$. The ICC for the repeatability was 0.98 (95\% confidence interval [CI], 0.97-0.99)

The overall mean CCT measurement in the analysis of agreement between two observers was $541.71 \pm 35.35 \mu \mathrm{m}$ (range, $480-619 \mu \mathrm{m}$ ). Their $S_{\mathrm{w}}$, precision, and reproducibility values were $7.58,14.85$, and $20.99 \mu \mathrm{m}$, respectively; and their $\mathrm{CV}_{\mathrm{w}}$ was $1.40 \%$. There was no statistical difference between the set of measurements obtained by each examiner $(P=$ $0.87)$. The mean difference between observers was $-0.13 \mu \mathrm{m}$ (95\% CI, -1.85 to 1.58 ).

A Bland-Altman plot created to assess the difference in individual measurement as a function of the mean of two measurements (Fig. 2) showed good agreement between the examiners; the width of the LoA was good. The upper limit of the LoA was 14.69 (95\% CI, 11.74-17.63), the lower limit was -14.95 (95\% CI, -17.90 to -12.01$)$; thus, the width of the LoA was $29.64 \mu \mathrm{m}$.

Mean Cirrus HD-OCT and US CCT measurements in the subgroup of 20 subjects were $544.0 \pm 28.16$ and $547.7 \pm 29.03$ $\mu \mathrm{m}$, respectively. The distribution of the differences between both devices was not normal (Shapiro-Wilk test, $P=0.001$ ). The median value of the difference between devices was -4.5 $\mu \mathrm{m}$ (IR, -7.0 to 0.0 ; range, -2.00 to +18.00 ), which was statistically significant $(P=0.04)$.

\section{Discussion}

CCT measurements have wide diagnostic applications. Regarding glaucoma diagnosis, it has been reported that thick or thin corneal pachymetry is clinically correlated with intraocular pressure (IOP) readings. ${ }^{35,36}$ In addition, Gordon et al. ${ }^{4}$ reported that each $40-\mu \mathrm{m}$ reduction in CCT is associated with a relative risk of 1.71 for development of primary open-angle 
glaucoma. Furthermore, progression of visual field loss in open-angle glaucoma was significantly associated with thinner CCT. ${ }^{37}$ Moreover, Doughty and Zaman ${ }^{38}$ published a metaanalysis study that found that a $10 \%$ difference in CCT results in a $3.4 \mathrm{~mm} \mathrm{Hg}$ difference in IOP. Likewise, when assessing candidates for refractive surgery, reliable CCT measurements are also demanded because it has been reported that a preoperative CCT thinner than $500 \mu \mathrm{m}$ is a relative contraindication for $\operatorname{LASIK}^{39}$ and a postoperative residual stroma thinner than $250 \mu \mathrm{m}$ or a total CCT thinner than $400 \mu \mathrm{m}$, should be avoided when planning excimer laser ablations. ${ }^{40,41}$ Currently, ultrasonic pachymetry remains the gold standard for measuring CCT; however, most authors agree ${ }^{15-21}$ that it has several disadvantages, such as risk of infection or epithelial damage, patient discomfort, and/or probe misplacement. Therefore, consistent noncontact pachymetry methods to measure CCT would be highly beneficial. The reliability of ultrasonic pachymetry is high, its repeatability coefficient $(2.77$ $\times S_{w}$ ) when assessing intraobserver variability has been reported recently to be about $5 \mu \mathrm{m}$, after averaging five consecutive measurements. ${ }^{42}$ Therefore, a noncontact technique that replaces ultrasonic pachymetry must provide similar variability values. Axial resolution using SD-OCT has been reported to be limited up to $2.1 \mu \mathrm{m}$ in laboratory studies. ${ }^{43}$ Thus, OCT may be a reliable alternative to ultrasonic pachymetry. Cirrus HD-OCT is a commercially available SDOCT device that provides a reported axial resolution of $5 \mu \mathrm{m}^{23}$; thus, it is worth assessing its reliability when measuring the CCT.

The intraobserver repeatability values obtained in the current study were outstanding, despite the fact that the CCT was measured manually. The intraobserver $\mathrm{CV}_{\mathrm{w}}$ value was below $0.90 \%$ and the ICC outcome exceeded 0.98 . These results indicated that reliable outcomes can be obtained by practitioners who possess normal skills. Furthermore, to avoid subjective bias, the corneal images were not evaluated until all subjects were included in the study, and our observers did not consecutively gauge the five CCT measurements of each subject. Actually, they determined all first measurements of each subject, and then all the second measurements, and so forth, so that they would not remember the CCT value from the previous corneal image for each patient. The five-line raster protocol of Cirrus HD-OCT provides a scan line comprised of 4096 A-scans; this feature results in high-quality images of the anterior and posterior corneal boundaries, which favors obtaining accurate positioning of the caliper tool and thus increasing measurement reliability.

The current study was the first to address Cirrus HD-OCT CCT measurement reliability; nonetheless, other authors have reported variability of other types of SD-OCT and time-domain (TD)-OCT devices when measuring pachymetry. Huang et al. ${ }^{18}$ studied the intraobserver repeatability of an anterior segment TD-OCT (Visante OCT, Zeiss Meditec, Dublin, CA) and a SDOCT (RTVue, Optovue, Inc., Fremont, CA) within the 2-mm central area and obtained a poorer $\mathrm{CV}_{\mathrm{w}}$ for the Visante OCT (1.02\%) than our value for Cirrus HD-OCT (0.89\%). However, the RTVue value $(0.72 \%)$ was superior. Nevertheless, RTVue provides the average of the corneal thickness in the central zone instead of a single-point thickness. ${ }^{42}$ Nam et al. ${ }^{42}$ and Li et al. ${ }^{6}$ reported even better intraobserver RTVue $\mathrm{CV}_{\mathrm{w}}$ values of $0.31 \%$ and $0.32 \%$, respectively. $\mathrm{Li}$ et al. ${ }^{16}$ studied the measurement reliability of Visante OCT and a slit-lamp OCT (SL-OCT, Heidelberg Engineering, Dossenheim, Germany) for measuring the CCT automatically and manually. For Visante OCT, they reported $\mathrm{CV}_{\mathrm{w}}$ values of $0.9 \%$ and $1.2 \%$ for automatic and manual measurements, respectively; while for the SL-OCT, the $\mathrm{CV}_{\mathrm{w}}$ was exactly the same for both procedures $\left(\mathrm{CV}_{\mathrm{w}}=\right.$ $1.0 \%$ ). Thus, these authors showed that manual CCT measure- ment also can provide highly reliable results. Day-to-day variability has been also studied by Prakash et al. ${ }^{17}$ who reported excellent ICC values for Visante (0.962) and RTVue OCT (0.999), which are similar to our intraobserver ICC results (0.98).

In the current study, we also evaluated the agreement between two independently trained examiners when measuring CCT. This analysis is extremely important because the same practitioners do not always perform the same diagnostic tests in the daily clinic. As expected, because of the inherent bias of the manual measurement method, the agreement outcomes were not as good as the repeatability outcomes; however, we did not find a significant difference between the practitioners. Moreover, the width of the LoA was acceptable considering that a $20-\mu \mathrm{m}$ measurement error results in a clinically allowable error of $1 \mathrm{~mm} \mathrm{Hg}$ in the Goldmann applanation tonometric IOP measurement. ${ }^{42}$ In addition, the scatterplot (Fig. 1) after BlandAltman analysis did not show an association between the mean magnitudes and the differences in the CCT measurement between observers; thus, we did not detect any tendency with the CCT magnitude.

Other authors also have considered the importance of assessing the interobserver reliability of the OCT CCT measurements. Using the RTVue, Chen et al. ${ }^{44}$ reported an interobserver CV of only $0.45 \%$ and a narrow width of $95 \%$ LoA $(10.2 \mu \mathrm{m})$. Mohamed et al. ${ }^{21}$ reported an interobsever $\mathrm{CV}$ of $0.5 \%$ when they studied the variability of CCT measurements within the 2-mm central area using Visante OCT. Our interobserver $\mathrm{CV}$ value (1.4\%) reporting the agreement between two examiners was higher than those reported by Chen et al. ${ }^{44}$ and Mohamed et al. ${ }^{21}$ as might be expected, because Visante OCT and RTVue calculate the CCT measurements automatically instead of manually as the Cirrus HD-OCT does. Furthermore, RTVue and Visante OCT provide average central corneal values; thus, the variability should be lower than when measuring only one point (corneal apex) as in the current study.

The outcomes of the aforementioned studies have shown that SD-OCT devices provide better reliability values than TDOCT values, as expected. First, the higher axial resolution of SD-OCT provides enhanced images because of higher reflectivity that improves edge detection; thus, either automatic or manual CCT measurements can be performed more accurately. Moreover, rapid acquisition scanning minimizes ocular movement artifacts and might make ocular movement negligible during measurement, which also accounts for lower variability. ${ }^{18}$ Therefore, SD-OCT devices might become the gold standard for measuring CCT because clinicians, researchers and patients demand noninvasive reliable procedures.

To establish the accuracy of Cirrus HD-OCT when measuring the central pachymetry, we also performed ultrasonic CCT gauging. Cirrus HD-OCT significantly $(P=0.04)$ underestimated the CCT measurements compared with ultrasonic pachymetry in a pilot study of 20 subjects. However, the median value $(4.50 \mu \mathrm{m})$ of the difference between devices can be considered clinically irrelevant. Several authors have already reported discrepancies between SD-OCT and ultrasonic pachymetry. Ishibazawa et al., ${ }^{7}$ who measured the CCT using SD-OCT and ultrasonic pachymetry in healthy corneas, found a mean underestimation of $14 \pm 8 \mu \mathrm{m}$ when using the RTVue. In contrast, Chen et al. ${ }^{44}$ using the same SD-OCT, reported an overestimation of $5.63 \pm 10.75 \mu \mathrm{m}$ using the RTVue. Nam et al. ${ }^{42}$ also found higher pachymetry values for the RTVue, 12.8 and $13.7 \mu \mathrm{m}$, depending on the centration of the CCT measurement, in the pupillary center and corneal vertex, respectively. These discrepancies between authors ${ }^{42,44}$ when comparing both methods are likely to arise because ultrasonic pachymetry is highly examiner dependent. ${ }^{45}$ 
The main limitation of the current study was that our results can be applied only when assessing normal corneas. Future studies are needed to assess variability in patients who have undergone excimer laser surgery or those with a corneal disease such as keratoconus. Another limitation is that we could have evaluated Cirrus HD-OCT interobserver reproducibility by using a higher number of examiners (more than two) to avoid statistical bias derived from measurement consistency between examiners. A higher measurement variability should be expected if a higher number of observers perform the CCT gauging because of the inherent subjective bias of any given manual procedure; it is also true that our two observers (MECP and SMA) were trained independently and carried out their routine examinations in an autonomous fashion, which makes it unlikely that both showed autocorrelation bias for the study and, conversely, may well reflect a good random combination representative of further independent examiners.

In conclusion, the current study showed for the first time that Cirrus HD-OCT provides reliable intraobserver CCT measurements and consistent agreement between two independently trained observers when gauging CCT in healthy corneas. In addition, its systematic difference with respect to the standard ultrasonic pachymetry technique can be considered minor, making it a clinically useful noncontact pachymeter. With the current model (4000) of the Cirrus HD-OCT, the corneal thickness can be measured only using the caliper tool. Cirrus HD-OCT does not have an automated corneal pachymetry analysis system as it does for retinal evaluations. Hence, although there are potential inherent errors in the manual measurements, the current data can alert researchers and clinicians to the expected low variability in values when performing this pachymetry technique. Despite the fact that Cirrus HD-OCT is used primarily for the posterior segment, ${ }^{22,23}$ investigators and clinicians can benefit from its ability to image the anterior segment structures, ${ }^{46,47}$ particularly to obtain valid noncontact pachymetry measurements. This expands the usefulness of Cirrus HD-OCT beyond the posterior segment and may help ophthalmologists conserve room space and costs in the research laboratory and in the clinic.

\section{References}

1. Muscat S, McKay N, Parks S, Kemp E, Keating D. Repeatability and reproducibility of corneal thickness measurements by optical coherence tomography. Invest Ophthalmol Vis Sci. 2002;43:1791-1795.

2. Schweitzer C, Roberts CJ, Mahmoud AM, Colin J, MauriceTison S, Kerautret J. Screening of forme fruste keratoconus with the ocular response analyzer. Invest Ophthalmol Vis Sci. 2010;51:2403-2410.

3. Chang DT, Pantcheva MB, Noecker RJ. Corneal thickness and intraocular pressure in edematous corneas before and after Descemet stripping with automated endothelial keratoplasty. Cornea. 2010;29:1125-1130.

4. Gordon MO, Beiser JA, Brandt JD, et al. The Ocular Hypertension Treatment Study: baseline factors that predict the onset of primary open-angle glaucoma. Arch Ophthalmol. 2002;120:714-720.

5. Sharma N, Singhvi A, Sinha R, Vajpayee RB. Reasons for not performing LASIK in refractive surgery candidates. $J$ Refract Surg. 2005;21:496-498.

6. Li Y, Tang M, Zhang X, Salaroli CH, Ramos JL, Huang D. Pachymetric mapping with Fourier-domain optical coherence tomography. J Cataract Refract Surg. 2010;36:826-831.

7. Ishibazawa A, Igarashi S, Hanada $\mathrm{K}$, et al. Central corneal thickness measurements with Fourier-domain optical coherence tomography versus ultrasonic pachymetry and rotating Scheimpflug camera. Cornea. 2011;30:615-619.
8. Maldonado MJ. Corneal epithelial alterations resulting from use of chlorine-disinfected contact tonometer after myopic photorefractive keratectomy. Ophthalmology. 1998;105: 1546-1549.

9. López-Miguel A, Nieto JC, Díez-Cuenca M, Piñero DP, Maldonado MJ. Agreement of non-contact pachymetry after LASIK: comparison of combined scanning-slit/Placido disc topography and specular microscopy. Eye. 2010;24:10641070.

10. Maldonado MJ, López-Miguel A, Nieto JC, Cano-Parra J, Calvo B, Alió JL. Reliability of noncontact pachymetry after laser in situ keratomileusis. Invest Ophthalmol Vis Sci. 2009;50:41354141 .

11. Yazici AT, Bozkurt E, Alagoz C, et al. Central corneal thickness, anterior chamber depth, and pupil diameter measurements using Visante OCT, Orbscan, and Pentacam. J Refract Surg. 2010;26:127-133.

12. Sedaghat MR, Daneshvar R, Kargozar A, Derakhshan A, Daraei M. Comparison of central corneal thickness measurement using ultrasonic pachymetry, rotating Scheimpflug camera, and scanning-slit topography. Am J Ophthalmol. 2010;150: 780-789.

13. Hitzenberger CK, Baumgartner A, Drexler W, Fercher AF. Interferometric measurement of corneal thickness with micrometer precision. Am J Ophthalmol. 1994;118:468-76.

14. Brugin E, Ghirlando A, Gambato C, Midena E. Central corneal thickness: z-ring corneal confocal microscopy versus ultrasound pachymetry. Cornea. 2007;26:303-307.

15. Kim HY, Budenz DL, Lee PS, Feuer WJ, Barton K. Comparison of central corneal thickness using anterior segment optical coherence tomography vs ultrasound pachymetry. Am J Ophthalmol. 2008;145:228-232.

16. Li H, Leung CK, Wong L, et al. Comparative study of central corneal thickness measurement with slit-lamp optical coherence tomography and Visante optical coherence tomography. Ophthalmology. 2008;115:796-801.

17. Prakash G, Agarwal A, Jacob S, Kumar DA, Agarwal A, Banerjee R. Comparison of Fourier-domain and time-domain optical coherence tomography for assessment of corneal thickness and intersession repeatability. Am J Opbthalmol. 2009;148: 282-290.

18. Huang JY, Pekmezci M, Yaplee S, Lin S. Intra-examiner repeatability and agreement of corneal pachymetry map measurement by time-domain and Fourier-domain optical coherence tomography. Graefes Arch Clin Exp Ophthalmol. 2010;248:1647-1656.

19. Maldonado MJ, Ruiz-Oblitas L, Munuera JM, Aliseda D, GarcíaLayana A, Moreno-Montañés J. Optical coherence tomography evaluation of the corneal cap and stromal bed features after laser in situ keratomileusis for high myopia and astigmatism. Ophthalmology. 2000;107:81-87.

20. Fukuda S, Kawana K, Yasuno Y, Oshika T. Repeatability and reproducibility of anterior ocular biometric measurements with 2-dimensional and 3-dimensional optical coherence tomography. J Cataract Refract Surg. 2010;36:1867-1873.

21. Mohamed S, Lee GK, Rao SK, et al. Repeatability and reproducibility of pachymetric mapping with Visante anterior segment-optical coherence tomography. Invest Ophthalmol Vis Sci. 2007;48:5499-5504.

22. Mwanza JC, Chang RT, Budenz DL, et al. Reproducibility of peripapillary retinal nerve fiber layer thickness and optic nerve head parameters measured with cirrus HD-OCT in glaucomatous eyes. Invest Ophthalmol Vis Sci. 2010;51:57245730.

23. Parravano M, Oddone F, Boccassini B, et al. Reproducibility of macular thickness measurements using Cirrus SD-OCT in neovascular age-related macular degeneration. Invest Ophthalmol Vis Sci. 2010;51:4788-4791. 
24. Srinivasan VJ, Wojtkowski M, Witkin AJ, et al. High-definition and 3-dimensional imaging of macular pathologies with highspeed ultrahigh-resolution optical coherence tomography. Ophthalmology. 2006;113:2054.e1-14.

25. Leung CK, Cheung CY, Weinreb RN, et al. Retinal nerve fiber layer imaging with spectral-domain optical coherence tomography: a variability and diagnostic performance study. $O p b$ thalmology. 2009;116:1257-1263.

26. Pournaras JA, Erginay A, Lazrak Z, Gaudric A, Massin P. Spectral domain optical coherence tomography in diabetic macular edema. Ophthalmic Surg Lasers Imaging. 2009;40:548-553.

27. Gupta V, Gupta P, Dogra MR, Gupta A. Spontaneous closure of retinal pigment epithelium microrip in the natural course of central serous chorioretinopathy. Eye. 2010;24:595-599.

28. Falkner-Radler CI, Glittenberg C, Binder S. Spectral domain high-definition optical coherence tomography in patients undergoing epiretinal membrane surgery. Ophthalmic Surg Lasers Imaging. 2009;40:270-276.

29. Leung CK, Choi N, Weinreb RN, et al. Retinal nerve fiber layer imaging with spectral-domain optical coherence tomography: pattern of RNFL defects in glaucoma. Ophthalmology. 2010; 117:2337-2344.

30. Carl Zeiss Meditec, Inc. Cirrus HD-OCT 4.0 User Manual Addendum. Dublin, CA: Anterior Segment Imaging. http:// www.thetechnologysource.biz/files/Cirrus_4.0_Anterior_ Segment_Addendum.pdf.

31. Bland M. An Introduction to Medical Statistics, 3rd ed. Oxford, UK: Oxford University Press; 2000;268-275.

32. Bland JM, Altman DG. Measurement error. BMJ. 1996;313:744.

33. Bland JM, Altman DG. Measurement error and correlation coefficients. BMJ. 1996;313:41-42.

34. Bland JM, Altman DG. Statistical methods for assessing agreement between two methods of clinical measurement. Lancet. 1986;1:307-310.

35. Herman DC, Hodge DO, Bourne WM. Increased corneal thickness in patients with ocular hypertension. Arch Ophthalmol. 2001;119:334-336.

36. Morad Y, Sharon E, Hefetz L, Nemet P. Corneal thickness and curvature in normal-tension glaucoma. Am J Ophthalmol. 1998; 125:164-168.
37. Kim JW, Chen PP. Central corneal pachymetry and visual field progression in patients with open-angle glaucoma. Ophthalmology. 2004;111:2126-2132.

38. Doughty MJ, Zaman ML. Human corneal thickness and its impact on intraocular pressure measures: a review and meta analysis approach. Surv Ophthalmol. 2000;44:367-408.

39. Randleman JB. Post-laser in situ keratomileusis ectasia: current understanding and future directions. Curr Opin Ophthalmol. 2006; 17:406-412.

40. Taneri S, Zieske JD, Azar DT. Evolution, techniques, clinical outcomes, and pathophysiology of LASEK: Review of the literature. Surv Ophthalmol. 2004;49:576-602.

41. Condon PI, O'Keefe M, Binder PS. Long-term results of laser in situ keratomileusis for high myopia: risk for ectasia. J Cataract Refract Surg. 2007;33:583-590.

42. Nam SM, Im CY, Lee HK, Kim EK, Kim TI, Seo KY. Accuracy of RTVue optical coherence tomography, Pentacam, and ultrasonic pachymetry for the measurement of central corneal thickness. Ophthalmology. 2010;117:2096-2103.

43. Wojtkowski M, Srinivasan VJ, Ko TH, Fujimoto J, Kowalczyk A, Duker J. Ultrahigh-resolution, high-speed, Fourier domain optical coherence tomography and methods for dispersion compensation. Opt Express. 2004;12:2404-2422.

44. Chen S, Huang J, Wen D, Chen W, Huang D, Wang D. Measurement of central corneal thickness by high-resolution Scheimpflug imaging, Fourier-domain optical coherence tomography and ultrasound pachymetry. Acta Ophthalmol. 2010; (in press).

45. Javaloy J, Vidal MT, Villada JR, Artola A, Alió JL. Comparison of four corneal pachymetry techniques in corneal refractive surgery. J Refract Surg. 2004;20:29-34.

46. Singh M, See JL, Aquino MC, Thean LS, Chew PT. Highdefinition imaging of trabeculectomy blebs using spectral domain optical coherence tomography adapted for the anterior segment. Clin Experiment Ophthalmol. 2009;37: 345-351.

47. Maldonado MJ, Nieto JC, Piñero DP. Advances in technologies for laser-assisted in situ keratomileusis (LASIK) surgery. Expert Rev Med Devices. 2008;5:209-229. 


\title{
Comparison of central corneal thickness using optical low-coherence reflectometry and spectral-domain optical coherence tomography
}

\author{
Alberto López-Miguel, MSc, María Encarnación Correa-Pérez, MD, Silvia Miranda-Anta, MD, \\ Darío Iglesias-Cortiñas, MD, María Begoña Coco-Martín, PhD, Miguel J. Maldonado, MD, PhD
}

PURPOSE: To assess intraobserver and interobserver reliability of central corneal thickness (CCT) measurements using optical low-coherence reflectometry (OLCR) technology and its agreement with spectral-domain optical coherence tomography (SD-OCT).

SETTING: Rio Hortega University Hospital, Valladolid, Spain.

DESIGN: Evaluation of diagnostic technology.

METHODS: To analyze OLCR intraobserver repeatability, 1 examiner obtained 4 successive measurements. To study interobserver reproducibility, a different examiner obtained another CCT measurement. To determine agreement with SD-OCT, the first examiner also obtained CCTs. Intraobserver and interobserver within-subject standard deviation $\left(S_{w}\right)$, coefficient of variation $\left(\mathrm{CV}_{\mathrm{w}}\right)$, and limits of agreement (LOA) were obtained for OLCR reliability analysis; for study agreement, data were analyzed using the paired-sample $t$ test and the LoA were calculated.

RESULTS: For OLCR intraobserver repeatability, the $S_{w}$ and precision $\left(1.96 \times S_{w}\right)$ were 2.33 and $4.56 \mu \mathrm{m}$, respectively. The intraobserver $\mathrm{CV}_{\mathrm{w}}$ was $0.42 \%$. For interobserver reproducibility, the $\mathrm{S}_{\mathrm{w}}$ and precision were 11.59 and $22.71 \mu \mathrm{m}$, respectively; the $\mathrm{CV}_{\mathrm{w}}$ was $2.10 \%$. The mean difference between observers was $-1.35 \mu \mathrm{m}$ (95\% confidence interval [Cl], -3.97 to 1.26). The width of the LoA was $45.27 \mu \mathrm{m}$. The mean CCT difference between OLCR and SD-OCT was $5.68 \pm 11.46 \mu \mathrm{m}$ $(95 \% \mathrm{Cl}, 8.29-3.08 \mu \mathrm{m} ; P=.0001)$, and the width of the LoA was $44.93 \mu \mathrm{m}$.

CONCLUSIONS: Optical low-coherence reflectometry technology provided reliable intraobserver and interobserver CCT measurements. Although OLCR underestimated the pachymetry by less than $6 \mu \mathrm{m}$ compared with SD-OCT, its interchangeability fell within the range of interobserver reproducibility. Both noncontact pachymetry measurements seem to be clinically useful and may be used interchangeably with minimum calibration adjustment.

Financial Disclosure: No author has a financial or proprietary interest in any material or method mentioned.

J Cataract Refract Surg 2012; 38:758-764 @ 2012 ASCRS and ESCRS

Central corneal thickness (CCT) measurements are clinically important. Corneal pachymetry is affected by endothelial, stromal, and epithelial cell health and function; thus, obtaining reliable corneal measurements is mandatory for diagnosing corneal diseases. ${ }^{1}$ Furthermore, variations in corneal thickness affect the accuracy of applanation tonometry, ${ }^{2}$ and each $40 \mu \mathrm{m}$ decrease in CCT is associated with a relative risk of 1.71 for development of primary open-angle glaucoma. ${ }^{3}$ Likewise, pachymetry is important when considering patient eligibility for corneal refractive and nonrefractive surgery to avoid postoperative complications such as ectasia ${ }^{4}$ or corneal edema. ${ }^{5}$

Ultrasound (US) pachymetry has been the most commonly used method for measuring the CCT and is considered the gold standard. ${ }^{6}$ However, the US method has inherent disadvantages associated with probe contact with the cornea, which include instillation of topical anesthesia and the risk for epithelial damage or infection, causing patient discomfort. ${ }^{7}$ 
Furthermore, US accuracy is highly examiner dependent because of epithelial compression and probe misplacement. ${ }^{8}$ In addition, the US posterior corneal reflection point is ill-defined and might be located between Descemet membrane and the anterior chamber. ${ }^{9}$ Therefore, clinicians increasingly seek CCT noncontact measurement techniques that can provide reliable data.

The Lenstar LS 900 (Haag-Streit AG) is a noncontact biometry instrument based on optical low-coherence reflectometry (OLCR) technology. The instrument was designed for cataract and refractive surgery procedures ${ }^{10,11}$; thus, it can measure the ocular axial length $(\mathrm{AL})$, anterior chamber depth (ACD), lens thickness, corneal curvature, white-to-white distance, and CCT.

The Cirrus HD-OCT (Carl Zeiss Meditec AG), a noncontact tomography device based on spectral-domain optical coherence tomography (SD-OCT) technology, is used primarily to assess the posterior segment, ${ }^{12,13}$ although it can also be used to image anterior segment structures. Because of its high axial resolution of $5 \mu \mathrm{m},{ }^{14}$ it should also be adequate for measuring CCT. Lenstar LS 900 intrasession, ${ }^{11,15,16}$ intersession, ${ }^{16}$ and interobserver ${ }^{17}$ reliability for CCT measurements has been studied recently in cataractous and healthy eyes, and its interchangeability with US, ${ }^{11,18}$ Pentacam (Oculus Optikgeräte GmbH), ${ }^{19}$ and Visante OCT (Carl Zeiss Meditec AG) ${ }^{15,20}$ has also been reported. However, to our knowledge, no study has assessed Lenstar LS 900 CCT measurement intraobserver reliability in a diverse group of individuals with different anomalies who presented to a general ophthalmology outpatient clinic. Furthermore, no report has compared CCT measurements using OLCR and higher axial resolution OCT techniques (eg, spectral domain), which are widely used in the daily clinic. In addition, Lenstar LS 900 interobserver reproducibility ${ }^{17}$ has been analyzed only in subjects having age-related cataract

Submitted: October 3, 2011.

Final revision submitted: November 14, 2011.

Accepted: November 18, 2011.

From the Institute of Applied Ophthalmobiology (López-Miguel, Coco-Martín, Maldonado), University of Valladolid; Visión I+D, SL (López-Miguel), and Rio Hortega University Hospital (Correa, Miranda-Anta, Iglesias-Cortiñas), Valladolid, Spain.

Supported in part by RETICS RD07/0062 (Oftalmología), and the Spanish Ministry of Science and Innovation through research projects FIS PI10/01842 and SAF2009-14724-C02.

Corresponding author: Miguel J. Maldonado, MD, PhD, IOBA, Paseo Belén, 17, 47011 Valladolid, Spain. E-mail: maldonado@ ioba.med.uva.es. surgery. Therefore, the current study sought to assess the intraobserver repeatability and interobserver reproducibility of Lenstar LS 900 measurements in patients with diverse anomalies who might present to any eye clinic and evaluate the intraobserver agreement between noncontact CCT measurements obtained with the Lenstar LS 900 and Cirrus HD-OCT devices.

\section{SUBJECTS AND METHODS}

All procedures were performed in accordance with the Declaration of Helsinki. All subjects received detailed information about the nature of the investigation and provided written informed consent. The institutional ethics committee approved this study.

Exclusion criteria included a history of corneal refractive surgery, contact lens wear, suspected clinical and subclinical keratectasia, history of ocular surgery within the past 4 months, and a corrected distance visual acuity (CDVA) worse than 20/40. Subjects younger than 18 years old were also excluded. All subjects had a complete ophthalmic examination that included measurement of the manifest refraction, slitlamp microscopy, applanation tonometry, and indirect ophthalmoscopy.

\section{Central Corneal Thickness Measurements}

One eye of each subject was selected randomly for CCT measurement. The testing sequence of the CCT measurements performed by each examiner and with each device was randomized to avoid methodology and statistical bias. Randomization was based on a computer-generated random-number table. All CCT measurements were performed within a 10-minute time frame. Subjects were properly aligned before measurement and instructed to stare at the internal fixation target of each device during the measurement. Subjects were instructed to blink immediately before each measurement to obtain an optically smooth tear film over the cornea, and the instrument was realigned after each acquisition. Pachymetry measurements were repeated if they were of poor quality because of an artifact. Manual CCT measurements using the SD-OCT device were gauged 1 week after acquisition to avoid examiner subjective bias because in that way, the examiner could not remember CCT readings provided by the OLCR device during the acquisition session.

\section{Optical Low-Coherence Reflectometry Imaging}

The Lenstar LS 900 is an ocular biometer that uses OLCR to provide different AL measurements along the visual axis. Thus, the instrument can simultaneously measure corneal thickness, ACD (with or without the corneal thickness), lens thickness, and total AL. ${ }^{16}$ The technology is based on Michelson interferometry ${ }^{17}$ and uses an $820 \mathrm{~nm}$ superluminescent diode as a light source. Its technical features provide higher spatial resolution than other reflectometry techniques. In addition, the device detects poor fixation and blinking; thus, hypothetically, only proper axial measurements are processed and thus automatic CCT measurements are obtained. ${ }^{16,17}$ 


\section{Spectral-Domain Optical Coherence Tomography Imaging}

The Cirrus HD-OCT device uses SD-OCT technology and is primarily used for imaging structures in the posterior segment, although if the focus is changed, the anterior segment structures are also imaged. ${ }^{21}$ In the current study, the 5-line raster protocol was used for corneal imaging with the SD-OCT device. This high-definition scan is comprised of 5 scan lines, each comprising 4096 A-scans, which is greater than that obtained with high-definition scans of the $512 \times 128$-cube scan protocol (1024 A-scans). The 5-line raster protocol makes CCT measurement easier because the corneal boundaries are defined more accurately. The HD-OCT system does not have the capability to automatically measure pachymetry; thus, the CCT was measured manually; the vertical distance between the 2 indicators of the caliper tool in the cross-line scan were considered to be the CCT. ${ }^{12}$ Pachymetry was always measured manually at the corneal apex. Only images with a signal strength score of 7 or higher were evaluated.

\section{Statistical Analysis}

To evaluate the intraobserver repeatability, 1 examiner performed 4 consecutive measurements using the OLCR device and the same method for each subject within the shortest time possible between successive sets of readings. Eyes were measured from 10:00 $\mathrm{AM}$ to 2:00 PM to minimize the effect of diurnal variations on corneal thickness. ${ }^{22}$

To calculate the intraobserver repeatability, the withinsubject standard deviation (SD) $\left(S_{w}\right)^{23}$ of 4 consecutive measurements was calculated by obtaining the square root of the value, referred to as the residual mean square in 1-way analysis of variance (ANOVA). ${ }^{23,24}$ Precision was defined as $\pm 1.96 \times S_{w}$; from a statistical standpoint, this is the difference between a subject's measurement and the true value for $95 \%$ of observations. ${ }^{23}$ Repeatability, or the value below which the difference between 2 measurements will lie with a probability of 0.95 , also was analyzed and defined as $2.77 \times \mathrm{S}_{\mathrm{w}} \cdot{ }^{23,24}$ The intersession coefficient of variation $\left(\mathrm{CV}_{\mathrm{w}}\right)$ was also calculated; this is defined as the SD divided by the mean measurement and expressed as a percentage. ${ }^{23}$ The intrasession reliability of the measurement method was also calculated with the intraclass correlation coefficient (ICC). ${ }^{25}$

To calculate the interobserver reproducibility, the first of the 4 measurements performed consecutively with the OLCR device for intraobserver analysis and the 1 measurement obtained by the other examiner were computed for agreement between observers. Graphs of the differences from the means were plotted to ascertain that there was no relation between the differences and the range of measurement and that the differences between the measurements were about normally distributed. ${ }^{23,26}$ The $95 \%$ limits of agreement (LoA) were defined as the mean difference in measurements performed by both examiners $\pm 1.96 \mathrm{SD}$, with lower values indicating higher reproducibility. ${ }^{23,26}$ Interobserver reproducibility was also analyzed, with calculation of the interobserver SD with ANOVA, ${ }^{23}$ the precision of the measurements (defined as 1.96 times the SD), ${ }^{26}$ the reproducibility of the measurement (defined as 2.77 times the SD), and the $\mathrm{CV}_{\mathrm{w}}{ }^{23}$

To analyze the agreement between the OLCR device and HD-OCT device, the first of the 4 consecutive CCT measurements performed for intraobserver repeatability analysis using the OLCR device and the 1 obtained with HD-OCT device were used. Bland-Altman graphs of the differences against the means were also plotted. ${ }^{26}$ The interchangeability of both measurement methods was assessed by calculating the $95 \%$ LoA. $^{23,26}$ The paired $t$ test was used to establish whether there was a significant systematic bias between measurements.

Data from the prospectively completed forms were entered into a database, and statistical calculations were performed using SPSS for Windows software (version 18.0, SPSS, Inc.). The mean and SD were calculated for normally distributed data. For all statistical tests, a 2-tailed $P$ value less than 0.05 was considered significant.

\section{RESULTS}

The OLCR device intraobserver repeatability and interobserver reproducibility and the agreement between the OLCR device and HD-OCT device were studied in 75 eyes of 75 consecutive subjects who attended the ophthalmic department for clinical refraction and general ophthalmology outpatient clinics. The mean age of the 38 men and 37 women was $61.38 \pm 17.26$ years (range 27 to 82 years). Forty-six subjects $(61.3 \%)$ had no ocular anomaly, $16(21.3 \%)$ were pseudophakic, $7(9.3 \%)$ had mild diabetic retinopathy, $4(5.3 \%)$ had previous epiretinal membrane peeling, and 2 (2.7\%) had ocular hypertension. Due to poor-quality readings and artifacts, CCT measurements using the OLCR device were repeated in 5 subjects (in 2 with epiretinal membrane peeling surgery, in 2 with diabetes, and in 1 with pseudophakia), while HD-OCT CCT measurements were repeated in 1 subject with epiretinal membrane peeling. Because 5 OLCR measurements of each subject were taken to calculate repeatability and reproducibility data and 1 HD-OCT measurement of each subject was taken to obtain the interchangeability, the incidence of faulty readings requiring repetition per measurement was $1.3 \%$ for both devices.

\section{Intraobserver Repeatability and Interobserver Reproducibility}

Table 1 shows the overall mean CCT values corresponding to the repeated measures from the intraobserver and interobserver $S_{\mathrm{w}}$, the precision, and the reproducibility. The ICC for the intraobserver repeatability was 0.996 (95\% confidence interval [CI], 0.994-0.997). There was no statistical difference between the CCT measurements performed by the 2 operators $(P=.307)$. The mean difference between the observers was $-1.35 \mu \mathrm{m}(95 \% \mathrm{CI},-3.97$ to 1.26$)$.

Table 2 shows the $95 \%$ LoA corresponding to the interobserver reproducibility. A Bland-Altman plot created to assess the difference in individual measurement as a function of the mean of 2 measurements 
Table 1. Intraobserver repeatability and interobserver reproducibility.

\begin{tabular}{|c|c|c|c|c|c|c|}
\hline Parameter & Overall Mean \pm SD & Range & $S_{w}$ & $\begin{array}{l}\text { Precision } \\
\left(1.96 \times S_{w}\right)\end{array}$ & $\begin{array}{l}\text { Repeatability/ Reproducibility } \\
\qquad\left(2.77 \times \mathrm{S}_{\mathrm{w}}\right)\end{array}$ & $\mathrm{CV}_{\mathrm{w}}(\%)$ \\
\hline Intraobserver repeatability & $551.18 \pm 35.02$ & $(492,636)$ & 2.33 & 4.56 & 6.47 & 0.42 \\
\hline Interobserver reproducibility & $551.86 \pm 37.0$ & $(491,638)$ & 11.59 & 22.71 & 32.10 & 2.10 \\
\hline
\end{tabular}

(Figure 1) showed good agreement between the operators; however, the LoA was wide.

\section{Agreement between Devices}

The mean CCT was $551.21 \pm 35.13 \mu \mathrm{m}$ (range 488 to $639 \mu \mathrm{m}$ ) with the OLCR device and $556.90 \pm 38.65 \mu \mathrm{m}$ (range 490 to $643 \mu \mathrm{m}$ ) with the HD-OCT device. The mean difference in the CCT between the 2 devices was 5.68 $\pm 11.46 \mu \mathrm{m}$ (95\% CI, 8.29-3.08 $\mu \mathrm{m}$; $P=.0001$ ). Table 3 shows the $95 \%$ LoA of the comparison between the 2 devices. Although there was systematic bias between devices, the Bland-Altman plot (Figure 2) showed good agreement between the instruments; however, the LoA was slightly wide.

\section{DISCUSSION}

Measurement of CCT is mandatory when planning refractive and nonrefractive surgeries, ${ }^{4,5,27}$ assessing corneal diseases, ${ }^{5}$ and evaluating ocular hypertension and glaucoma. ${ }^{3}$ Pachymetry can be performed using several techniques. Ultrasound is still the gold standard method ${ }^{6}$; however, it has numerous disadvantages, which underscores the importance of developing noncontact methods. The Lenstar LS 900 is a noncontact biometry device that can provide consistent ocular biometry, ${ }^{17}$ while the Cirrus HD-OCT is also a noncontact instrument based on a different acquisition technique capable of determining ocular images with a resolution of $5 \mu \mathrm{m} .{ }^{14}$ Therefore, establishing CCT measurement agreement between these 2 noncontact instruments can be valuable for clinicians worldwide.

The Lenstar LS 900 is based on an OLCR technique and provides reliable intrasession CCT

Table 2. The 95\% interobserver reproducibility.

\begin{tabular}{lc}
\hline Parameter & Value $(\mu \mathrm{m})$ \\
\hline Upper LoA $(95 \% \mathrm{CI})$ & $21.28(16.78,25.78)$ \\
Lower LoA $(95 \% \mathrm{CI})$ & $-23.99(-28.49,-19.49)$ \\
LoA width & 45.27 \\
\hline CI $=$ confidence interval; LoA $=$ limits of agreement
\end{tabular}

measurements, ${ }^{11,15,16}$ as our intraobserver repeatability outcomes also showed. The device obtains 16 scans within a short time. The scans are averaged for each measurement; therefore, this methodology can obtain highly reliable results for intrasession biometry data because using the mean of the repeated measurements decreases variability. Our ICC value was close to 1 , and the intrasession $\mathrm{CV}_{\mathrm{w}}(0.42 \%)$ was excellent. Furthermore, our intraobserver $S_{w}$ outcomes were similar to those in other studies, ${ }^{11,15,16}$ which report values ranging from 1.5 to $3.0 \mu \mathrm{m}$. This excellent intraobserver data result is similar to results with well-known anterior segment techniques in healthy subjects, such as Scheimpflug photography, the reported $\mathrm{CV}_{\mathrm{w}}$ values of which range from $0.67 \%$ (Pentacam) ${ }^{28}$ to $0.4 \%$ (Galilei, Ziemer Group), ${ }^{29}$ and time-domain OCT (Visante), which achieved a $\mathrm{CV}_{\mathrm{w}}$ of $0.3 \%{ }^{30}$ The current $\mathrm{CV}_{\mathrm{w}}$ value was more consistent than scanning-slit pachymetry (Orbscan II, Bausch \& Lomb), which has $\mathrm{CV}_{\mathrm{w}}$ values ranging from $0.67 \%$ to $0.80 \%{ }^{27}$

Regarding the interobserver reproducibility with the Lenstar LS 900 device, we did not find a significant

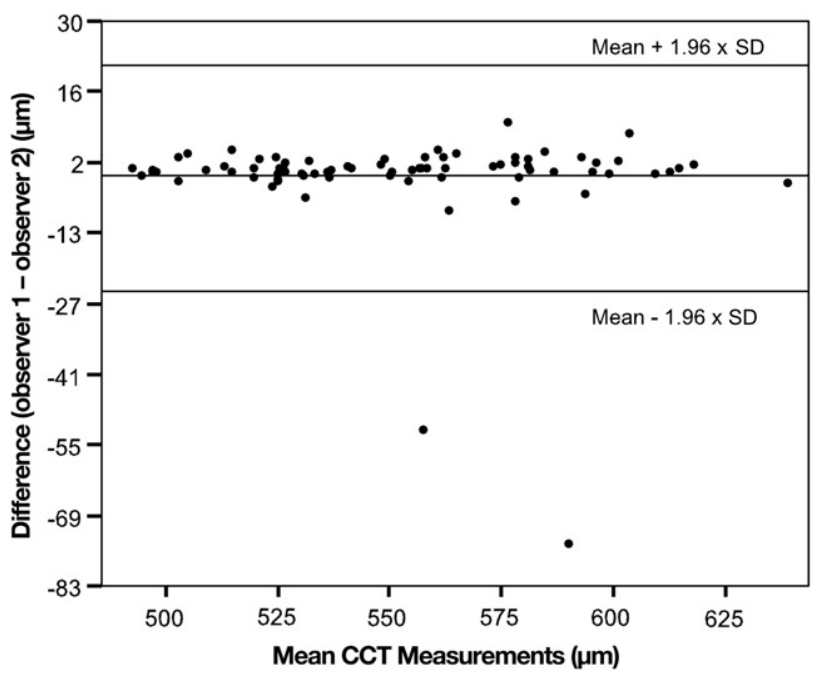

Figure 1. Comparison of the CCT measurements obtained by both examiners. The upper and lower solid lines represent the crude 95\% LoA; the middle solid line represents the mean difference in CCT values between observers (Bland-Altman plot). 
Table 3. The 95\% LoA for OLCR and HD-OCT.

\begin{tabular}{lc}
\hline Parameter & Value $(\mu \mathrm{m})$ \\
\hline Upper LoA $(95 \% \mathrm{CI})$ & $16.79(13.55,20.02)$ \\
Lower LoA $(95 \% \mathrm{CI})$ & $-28.14(-31.38,-24.91)$ \\
LoA width & 44.93 \\
\hline CI = confidence interval; LoA $=$ limits of agreement
\end{tabular}

difference between the CCT data obtained by the 2 examiners and the mean difference between a set of measurements was clinically negligible $(1.35 \mu \mathrm{m})$. However, the interobserver $\mathrm{CV}_{\mathrm{w}}(2.10 \%)$ was not as good as the intraobserver $\mathrm{CV}_{\mathrm{w}}$ value $(0.42 \%)$. Likewise, the interobserver LoA was wide $(45.27 \mu \mathrm{m})$; thus, the differences might be clinically relevant. To the contrary, Bjeloš Rončević et al. ${ }^{17}$ report the same excellent $C_{\mathrm{w}}$ value $(0.4 \%)$ for intraobserver and interobserver CCT measurements and a narrow interobserver LoA $(7.08 \mu \mathrm{m})$ in patients before cataract surgery. These discrepancies between observers in the current study using an automatic (OLCR) instrument might arise from patient variability. The Lenstar LS 900 device determines CCT by patient fixation because CCT measurements are performed while patients stare at the internal target. The current study included patients with a CDVA of 20/40 or better; however, some had epiretinal membrane peeling or diabetic retinopathy and their ability to maintain fixation might have been less than that of subjects

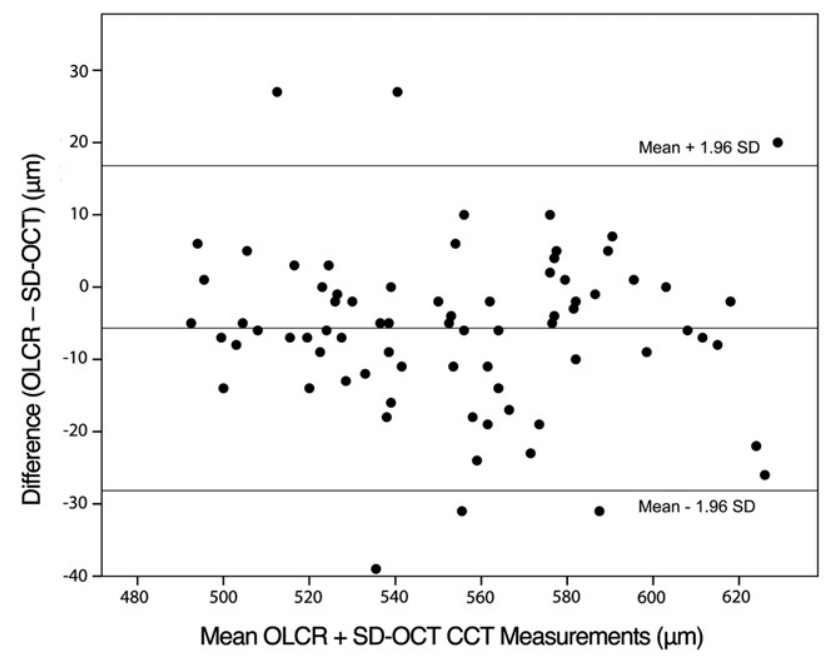

Figure 2. Comparison of the CCT measurements obtained by both instruments. The upper and lower solid lines represent the crude 95\% LoA; the middle solid line represents the mean difference in CCT values between observers (Bland-Altman plot) $(\mathrm{CCT}=$ central corneal thickness; OLCR = optical low-coherence reflectometry; $\mathrm{SD}-\mathrm{OCT}=$ spectral-domain optical coherence tomography). whose CDVA was better. Hence, the Lenstar LS 900 CCT measurement reproducibility might decrease in patients with decreased CDVA because the biometry acquisition is based on the stability of the patient fixation. This was the case of the 2 outliers shown in Figure 1; both subjects had epiretinal membrane surgery and had a CDVA of 20/40 and 20/32, respectively. Clinicians must ensure that patients are properly viewing the fixation target while measurements are being obtained.

The current results showed a systematic bias toward underestimation (mean $5.68 \pm 11.46 \mu \mathrm{m}$ ) by the OLCR device compared with the HD-OCT device. However, the Bland-Altman graph showed good agreement between the devices and no relationship between the differences and the range of measurement. Therefore, after application of an appropriate correction factor $(6 \mu \mathrm{m})$, measurements between the devices should show a narrower LoA and even better interchangeability. Other authors have established the interchangeability between the Lenstar LS 900 device and anterior segment time-domain OCT (Visante, Carl Zeiss Meditec, Inc) with lower resolution. Unlike our results, Cruysberg et al. ${ }^{15}$ and Mylonas et al. ${ }^{20}$ report a systematic bias toward underestimation with the Visante OCT of $11.1 \mu \mathrm{m}$ and $10.0 \mu \mathrm{m}$, respectively. These small mean differences between devices might not be clinically relevant. Nevertheless, they should be considered when evaluating corneal pachymetry for glaucoma diagnosis and especially for refractive surgery purposes because in the normally distributed set of measurement differences, we found the difference between devices would exceed $28.14 \mu \mathrm{m}$ in 1 of 40 observations $(2.5 \%)$. Such a magnitude of a difference may be relevant because it has been reported that each $40 \mu \mathrm{m}$ reduction in CCT is associated with a relative risk of 1.71 for development of primary open-angle glaucoma ${ }^{3}$ and a preoperative CCT thinner than $500 \mu \mathrm{m}$ is a relative contraindication to laser in situ keratomileusis. ${ }^{31}$

The main limitation of the current study was that US pachymetry was not performed, which precluded a direct comparison of these noncontact methods and the conventional gold standard. However, other authors have compared the Lenstar LS 900 and US pachymetry devices. Tappeiner et al. ${ }^{18}$ report a mean CCT overestimation of $3.6 \mu \mathrm{m}$ by the Lenstar LS 900 device in patients with cataract; however, Rohrer et al. ${ }^{11}$ found a mean underestimation of $0.2 \mu \mathrm{m}$ by the Lenstar LS 900 device when they evaluated cataractous, pseudophakic, aphakic, silicone oil-filled, and healthy eyes. Another limitation was that although the CCT measurement performed using the Lenstar LS 900 device was determined by patient fixation and analyzed automatically, the Cirrus HD-OCT 
instrument only provides pachymetry data using a caliper tool. Thus, we performed manual CCT measurement at the corneal apex; it is likely that in some patients, the CCT along the visual axis did not correspond with the location of the CCT at the corneal apex, which should explain why there are some outliers in the Bland-Altman agreement graph between both devices. Finally, the Cirrus HD-OCT CCT measurement might be affected by the pixel size of the corneal image when the caliper tool is managed, as in Stratus OCT (Carl Zeiss Meditec AG). ${ }^{6}$ However, we used the 5-line raster protocol, which provides high-definition images comprised of 4096 A-scans; thus, it was much easier for examiners to accurately gauge the CCT.

In conclusion, the current study reports for the first time a comparison between 2 noncontact pachymetry methods based on cutting-edge technology: OLCR (Lenstar LS 900) and SD-OCT (Cirrus HD-OCT). The Lenstar LS 900 device provided excellent intraobserver and interobserver reliability for CCT measurements in a diverse group of subjects and agreed well with Cirrus HD-OCT measurements. Only a minor systematic underestimation of less than $6 \mu \mathrm{m}$ was detected. Therefore, clinicians might use the 2 methods as reliable noncontact pachymetry methods when diagnosing and counseling all patients, as in the current study. Although neither ophthalmic device was specifically designed for pachymetry measurements, ophthalmic clinics can use them to obtain reliable noncontact CCT measurement and might also use them interchangeably with minimum measurement conversion.

\section{REFERENCES}

1. Christensen A, Narváez J, Zimmerman G. Comparison of central corneal thickness measurements by ultrasound pachymetry, Konan noncontact optical pachymetry, and Orbscan pachymetry. Cornea 2008; 27:862-865

2. Zhao PS, Wong TY, Wong W-L, Saw S-M, Aung T. Comparison of central corneal thickness measurements by Visante anterior segment optical coherence tomography with ultrasound pachymetry. Am J Ophthalmol 2007; 143:1047-1049

3. Gordon MO, Beiser JA, Brandt JD, Heuer DK, Higginbotham EJ, Johnson CA, Keltner JL, Miller JP, Parrish RK II, Wilson MR, Kass MA. The Ocular Hypertension Treatment Study; baseline factors that predict the onset of primary open-angle glaucoma; for the Ocular Hypertension Treatment Study Group. Arch Ophthalmol 2002; 120:714-720. Available at: http://archopht. ama-assn.org/cgi/reprint/120/6/714. Accessed December 29, 2011

4. Maldonado MJ, Nieto JC, Piñero DP. Advances in technologies for laser-assisted in situ keratomileusis (LASIK) surgery. Expert Rev Med Devices 2008; 5:209-229

5. Claesson M, Armitage WJ, Stenevi U. Corneal oedema after cataract surgery: predisposing factors and corneal graft outcome. Acta Ophthalmol (Oxf) 2009; 87:154-159. Available at: http://onlinelibrary. wiley.com/doi/10.1111/j.1755-3768.2008. 01180.x/pdf. Accessed December 29, 2011

6. Ceylan OM, Turk A, Erdurman C, Mumcuoglu T, Erdem U, Gokce G, Dagli S. comparison of Oculus Pentacam and Stratus optical coherence tomography for measurement of central corneal thickness. Cornea 2011; 30:670-674

7. López-Miguel A, Nieto JC, Díez-Cuenca M, Piñero DP, Maldonado MJ. Agreement of non-contact pachymetry after LASIK: comparison of combined scanning-slit/Placido disc topography and specular microscopy. Eye 2010; 24:1064-1070. Available at: http://www.nature.com/eye/journal/v24/n6/pdf/ eye2009233a.pdf. Accessed December 29, 2011

8. Ishibazawa A, Igarashi S, Hanada K, Nagaoka T, Ishiko S, Ito H, Yoshida A. Central corneal thickness measurements with Fourier-domain optical coherence tomography versus ultrasonic pachymetry and rotating Scheimpflug camera. Cornea 2011; 30:615-619

9. Kawana K, Tokunaga T, Miyata K, Okamoto F, Kiuchi T, Oshika T. Comparison of corneal thickness measurements using Orbscan II, non-contact specular microscopy, and ultrasonic pachymetry in eyes after laser in situ keratomileusis. Br J Ophthalmol 2004; 88:466-468. Available at: http://www. pubmedcentral.nih.gov/picrender.fcgi?artid = 1772070\&blobtype $=$ pdf. Accessed December 29, 2011

10. Rabsilber TM, Jepsen C, Auffarth GU, Holzer MP. Intraocular lens power calculation: clinical comparison of 2 optical biometry devices. J Cataract Refract Surg 2010; 36:230-234

11. Rohrer K, Frueh BE, Wälti R, Clemetson IA, Tappeiner C, Goldblum D. Comparison and evaluation of ocular biometry using a new noncontact optical low-coherence reflectometer. Ophthalmology 2009; 116:2087-2092

12. Falkner-Radler $\mathrm{Cl}$, Glittenberg C, Binder S. Spectral domain high-definition optical coherence tomography in patients undergoing epiretinal membrane surgery. Ophthalmic Surg Lasers Imaging 2009; 40:270-276

13. Leung CKS, Choi N, Weinreb RN, Liu S, Ye C, Liu L, Lai GW, Lau J, Lam DSC. Retinal nerve fiber layer imaging with spectraldomain optical coherence tomography; pattern of RNFL defects in glaucoma. Ophthalmology 2010; 117:2337-2344

14. Leung CK-s, Cheung CY-I, Weinreb RN, Qiu Q, Liu S, Li H, Xu G, Fan N, Huang L, Pang C-P, Lam DSC. Retinal nerve fiber layer imaging with spectral-domain optical coherence tomography; a variability and diagnostic performance study. Ophthalmology 2009; 116:1257-1263

15. Cruysberg LPJ, Doors M, Verbakel F, Berendschot TTJM, De Brabander J, Nuijts RMMA. Evaluation of the Lenstar LS 900 non-contact biometer. Br J Ophthalmol 2010; 94:106-110

16. Buckhurst PJ, Wolffsohn JS, Shah S, Naroo SA, Davies LN, Berrow EJ. A new optical low coherence reflectometry device for ocular biometry in cataract patients. Br J Ophthalmol 2009; 93:949-953

17. Bjeloš Rončević M, Bušić M, Čima I, Kuzmanović Elabjer B, Bosnar D, Miletić D. Intraobserver and interobserver repeatability of ocular components measurement in cataract eyes using a new optical low coherence reflectometer. Graefes Arch Clin Exp Ophthalmol 2011; 249:83-87

18. Tappeiner C, Rohrer K, Frueh BE, Waelti R, Goldblum D. Clinical comparison of biometry using the non-contact optical low coherence reflectometer (Lenstar LS 900) and contact ultrasound biometer (Tomey AL-3000) in cataract eyes [letter]. $\mathrm{Br}$ J Ophthalmol 2010; 94:666-667

19. Huang J, Pesudovs K, Wen D, Chen S, Wright T, Wang X, Li Y, Wang $Q$. Comparison of anterior segment measurements with rotating Scheimpflug photography and partial coherence reflectometry. J Cataract Refract Surg 2011; 37:341-348 
20. Mylonas G, Sacu S, Buehl W, Ritter M, Georgopoulos M, Schmidt-Erfurth U. Performance of three biometry devices in patients with different grades of age-related cataract. Acta Ophthalmol (Oxf) 2011; 89:e237-e241

21. Singh M, See JLS, Aquino MC, Thean LSY, Chew PTK. Highdefinition imaging of trabeculectomy blebs using spectral domain optical coherence tomography adapted for the anterior segment. Clin Exp Ophthalmol 2009; 37:345-351

22. Muscat S, McKay N, Parks S, Kemp E, Keating D. Repeatability and reproducibility of corneal thickness measurements by optical coherence tomography. Invest Ophthalmol Vis Sci 2002; 43:1791-1795. Available at: http://www.iovs.org/cgi/ reprint/43/6/1791. Accessed December 29, 2011

23. Bland M. An Introduction to Medical Statistics, 3rd ed. Oxford, UK, Oxford University Press, 2000; 268-275

24. Bland JM, Altman DG. Statistical notes. Measurement error. BMJ 1996; 313:744. Available at: http://www.ncbi.nlm.nih.gov/ pmc/articles/PMC2352111/pdf/bmj00560-0056b.pdf. Accessed December 29, 2011

25. Bland JM, Altman DG. Statistical notes. Measurement error and correlation coefficients. BMJ 1996; 313:41-42. correction, 744. Available at: http://www.ncbi.nlm.nih.gov/pmc/articles/ PMC2351452/pdf/bmj00549-0045.pdf. Accessed December 29, 2011. Correction available at: http://www.ncbi.nlm.nih.gov/ pmc/articles/PMC2352111/pdf/bmj00560-0056b.pdf. Accessed December 29, 2011

26. Bland JM, Altman DG. Statistical methods for assessing agreement between two methods of clinical measurement. Lancet 1986; 1:307-310. Available at: http://www-users.york. ac.uk/ mb55/meas/ba.pdf. Accessed December 29, 2011
27. Fam H-B, Lim K-L, Reinstein DZ. Orbscan global pachymetry; analysis of repeated measures. Optom Vis Sci 2005; 82:1047-1053

28. Nam SM, Im CY, Lee HK, Kim EK, Kim T-I, Seo KY. Accuracy of RTVue optical coherence tomography, Pentacam, and ultrasonic pachymetry for the measurement of central corneal thickness. Ophthalmology 2010; 117:2096-2103

29. Savini G, Carbonelli M, Barboni P, Hoffer KJ. Repeatability of automatic measurements performed by a dual Scheimpflug analyzer in unoperated and post-refractive surgery eyes. J Cataract Refract Surg 2011; 37:302-309

30. Mohamed S, Lee GKY, Rao SK, Wong AL, Cheng ACK, Li EYM, Chi SCC, Lam DSC. Repeatability and reproducibility of pachymetric mapping with Visante anterior segment-optical coherence tomography. Invest Ophthalmol Vis Sci 2007; 48:5499-5504. Available at: http://www.iovs.org/cgi/reprint/48/ 12/5499. Accessed December 29, 2011

31. Randleman JB. Post-laser in situ keratomileusis ectasia: current understanding and future directions. Curr Opin Ophthalmol 2006; 17:406-412

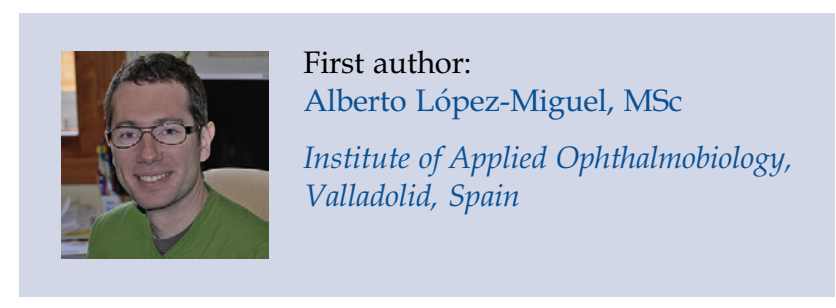





\section{Repeatability and Reproducibility of Posterior-Segment Spectral-Domain Optical Coherence Tomography for Measuring Central Corneal Thickness}

María E Correa-Pérez, MD, ${ }^{1,2}$ Natalia Olmo, ${ }^{2}$ Alberto López-Miguel, ${ }^{1,3,4}$ Itziar Fernández, ${ }^{1,4}$ María B. Coco-Martín, ${ }^{1,4}$ Miguel J Maldonado. ${ }^{1}$

${ }^{1}$ IOBA, Universidad de Valladolid, Valladolid, Spain.

${ }^{2}$ Hospital La Inmaculada, Huércal-Overa (Almería), Spain.

${ }^{3}$ VISIÓN I+D, SL, Valladolid, Spain.

${ }^{4}$ CIBER-BBN (Centro de Investigación Biomédica en Red en Bioingeniería, Biomateriales y Nanomedicina), Spain.

Word count: 3403 .

None of the authors has a financial, commercial, or proprietary interest in any device mentioned or competing ones. No conflicting relationship exists for any author.

Supported in part by RETICS RD07/0062 (Oftalmología), and the Spanish Ministry of Science and Innovation through the research project SAF2009-14724-C02-01.

Reprint requests to Miguel J. Maldonado, MD, PhD, IOBA, Paseo Belén, 17, 47011 Valladolid, Spain. Phone: 983184750; E-mail: maldonado@ioba.med.uva.es. 
Correa et al.--2

\begin{abstract}
Purpose: To assess the intrasession, intersession and interobserver reliability of central corneal thickness (CCT) measurements using a posterior-segment spectraldomain optical coherence tomography (SD-OCT) device in patients having no corneal anomalies.
\end{abstract}

Methods: Sixty patients were examined with Topcon 3D-OCT. To analyze intrasession repeatability, one examiner measured 60 eyes six times consecutively. To study intersession reproducibility, the same examiner obtained CCT measurements in the same patients 1 week apart and, to study interobserver reproducibility, a second examiner obtained another CCT measurement. Within-subject repeatability and reproducibility, coefficients of repeatability and reproducibility (CR), and intraclass correlation coefficients (ICC) were calculated.

Results: The Topcon 3D-OCT showed an intrasession repeatability of $14.29 \mu \mathrm{m}$ $(\mathrm{CR}=2.72 \%)$ and an excellent ICC (0.97). No systematic difference between sessions was found (average difference, $1.7 \mu \mathrm{m} ; \mathrm{p}=0.15$ ). The intersession reproducibility was $12.74 \mu \mathrm{m}(\mathrm{CR}=2.42 \%)$ and the ICC 0.96 . We found no significant bias between observers (mean difference, $-1.53 \mu \mathrm{m} ; \mathrm{p}=0.29$ ). The interobserver reproducibility was $16.45 \mu \mathrm{m}(\mathrm{CR}=3.13 \%)$ and the ICC 0.94 .

Conclusions: With a commercially available retinal SD-OCT, reliable intrasession, intersession and interobserver CCT measurements can be feasibly obtained. Therefore, eye clinics and research laboratories using this SD-OCT system for imaging the posterior segment, can also obtain consistent non-contact CCT measurements in the routine patient. The criteria for a significant change, which would be one exceeding the reproducibility, indicate that intersession and interobserver variations in $\mathrm{CCT}$ of more than $13 \mu \mathrm{m}$ and $16 \mu \mathrm{m}$, respectively, may reflect true corneal 
Correa et al.--3

change with this particular device. These estimates should help investigators and clinicians differentiate actual CCT modification from measurement random error. 
The measurement of central corneal thickness (CCT) is clinically relevant from a diagnostic and therapeutic point of view. A reliable CCT is mandatory to evaluate corneal anomalies like keratectasia ${ }^{1}$ or persistent corneal edema after cataract surgery. ${ }^{2}$ Besides, a consistent pachymetry gauging is also essential for an appropriate counseling of laser refractive surgery candidates ${ }^{3}$ and for diagnosis and management of patients with glaucoma. ${ }^{4}$

Ultrasound pachymetry (USP) has been traditionally considered the gold-standard to evaluate CCT because it is a simple and reliable technique. ${ }^{5}$ Nonetheless, this technique has got several limitations associated first, to the probe contact because it can produce risk of microbial contamination and epithelial alterations, ${ }^{6}$ especially in patients having pre-existing corneal alterations; ${ }^{7}$ and second, to the clinician ability, because the accuracy of the technique can vary depending on the amount of epithelial indentation and the location of the probe related to the center of the cornea. Hence, non-contact rapid techniques are nowadays preferred in the clinical and research settings.

Ocular coherence tomography (OCT) is a technique that has been routinely used to diagnose and monitor posterior segment anomalies, ${ }^{8}$ however, during the last years it has been also used for anterior segment purposes ${ }^{9,10}$ because it provides high quality imaging of the anterior structures of the eye. The Topcon 3D-OCT (version 1000; Topcon Corp., Tokyo, Japan) is a spectral-domain (SD)-OCT system that has been primarily used for diagnosing macular diseases ${ }^{11}$ and optic nerve anomalies, ${ }^{12}$ nonetheless, having an axial resolution of $6 \mu \mathrm{m},{ }^{8}$ it should be also an adequate system to image the cornea that could provide consistent CCT measurements.

The consistency of the data provided by any given ophthalmic instrument is usually tested in laboratory settings prior to its market landing and approval; however, its reliability must be also assessed in real conventional clinical and research settings in 
order to avoid misdiagnosis or incorrect treatment relying on their data. The intrasession repeatability of Topcon 3D-OCT for measuring the retinal thickness in age-related macular degeneration ${ }^{8}$ and subfoveal choroidal thickness has been reported. ${ }^{13}$ Nevertheless, we were unable to find in the literature the reliability of this FD-OCT system for measuring the CCT in patients seeking routine eye-care as opposed to normal volunteers, which may have implications on target fixation and thus, on repeatability and reproducibility (random error). Hence, the aim of the present study was to determine the intrasession repeatability, the intersession reproducibility as well as the interobserver reproducibility of this SD-OCT unit when measuring CCT in a routine outpatient clinic, because researchers and clinicians could also reliably use this SD-OCT system when assessing patients presenting with conditions other than retinal.

\section{$\underline{\text { Methods }}$}

All procedures were performed in accordance with the Declaration of Helsinki. All candidates received detailed information about the nature of the investigation and provided written informed consent. The institutional ethics committee approved this study.

Exclusion criteria included subjects with a history of corneal surgery, contact lens wear, suspected clinical and subclinical keratectasia, ocular pathology that might alter the optical quality or preclude proper viewing of the internal fixation target of the instrument, and a best-corrected visual acuity below 20/40. Before inclusion in the study, all eyes underwent a complete ophthalmic examination that included visual acuity, slit-lamp biomicroscopy, applanation tonometry, and indirect ophthalmoscopy assessment.

\section{Optical Coherence Tomography Imaging}


Topcon 3-D OCT (version 1000) is primarily designed for imaging and measuring the posterior eye having a 6- $\mu \mathrm{m}$ axial resolution and imaging speed of 18,000 axial scans per second. ${ }^{14}$ When an anterior segment analysis is going to be performed, an anterior attachment onto the forehead rest must be mounted and the focus of the SD-OCT must be changed using an external knob according to the manufacturer's instructions. Scanning with the SD-OCT system was carried out using the radial scan protocol that produces in 0.30 seconds six radial scans with 1024 A-scans each, ${ }^{15}$ which is recommended by the manufacturer for corneal analysis.

One eye of each subject was selected randomly for CCT measurement. All patients were equally instructed and they were staring at the internal fixation target during image acquisition while being seated; prior to acquisition, the clinician properly placed the center of the radial scan on the corneal center. Patients were realigned after each SD-OCT scan. SD-OCT images having a poor quality were discarded. Examinations were carried out from 10:00 AM to 2:00 PM to minimize the effect of diurnal variations of pachymetry. ${ }^{16}$ The CCT was measured manually with the caliper tool of the SD-OCT system (software version 3.51) in the horizontal scan. ${ }^{17}$ The CCT magnitude was obtained after measuring the vertical distance between the two limits of the corneal image using the caliper tool. ${ }^{17}$ The corneal apex was the location used to perform CCT measurements. Two different examiners (MECP and NO) obtained and manually gauged CCT measurements to evaluate Topcon 3-D OCT intrasession repeatability as well as intersession and interobserver reproducibility. To avoid subjective bias, first, the pachymetry images were not gauged until all patients were included in the study, and second, the examiner did not consecutively measure the 6 CCT images corresponding to each patient. In fact, the examiner gauged all first OCT images of each patient, and then all the second OCT images, and so forth, so that the 
examiner could not memorize the CCT value from the previous corneal image for each patient, as we previously described. ${ }^{17}$ This measurement order was also followed for the intersession and interobserver reproducibility analysis in the present study.

\section{Statistical Analyses}

Intrasession repeatability

To investigate the intrasession repeatability of Topcon 3-D OCT 1000 for CCT, the first examiner (MECP) obtained independent test results using the same method on the same subject and the same equipment with the shortest time possible between successive sets of readings. This first examiner performed six consecutive examinations in 60 eyes after ensuring proper focusing and alignment. To calculate the intrasession repeatability, the within-subject standard deviation $\left(\mathrm{S}_{\mathrm{w}}\right)^{18}$ of the six consecutive measurements was calculated by obtaining the square root of the value, referred to as the residual mean square, in one-way analysis of variance. ${ }^{18}$ The precision was the difference between a subject's measurement and the true value (average value that would be obtained over many measurements) for $95 \%$ of observations and was defined as $\pm 1.96 \times \mathrm{S}_{\mathrm{w}}{ }^{18}$ Repeatability, or the value below which the difference between two measurements would lie with a probability of 0.95 , was also analyzed and was defined as $2.77 \times \mathrm{S}_{\mathrm{w}}{ }^{18}$ Additionally, we expressed the repeatability as a percentage of the mean measurement for each category of measurement (Coefficient of repeatability $=2.77 \times \mathrm{S}_{\mathrm{w}} /$ mean measurement) as previously detailed. ${ }^{19} \mathrm{We}$ also calculated the intrasession coefficient of variation $\left(\mathrm{CV}_{\mathrm{w}}\right) .{ }^{18}$ The intrasession reliability of the measurement method also was calculated with the intraclass correlation coefficient (ICC). ${ }^{20}$

\section{$\underline{\text { Intersession reproducibility }}$}


To evaluate intersession reproducibility, a second session was scheduled one week after the first one to obtain CCT measurements by the first examiner (MECP). The first of the six CCT measurements obtained during the first session was computed to establish agreement between both sessions. The $95 \%$ limits of agreement (LoA) were defined as the mean difference in measurements performed in two different days $\pm 1.96 \times$ standard deviation $(\mathrm{SD})$ of the differences. ${ }^{18}$ The intersession $\mathrm{Sw}$, precision, reproducibility, $\mathrm{CV}_{\mathrm{w}}$ and ICC were also calculated. ${ }^{18,20}$ As it happens, 2.77 times this $S_{\mathrm{w}}$ is equal to the reproducibility of the measurement in the different sessions. ${ }^{18}$ Besides, we also expressed the reproducibility as a percentage of the mean measurement for each category of measurement (Coefficient of reproducibility $=2.77 \times \mathrm{S}_{\mathrm{w}} /$ mean measurement). ${ }^{19}$

\section{$\underline{\text { Interobserver reproducibility }}$}

To calculate interobserver reproducibility, a second examiner (NO) obtained only one CCT measurement during the second CCT measurement session. The order of the CCT acquisition was randomized between examiners. To establish agreement between examiners, both CCT measurements acquired during the second session were computed. The paired t-test was used to establish whether there was a significant systematic bias between observers. The $95 \%$ LoA, the interobserver $S_{w}$, precision, reproducibility, $\mathrm{CV}_{\mathrm{w}}$ and ICC were calculated. ${ }^{18,20}$ As it happens, 2.77 times this $S_{w}$ is equal to the reproducibility of the measurement by different observers. ${ }^{16}$ In addition, we also expressed the reproducibility as a percentage of the mean measurement for each category of measurement (Coefficient of reproducibility $=2.77 \mathrm{xS}_{\mathrm{w}} /$ mean measurement). ${ }^{19}$ The paired t-test was used to establish whether there was a significant systematic bias between sessions. 


\section{$\underline{\text { Basic Statistical Procedures. }}$}

Data from the prospectively completed forms were entered into a database, and statistical calculations were performed using SPSS version 18.0 for Windows (SPSS, Cary, NC). Data distribution was evaluated using the Lilliefors test and normality was found to hold for all analyses. The mean and SD were then calculated. Spearman's rank correlation coefficient $\left(\mathrm{r}_{\mathrm{s}}\right)$ was used to measure the association between the mean of pachymetry readings and the absolute value of the difference between 2 readings, or the SD of 6 readings, prior to proceed with repeatability and reproducibility analyses. ${ }^{18}$ For all statistical tests, a two-tailed $\mathrm{P}<0.05$ was considered significant.

\section{$\underline{\text { Results }}$}

The study was performed in 60 eyes of 60 patients $(37$ men, 23 women; average age, $64.3 \pm 14.7$ years; range, 26-86). Twenty-four individuals (40.0\%) were found to have no ocular anomaly, $10(16.7 \%)$ were pseudophakic, 9 (15.0\%) had mild cataracts, 8 (13.3\%) had mild diabetic retinopathy, $6(10.0 \%)$ had glaucoma and 3 had mild agerelated macular degeneration $(5.0 \%)$.

The intrasession overall mean CCT measurement was $525.07 \pm 33.21 \mu \mathrm{m}$ (range, 446-602). The intrasession $S_{\mathrm{w}}$, precision, and repeatability values were $5.16(95 \%$ confidence interval [CI], 4.59 / 5.72), 10.11, and $14.29 \mu \mathrm{m}$, respectively. Consequently, the intrasession coefficient of repeatability was $2.72 \%(95 \% \mathrm{CI}, 2.42 \% / 3.01 \%)$ and the intrasession $\mathrm{CV}_{\mathrm{w}}$ was $0.99 \%(95 \% \mathrm{CI}: 0.87 / 1.10)$. The ICC for the repeatability was 0.97 (95\% CI, 0.96/0.98).

The intersession overall mean CCT measurement was $524.87 \pm 33.69 \mu \mathrm{m}$ (range, 443 - 603). The intersession $S_{w}$, precision and reproducibility values were $4.60(95 \%$ 
CI, 3.40/5.78), 9.01, and $12.74 \mu \mathrm{m}$, respectively. Thus, the intersession coefficient of reproducibility was $2.42 \%(95 \% \mathrm{CI}, 1.79 \% / 3.05 \%)$ and the $\mathrm{CV}_{\mathrm{w}}$ was $0.89 \%(95 \% \mathrm{CI}$, $0.66 / 1.11)$. There was no statistical difference between the set of measurements obtained during each session $(\mathrm{p}=0.15)$ and the mean difference between sessions was $1.7 \mu \mathrm{m}(95 \% \mathrm{CI},-0.64$ / 4.04). The ICC for the intersession reproducibility was 0.96 (95\% CI, 0.94/0.98). A Bland-Altman plot created to assess the difference in individual measurement as a function of the mean of two measurements (Figure 1) showed good agreement between both sessions; the width of the LoA was good. The upper limit of the LoA was $19.85 \mu \mathrm{m}(95 \% \mathrm{CI}, 16.46 / 23.24)$, the lower limit was $-16.45 \mu \mathrm{m}(95 \% \mathrm{CI}$, -19.84/-13.06); thus, the width of the LoA was $36.30 \mu \mathrm{m}$.

The interobserver overall mean CCT measurement was $525.63 \pm 33.22 \mu \mathrm{m}$ (range, 441-605). The interobserver $S_{\mathrm{w}}$, precision and reproducibility values were 5.94 (95\% CI, 4.56/7.31), 11.64, and $16.45 \mu \mathrm{m}$, respectively. Therefore, the interobserver coefficient of reproducibility was 3.13\% (95\% CI, $2.40 \% / 3.86 \%)$ and the $\mathrm{CV}_{\mathrm{w}}$ was $1.13 \%(95 \% \mathrm{CI}, 0.87 / 1.38)$. There was no statistical difference between the set of measurements obtained by each observer $(p=0.29)$ and the mean difference between observers was $-1.53 \mu \mathrm{m}(95 \% \mathrm{CI},-4.43 / 1.36)$. The ICC for the interobserver reproducibility was 0.94 (95\% CI, 0.91/0.97). The Bland-Altman plot (Figure 2) showed also good agreement between both observers; the width of the LoA was good. The upper limit of the LoA was $20.90 \mu \mathrm{m}$ (95\% CI, 16.70/25.08), the lower limit was $23.96 \mu \mathrm{m}(95 \% \mathrm{CI},-28.15 /-19.77)$; hence, the width of the LoA was $44.86 \mu \mathrm{m}$.

\section{$\underline{\text { Discussion }}$}

Pachymetry measurements are constantly performed in the clinical setting due to its numerous applications for diagnosing, monitoring and counseling patients attending a 
conventional outpatient clinic. Reliable CCT gauging is needed when diagnosing glaucoma and ocular hypertension patients, ${ }^{21}$ assessing candidates for primary corneal refractive surgery ${ }^{22}$ or retreatments, ${ }^{23}$ and planning non-refractive corneal surgery procedures. ${ }^{24}$ Despite USP still remains the gold standard for evaluating pachymetry, clinicians tend to use non-contact methods that avoid shortcomings associated to the probe contact. Thus, technologies like SD-OCT would be desirable to be reliably used in the clinical and research settings for corneal analysis because it is constantly needed for posterior segment anomalies and has got an adequate axial resolution, $6 \mu \mathrm{m}$ in case of Topcon 3D-OCT. ${ }^{14}$

The intrasession repeatability $\left(2.77 \times \mathrm{S}_{\mathrm{w}}\right)$ of USP in healthy individuals after performing 5 consecutive measurements has been reported to be around $15 \mu \mathrm{m},{ }^{25}$ thus, it would be mandatory for a pachymetry technique aiming to replace USP, having at least similar reliability. The intrasession repeatability that we obtained for the SD-OCT device that we tested was $14.29 \mu \mathrm{m}$, with an inter-scan variation below $1 \%\left(\mathrm{CV}_{\mathrm{w}}=\right.$ 0.99\%), thus, Topcon 3D-OCT matches the USP consistency. In our study, the 6 scans for repeatability analysis were obtained in the less time possible and were gauged by an experienced examiner, which might have played an important role in achieving reliable CCT measurements. Additionally, it must be taken into account first, that the examiner (MECP) did not consecutively measure with the caliper tool the six OCT images corresponding to the same patient. Therefore, we avoided examiner bias related to the consecutive CCT measurement of OCT images corresponding to the same patient, which could have improved erroneously repeatability outcomes.

Previous authors have already reported the repeatability of several OCT devices when assessing CCT. As expected, time-domain OCT (TD-OCT) devices might achieve poorer intrasession variability than a SD-OCT one because they have lower axial 
resolution. ${ }^{26}$ The $\mathrm{CV}_{\mathrm{w}}$ values reported for an anterior segment TD-OCT (Visante OCT, Zeiss Meditec, Dublin, CA) have ranged from 0.9 to $1.02 \%,{ }^{27,28}$ while for a slit-lamp OCT system (SL-OCT, Heidelberg Engineering, Dossenheim, Germany), Li et al. ${ }^{28}$ have reported a $\mathrm{CV}_{\mathrm{w}}$ value of $1.0 \%$. In both cases, $\mathrm{CCT}$ measurements were obtained in healthy volunteers using an automatic mode that provides CCT average of the central area instead of a single-point thickness as we measured in common older patients; thus, repeatability outcomes are similar despite our SD-OCT device had better axial resolution. Regarding SD-OCT devices, Northey et al. ${ }^{25}$ evaluated also the intrasession repeatability of an upgraded version of our SD-OCT device (version 2000) obtaining a similar outcome $(14.07 \mu \mathrm{m})$. Again, they included solely healthy volunteers $(33 \pm 14$ years old) despite this type of ophthalmic devices are going to be used not only for screening but also for diagnostic purposes in patients with suboptimal visual function, which may influence fixation stability. Besides, repeatability might be similar in both Topcon 3D-OCT systems because the upgraded version does not achieve better axial resolution, which is $6 \mu \mathrm{m}$ in both versions. ${ }^{25}$ Other authors have also studied the intrasession repeatability of several SD-OCT devices for gauging CCT and results were also outstanding. For RTVue (Optovue, Inc., Fremont, CA), $\mathrm{CV}_{\mathrm{w}}$ values have ranged from $0.31 \%{ }^{29}$ to $0.72 \%{ }^{27}$ when automatically averaging the corneal thickness in the central zone. For Cirrus HD-OCT (Carl Zeiss Meditec, Inc., Dublin, CA) that allows manual CCT gauging, $\mathrm{CV}_{\mathrm{w}}$ values have ranged from $0.49 \%{ }^{30}$ to $0.89 \% ;^{17}$ and for SOCT Copernicus HR (Optopol SA, Poland), $\mathrm{CV}_{\mathrm{w}}$ values have ranged from $0.33 \%$ to $0.49 \%$ for automatic and manual CCT gauging, respectively. ${ }^{31}$

We did not find significant differences between sets of CCT measurements performed 1 week apart by the same examiner (MECP), besides intersession reproducibility value $\left(2.77 \times \mathrm{S}_{\mathrm{w}}\right)$ was even slightly better $(12.74 \mu \mathrm{m})$ than the 
intrasession one. Intersession reproducibility outcomes are even more valuable than intrasession ones for clinicians when assessing the consistency of any given ophthalmic device, because they show the difference that should be expected between two consecutive CCT measurements in the same subject for $95 \%$ of the observed pairs. Hence, any CCT difference above these values obtained between visits must be considered as an actual change, rather than attributable to day-to-day variability, for appropriate diagnostic purposes and therapeutic decisions. Taking into account in one hand that Topcon 3D-OCT is able to detect inter-visit CCT changes above $13 \mu \mathrm{m}$; and in the other hand that each $40-\mu \mathrm{m}$ reduction in $\mathrm{CCT}$ is associated with a relative risk of 1.71 for development of primary open-angle glaucoma, ${ }^{4}$ a $10 \%$ difference $(\sim 50 \mu \mathrm{m})$ in CCT results in a $3.4 \mathrm{~mm} \mathrm{Hg}$ difference in intraocular pressure, ${ }^{32}$ and a preoperative CCT thinner than $500 \mu \mathrm{m}$ or a postoperative thinner than $400 \mu \mathrm{m}$ should be avoided when planning excimer laser treatments and re-treatments, respectively; ${ }^{33,34}$ Topcon 3DOCT should be an adequate device to reliably monitor CCT for glaucoma, and refractive surgery purposes. Moreover, in penetrating o lamellar keratoplasties, this technology can be used to assess central corneal thickness and pachymetry maps, as well as precise measurements of deep stromal opacities, thereby guiding the surgeon to choose the best treatment option. OCT has also been used to evaluate the keratoplasty postoperative period, for early identification of possible complications, such as secondary glaucoma, graft rejection or donor disc detachments in endothelial keratoplasties. $^{35}$

Intersession variability for CCT measurements using TD-OCT (Visante) and SDOCT (RTVue) devices has been also previously determined. Mohamed et al. ${ }^{36}$ and Prakash et al. $^{37}$ obtained CCT measurements separated one week and one day, respectively, and they reported $\mathrm{CV}_{\mathrm{w}}$ values of $0.6 \%$ and $0.80 \%$, for Visante and RTVue, 
respectively. Their outcomes were better than ours $(0.89 \%)$, however, they computed for analysis the pachymetry corresponding to the average central 2-mm, while we obtained a single-point thickness, thus, it should be expected higher variability with the device we used in the current study.

Additionally, we also calculated the interobserver reproducibility when gauging CCT using the Topcon 3D-OCT system. This part of the study is also of paramount importance because the same clinicians do not always carry out the same diagnostic tests on the same patients. Thus, if a clinical test is highly dependent on examiner's skills, as USP is, consistency of the results is going to vary greatly, and might mislead diagnostic and therapeutic decisions. The interobserver reproducibility value $\left(2.77 \times \mathrm{S}_{\mathrm{w}}\right)$ in our study was $16.45 \mu \mathrm{m}$, which is an outstanding value taking into account that the intraobserver one was only $2 \mu \mathrm{m}$ better. Both examiners were already skilled when they performed the CCT gauging, thus, it is quite likely that they precisely positioned the caliper tool of the SD-OCT device in the air-epithelial and the endothelial-aqueous humor interfaces. Nonetheless, other OCT systems that automatically analyze CCT have been reported to obtain even better interobserver reproducibility; which is the case of Visante despite being a TD-OCT system, this device had a reproducibility value of $12.38 \mu \mathrm{m}$ in healthy subjects, ${ }^{38}$ and narrower LoA than ours $\left(26.71 \mu \mathrm{m}^{39}\right.$ vs $\left.44.86 \mu \mathrm{m}\right)$. Other SD-OCT devices like RTVue obtained an excellent $\mathrm{CV}_{\mathrm{w}}$ value of only $0.45 \%{ }^{36}$ that was similar to the SOCT Copernicus HR one $(0.50 \%)^{27}$ and much better than Topcon 3D-OCT value (1.13\%).

The main limitation of the present study was that our outcomes were obtained from patients having no severe corneal anomalies with a visual acuity above 20/40, thus, the reliability in eyes with other conditions is unknown. Nonetheless, Mohamed et al. ${ }^{36}$ demonstrated that the intrasession $\mathrm{CV}_{\mathrm{w}}$ did not worsen very much when evaluating 
healthy subjects and keratoconus patients $(0.3 \%$ vs $0.6 \%$, respectively) neither the interobserver $\mathrm{CV}_{\mathrm{w}}$ did $(0.5 \%$ vs $1.2 \%)$ as measured with an anterior segment OCT. A second limitation is that we did not perform a direct comparison analysis with USP; nonetheless, the accuracy of Topcon 3D-OCT related to USP had already been performed by Northey et $\mathrm{al} ;{ }^{25}$ they found a mean underestimation of $16 \mu \mathrm{m}$ in healthy volunteers, which agrees with previous authors that have also reported an underestimation ranging from 6 to $19 \mu \mathrm{m}$ (RTVue vs USP). ${ }^{40-42}$

In conclusion, the present study showed for the first time that Topcon 3D-OCT is able to carry out reliable intrasession, intersession and interobserver CCT measurements in patients with no severe corneal anomalies who presented to a general ophthalmology outpatient clinic for routine eye-care examination because the random error was low. The current marketed models of Topcon 3D-OCT (1000 \& 2000) only allow manual pachymetry measurements; however, experienced examiners are able to achieve unremarkably variable CCT measurements, which is highly useful in the clinical and research settings for glaucoma, cornea, and refractive surgery purposes taking into account that this SD-OCT tends to slightly underestimate pachymetry magnitude. ${ }^{25} \mathrm{On}$ top of the main application of Topcon 3D-OCT, which is usually imaging the posterior segment, ${ }^{8,11,12}$ clinicians and investigators can obtain advantage of its ability to reliably monitor the corneal thickness, as we showed. Therefore, this SD-OCT system could be used in the clinical and research settings not only for retinal purposes, but also for pachymetry analysis being a good economical and space saving option. 


\section{REFERENCES}

1. Rocha KM, Perez-Straziota E, Stulting RD, Randleman JB. SD-OCT analysis of regional epithelial thickness profiles in keratoconus, postoperative corneal ectasia, and normal eyes. J Refract Surg. 2013;29:173-179.

2. Claesson M, Armitage WJ, Stenevi U. Corneal oedema after cataract surgery: predisposing factors and corneal graft outcome. Acta Ophthalmol. 2009;87:154159.

3. Binder PS, Trattler WB. Evaluation of a risk factor scoring system for corneal ectasia after LASIK in eyes with normal topography. $J$ Refract Surg. $2010 ; 26: 241-250$

4. Gordon MO, Beiser JA, Brandt JD, et al. The Ocular Hypertension Treatment Study: baseline factors that predict the onset of primary open-angle glaucoma. Arch Ophthalmol. 2002;120:714-720.

5. Ishibazawa $\mathrm{A}$, Igarashi $\mathrm{S}$, Hanada $\mathrm{K}$, et al. Central corneal thickness measurements with Fourier-domain optical coherence tomography versus ultrasonic pachymetry and rotating Scheimpflug camera. Cornea. 2011;30:615619.

6. Maldonado MJ. Corneal epithelial alterations resulting from use of chlorinedisinfected contact tonometer after myopic photorefractive keratectomy. Ophthalmology. 1998;105:1546-1549.

7. Liu Z, Pflugfelder SC. Corneal thickness is reduced in dry eye. Cornea. 1999;18:403-407.

8. Menke MN, Dabov S, Knecht P, Sturm V. Reproducibility of retinal thickness measurements in patients with age-related macular degeneration using 3D 
Fourier-domain optical coherence tomography (OCT) (Topcon 3D-OCT 1000). Acta Ophthalmol. 2011;89:346-351.

9. Maldonado MJ, Ruiz-Oblitas L, Munuera JM, Aliseda D, García-Layana A, Moreno-Montañés J. Optical coherence tomography evaluation of the corneal cap and stromal bed features after laser in situ keratomileusis for high myopia and astigmatism. Ophthalmology. 2000;107:81-87.

10. Aptel F, Beccat S, Fortoul V, Denis P. Biometric analysis of pigment dispersion syndrome using anterior segment optical coherence tomography. Ophthalmology. 2011;118:1563-1570.

11. Domalpally A, Gangaputra S, Peng Q, Danis RP. Repeatability of retinal thickness measurements between spectral-domain and time-domain optical coherence tomography images in macular disease. Ophthalmic Surg Lasers Imaging. 2010;41:34-41.

12. Pierro L, Gagliardi M, Iuliano L, Ambrosi A, Bandello F. Retinal nerve fiber layer thickness reproducibility using seven different OCT instruments. Invest Ophthalmol Vis Sci. 2012;53:5912-5920.

13. Yamashita T, Yamashita T, Shirasawa M, Arimura N, Terasaki H, Sakamoto T. Repeatability and reproducibility of subfoveal choroidal thickness in normal eyes of Japanese using different SD-OCT devices. Invest Ophthalmol Vis Sci. 2012;53:1102-1107.

14. Sull AC, Vuong LN, Price LL, et al. Comparison of spectral/Fourier domain optical coherence tomography instruments for assessment of normal macular thickness. Retina. 2010;30:235-245. 
15. Ho J, Sull AC, Vuong LN, et al. Assessment of artifacts and reproducibility across spectral- and time-domain optical coherence tomography devices. Ophthalmology. 2009;116:1960-1970.

16. Lattimore MR Jr, Kaupp S, Schallhorn S, Lewis R 4th. Orbscan pachymetry: implications of a repeated measures and diurnal variation analysis. Ophthalmology. 1999;106:977-981.

17. Correa-Pérez ME, López-Miguel A, Miranda-Anta S, Iglesias-Cortiñas D, Alió JL, Maldonado MJ. Precision of high definition spectral-domain optical coherence tomography for measuring central corneal thickness. Invest Ophthalmol Vis Sci. 2012;53:1752-1757.

18. Bland M. Clinical Measurement. In: Bland M, ed. An Introduction to Medical Statistics, 3rd ed. Oxford, UK: Oxford University Press; 2000:269-294.

19. 100. Maldonado MJ, López-Miguel A, Nieto JC, Cano-Parra J, Calvo B, Alió JL. Reliability of noncontact pachymetry after laser in situ keratomileusis. Invest Ophthalmol Vis Sci. 2009;50:4135-4141.

20. Bland JM, Altman DG. Measurement error and correlation coefficients. $B M J$. 1996;313:41-42.

21. European Glaucoma Prevention Study Group, Pfeiffer N, Torri V, Miglior S, Zeyen T, Adamsons I, Cunha-Vaz J. Central corneal thickness in the European Glaucoma Prevention Study. Ophthalmology. 2007;114:454-459.

22. Randleman JB, Trattler WB, Stulting RD. Validation of the Ectasia Risk Score System for preoperative laser in situ keratomileusis screening. Am J Ophthalmol. 2008;145:813-818.

23. Maldonado MJ. Undersurface ablation of the flap for laser in situ keratomileusis retreatment. Ophthalmology. 2002;109:1453-1464. 
24. Keenan TD, Jones MN, Rushton S, Carley FM; National Health Service Blood and Transplant Ocular Tissue Advisory Group and Contributing Ophthalmologists (Ocular Tissue Advisory Group Audit Study 8). Trends in the indications for corneal graft surgery in the United Kingdom: 1999 through 2009. Arch Ophthalmol. 2012;130:621-628.

25. Northey LC, Gifford P, Boneham GC. Comparison of topcon optical coherence tomography and ultrasound pachymetry. Optom Vis Sci. 2012;89:1708-1714.

26. Ge L, Yuan Y, Shen M, Tao A, Wang J, Lu F. The role of axial resolution of optical coherence tomography on the measurement of corneal and epithelial thicknesses. Invest Ophthalmol Vis Sci. 2013;54:746-755

27. Huang JY, Pekmezci M, Yaplee S, Lin S. Intra-examiner repeatability and agreement of corneal pachymetry map measurement by time-domain and Fourierdomain optical coherence tomography. Graefes Arch Clin Exp Ophthalmol. 2010;248:1647-1656.

28. Li H, Leung CK, Wong L, et al. Comparative study of central corneal thickness measurement with slit-lamp optical coherence tomography and Visante optical coherence tomography. Ophthalmology. 2008;115:796-801.

29. Nam SM, Im CY, Lee HK, Kim EK, Kim TI, Seo KY. Accuracy of RTVue optical coherence tomography, Pentacam, and ultrasonic pachymetry for the measurement of central corneal thickness. Ophthalmology. 2010;117:2096-2103.

30. Vollmer L, Sowka J, Pizzimenti J, Yu X. Central corneal thickness measurements obtained with anterior segment spectral domain optical coherence tomography compared to ultrasound pachymetry in healthy subjects. Optometry. 2012;83:167172. 
31. Vidal S, Viqueira V, Mas D, Domenech B. Repeatability and reproducibility of corneal thickness using SOCT Copernicus HR. Clin Exp Optom. 2013;96:278-85.

32. Doughty MJ, Zaman ML. Human corneal thickness and its impact on intraocular pressure measures: a review and meta analysis approach. Surv Ophthalmol. 2000;44:367-408.

33. Randleman JB. Post-laser in situ keratomileusis ectasia: current understanding and future directions. Curr Opin Ophthalmol. 2006;17:406-412.

34. Condon PI, O'Keefe M, Binder PS. Long-term results of laser in situ keratomileusis for high myopia: risk for ectasia. J Cataract Refract Surg. 2007;33:583-590.

35. Nesi TT, Leite DA, Rocha FM, Tanure MA, Reis PP, Rodrigues EB, Campos MS. Indications of optical coherence tomography in keratoplasties: literature review. $J$ Ophthalmol. 2012 (Forthcoming)..

36. Mohamed S, Lee GK, Rao SK, et al. Repeatability and reproducibility of pachymetric mapping with Visante anterior segment-optical coherence tomography. Invest Ophthalmol Vis Sci. 2007;48:5499-5504.

37. Prakash G, Agarwal A, Jacob S, Kumar DA, Agarwal A, Banerjee R. Comparison of fourier-domain and time-domain optical coherence tomography for assessment of corneal thickness and intersession repeatability. Am J Ophthalmol. 2009;148:282-290

38. Fukuda S, Kawana K, Yasuno Y, Oshika T. Repeatability and reproducibility of anterior ocular biometric measurements with 2-dimensional and 3-dimensional optical coherence tomography. J Cataract Refract Surg. 2010;36:1867-1873.

39. Chan JB, Yuen LH, Huang EH, et al. Reproducibility of cornea measurements in anterior segment OCT images of normal eyes and eyes with bullous keratopathy 
analyzed with the Zhongshan Assessment Program. Invest Ophthalmol Vis Sci. 2011;52:8884-8890.

40. Chen S, Huang J, Wen D, Chen W, Huang D, Wang D. Measurement of central corneal thickness by high-resolution Scheimpflug imaging, Fourier-domain optical coherence tomography and ultrasound pachymetry. Acta Ophthalmol. 2012;90:449-455

41. Rao HL, Kumar AU, Kumar A, Chary S, Senthil S, Vaddavalli PK, Garudadri CS. Evaluation of central corneal thickness measurement with RTVue spectral domain optical coherence tomography in normal subjects. Cornea. 2011;30:121-126.

42. Li Y, Tang M, Zhang X, Salaroli CH, Ramos JL, Huang D. Pachymetric mapping with Fourier-domain optical coherence tomography. J Cataract Refract Surg. 2010;36:826-831. 


\section{FIGURE LEGENDS}

Figure 1. Bland-Altman plot showing agreement between sessions.

The solid lines represent the upper and the lower limit of agreement (mean \pm 1.96 standard deviations). The dotted lines situated above and below the solid lines, represent the $95 \%$ confidence interval for each limit of agreement. The middle dashed line represents the mean difference value between sessions 1 and 2; the shaded area represents the magnitude between this mean difference value and zero.

Figure 2. Bland-Altman plot showing agreement between observers. The solid lines represent the upper and the lower limit of agreement (mean \pm 1.96 standard deviations). The dotted lines situated above and below the solid lines, represent the $95 \%$ confidence interval for each limit of agreement. The middle dashed line represents the mean difference value between observer 1 and 2; the shaded area represents the magnitude between this mean difference value and zero. 


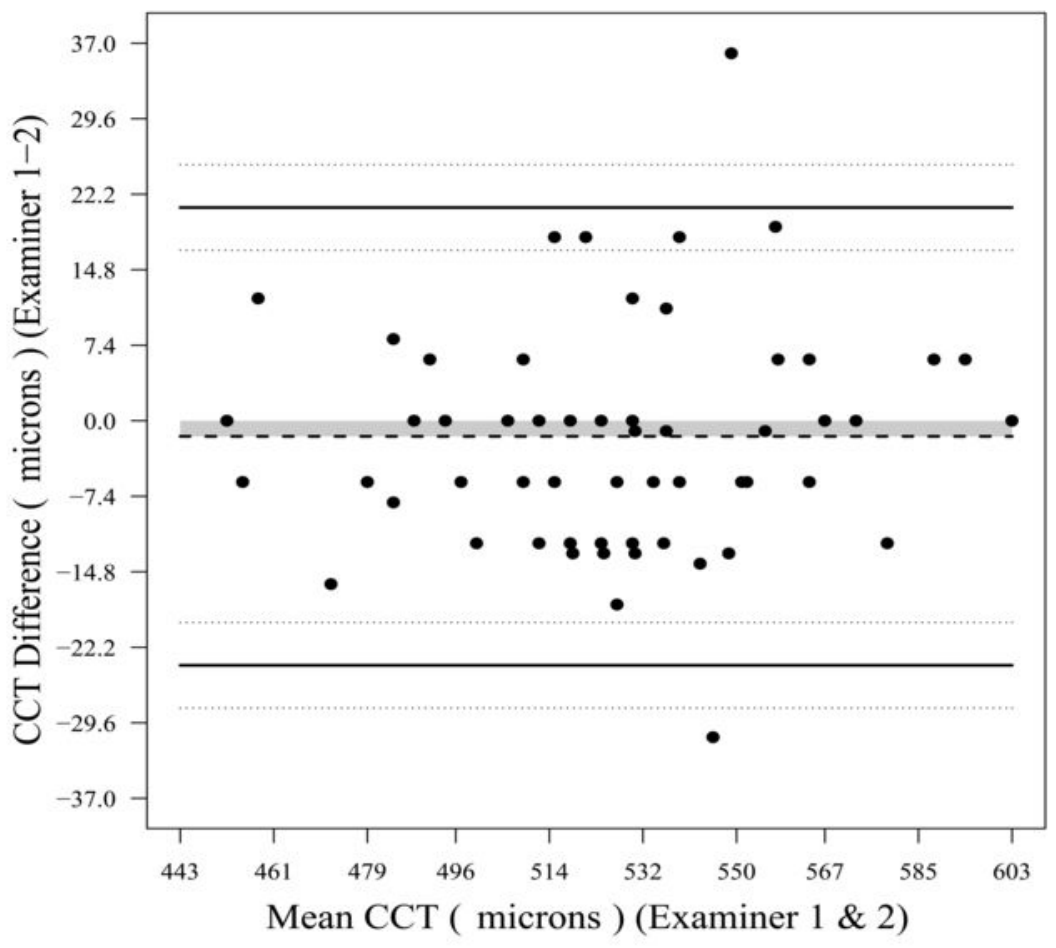


